\title{
LOS PROCESOS DE PLANIFICACIÓN HIDROLÓGICA EN LA PENÍNSULA IBÉRICA E ISLAS EN UN CONTEXTO DE CAMBIO CLIMÁTICO
}

\section{JUAN CARLOS SANTAMARTA CEREZAL JESICA RODRÍGUEZ MARTÍN}




\title{
LOS PROCESOS DE PLANIFICACIÓN HIDROLÓGICA EN LA PENÍNSULA IBÉRICA E ISLAS EN UN CONTEXTO DE CAMBIO CLIMÁTICO
}

\author{
Juan Carlos Santamarta Cerezal
}

Jesica Rodríguez Martín

(editores) 
Los procesos de planificación hidrológica en la península ibérica e islas en un contexto de cambio climático

\section{(C) Los autores}

\section{Coordinación científica y edición:}

Dr. Juan Carlos Santamarta Cerezal

Dra. Jesica Rodríguez Martín

\section{Colabora:}

Vicerrectorado de Cultura, Participación

Social y Campus Ofra y La Palma

Universidad de La Laguna

Aula Cultural del Agua

Universidad de La Laguna

\section{Edita:}

\section{Colegio Oficial de \\ Ingenieros de Montes}

Colegio Oficial de Ingenieros de Montes

Calle Cristóbal Bordiú, 19

28003, Madrid

9153406005

$1^{\text {a }}$ Edición: octubre 2020

ISBN: 978-84-09-24957-2

Depósito legal: TF 694-2020

DOI: https://doi.org/10.25145/b.Planificacionhidrologica.2020

\section{Cómo citar este libro:}

Santamarta, J.C., Rodríguez-Martín, J. (2020). Los procesos de planificación hidrológica en la península ibérica e islas en un contexto de cambio climático. Madrid: Colegio Oficial de Ingenieros de Montes. doi: https://doi.org/10.25145/b.Planificacionhidrologica.2020

Ninguna parte de este libro puede ser reproducida o transmitida en cualquier forma o por cualquier medio, electrónico o mecánico, incluido fotografías, grabación o por cualquier sistema de almacenar información sin el permiso escrito del autor y editores. 


\section{Índice}

\section{BLOQUE I \\ Agua y cambio climático}

Capítulo 1. La Transición Hidrológica desde la Nueva Cultura del Agua

1.1. La Transición Hidrológica

Capítulo 2. Impacto del cambio climático en los recursos hídricos en la Península ibérica e Islas Canarias

2.1. Introducción al Cambio Climático

2.2. Análisis de los Recursos Hídricos en España en relación con el Cambio Climático

Referencias bibliográficas

Capítulo 3. Retos de la gestión del agua en los países mediterráneos frente al cambio climático: casos concretos en diferentes ciudades de España y otros países mediterráneos

3.1. Introducción al cambio climático

3.2. Qué vemos a nuestro alrededor en España como cambio climático

3.3. Cambios que nos afectan a todos

3.4. Descripción del cambio climático ............................................................. 32

3.5. Cambios naturales y antrópicos ............................................................. 32

3.6. Alteraciones y extinciones ............................................................................. 34

3.7. Cambios locales ..................................................................................................... 37

3.8. Posibles soluciones para frenar estos cambios ....................................... 40

Referencias bibliográficas ............................................................................................ 41 
Capítulo 4. Los bosques y los recursos hídricos en un contexto de cambio climático

4.1. Introducción

4.2. El nexo bosques-aguas

44

4.3. Evolución reciente de la cubierta forestal en España ........................ 52

4.4. Los retos planteados ............................................................................................. 54

4.5. Las respuestas propuestas ........................................................................... 54

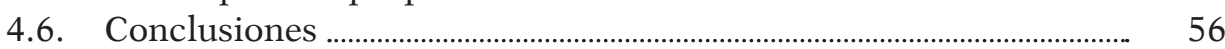

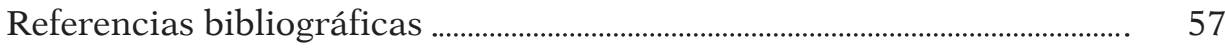

Capítulo 5. Recarga de acuíferos en un contexto de cambio climático ............ 59

5.1. Introducción ........................................................................................................ 59

5.2. Recarga natural difusa y variabilidad climática ...................................... 61

5.3. Recarga y cambio climático ................................................................................ 65

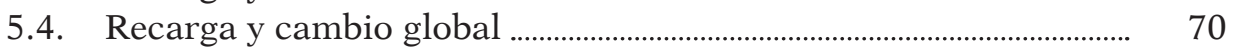

Referencias bibliográficas .......................................................................................... 74

\section{BLOQUE II \\ Planes Hidrológicos}

Capítulo 6. Retos de la planificación hidrológica española ante el $3^{\text {er }}$ ciclo de la Directiva Marco del Agua

6.1. La planificación hidrológica en España. Contexto y objetivos ......

6.2. El proceso de planificación hidrológica para el tercer ciclo

6.3. Principales retos de la planificación hidrológica para el tercer ciclo

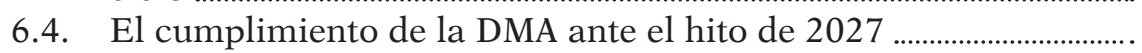

Referencias bibliográficas

Capítulo 7. Transición hidrológica y nueva gobernanza del agua en España

7.1. Introducción

7.2. Situación Actual

7.3. Diagnóstico: Contexto para la Transición

7.4. La Necesaria Transición Hidrológica

7.5. Nueva Gobernanza del Agua

7.6. Conclusiones: Paradigmas de la Transición Hidrológica y la Nueva Gobernanza

Referencias bibliográficas

Capítulo 8. La participación activa en el tercer ciclo de planificación hidrológica

8.1. Introducción a la participación activa

8.2 La participación en la planificación hidrológica

8.3 La participación en el tercer ciclo de planificación 
Capítulo 9. SSD en el marco de la DMA. Experiencia en España y aplicación en otros países

9.1. Introducción

9.2. La necesidad de empleo de SSD

9.3. SSD más empleados - AQUATOL

9.4. Ejemplos de simulaciones de cantidad - SIMGES ............................ 139

9.5. Ejemplos de simulaciones de calidad- GESCAL ............................... 142

9.6. Modelos numéricos aplicados en demarcaciones turcas .................. 145

9.7. Resultados y conclusiones ..................................................................... 147

Referencias bibliográficas .............................................................................. 148

\section{BLOQUE III \\ Gestión de los recursos hídricos en las islas}

Capítulo 10. El ejercicio de la planificación hidrológica en las Islas Canarias .

10.1. Consideraciones ................................................................................. 153

10.2. Directiva Marco del Agua en Canarias ................................................ 154

10.3. Directiva de Inundaciones en Canarias ................................................. 158

10.4. Directiva de Estrategia Marina en Canarias ......................................... 158

10.5. Retos/Obligaciones/Mejoras .............................................................................. 159

Capítulo 11. La gobernanza del agua en las Islas Canarias ................................. 161

11.1. Introducción .................................................................................... 161

11.2. La planificación hidrológica en las Islas Canarias .............................. 168

11.3. Desarrollo histórico del agua en las Islas Canarias ............................. 169

11.4. Gobernanza del agua en las Islas Canarias ......................................... 176

11.5. La participación ciudadana en materia de aguas .................................. 180

11.6. El libro verde de la gobernanza del agua ........................................... 181

11.7. El papel de la universidad en la gobernanza del agua ....................... 182

11.8. Algunas conclusiones sobre la gobernanza del agua en las Islas Canarias

Referencias bibliográficas ............................................................................. 185

Capítulo 12. Retos de futuro de los recursos hídricos en las Islas Canarias ..... 187

12.1. Introducción ............................................................................................. 187

12.2. El agua en las Islas Canarias ............................................................ 189

12.3. Análisis de las Debilidades, Amenazas, Fortalezas y Oportunidades (DAFO) de los recursos hídricos en las Islas Canarias .............. 199

12.4. La planificación hidrológica en las Islas Canarias .............................. 200

12.5. La agricultura y el agua .................................................................... 201

12.5. Las masas forestales y el agua ............................................................... 203

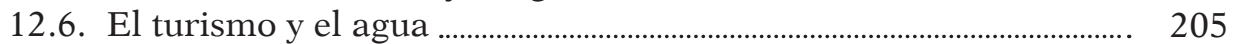

12.7. El binomio agua y energía ............................................................................ 206

12.8. Algunas conclusiones y retos planteados ........................................... 208

Referencias bibliográficas ....................................................................................... 210 
Capítulo 13. Retos de futuro de los recursos hídricos en Baleares ................... 213

13.1. Características hidrogeológicas de las Islas Baleares ....................... 213

13.2. Características climáticas de Baleares .................................................... 216

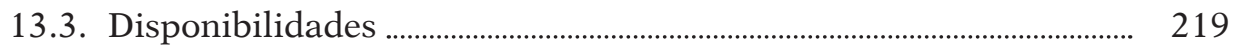

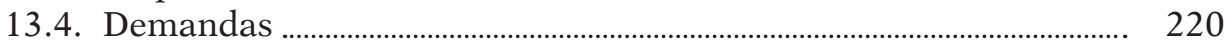

13.5. Estado de las Masas de Agua Subterránea ............................................... 224

13.6. Retos de futuro ................................................................................................. 226

Referencias bibliográficas ................................................................................. 228

Capítulo 14. Cinco aspectos clave en la gestión del agua en las Islas Ba-

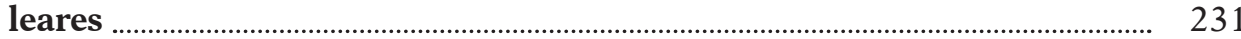

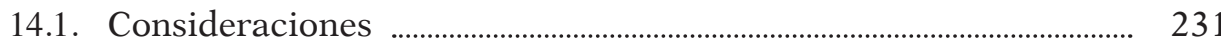

14.2. Las masas de agua subterránea: sobreexplotación y salinización

14.3. El estado ecológico de las masas de agua superficial categoría río

14.4. Las sequías ..................................................................................... 237

14.5. Las desaladoras y la producción de agua desalada ............................... 240

14.6. La gestión de la demanda de agua en función de la tipología del

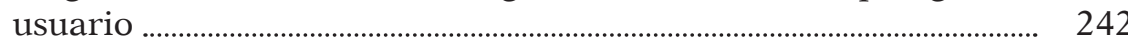

Referencias bibliográficas ........................................................................................... 244

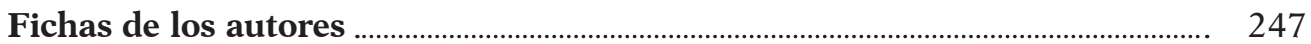




\section{Prólogo}

Hugo Morán Fernández

Secretario de Estado de Medio Ambiente

Corría el año 1947, cuando un grupo de científicos de la Universidad de Chicago iniciaba la publicación de un boletín en el que anticipaban, simbólicamente, la expectativa de vida de nuestro Planeta medida en un período de 24 horas; desde entonces ese grupo, en el que se integran 15 premios Nobel, adelantan o retrasan el reloj atendiendo a la evolución de los riesgos que amenazan a la Tierra. Cierto que en todo este tiempo no habían venido siendo halagüeñas las actualizaciones periódicas del boletín, pero la irrupción de la pandemia de la COVID-19 ha sumado a nuestra creciente capacidad de autodestrucción, la evidencia de una enorme debilidad de gobernanza para hacer frente a crisis de alcance global. Así las cosas, las manillas del reloj se han fijado este año a las 23:58:20, situándose más cerca de la medianoche de lo que nunca antes habían estado.

La principal enseñanza que habríamos de extraer de esta crisis sanitaria es la de no hacer oídos sordos a la voz de la ciencia; esa que nos dice que el 2020 ha sido el año más caluroso de la historia, y que los pavorosos incendios forestales, la inédita sucesión de ciclones, o la alarmante curva de pérdida de biodiversidad, dan cuenta de la necesidad imperiosa de repensar el que hasta ahora había venido siendo considerado como modelo de desarrollo, para dar paso a un modelo más resiliente y adaptativo.

La relación del ser humano con el medio que le da vida tiene que cambiar. La evidencia científica del cambio climático y sus efectos nos enfrentan a retos que exigen actuar ya; y Europa ha decidido hacerlo siguiendo la hoja de ruta del Pacto Verde, con el que España ha establecido un sólido compromiso, y que transitará por las sendas de la mitigación y la adaptación al cambio climático, la conservación de la biodiversidad y la puesta en valor de los servicios ecosistémicos. 
En este contexto de amenazas aparece el concepto de la seguridad hídrica. Asegurar la disponibilidad de agua, tanto en calidad como en cantidad, es imprescindible para la salud, esencial para preservar los ecosistemas, e insustituible para el desarrollo socioeconómico. Sólo actuando en la recuperación de nuestros ríos y acuíferos, en la prevención y lucha contra la contaminación de las aguas, en la protección y puesta en valor de los ecosistemas naturales, y en la necesidad de revertir la continua pérdida de biodiversidad, podremos aspirar a un modelo de gestión robusto y con capacidad de adaptación.

Las páginas que siguen a esta presentación no han sido ajenas a las dificultades del momento que vivimos; por ello salen a la luz en un momento de indudable oportunidad, para reflexionar sobre los retos a los que la necesaria transición ecológica debe hacer frente desde el punto de vista de la gestión del agua. A ello se suma el hecho de que nos encontramos en la etapa final del proceso de planificación hidrológica del tercer ciclo de la Directiva Marco del Agua.

Así, esta publicación aborda diversos aspectos esenciales para profundizar en un modelo de gestión del agua alineado con el Pacto Verde. Se plantean las bases de la necesaria transición hidrológica, los principales retos que la gestión y la planificación hidrológica han de afrontar en el contexto de cambio climático, y algunos elementos que merecen una consideración especialmente relevante en este proceso, como la gestión de las aguas subterráneas, de los bosques y la biodiversidad, la participación ciudadana en los procesos de toma de decisiones, la digitalización de datos y sistemas, o la singularidad de los territorios insulares.

Es, sin duda, una solvente aportación al debate que precede o acompaña siempre a la toma de decisiones; por ello merece la pena su atenta lectura. 


\section{BLOQUE I}

Agua y cambio climático 



\title{
Capítulo 1 \\ La Transición Hidrológica desde la Nueva Cultura del Agua
}

\author{
Pedro Arrojo Agudo \\ Doctor en Ciencias Físicas
}

\subsection{La Transición Hidrológica}

El pasado 13 de diciembre del 2018 se aprobó en el Congreso de los Diputados el Dictamen de Conclusiones y Recomendaciones al Gobierno en materia de Gestión de Aguas en Perspectivas de Cambio Climático. Con esta votación, precedida del correspondiente debate, se culminaba un largo y fructífero trabajo basado en las comparecencias de casi 30 expertos y expertas, a lo largo de varios meses, que ofrecieron un poderoso caudal de información y de propuestas, en gran medida confluyentes y complementarias, a pesar de haber sido propuestas por los diversos grupos parlamentarios. Se produjo así un hito sin precedentes en el Congreso: la aprobación, por mayoría absoluta, de un documento en materia de planificación y gestión de aguas en línea con la Nueva Cultura del Agua, que abre y marca el camino de la necesaria TRANSICIÓN HIDROLÓGICA a desarrollar.

Hoy se parte de un consenso general que asume el vector energético como generador principal del cambio climático, por lo que el reto clave de las políticas de mitigación está en la TRANSICIÓN ENERGÉTICA. En lo que se refiere a los impactos socio ambientales, el vector principal de afección es, a mi entender, el VECTOR AGUA, por lo que el reto clave en las políticas de adaptación es el de la necesaria TRANSICIÓN HIDROLÓGICA.

En realidad, la necesidad de esa Transición Hidrológica se empieza a hacer patente en los 90, con las movilizaciones por la Nueva Cultura del Agua; pronto se transformaría en exigencia legal, con la aprobación de la Directiva Marco del Agua; y hoy, ante la evidencia del Cambio Climático, pasa a ser una urgencia inaplazable. Urgencia de pasar de las viejas estrategias de «oferta» subvencionada, a nuevas estrategias de gestión de la demanda y conservación de nuestros ecosistemas. Se trata de transitar de la vieja lógica del hormigón, a la nueva inteligencia ambiental de la sostenibilidad; del viejo productivismo subvencionado a la necesaria racionalidad económica; y sobre todo, de la suicida miopía negacionista, a la aplicación rigurosa del Principio de Precaución frente al cambio climático. 
El Dictamen aprobado por el Congreso de los Diputados se basa en los estudios del CEDEX referentes al impacto del cambio climático sobre caudales fluviales y aguas subterráneas. La recesión de caudales prevista, a lo largo del presente siglo se eleva, en media, al $24 \%$, y hasta al 30 y $40 \%$ en las cuencas más sensibles, si no se cumplen los acuerdos de París, que de hecho se están incumpliendo clamorosamente. Y no tanto por las menores precipitaciones medias, que prevén la mayoría de modelos de simulación utilizados, sino, sobre todo, por el tremendo aumento de la evapotranspiración, es decir del agua usada por las masas vegetales, cultivadas o silvestres, que impone la elevación de temperaturas. Por otro lado, crecerán de forma drástica los riesgos de sequía y de crecida, al intensificarse la tradicional variabilidad climática mediterránea. La sequías tenderán a ser más largas, intensas y frecuentes, al tiempo que los riesgos de tormenta y de gota fría tenderán a intensificarse, produciendo puntas de crecida más fuertes y mayores riesgos de inundación.

Ciertamente estas previsiones están sometidas a márgenes de incertidumbre, por lo que, en rigor, lo que exige la legislación europea es la aplicación del Principio de Precaución en la gestión de estos riesgos; principio que, lejos de disculpar la inacción frente a la incertidumbre, exige prevenir los escenarios plausibles más desfavorables. No se trata de ser optimistas o pesimistas, sino de ser prudentes, preparándonos para los peores escenarios plausibles, que de hecho, cada vez son más probables, en la medida en que ya se asume como inevitable el incumplimiento de los acuerdos de Paris.

En este contexto, pretender gestionar las futuras sequías con nuevas grandes presas y trasvases no sólo es una estrategia errónea e insensata, sino que comporta una masiva malversación de fondos públicos. En la medida que las sequías no suelen ser locales sino regionales, cuando el Segura entra en sequía, suele hacerlo también el Júcar, el Ebro y la Cabecera del Tajo, razón por la cual los trasvases pasan a ser perfectamente inútiles, como ocurrió con el trasvase Tajo/Segura en la última sequía.

Por otro lado, construir más embalses para gestionar esas futuras sequías, equivale a regalar un monedero a un pobre o abrir nuevas cuentas corrientes ante una situación de ruina económica. No tiene sentido. El pobre no necesita un monedero, sino dinero, y disponer de más cuentas corrientes vacías no resuelve la ruina. Pues bien, de la misma forma, si nos dedicamos a construir nuevos grandes embalses, en el país del mundo con más infraestructura hidráulica por habitante y kilómetro cuadrado, lo que se conseguirá será tener más embalses vacíos en la siguiente sequía. En rigor, no se trata de estar en contra de nuevos embalses y trasvases, o de estar en contra de nuevas autopistas y aeropuertos; pero si de evitar malgastar el dinero público en nuevas autopistas sin coches, nuevos aeropuertos sin aviones y nuevas presas y trasvases sin agua.

El Dictamen ofrece un amplio abanico de medidas y estrategias frente al Cambio Climático, de las que citaré las que considero más importantes, tanto para minimizar nuestra vulnerabilidad frente a ciclos de sequía como frente a riesgos de inundación. 
Si queremos afrontar seriamente los crecientes riesgos de sequía que nos ha empezado a imponer el cambio climático, es fundamental acabar con la sobreexplotación de nuestros acuíferos, generada por ese millón largo de pozos ilegales, que para colmo se concentran en las zonas más sensibles. Recuperar el buen estado cuantitativo y cualitativo de estos enormes embalses de agua subterránea, que son nuestros pulmones hídricos naturales, y acabar con la vergüenza nacional que representan esos cientos de miles de pozos y regadíos ilegales en nuestro país, es una de las claves que nos debe permitir hacer de esos acuíferos reservas estratégicas vitales para gestionar los ciclos de sequía.

Por otro lado, se necesita una planificación hidrológica prudente y realista, al tiempo que valiente y responsable, que redimensione las demandas futuras, tanto agrarias como urbanas, adaptándolas a la disponibilidad de caudales prevista en los escenarios de cambio climático. Ello supondrá, sin duda, frenar desarrollos urbanísticos en zonas sensibles, acabar con los modelos depredadores de recursos hídricos, reducir drásticamente las expectativas planificadas de crecimiento del regadío e incluso retirar regadíos no rentables, con compensaciones negociadas, en zonas salobres y de mal drenaje, a fin de rescatar caudales que permitan ofrecer mejores garantías en sequía y recuperar los regímenes fluviales ecológicos que establece la legislación vigente.

En los territorios insulares y en las zonas costeras mediterráneas más sensibles a los problemas de escasez, se debe promover un desarrollo modular, razonable y prudente de las nuevas tecnologías de desalación, regeneración y reutilización, pero alimentadas con energía eólica y solar, a fin de abrir perspectivas efectivas de autosuficiencia sostenible, como ocurre por cierto en las islas del Hierro, de Fuerteventura o de Lanzarote, donde prácticamente no llueve.

El Dictamen presta especial atención al medio rural y a la lucha contra su despoblación, como clave en las estrategias de adaptación al cambio climático, recomendando extender el sistema de seguros agrarios a la compensación de daños por sequía en el regadío (hoy desprotegido), con apoyo público específico a la explotación familiar agro-ganadera; al tiempo que insiste en la reactivación de la Ley de Desarrollo Sostenible del Medio Rural, vinculando la vertebración social del territorio a la preservación de suelos, la gestión forestal y la prevención de incendios, frente al avance de la desertización.

En cuanto a las medidas y estrategias para gestionar los crecientes riesgos de inundación, el Dictamen saluda como muy positiva la Directiva de Inundaciones, así como los últimos Planes de Gestión de Riesgos de Inundación elaborados por Confederaciones como la del Ebro.

A lo largo de las últimas décadas, el estrechamiento del espacio fluvial, con motas y diques, junto al talado de bosques de ribera e incluso la eliminación de meandros, ha favorecido el incremento de la energía cinética y el nivel de las crecidas. Por otro lado, el deficiente control sobre el dominio público hidráulico ha llevado a que, en la actualidad, 3 millones de personas vivan en zonas inundables, considerando un periodo de retorno de 500 años (que el cambio climático está acortando) 
En coherencia con la Directiva de Inundaciones, los Planes de Gestión del Riesgo de Inundación han empezado a priorizar nuevas estrategias basadas en:

- la reordenación del dominio público y de los espacios bajo riesgo de inundación, evitando su urbanización y la construcción de granjas e instalaciones industriales;

- la ampliación del espacio fluvial, retranqueando o eliminando motas y diques y creando cauces de alivio;

- la instalación de compuertas en las motas que permitan, en crecidas extraordinarias, expandir inundaciones blandas, previo acuerdo de adecuadas compensaciones a los propietarios, y evacuar el agua cuando el nivel del río baje (hoy las inundaciones, que se producen por debajo de las motas, por vasos comunicantes, se mantienen durante semanas, al evitar las propias motas el drenaje hacia el rio).

En suma, estrategias que, sin despreciar la función laminadora de las infraestructuras de regulación, priorizan recuperar el buen estado de los ecosistemas ribereños, reordenar territorialmente los entornos fluviales y proteger rigurosamente los espacios urbanos. 


\title{
Capítulo 2 Impacto del cambio climático en los recursos hídricos en la Península ibérica e Islas Canarias
}

\author{
Noelia Cruz Pérez \\ Ingeniera Civil \\ Juan Carlos Santamarta Cerezal \\ Doctor Ingeniero de Montes
}

\subsection{Introducción al Cambio Climático}

Las Naciones Unidas definen el cambio climático como «... un cambio de clima atribuido directa o indirectamente a la actividad humana que altera la composición de la atmósfera mundial y que se suma a la variabilidad natural del clima observada durante períodos comparables»(ONU, 1992). Teniendo en cuenta que el planeta Tierra posee un sistema climático, constituidos a su vez por cinco subsistemas (atmósfera, hidrosfera, criosfera, litosfera y biosfera), es evidente que los cambios sufridos en el clima afectarán a su vez a dichos subsistemas, generando impactos en el aprovechamiento de los recursos naturales.

El cambio climático está directamente relacionado con la emisión de gases de efecto invernadero (en adelante, GEI) a la atmósfera, desprendidos en el proceso de producción de energía. Los GEI se definen como «... componentes gaseosos de la atmósfera, tanto naturales como antropogénicos, que absorben y emiten radiación a longitudes de onda específicas dentro del espectro de radiación infrarroja emitida por la superficie de la Tierra, la atmósfera y las nubes» (ISO 14064, 2015). Esta característica que poseen los GEI de absorber y emitir radiación infrarroja, los hace responsables de ser la principal causa de calentamiento global. recuperación. El dióxido de carbono $\left(\mathrm{CO}_{2}\right)$, el metano $\left(\mathrm{CH}_{4}\right)$ y el óxido nitroso $\left(\mathrm{N}_{2} \mathrm{O}\right)$ son los tres gases principales que contribuyen al efecto invernadero y, por lo tanto, al calentamiento global. En España, las emisiones de estos gases, en relación con el total de emisión de gases en 2017, fueron del orden del $81 \%$, $12 \%$ y $5 \%$, respectivamente (Ministerio para la Transición Ecológica, 2019b). La huella de carbono es una herramienta que contabiliza la totalidad de los gases de efecto invernadero (Figura 2.1) asociados a la producción de un producto, la prestación de un servicio o la realización de una actividad, generados tanto de forma directa como indirecta por la organización (Blasco Hedo, 2014). Por lo tanto, la huella de carbono permite medir el impacto de un producto, servicio o actividad sobre el medioambiente. 
Figura 2.1. Efecto invernadero

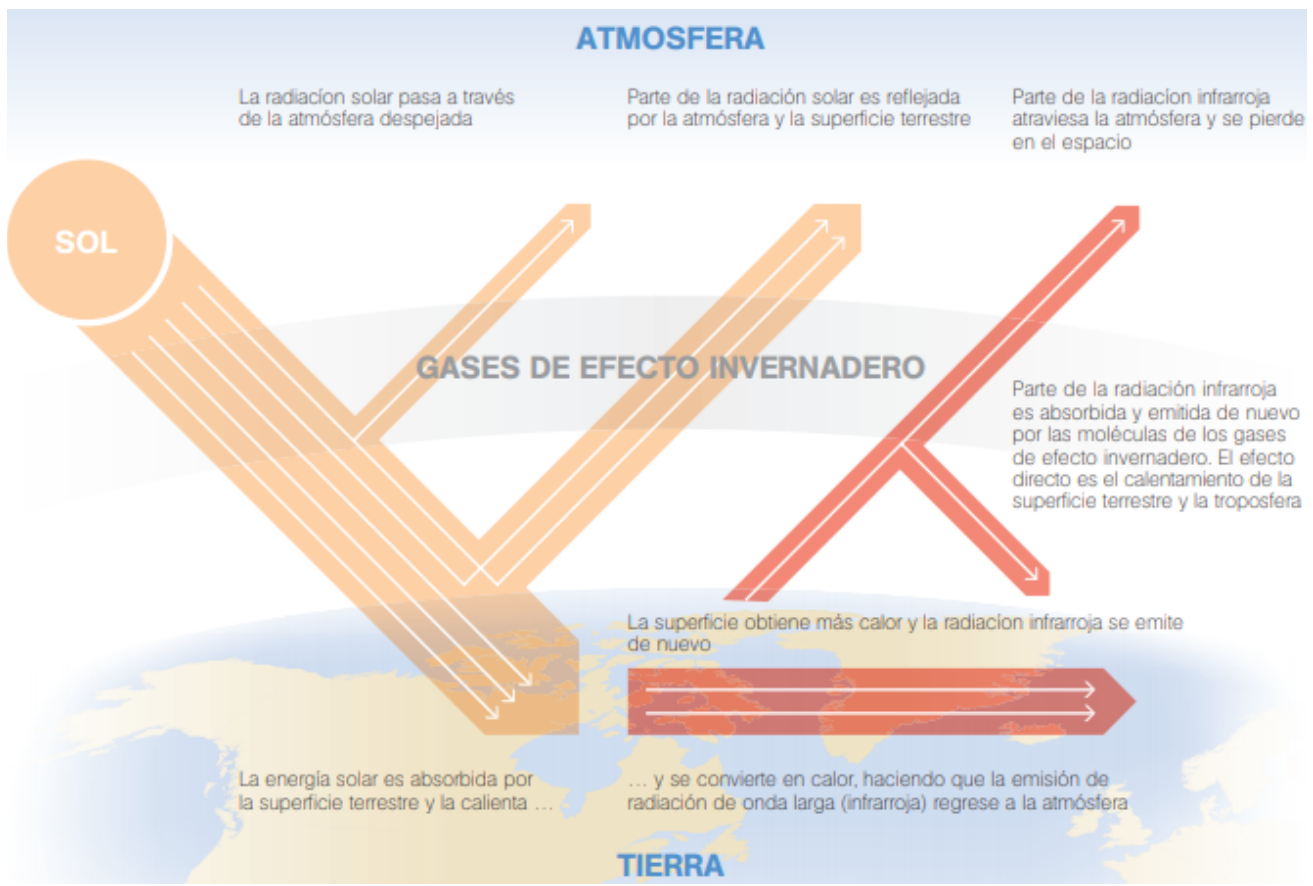

Fuente: UNFCCC (2006)

El calentamiento global se define como el aumento de las temperaturas en el sistema climático y los efectos que produce, observado en un periodo superior a un siglo (IPCC, 2013). Según el IPCC, es la actividad humana la causante del calentamiento del planeta que se observa desde finales del siglo XIX, ya que esta actividad ha multiplicado los gases de efecto invernadero emitidos a la atmósfera, provocando una descompensación en el sistema que existía, aumentando la temperatura de la Tierra.

Las observaciones del clima comenzaron a realizarse desde mediados del siglo XIX y, junto a las reconstrucciones paleoclimáticas, aportan registros que se remontan a siglos o millones de años, proporcionando una visión global de la variabilidad y los cambios observados en el clima del planeta. La temperatura media global en la superficie terrestre no ha dejado de aumentar desde finales del siglo XIX y cada uno de los últimos tres decenios ha sido más cálido que cualquier otro decenio del que se tengan registros, siendo el decenio de 2000 el más cálido de todos (IPCC, 2014). Estas observaciones del clima del planeta han llevado a los Estados a incluir el cambio climático en sus agendas. Entre las convenciones internacionales cuya finalidad ha sido limitar el efecto negativo del cambio climático (Tabla 2.1), se destacan las siguientes:

- 1992: Tiene lugar el primer compromiso internacional para afrontar el calentamiento global con la creación de la Convención Marco de las Na- 
ciones Unidas (CMNUCC), cuyo objetivo último es lograr la estabilización de gases de efecto invernadero en la atmósfera.

- 1997: Protocolo de Kyoto, donde los países participantes se comprometieron a cumplir unas metas en la reducción de sus emisiones .

- 2015: Acuerdo de París, se acuerda mantener el aumento de la temperatura mundial en este siglo por debajo de los $2{ }^{\circ} \mathrm{C}$ con respecto a los niveles preindustriales e intentar que no se superen los $1,5^{\circ} \mathrm{C}$ (UNFCCC, 2016).

- 2019: Cumbre del Clima de Madrid, los países participantes comparten impresiones acerca de los sectores sobre los que incidir para reducir las emisiones de manera más radical y se anima a continuar implementando medidas para lograr el objetivo marcado en el Acuerdo de París.

Tabla 2.1. Cronología de negociaciones sobre el Clima

\begin{tabular}{ll}
\multicolumn{2}{c}{ Conveniones internacionales sobre el Clima } \\
Primera Conferencia Mundial sobre el Clima & 1979 \\
Se crea el Grupo Intergubernamental de Expertos sobre el Cambio Climático (IPCC) & 1988 \\
Creación de la Convención Marco de las Naciones Unidas (CMNUCC) & 1992 \\
Protocolo de Kyoto & 1997 \\
Acuerdos de Marrakech & 2001 \\
Programa de Trabajo de Nairobi & 2005 \\
Hoja de Ruta de Bali & 2007 \\
Acuerdo de Copenhage & 2009 \\
Acuerdos de Cancún & 2010 \\
Plataforma de Durban & 2011 \\
Enmienda de Doha al Protocolo de Kyoto & 2012 \\
Acuerdo de París & 2015
\end{tabular}

Fuente: (UNFCCC, 2006)

En la actualidad, la Organización Meteorológica Mundial (OMM), el Grupo Intergubernamental de Expertos sobre el Cambio Climático (IPCC) y la Convención Marco de las Naciones Unidas sobre el Cambio Climático (CMNUCC) son las tres principales organizaciones encargadas de estudiar las variaciones del clima y sus efectos en la superficie terrestre, los océanos y los seres vivos. Estas organizaciones publican asiduamente documentos en los que repasan el estado actual de las emisiones, los efectos del cambio climático en la salud de las personas, los desplazamientos humanos debido al calentamiento global y los efectos de la subida de las temperaturas en los mares y en los cultivos. En efecto, una de las últimas publicaciones de la Organización Meteorológica Mundial ha sido la «Declaración de la OMM sobre el estado del clima mundial en 2017», en cuyo resumen ejecutivo de 2017 recoge que las temperaturas medias mundiales superaron en $1,1^{\circ} \mathrm{C} \pm$ $0,1^{\circ} \mathrm{C}$ las de los niveles preindustriales. En 2017, además, hubo numerosos fenó- 
menos climáticos y meteorológicos significativos, entre los que cabe citar los huracanes del Atlántico Norte (temporada ciclónica muy activa), las graves inundaciones debido a los monzones en el subcontinente indio y las continuas sequías en algunos lugares del África oriental. Todo ello desencadenó que el 2017 se haya calificado como el año en el que mayores pérdidas económicas han sido relacionadas con fenómenos meteorológicos extremos (WMO, 2018).

\subsubsection{Impactos del Cambio Climático en el planeta}

Los impactos del cambio climático pueden definirse como los efectos en los medios de subsistencia, la salud, los ecosistemas, la economía y la sociedad, fruto de la interacción de las variaciones en el clima y la vulnerabilidad de los sistemas expuestos a ellas (IPCC, 2014), que se detallan a continuación:

- Impactos en los medios de subsistencia (agricultura y ganadería): la disminución de las precipitaciones y el aumento de la temperatura favorece la aparición de plagas agrícolas, el desplazamiento de cultivos de unas zonas del planeta a otras, disminución de rendimientos debido a las altas temperaturas y/o a fenómenos meteorológicos adversos (ej. Lluvias torrenciales), variabilidad en la disponibilidad de los recursos hídricos con el consecuente riesgo de estrés hídrico para las plantas, etc.

- Impactos en la salud: los efectos en la salud pueden ser de tipo directo, como podría ser un golpe de calor producido por un aumento anormal en las temperaturas, o de tipo indirecto, como las enfermedades respiratorias causadas por la calidad del aire.

- Impactos en los ecosistemas: el cambio del clima genera alteraciones fisiológicas y demográficas que modifican el funcionamiento de los ecosistemas. Dentro de los impactos que se están produciendo en los hábitats podemos encontrar los siguientes: alteración de la migración de las aves, defoliaciones en los árboles, desplazamiento de especies vegetales, aceleración de la duración de las fases larvarias de los insectos y acidificación de los océanos y consecuente destrucción de los corales, entre otros.

- Impactos en la economía: los efectos del cambio climático en los ecosistemas se traducen en pérdidas económicas para el conjunto global. Tanto pérdidas debido a mermas en la agricultura, como pérdidas debido a los destrozos causados por fenómenos meteorológicos adversos (cada vez más frecuentes), alteración en las épocas turísticas tradicionales, aumento de la frecuencia y duración de los incendios forestales, etc.

Desde los años setenta, la comunidad científica viene alertando acerca de cómo el sistema actual puede colapsar debido a no ser sostenible. Dentro de los informes más relevantes que recogen estas hipótesis, encontramos el Informe Meadows «Los límites del crecimiento» (Figura 2.2) y el Informe Brundtland, donde se establece por primera vez el concepto de desarrollo sostenible definido 
como «el desarrollo que satisface las necesidades de la generación presente sin comprometer la capacidad de las generaciones futuras para satisfacer sus propias necesidades» (Keeble, 1988).

Figura 2.2. Proyección acerca del crecimiento de la población, alimentos, recursos, contaminación y producción industrial desde 1900 hasta 2100. Inspirado en el Informe Meadows

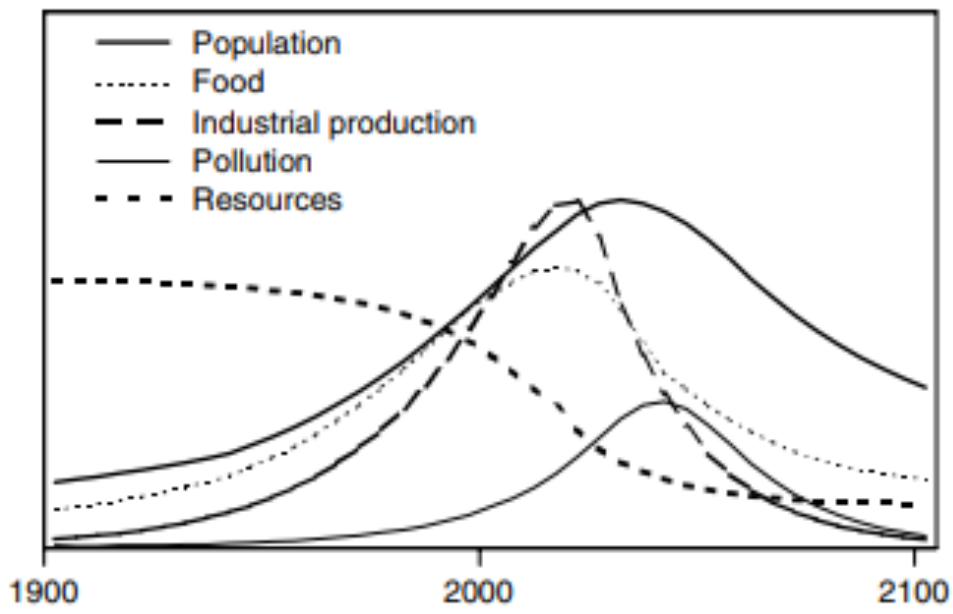

Fuente: (Janssen \& Timmerman, 2014)

En efecto, en el informe Brundtland se recoge textualmente que "... ha existido una fuerte correlación entre las emisiones de $\mathrm{CO}_{2}$ y el PIB per cápita y, como resultado de ello, desde 1850, Norteamérica y Europa han producido alrededor del $70 \%$ de todas las emisiones de $\mathrm{CO}_{2}$, mientras que la aportación de los países en desarrollo ha sido inferior al $25 \%$. La mayor parte de las emisiones futuras procederán de los países hoy día en desarrollo, debido al más rápido crecimiento de su población y de su PIB y a su creciente porcentaje de industrias con uso energético intensivo.» (Ministerio para la Transición Ecológica, 2006).

\subsection{Análisis de los Recursos Hídricos en España en relación con el Cambio Climático}

\subsubsection{Recursos Hídricos en la península ibérica}

En la península ibérica el régimen hídrico es variable, debido principalmente al clima mediterráneo predominante en España y en el resto del sur de Europa. Las características del clima mediterráneo son veranos secos y calurosos, con inviernos lluviosos y fríos y primaveras que presentan heterogeneidad en sus temperaturas y sus precipitaciones. La precipitación media anual puede establecerse en $670 \mathrm{~mm} / \mathrm{año}$, con grandes desigualdades entre el norte $(2200 \mathrm{~mm})$ y el sur $(120$ mm) (Adhikari \& Nejadhashemi, 2016). 
A estas circunstancias climáticas, hay que sumarle el uso que hacen del agua los principales sectores económicos en España. Por una parte, la agricultura en España es principalmente de regadío, que además exige una elevada demanda hídrica en verano, precisamente cuando hay menor disponibilidad de recursos hidrológicos. Otro de los sectores clave en la economía española es el turismo, ya que España recibió 83 millones de turistas en 2019, siendo el segundo país con mayor número de llegadas de turistas en el mundo, y donde el impacto de esta actividad representa el 11,7\% de su Producto Interior Bruto. Según datos de la compañía SUEZ, el consumo de agua por turista y día puede estimarse entre 450 y 800 litros, mientras que el de un habitante local es de 150 litros al día (en Europa). Una vez más, la mayor demanda hídrica para el turismo se concentra en los meses estivales, por lo tanto, existe un desfase entre las épocas de disponibilidad de agua y las épocas de mayor demanda, que agudizan el agotamiento de los recursos hídricos del país.

\section{Variación de los recursos hídricos en la Península Ibérica debido al Cambio Climático}

Las sequías son un fenómeno habitual en la península ibérica, sin embargo, con el cambio climático se esperan periodos secos que serán cada vez más largos e intensos (WWF, 2019). En la Figura 12.3 puede apreciarse el nivel del estrés hídrico en España, observándose más escasez en el sur. Esta situación de escasez hídrica se ve a su vez agravada por los siguientes elementos: intrusión marina en los acuíferos, desaparición paulatina de la costa, contaminación de las aguas su-

Figura 12.3. Estrés hídrico en la Península Ibérica (en rojo las zonas más afectadas)

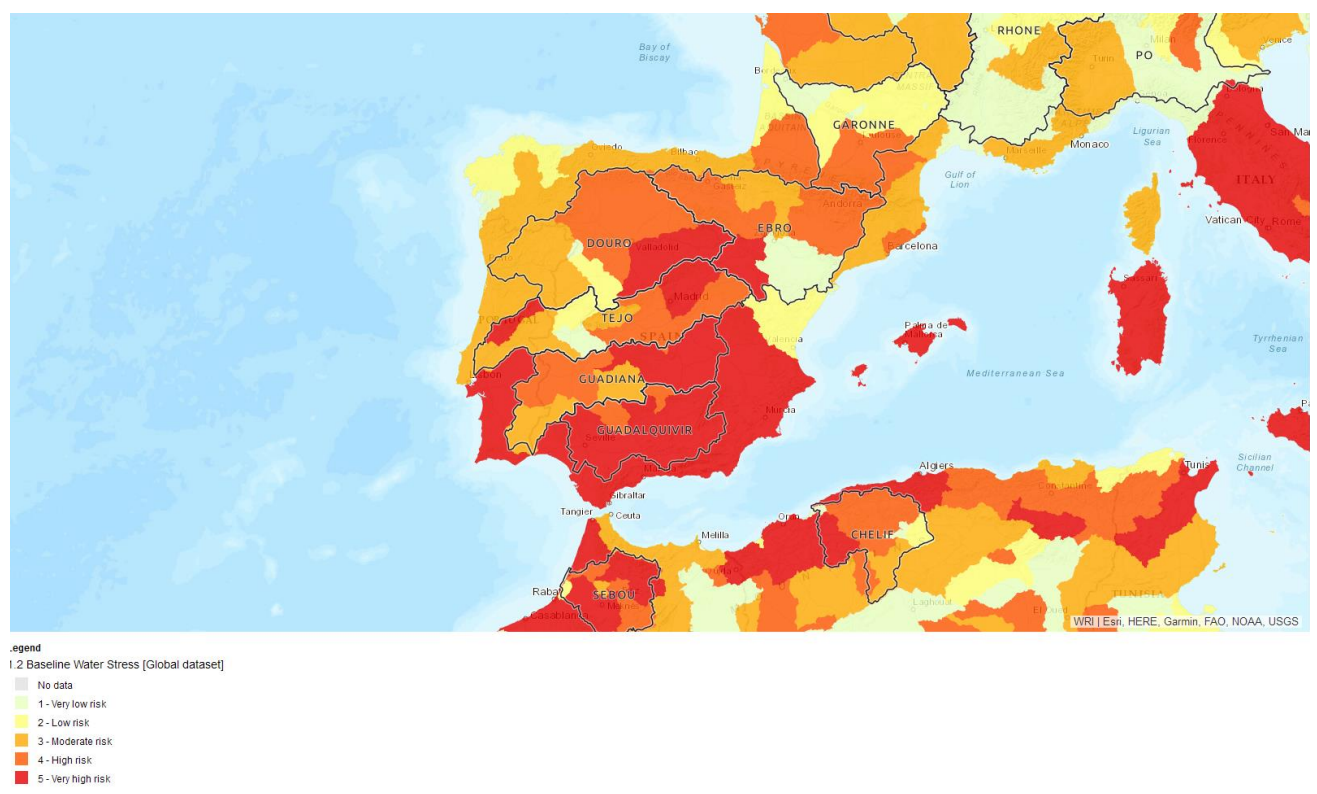

Fuente: WWF (2019) 
perficiales y subterráneas y presiones de la agricultura sobre las demandas de agua (Escribano et al., 2017).

En la península ibérica el agua no solamente funciona como un bien de consumo, sino que también es utilizada para la producción de energía a través de centrales hidroeléctricas. Por lo tanto, los años hidrológicos tienen un impacto significativo en la cantidad de energía que se puede producir por este medio. Por lo tanto, cuanta menos energía se produzca por fuentes renovables, mayor generación de gases de efecto invernadero asociados a la producción de energía a través de combustibles fósiles. En efecto, en el último Informe de Inventario Nacional de Gases de Efecto Invernadero, realizado por el Ministerio para la Transición Ecológica de España (Ministerio para la Transición Ecológica, 2019a), destaca que en el periodo 2011/2017: "se alternan ciclos en los que aumentan y disminuyen las emisiones, debido a variaciones en el mix energético, por la influencia del año hidrológico en la producción de electricidad. Los años con mayores emisiones se producen por la mayor participación de las centrales termoeléctricas unida a los años secos, con menor producción hidroeléctrica; y los años en los que decaen, se debe a una mayor presencia de energías renovables. En el año 2017 la demanda de la electricidad ha subido. Ha sido un año más caluroso y seco que 2016, con mucha menor aportación de la hidráulica, por lo que han aumentado las emisiones procedentes de ciclos combinados y centrales de carbón.»

\subsubsection{Recursos hídricos en las Islas Canarias}

Las fuentes de los recursos hídricos en las islas son diversos entre sí, debido a que la disponibilidad de estos cambia en función de la isla estudiada. En el caso de las islas orientales, como Lanzarote y Fuerteventura, al contar con un menor relieve comparadas con el resto de las islas del archipiélago, han tenido que recurrir desde hace más de treinta años a la desalación de agua de mar. Esto es debido a que debido a sus condiciones orográficas cuentan con menor pluviometría anual y, por lo tanto, con una menor cantidad de recursos hídricos superficiales y subterráneos. Sin embargo, en las islas occidentales como La Palma o Tenerife (Tabla 2.2), los recursos hídricos subterráneos suponen un elevado porcentaje que ayuden a cubrir las diferentes demandas en estas islas (agrícola, industrial, urbana y turística).

Las islas oceánicas de origen volcánico, en particular las Islas Canarias, tienen una hidrología singular. En Canarias no existen grandes ríos como en los terrenos continentales, pero si existen pequeños arroyos permanentes en zonas donde las condiciones hidrológicas son favorables (Santamarta, 2013).

Las islas volcánicas, y en particular las islas occidentales de Canarias, disponen de acuíferos importantes. Al igual que la hidrología superficial, las aguas subterráneas son singulares en las islas y merecen un estudio aparte. Los acuíferos en general se encuentran dispuestos a grandes cotas sobre el nivel del mar, es decir, están sobreelevados. Se desarrollan desde la cota 0 , a nivel del mar, formando el acuífero costero, hasta cotas que en algunas islas superan los 1500 metros 
sobre el nivel del mar. Esto ha generado toda una «minería del agua», para extraer el recurso hídrico mediante galerías de agua (Santamarta, 2017).

Tabla 2.2. Recursos hídricos principales por isla en el archipiélago canario

\begin{tabular}{ccc}
\multicolumn{3}{c}{ Recurso hídrico principal por isla } \\
Isla & Recurso convencional & Recurso no convencional \\
\hline Fuerteventura & - & Desalación \\
Lanzarote & - & Desalación \\
Gran Canaria & Agua subterránea & Desalación \\
Tenerife & Agua subterránea & Desalación \\
La Gomera & Agua subterránea & Desalación \\
El Hierro & Agua subterránea & Desalación \\
La Palma & Agua subterránea & Desalación \\
\hline
\end{tabular}

La gestión de los recursos hidrológicos del archipiélago se desarrolla mediante los planes hidrológicos insulares, que se elaboran por el Consejo Insular de Aguas de cada isla para el ámbito territorial de cada una de las demarcaciones hidrográficas (en el caso de Canarias una demarcación por cada isla) y que consisten en la principal herramienta para alcanzar los objetivos recogidos en la Directiva Marco del Agua. A través de ellos se establecen las directrices en materias de usos, cuantificación de las masas de agua subterráneas y costeras y estado de estas, proyecciones de futuro en cuanto a demanda y recursos hídricos, y demás aspectos relevantes para una correcta planificación hidrológica en Canarias.

\section{Variación de los recursos hídricos en las Islas Canarias debido al Cambio Climático}

En el caso concreto de la isla de Tenerife, el acuífero de la isla comenzó a explotarse a partir de 1920 mediante la construcción de galerías y pozos por iniciativa privada. La intensificación de la demanda de agua en la isla, debido principalmente a la actividad agrícola y turística, ha propiciado que la situación de equilibrio que se tenía anteriormente se haya perdido. Este hecho es constatado en los planes hidrológicos realizados por el Consejo Insular de Aguas, donde se muestran los resultados de los sucesivos balances hídricos anuales del acuífero de la isla, observándose cada vez más déficit.

Con la intención de conocer el efecto del cambio climático en los recursos hídricos de la isla de Tenerife, el Consejo Insular de Aguas de Tenerife (CIATF) ha realizado un proceso de recopilación y revisión de la información meteorológica histórica, con lo que se han logrado componer series de registros de lluvia y temperatura para el conjunto de la isla de hasta 60 años de extensión (1944/2004). Los resultados arrojados por dicho estudio reflejan que los efectos del cambio climático son ya apreciables, encontrándose un descenso tendencial de $-3 \mathrm{~mm} /$ 
año (Braojos, Farrujia, \& Fernández, 2007). La disminución de las precipitaciones en las islas, afectan directamente a la recarga del acuífero insular, ya que parte de la lluvia que recibe el terreno se convierte en infiltración. Por lo tanto, al disminuir la precipitación, disminuye la infiltración y, en consecuencia, la recarga del acuífero. Una de las conclusiones que se pueden extraer es que se hace necesario contemplar la recarga artificial del acuífero de Tenerife, como alternativa a medio y largo plazo.

Teniendo en cuenta que las previsiones de los expertos auguran una disminución de las precipitaciones en los años venideros, un aumento de las temperaturas $\mathrm{y}$ variabilidad en los vientos (lo que puede afectar a la lluvia horizontal en Canarias), es necesario asegurar la optimización de la distribución de los recursos hídricos en las islas del archipiélago, para minimizar todo lo posible las pérdidas de agua reales y aparentes (Tabla 2.3). Además, se considera vital aumentar la producción de regeneración de aguas residuales en Canarias, para disminuir la demanda de recursos convencionales y no convencionales.

Tabla 2.3. Distribución del agua en Canarias (datos del año 2016)

\begin{tabular}{|cc|}
\hline Distribución del agua en Canarias. Año 2016 & \\
\hline Volumen de agua suministrada a la red de abastecimiento & 226.846 \\
Volumen de agua registrada y distribuida & 157.510 \\
Volumen de agua no registrada & 69.336 \\
Pérdidas reales & 52.254 \\
Pérdidas aparentes & 17.082
\end{tabular}

En términos socioeconómicos, nos enfrentaremos también a inconvenientes derivados de la disponibilidad hídrica en las islas. Por ejemplo, si disminuyen las precipitaciones, disminuye la recarga del acuífero, con lo que se hace necesario aumentar la capacidad de desalación de las islas, que se traduce a su vez en un mayor consume energético. Por otra parte, los episodios de sequías que puedan sufrirse afectarán inexorablemente a la agricultura, aumentando la dependencia del archipiélago en el exterior. Es decir, la disminución de precipitaciones que se auguran por efecto del cambio climático, podrá tener repercusiones no solo directamente en la disponibilidad hídrica, sino indirectamente en otros muchos sectores que dependen de ella.

Riesgos de inundaciones por fenómenos meteorológicos adversos, agravados por los efectos del cambio climático

Los modelos climáticos son representaciones numéricas del sistema climático basadas en las propiedades físicas, químicas y biológicas de sus componentes, sus interacciones y los procesos de retroalimentación (IPCC, 1997). Por su parte, el Centro Español de Estudios y Experimentación de Obras Públicas ha elaborado, a partir de los resultados del Informe Especial sobre Escenarios de Emisiones A2 (IPCC, 2014), planes en los que se proyecta la tendencia descendente de las precipitaciones en Canarias desde 2011 hasta 2040. Otra de las amenazas a las que se 
enfrenta el archipiélago es el aumento del nivel del mar, ya que según la Agencia Estatal de Meteorología, a través de la asignación del IPCC-AR5 (AEMET, 2017), se sigue la tendencia media global de aumento del nivel del mar en el área atlántico-cantábrica española, estimada en 3,6 mm/año entre 1993 y 2010. De continuar así, nos enfrentamos al riesgo de inundaciones debidas al mar, lo que será especialmente importante en zonas de espacio geográfico limitado, como las islas.

El Real Decreto 903/2010, sobre evaluación y gestión de riesgos de inundación, en su artículo 2 establece: "Las disposiciones contenidas en el presente real decreto se aplicarán a las inundaciones causadas por desbordamiento de ríos, torrentes de montaña y otros cursos de agua continuos o intermitentes, así como a las inundaciones causadas por el mar en las zonas costeras y a las producidas por la acción conjunta de los ríos y el mar en las zonas de transición» (BOE, 2010). Por lo tanto, en las Islas Canarias existen tres escenarios que favorecen las inundaciones:

\section{- Inundación fluvial}

Esta sección incluye las inundaciones causadas por el desbordamiento de los lechos de los barrancos en episodios de lluvias intensas. Dependen de la orografía de la isla, siendo las más abruptas las que tienen mayor probabilidad de sufrir estas inundaciones, por lo que son las islas occidentales del archipiélago las que más sufren estos episodios. Debido a las inundaciones históricas causadas por los desbordamientos de los barrancos, en las Islas Canarias se han ejecutado numerosas obras hidráulicas conocidas como «encauzamientos de barrancos». Estas obras han logrado minimizar el efecto sobre la población al proporcionar un espacio por el que las aguas de escorrentía pueden fluir siguiendo su curso natural. Esto ha permitido que, en las islas de menor relieve, como Lanzarote y Fuerteventura, se haya podido controlar este problema. En las islas de mayor relieve, estas obras también han logrado minimizar los daños por riesgos fluviales.

\section{- Inundaciones pluviales}

Un rasgo característico y distintivo de las precipitaciones en Canarias es la notable intensidad y concentración de estas en un breve espacio de tiempo (Marzol \& Máyer, 2012). Este fenómeno puede dar lugar a inundaciones localizadas que causan importantes daños materiales y personales, debido a que toda la precipitación se convierte en escorrentía. Las islas más expuestas a este riesgo son las más pobladas, ya que el hecho de tener zonas más urbanizadas y, por lo tanto, menos permeables, aumenta el riesgo de inundación en caso de lluvias extremas.

Este aspecto de torrencialidad de las lluvias puede verse agravado con el cambio climático, sucediéndose más a menudo los temporales de este tipo en el archipiélago canario, con los consecuentes daños de diversa índole que acarrean estos fenómenos meteorológicos adversos.

- Inundaciones debidas al mar

El cambio climático al que nos enfrentamos tiene graves consecuencias para el planeta, incluyendo el derretimiento de los polos, que está causando el aumen- 
to del nivel del mar. Hay muchas predicciones sobre la pérdida de terreno a nivel mundial e, incluso, la desaparición de las islas con menor relieve. En las Islas Canarias hay muchos núcleos de población costeros, así como obras de defensa marítima que podrían verse amenazadas por este fenómeno. Por lo tanto, podríamos decir que las islas presentan un riesgo de pérdida de territorio costero tanto por el aumento del nivel del mar como por fenómenos de oleaje extremo.

Debido a los riesgos reales que suponen las inundaciones en las Islas Canarias, y que han causado problemas históricos en el archipiélago, la Administración Regional ha creado un "Plan de Riesgo de Inundaciones» para cada una de las islas, donde se ha recogido la siguiente información principal: Selección de las zonas potencialmente inundables y de alto riesgo de las cuencas hidrográficas; Evaluación de los riesgos derivados de la escorrentía; Delimitación de las zonas inundables; Selección de las zonas costeras potencialmente inundables; Estudio de la evolución del clima; Estudio de la influencia del cambio climático sobre el nivel del mar y Consideraciones a tener en cuenta en caso de inundaciones costeras y de aguas pluviales.

\section{Referencias bibliográficas}

Adhikari, U., \& Nejadhashemi, A. P. (2016). Impacts of climate change on water resources in Malawi. Journal of Hydrologic Engineering, 21(11), 1154-1168. https://doi.org/10.1061/(ASCE)HE.1943-5584.0001436

AEMET. (2017). Guía de los escenarios regionalizados de cambio climático sobre España a partir de los resultados del IPCC-AR5 (p. 102). p. 102. Madrid.

Blasco Hedo, E. (2014). Real Decreto 163/2014, de 14 de marzo, por el que se crea el registro de huella de carbono, compensación y proyectos de absorción de dióxido de carbono. (BOE núm. 77, de 29 de marzo de 2014). Actualidad Jurídica Ambiental, (34), 39-40.

BOE. (2010). Real Decreto 903/2010, de 9 de julio, de evaluación y gestión de riesgos de inundación. Boletín Oficial Del Estado, (171, de 15 de julio), 61954-61967. Retrieved from http://www.boe.es/buscar/doc.php?id=BOE-A-2010-11184

Braojos, J. J., Farrujia, I., \& Fernández, J. (2007). Los recursos hídricos en tenerife frente al cambio climático. Jornadas Sobre «Las Aguas Subterráneas En La Directiva Marco de Aguas,» 1-16.

Gonzalo, Escribano; Philippe, Quevauviller; Enrique, S. M. E. V. (2017). Climate change policy and water resources in the EU and Spain. A closer look into the Water Framework Directive. Environmental Science and Policy, 69, 1-12.

IPCC. (1997). Introducción a los Modelos Climáticos simples utilizados en el segundo informe de evaluación del IPCC.

IPCC. (2013). Cambio Climático 2013. Bases físicas (p. 34). p. 34. Retrieved from http://www.climatechange2013.org/

IPCC. (2014). Climate Change 2014: Impacts, Adaptation and Vulnerability. 
Janssen, M., \& Timmerman, P. (2014). Modeling Human Dimensions of Global Environmental Change Modeling Human Dimensions of Global Environmental Change Editor-in-Chief. (June).

Keeble, B. R. (1988). The Brundtland Report: «Our Common Future.» Medicine and War, 4(1), 17-25. https://doi.org/10.1080/07488008808408783

Marzol, Maria Victoria; Máyer, P. (2012). Algunas reflexiones acerca del clima de las Islas Canarias. Nimbus, 29-30, 18.

Ministerio para la Transición Ecológica. (2006). Stern review: La economía del cambio climático Sinopsis (p. 32). p. 32.

Ministerio para la Transición Ecológica. (2019a). Informe de inventario nacional gases de efecto invernadero. 2019, 990. Retrieved from https://www.miteco.gob. es/es/calidad-y-evaluacion-ambiental/temas/sistema-espanol-de-inventario-sei-/Inventario-GEI.aspx

Ministerio para la Transición Ecológica. (2019b). Inventario Nacional de emisiones a la atmósfera. Serie 1990-2017. Informe resumen.

ONU. (1992). Convención marco de las naciones unidas sobre el cambio climático.

Santamarta, J.C.;(2013). Hidrología y recursos hídricos en islas y terrenos volcánicos. Madrid: Colegio de Ingenieros de Montes.

Santamarta, J.C.; (2017). Tratado de Minería de Recursos Hídricos en Islas Volcánicas Oceánicas. Colegio de Ingenieros de Minas del Sur y Canarias.

UNE EN ISO 14064. (2015). Parte 1: Especificación con orientación, a nivel de las organizaciones, para la cuantificación y el informe de las emisiones y remociones de gases de efecto invernadero. Aenor.

UNFCCC. (2006). Manual Convención Marco de las Naciones Unidas sobre el Cambio Climático. 72(3), 247. https://doi.org/10.3917/ridp.723.0975

UNFCCC. (2016). 1/CP.21 Aprobación del Acuerdo de París. Unfccc, 01194, 40. Retrieved from http://unfccc.int/resource/docs/2015/cop21/spa/109s.pdf

WMO. (2018). "WMO Statement on the Status of the Global Climate in 2017.» World Meteorological Organization, 2017. WMO_1108_EN_web_000.pdf. WMO statement on the status of the global climate in 2017 . In World Meteorological Organization. Retrieved from http://www.wmo.int/pages/mediacentre/ press_releases/documents/WMO_1108_EN_web_000.pdf

WWF. (2019). Water scarcity and droughts in the Iberian Peninsula. Family Court Review, 57(4), 459-460. https://doi.org/10.1111/fcre.12450 


\title{
Capítulo 3
}

\section{Retos de la gestión del agua en los países mediterráneos frente al cambio climático: casos concretos en diferentes ciudades de España y otros países mediterráneos}

\author{
Romina Álvarez Troncoso \\ Doctora en Ciencias Biológicas
}

\subsection{Introducción al cambio climático}

Antes de adentrarnos en los problemas reales y concretos a nuestro alrededor en la región Mediterránea será necesario definir qué es el cambio climático y cuáles son esos cambios que vemos tanto a nivel global como a nivel local a nuestro alrededor.

En la web ${ }^{1}$ del Ministerio para la Transición Ecológica (MITECO) nos encontramos la siguiente definición de cambio climático: Se llama cambio climático a la variación global del clima de la Tierra. Esta variación se debe a causas naturales y a la acción del hombre y se produce sobre todos los parámetros climáticos: temperatura, precipitaciones, nubosidad, etc, a muy diversas escalas de tiempo.

En la actualidad existe un consenso científico, casi generalizado, en torno a la idea de que nuestro modo de producción y consumo energético está generando una alteración climática global, que provocará, a su vez, serios impactos tanto sobre la tierra como sobre los sistemas socioeconómicos.

Ya en el año 2001 el Tercer Informe de Evaluación del Grupo Intergubernamental de Expertos sobre Cambio Climático (IPCC) señalaba que se están acumulando numerosas evidencias de la existencia del cambio climático y de los impactos que de él se derivan. En promedio, la temperatura ha aumentado aproximadamente $0,6^{\circ} \mathrm{C}$ en el siglo XX. El nivel del mar ha crecido de 10 a 12 centímetros y los investigadores consideran que esto se debe a la expansión de océanos, cada vez más calientes.

El Informe de Síntesis del Quinto Informe de Evaluación del IPCC, publicado en noviembre de 2014, concluye que «la influencia humana en el sistema climático es clara y va en aumento, y sus impactos se observan en todos los continentes. Si no se le pone freno, el cambio climático hará que aumente la probabilidad de impactos graves, generalizados e irreversibles en las personas y los ecosistemas. Sin embargo, existen opciones para la adaptación al cambio climático, y con ac-

${ }^{1}$ https://www.miteco.gob.es/es/cambio-climatico/temas/default.aspx 
tividades de mitigación rigurosas se puede conseguir que los impactos del cambio climático permanezcan en un nivel controlable, creando un futuro más claro y sostenible».

El cambio climático nos afecta a todos. El impacto potencial es enorme, con predicciones de falta de agua potable, grandes cambios en las condiciones para la producción de alimentos y un aumento en los índices de mortalidad debido a inundaciones, tormentas, sequías y olas de calor. El Informe de Síntesis confirma que «el cambio climático se constata en todo el mundo y que el calentamiento del sistema climático es inequívoco. Desde la década de 1950, muchos de los cambios observados no han tenido precedentes en los últimos decenios a milenios y los impactos del cambio climático ya se han sentido en los últimos decenios en todos los continentes y océanos». El cambio climático no es un fenómeno sólo ambiental sino de profundas consecuencias económicas y sociales. Los países más pobres, que están peor preparados para enfrentar cambios rápidos, serán los que sufrirán las peores consecuencias. El Informe de Síntesis de 2014 sostiene con claridad que «muchos riesgos son particularmente problemáticos para los países menos adelantados y las comunidades vulnerables, dada su limitada capacidad para afrontarlos. Las personas marginadas en los ámbitos social, económico, cultural, político, institucional u otro son especialmente vulnerables al cambio climático».

Dicho Informe de Síntesis señala que «para limitar realmente los riesgos del cambio climático, es necesario reducir de forma sustancial y sostenida las emisiones de gases de efecto invernadero. Y en la medida en que la mitigación reduce la tasa y la magnitud del calentamiento, también dilata el tiempo de que disponemos para la adaptación a un nivel determinado del cambio climático, potencialmente en varios decenios».

En consecuencia, aunque existen incertidumbres que no permiten cuantificar con la suficiente precisión los cambios del clima previstos, la información validada hasta ahora es suficiente para tomar medidas de forma inmediata, de acuerdo al denominado "Principio de Precaución» al que hace referencia el Artículo 3 de la Convención Marco sobre Cambio Climático.

\subsection{Qué vemos a nuestro alrededor en España como cambio climático}

Desde la industrialización, llevada a cabo durante el siglo $\mathrm{XX}$, la temperatura de nuestro planeta ha aumentado $0,6^{\circ} \mathrm{C}$ y el nivel del mar ha subido de 10 a 12 centímetros. El mayor riesgo de incendios, la falta de agua potable, las inundaciones, las sequías y la pérdida de cosechas estarán sobre la mesa en un futuro cada vez más cercano.

Según el Ministerio para la Transición Ecológica, el 74\% del suelo español está en proceso de desertización y se prevé que un $20 \%$ de lo que hoy está a salvo se verá en riesgo dentro de 50 años. Andalucía, Extremadura, Castilla-La Mancha y prácticamente todo el Levante ya presentan una gran proporción de suelo con 
susceptibilidad de degradarse. Esto afectará negativamente a las actividades agropecuarias y los ecosistemas acabarán visiblemente afectados. Greenpeace ha lanzado la alerta sobre la desertificación del territorio español.

La pérdida de suelo fértil es irreversible y está aumentando la vulnerabilidad de todas las especies españolas incluida la humana. Pero la desertificación tiene consecuencias más allá de la pérdida de la fertilidad del suelo. El éxodo hacia las grandes ciudades debido a la crisis de la agricultura tradicional, motivará que los recursos naturales de las zonas colindantes con estas urbes se verán sobreexplotados, incluyendo los recursos hídricos subterráneos, y se elevarán los niveles de contaminación de estas áreas motivando que el cambio climático siga retroalimentándose.

El cambio climático ha motivado que los ecosistemas acuáticos continentales pasen de ser permanentes a estacionales. Lagos, arroyos de montaña o humedales costeros ven como su biodiversidad empieza a fluctuar en función de la estación del año. En los ecosistemas acuáticos marinos se ha cuantificado el impacto del aumento de la temperatura y de $\mathrm{CO}_{2}$ que desencadenan alteraciones en el régimen de vientos, afloramientos o evaporación del agua con resultados preocupantes.

\subsubsection{Eventos extremos más frecuentes}

Existen varios efectos causados por fenómenos naturales extremos ocasionados por el cambio climático y su aceleración. Fuertes lluvias, sequía, desde Galicia, pasando por el País Vasco, centro de España y Levante hasta Túnez, Egipto y Jordania. En todos ellos el fenómeno extremo de sequías cada año más tempranas y de mayor duración es patente. En países como Túnez, Jordania y Egipto, y otros países Mediterráneos, la sequía es común en los últimos siglos, sin embargo la escasez de agua se ha ido agravando hasta llegar a niveles como en Amman donde no tienen agua corriente en sus grifos a diario a pesar que el consume de agua por habitante es mucho más bajo que otros países europeos o EEUU.

\subsection{Cambios que nos afectan a todos}

La lucha contra el cambio climático es fundamental para un futuro sostenible. No hay país que no esté experimentando los drásticos efectos del cambio climático. Las personas de todo el mundo sufren escasez de alimentos, desplazamientos masivos y riesgos para sus medios de subsistencia y sus vidas. El promedio anual de pérdidas económicas por desastres relacionados con el clima es de cientos de miles de millones de dólares. El Objetivo de Desarrollo Sostenible 13 sobre acción climática tiene por objeto movilizar 100.000 millones de dólares anuales para 2020 a fin de atender las necesidades de los países en desarrollo de adaptarse al cambio climático e invertir en el desarrollo con bajas emisiones de carbono. Apuntar al aumento de la temperatura media mundial a $1,5^{\circ} \mathrm{C}$ y limitarlo a $2^{\circ} \mathrm{C}$ exigirá una acción colectiva urgente y ambiciosa, junto con una fuerte voluntad política, tecnología y una mayor inversión. 


\subsection{Descripción del cambio climático}

El estudio del clima es un campo de investigación complejo y en rápida evolución, debido a la gran cantidad de factores que intervienen.

El clima de la Tierra nunca ha sido estático. Como consecuencia de alteraciones en el balance energético, está sometido a variaciones en todas las escalas temporales, desde decenios a miles y millones de años. Entre las variaciones climáticas más destacables que se han producido a lo largo de la historia de la Tierra, figura el ciclo de unos 100.000 años, de períodos glaciares, seguido de períodos interglaciares.

Figura 3.1. James Hansen y Syukuro Manabe, definieron el concepto de cambio climático

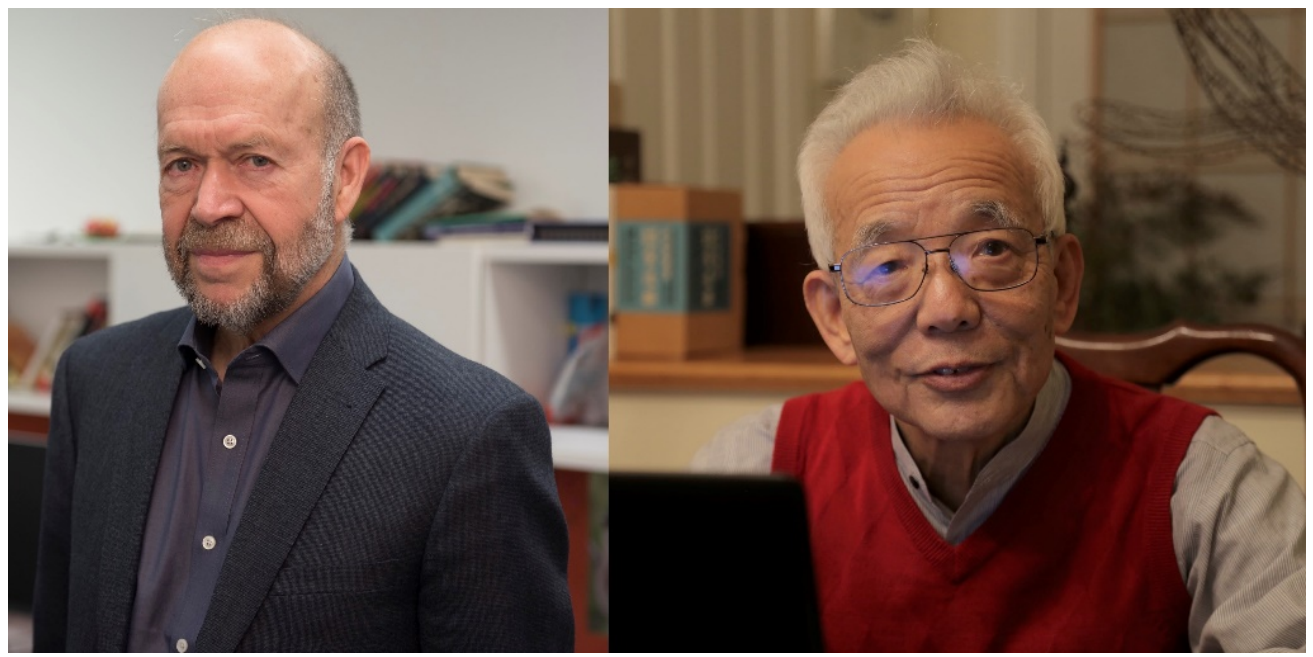

Fuente: FUNDACIÓN BBVA

Fueron los científicos, a principios-mediados del siglo XX, los que dieron la voz de alerta a la sociedad sobre este cambio en la naturaleza. Durante las décadas de 1950 a 1980 se recogieron datos que pasaron a confirmar términos como efecto invernadero, emisiones de $\mathrm{CO}_{2}$ y erosión de la capa de ozono.

Los climatólogos Syukuro Manabe y James Hansen crearon, hace 50 años, los primeros modelos para medir el cambio climático por la influencia humana, y ya entonces predijeron que la temperatura subiría dos grados este siglo.

\subsection{Cambios naturales y antrópicos}

Antes de la Revolución Industrial, el clima de la Tierra cambió debido a eventos naturales como la actividad volcánica y las variaciones de la energía solar. Estos fenómenos naturales siguen contribuyendo al cambio climático en la actua- 
lidad, pero su impacto es muy pequeño en comparación con los crecientes niveles de gases de efecto invernadero añadidos a la atmósfera por los seres humanos que queman combustibles fósiles. Las misiones, investigaciones y modelos informáticos de la NASA nos ayudan a comprender mejor los cambios globales a largo plazo que se producen hoy en día, tanto por causas naturales como provocadas por el hombre.

Los impactos del cambio climático van desde un aumento de los fenómenos meteorológicos extremos y las inundaciones hasta temperaturas más altas y problemas de salud pública

El impacto potencial es enorme, con predicciones de falta de agua potable, grandes cambios en las condiciones para la producción de alimentos y un aumento en los índices de mortalidad debido a inundaciones, tormentas, sequías y olas de calor

\subsubsection{Hielo}

En el cuarto informe de evaluación del IPCC, Grupo Intergubernamental sobre el Cambio Climático, se puso de manifiesto observaciones tan importantes como las siguientes:

Desde 1978 los hielos marítimos árticos han disminuido, al igual que los glaciares de montaña y la cubierta de nieve.

Figura 3.2. Evolución del grosor del hielo marino del Ártico

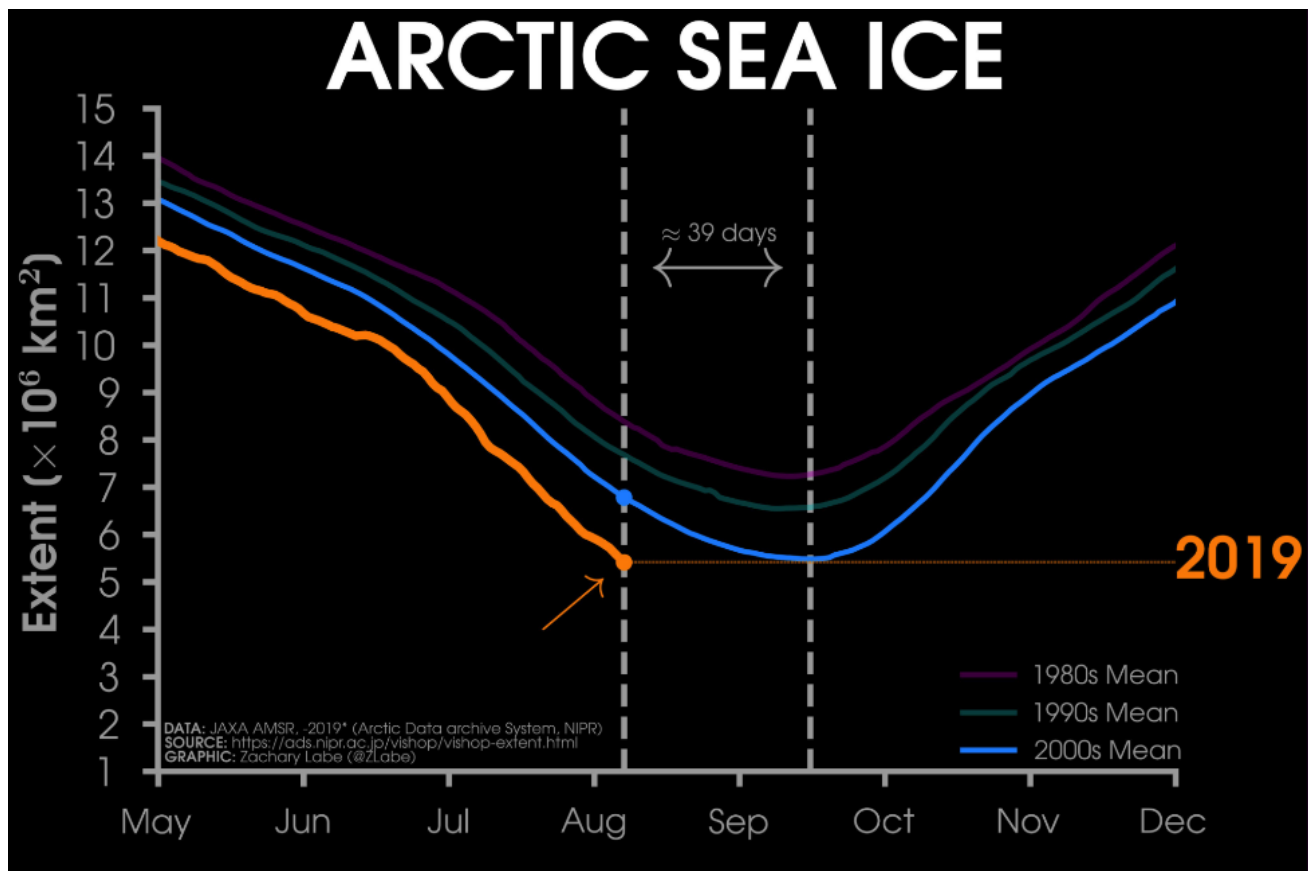

Fuente: Zacary Labe 
El deshielo de los casquetes polares y los glaciares, el aumento del nivel del mar, la sequía, las lluvias torrenciales... El calentamiento global cambiará también nuestra relación con el agua, tanto dulce como salada y la pregunta es, cestamos preparados para afrontar el cambio?

Así es como se ve el hielo marino ártico en 2019 (Figura 3.2). Cada año el hielo en el ártico crece y se encoge como parte de su ciclo estacional. Alcanza su extensión mínima anual al final de cada verano (principios de septiembre). Actualmente, la extensión del hielo marino de 2019 ya está por debajo de los mínimos de los promedios dedecadales de 1980, 1990 y 2000. Datos: Zack Labe.

\subsubsection{Lluvia y viento}

Desde la Revolución Industrial ha habido grandes cambios en los regímenes de lluvias del planeta. La superficie mundial afectada por la sequía sigue aumentando. Desde 1970 se observa un mayor número de ciclones y huracanes, propiciado por el aumento de aire caliente en la atmósfera.

\subsubsection{Temperatura}

A lo largo de los últimos 50 años ha aumentado la temperatura media global del planeta. Los cambios de estación han alterado su ritmo. La primavera se adelanta afectando al florecimiento de árboles y plantas y a las migraciones de los animales. En general, la naturaleza se está viendo afectada por el cambio climático.

\subsection{Alteraciones y extinciones}

Impactos en las comunidades como el funcionamiento de los ecosistemas, afectando a servicios clave que proveen los ecosistemas.

Además, los cambios en el clima afectan a las interacciones bióticas, alterándolas o estableciendo interacciones diferentes. Adelanto de la foliación y retraso de la caída de la hoja. Alteraciones en la fenología de las migraciones de las aves.

Aceleración en las fases larvarias de especies de insectos: El proyecto CLIMINSECTS $^{2}$ (The effect of expected climate change on insect performance: physiology, behaviour and life history) surgió a partir de la observación de que los insectos presentan una gran adaptabilidad al cambio climático.

Los resultados más importantes de este proyecto presentados oficialmente en su informe final concluyen los siguientes datos:

(1) Se esperaba que el calentamiento global y el aumento de las temperaturas redujeran el tamaño del cuerpo. En contraste con la mayoría de los estudios sobre

\footnotetext{
${ }^{2}$ https://cordis.europa.eu/project/rcn/107308/reporting/es
} 
vertebrados que muestran una disminución en el tamaño corporal en los últimos 100 años, no se detectó tal cambio cuando se midieron más de 4.000 especímenes de 29 especies de escarabajos. Puede ser que otros factores, como la disponibilidad de alimentos, sean más importantes, o que la variabilidad entre años sea demasiado alta para detectar tal patrón.

(2) El estado fisiológico estresante llevó a una tolerancia térmica defectuosa en los escarabajos de la harina. Por ejemplo, la inanición y la vejez deterioraron la tolerancia térmica. El efecto de la inanición era reversible. El estrés no siempre conduce a una disminución de la tolerancia térmica. Por ejemplo, el choque frío aumenta la tolerancia al calor y, en algunos casos, el choque térmico aumenta la tolerancia al frío en los escarabajos de la harina, ejemplificando la "tolerancia cruzada» entre los factores estresantes. Es importante entender cómo los animales equilibran las demandas conflictivas y si el estrés es siempre perjudicial o puede ser beneficioso bajo ciertas circunstancias, para entender cómo podrían responder a los cambios en su entorno.

(3) Está demostrado que el crecimiento y las temperaturas de los adultos tienen efectos considerablemente diferentes sobre la tolerancia térmica. La temperatura experimentada en la edad adulta, antes de la exposición a una temperatura más estresante en la misma dirección (por ejemplo, una temperatura cálida suave seguida de una temperatura cálida estresante), una aclimatación inducida y una mejor respuesta al estrés. La temperatura de crecimiento jugó un papel diferente: Una temperatura más alta llevó a una mayor tolerancia al calor y al frío. Este resultado contradice la hipótesis de aclimatación beneficiosa y no apunta a la aclimatación.

(4) En un estudio macroecológico sobre unas 1.000 especies de reptiles, se ha demostrado que los reptiles de las regiones más frías viven más tiempo, lo que es plausible debido a un desarrollo más lento y a una edad más avanzada en el momento de la primera reproducción. Los factores que determinan la longevidad de las diferentes especies y las razones básicas por las que la edad de los animales sigue siendo objeto de debate y se ven definitivamente afectados por el clima.

(5) El estrés repetido o crónico tiene un efecto diferente sobre el rendimiento de los insectos que un solo estrés leve. No es de extrañar que el estrés crónico afecte al rendimiento con más fuerza que un estrés leve, expresado, por ejemplo, en una menor actividad de movimiento, una menor tendencia al apareamiento y una intensidad de reproducción más débil. Sin embargo, en contraste con el estrés leve, el estrés crónico llevó a mayores reservas de grasa, mayor tolerancia al hambre y mejor tolerancia al frío. Sugiere que mientras están estresados, los insectos cambian su enfoque de la reproducción a la supervivencia. Estos cambios son claramente costosos, ya que perjudican la reproducción, pero podrían ayudarles a sobrevivir en condiciones difíciles.

(6) El proyecto actual condujo a muchas otras publicaciones que no eran el foco principal de la propuesta de investigación, pero que están estrechamente relacionadas con las respuestas de los insectos a la temperatura desfavorable. Por citar un ejemplo, se estudió cómo los insectos tienen en cuenta las demandas conflictivas en su procedimiento de elección de hábitat. Específicamente, el gusano, 
un insecto que habita en la arena, prefiere la sombra que asegura temperaturas más bajas y riesgo de desecación. Sin embargo, la sombra se ve comprometida si la arena está obstruida con piedras o es poco profunda. La capacidad de los insectos para considerar simultáneamente tres factores o más y alcanzar una decisión óptima (similar quizás al cálculo metafórico de un "promedio ponderado») es sorprendente. Curiosamente, mientras que la sombra se prefiere bajo temperaturas más cálidas, la preferencia por la luz aumenta cuando se prueban los millones de gusanos bajo temperaturas más frías, lo que demuestra la interacción entre las condiciones de iluminación y la temperatura y su efecto conjunto sobre la preferencia de hábitat por parte de los insectos.

Los resultados obtenidos tienen varias implicaciones importantes para los insectos en condiciones de estrés. En primer lugar, los insectos podrían verse menos afectados por el cambio climático que los vertebrados, o que su variabilidad de tamaño entre años es demasiado alta para detectar un cambio. La mayoría de los estudios hasta ahora se centraban en los vertebrados. Los insectos, como grupo, podrían adaptarse más fácilmente a los cambios ambientales. En segundo lugar, el estrés es en su mayor parte negativo, pero en algunas circunstancias puede dar lugar a respuestas beneficiosas, como la "tolerancia cruzada» a otros factores estresantes o el aumento de la supervivencia debido a un cambio en el punto de equilibrio en el equilibrio entre la reproducción y la supervivencia. En diferentes animales se sabe que un bajo nivel de estrés puede tener un efecto beneficioso (llamado «hormesis»), y también tiene implicaciones para los humanos. Hace más difícil predecir si el cambio ambiental sería perjudicial o no. Este último punto es válido también para el efecto potencialmente diferente e incluso contradictorio del estrés térmico experimentado durante las distintas etapas de la vida de los insectos.

Otras alteraciones en el medio natural que se ha determinado es el decaimiento forestal donde el vigor del arbolado se puede ver comprometido hasta el punto de la muerte de un importantísimo número de árboles: defoliaciones, reducciones en el crecimiento, aumento de la mortalidad. En la actualidad, debido al periodo de alternancia climática entre años secos y lluviosos, se observa una reactivación del proceso de deterioro y muerte de árboles, razón por la que se considera necesaria la realización de una importante labor formativa y divulgativa de los avances alcanzados.

Desplazamientos altitudinales en especies leñosas y Lepidopteros. Según Gutiérrez Illan, en el trabajo de tesis» Efectos del cambio climático sobre las poblaciones de lepidópteros de la Sierra de Guadarrama modelos predictivos», el cambio climático es una realidad desde hace varias décadas y sus efectos pueden ya medirse en términos de pérdida de biodiversidad. Las poblaciones de los sistemas montañosos, por su parte, representan un excelente sistema de estudio para evaluar los efectos del cambio climático sobre la biodiversidad debido a que están fuertemente controlados por las condiciones ambientales y a que estas especies disponen de gradientes altitudinales que facilitan desplazamientos hacia zonas con climas más adecuados en pequeñas distancias geográficas. Además, estas especies son especialmente vulnerables a los cambios climáticos ya que, en muchas ocasiones, el desplazamiento migratorio altitudinal no es posible si los hábitats 
superiores ya han sido colonizados o no hay más territorio al que desplazarse. Sin embargo, y a pesar de que las alteraciones sobre las especies han sido ampliamente estudiadas en los límites de distribución altitudinales y latitudinales superiores, existe un notable déficit de estudios llevados a cabo en los márgenes inferiores o cálidos de distribución. La principal motivación de ésta tesis fue cubrir este deficiencia, estudiando los efectos del cambio climático sobre la distribución, riqueza y fenología de las poblaciones de mariposas de la Sierra de Guadarrama, un sistema donde muchas especies hayan su límite sur de distribución. Para cumplir los objetivos de esta tesis, llevamos a cabo diversas técnicas de modelización ecológica, a partir de muestreos de campo realizados durante cinco años, y variables ambientales procedentes de varias fuentes e implementadas en Sistemas de Información Geográfica.

Establecimiento de nuevas interacciones bióticas negativas para algunas especies: El mosquito tigre, proveniente del sudeste de Asia, ha empezado a colonizar gran parte de Cataluña y la Comunidad Valenciana y la proliferación de grandes bancos de medusas en las costas españolas en verano se debe principalmente al descenso de las precipitaciones.

\subsection{Cambios locales}

Las proyecciones y los modelos de predicción del clima actuales muestran que el Mediterráneo, en menos de cien años será un mar de aguas mucho más calientes. El impacto previsto es la migración o la substitución de especies. Algunos investigadores del Instituto Mediterráneo de Estudios Avanzados (IMEDEA, UIBCSIC) señalan que puede conducir incluso a la mortalidad de algunas de ellas, especialmente de las praderas de Posidonia, cuya principal amenaza no es una subida de la temperatura media, sino los episodios de temperaturas extremas que superen los 28 grados durante varios días, lo que puede llegar a ser mortal para esta planta.

\subsubsection{Túnez}

En la zona norte del país el nivel de agua cada año es más reducido, cada año hay menos recursos disponibles en las cuencas del país. Como se puede apreciar, estas áreas se caracterizan por la presencia importante de procesos de desertización.

\subsubsection{Jordania}

En muchas de las cuencas, los embalses están colmatados de sedimentos y solo están disponibles $20 \%$ de su capacidad total. 
En este marco, y aunque parezca evidente, es necesario señalar que el agua es un recurso natural fundamental para la vida humana, por lo cual su importancia atraviesa horizontalmente todos los sectores de la vida económica y social. En este contexto, debería entenderse que la gestión de un recurso de este tipo, tendría que hacerse desde una perspectiva que integre todos los factores en el análisis. Es decir, el agua demanda una integralidad en su gestión, integralidad que posee una urgencia mucho mayor en zonas áridas y semiáridas por la escasez y fragilidad ambiental de este recurso, y por la urgencia que demandan las poblaciones humanas involucradas. Por consiguiente, sería interesante estudiar evaluativamente si esta premisa se cumple o si sólo es un ideal de actuación.

\subsubsection{Azerbaijan}

Un agricultor del pueblo de Abrikh, en Azerbaiyán, tenía una buena vida ya que era propietario de varias hectáreas de tierra donde cultivaba frutas y avellanas. Pero en 2008, el medio ambiente del cual dependía se volvió contra él y una crecida repentina bajó de las montañas y destruyó sus tierras. Para él y su familia la vida es ahora una lucha constante.

Los patrones meteorológicos extremos son comunes en la región del Gran Cáucaso, pero están aumentando a causa del cambio climático. El promedio anual de daños causados por inundaciones en la región se estima entre US\$18 y US\$ 25 millones solo en infraestructura. Además, Azerbaiyán recién sale de una prolongada sequía que se estima afectará la agricultura en los próximos años. En algunas partes del país, las cosechas se estropearon sin posibilidad de recuperación y las tierras de pastoreo se secaron, afectando a miles de animales. Según la Convención Marco de las Naciones Unidas sobre el Cambio Climático (CMNUCC), es probable que las sequías reduzcan el abastecimiento de agua en el país en un 23 por ciento entre 2021 y 2050. Mejorar la resiliencia comunitaria al estrés por falta de agua requiere de una adaptación proactiva a los efectos del cambio climático. Sin embargo, las políticas actuales de Azerbaiyán en gestión acuífera no son lo suficientemente flexibles y la capacidad institucional no alcanza para abordar los daños y peligros asociados con el clima. Por otra parte, las comunidades locales aún no han podido participar activamente en las decisiones sobre la gestión del agua y las inundaciones.

\subsubsection{Egipto}

De entre todas las catástrofes atribuibles al cambio climático, pocas resultan tan gráficas para el ser humano como el aumento del nivel del mar. La mayor parte de la humanidad se aglutina en las costas, tradicionales focos de comercio y desarrollo, y una fracción no menor de los residentes litorales se asientan sobre depresiones amables o llanuras fácilmente inundables. A larguísimo plazo, su situación podría resultar dramática. 
Desde finales del siglo XIX se cree que el mar ha subido unos 18 centímetros. 7 de ellos son atribuibles a los últimos veinte años. Es decir: el ritmo se está acelerando. En Egipto se calcula que hay un $21 \%$ de población expuesta al bajo cauce del Nilo.

El paseo marítimo de Alexandria está bordeado por barreras de hormigón para evitar el aumento de las olas.

Alejandría es una ciudad en primera línea del cambio climático. Según las cifras de las Naciones Unidas, incluso un aumento del nivel del mar de $50 \mathrm{~cm}$ destruirá por completo sus playas, mientras que «las tierras bajas de Alejandría -en las que se desarrolló originalmente la ciudad de Alejandría- son vulnerables a las inundaciones, a la saturación, al aumento de las inundaciones y a la salinización bajo el aumento acelerado del nivel del mar».

El Grupo Intergubernamental de Expertos sobre el Cambio Climático de las Naciones Unidas ha dicho que se espera que el nivel mundial del mar aumente hasta $68 \mathrm{~cm}$ para 2050, inundando partes de Alejandría y filtrándose en las aguas subterráneas. También causará derrumbes de edificios y forzará al agua salada a entrar en tierras de cultivo vitales en la cercana región del Delta del Nilo, destruyendo los medios de subsistencia y forzando un mayor desplazamiento interno.

En la «Pequeña Venecia» de Alejandría, una comunidad pesquera pobre se enfrenta a la demolición de sus casas y a la pérdida de sus medios de subsistencia debido al aumento del nivel del mar, y un gobierno local deseoso de limpiar sus barrios de tugurios.

Figura 3.2. Al Max, la pequeña Venecia de Alejandría y los efectos de la subida del nivel del mar

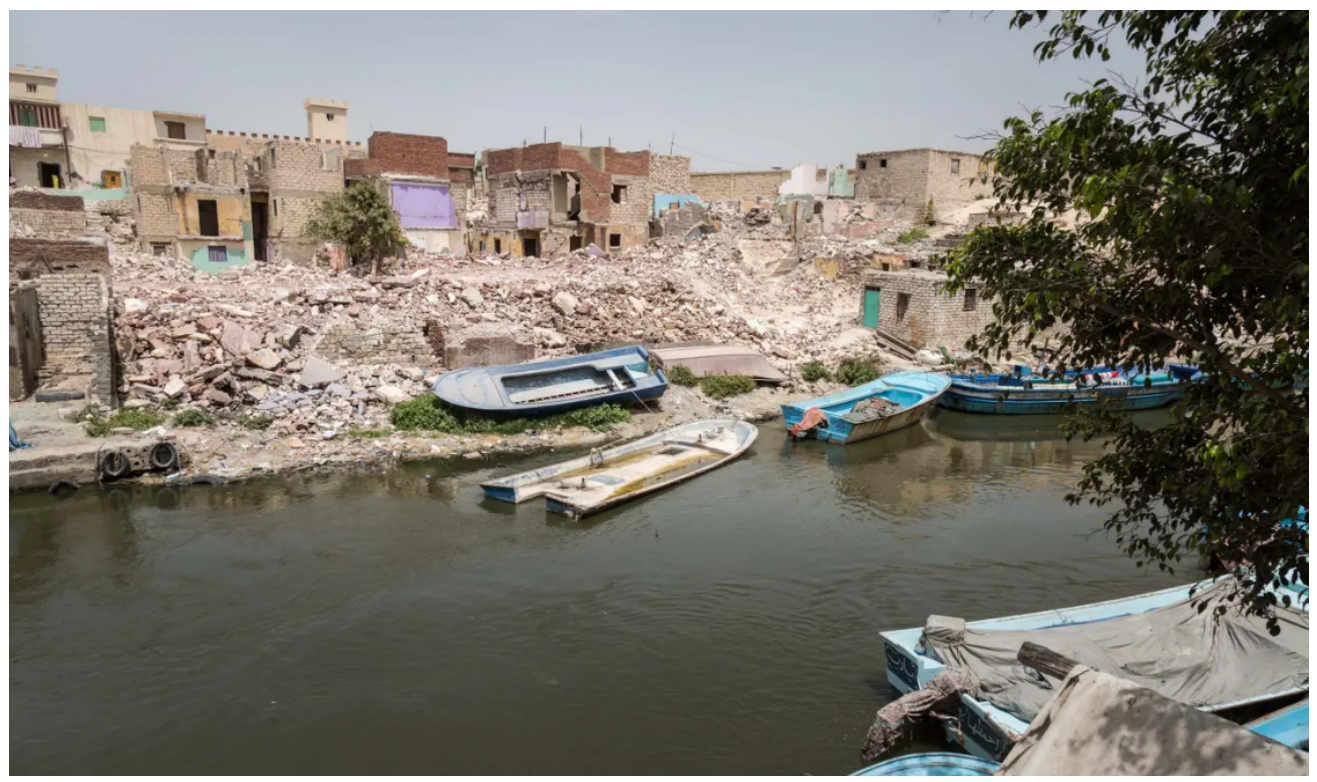

Fuente: y Sima Diab for the Guardian 
A orillas del canal de Al Max, cerca de la ciudad portuaria egipcia de Alejandría, un hombre desenreda las redes de pesca en su barco pintado de turquesa cuando el sonido de un mazo que golpea ladrillos rebota en la vía fluvial. Otros se asoman por las ventanas de una orilla del canal, mirando los crecientes montones de escombros de lo que una vez fueron filas de casas en la orilla opuesta. Los anteriores ocupantes, así como los que los miran, son un presagio de miles de personas que se verán obligadas a abandonar sus hogares debido al cambio climático.

Durante años los vecinos sufrieron numerosas avenidas e inundaciones. La difícil situación de los residentes de Al Max es una señal de alerta temprana, la primera ola de miles de personas que se verán obligadas a desplazarse debido a los efectos del cambio climático en la zona, en particular en las proximidades del lago Mariout.

\subsubsection{España}

Según un estudio realizado por el CEDEX en 2017 acerca del cambio climático se determinaron cierto pronóstico futuro.

En relación al impacto del cambio climático en el régimen de sequías, se pronostica de manera general una reducción de recursos hídricos en España conforme avance el siglo XXI y por lo tanto un aumento de la escasez de agua en España. Por otro lado, también se pronostica un cambio en el régimen de sequías para cada periodo de impacto futuro con relación al periodo de control. La mayoría de las proyecciones climáticas muestran un futuro en el que las sequías serían más frecuentes, acusándose ese efecto cuanto más nos alejamos en el siglo XXI. No obstante, hay proyecciones que no muestran tan clara esa señal, especialmente en cuencas del Levante y Canarias. Se aprecian escasas diferencias entre los resultados aportados por ambos escenarios de emisiones, si bien las sequías tenderían a ser más frecuentes para el escenario RCP 8.5, sobre todo para los últimos periodos del siglo XXI.

En relación al impacto sobre los recursos hídricos, se estiman mayoritariamente descensos de precipitación, siendo mayores estos descensos en el cuadrante SO de la Península y en los archipiélagos. Se estiman aumentos de ETP en todos los ámbitos y estaciones climáticas según todas las proyecciones, con muy contadas excepciones. Los aumentos serán menores en las zonas de costa que en las de interior.

De ese modo, se estiman descensos generalizados en la recarga de acuíferos para el siglo XXI, si bien hay grandes discrepancias entre las estimaciones según la proyección climática.

\subsection{Posibles soluciones para frenar estos cambios}

La factura ambiental de la industrialización es muy alarmante ya que es mundial la producción de energía eléctrica y el transporte suponen un grave impacto 
por las elevadas emisiones que producen. De ahí radica la necesidad de implicar a investigadores, instituciones y a la ciudadanía para reducir los impactos del cambio climático en el Mediterráneo del siglo que viene.

En relación al agua, tal y como señala el MITECO $^{3}$ en sus planes PIMA, los proyectos que reduzcan la vulnerabilidad ante los efectos del cambio climático pueden ir encaminados en las siguientes líneas:

- Medidas de gestión y adaptación de las reservas naturales fluviales (RNF).

- Adaptación a los fenómenos extremos.

- Evaluación del impacto del cambio climático en los recursos hídricos y desarrollo de estrategias de adaptación.

- Desarrollo de proyectos de adaptación al cambio climático en el dominio público hidráulico.

Además se pueden implementar otras medidas como son:

- La reducción de la extensión de superficies impermeables.

- El rediseño y reconstrucción a largo plazo de los sistemas de drenaje actuales.

- Mejora en la legislación.

- Revisión de la agricultura actual y sus políticas para centrarse en la agricultura rural y el desarrollo.

- Demolición de estructuras.

- Mayor conciencia y educación.

- Aplicar los resultados de la investigación Dragado regular de cuerpos de agua y arroyos urbanos y limpieza de desagües abiertos.

- Mejoramiento de los sistemas de alerta / preparación ante inundaciones y aviso a la población.

- Planificación adecuada del uso de la tierra: los estudios futuros deberían considerar los problemas técnicos involucrados, como el potencial de propensión a inundaciones del área.

- Verificación de las prácticas de deforestación y la implementación de programas de forestación siempre que sean necesarios.

\section{Referencias bibliográficas}

Frihy, O. E., E.A. Deabes, S.M. Shereet, F.A. Abdalla (2010), «Alexandria-Nile Delta coast, Egypt: update and future projection of relative sea-level rise», Environ. Earth Sci., 61, 253-273.

\footnotetext{
${ }^{3}$ https://www.miteco.gob.es/es/cambio-climatico/planes-y-estrategias/PIMA-Adapta.aspx
} 
Pizarro Tapia, R. (1999)»Análisis de la gestión del agua en zonas áridas y semiáridas: una propuesta de actuación» en Afers Internacionals, núm. 45-46, pp. 11 33.

CEDEX (2017) Evaluación del impacto del cambio climático en los recursos hídricos y sequías en España. Centro de Estudios Hidrográficos. España. 320 pp.

CMCC (2005) Cuidar el clima Guía de la Convención Marco sobre el Cambio Climático y el Protocolo de Kyoto (edición revisada, 2005). Alemania. 50 pp

Herrero A \& Zavala MA, editores (2015) Los Bosques y la Biodiversidad frente al Cambio Climático: Impactos, Vulnerabilidad y Adaptación en España. Ministerio de Agricultura, Alimentación y Medio Ambiente, Madrid.

UNDP (2014) Government of Egypt :Project Document 3748: Adaptation to Climate Change in the Nile Delta through Integrated Coastal Zone Management. United Nations Development Programme

REC, 2018, Guide for Water Monitoring Techniques applicable in MENA region $<$ http://www.rec.org/publication.php?id=668>

Gutiérrez Illán, J. (2009). Efectos del cambio climático sobre las poblaciones de lepidópteros de la Sierra de Guadarrama modelos predictivos. Tesis doctoral. Madrid: Universitat Rey Juan Carlos, < https://eciencia.urjc.es/handle/10115/5085> [Consulta: 20 de septiembre 2019]

Portal de la NASA < https://climate.nasa.gov/interactives/climate-time-machine> [Consulta: 20 de septiembre de 2019]

Visor de Escenarios de Cambio Climático una herramienta para la visualización y la descarga de datos relativos al clima futuro de España $<$ http://escenarios. adaptecca.es/\#\&model $=$ multimodel \&variable $=$ tasmax \&scenario $=r c p 85 \&-$ temporalFilter $=$ YEAR\&layers $=$ AREAS\&period $=$ MEDIUM_FUTURE\&anomaly $=$ RAW_VALUE $>$ [Consulta: 20 de septiembre de 2019] 


\title{
Capítulo 4 \\ Los bosques y los recursos hídricos en un contexto de cambio climático
}

\author{
Eduardo RoJas BRIALES \\ Doctor Ingeniero de Montes
}

\subsection{Introducción}

La estrecha relación entre la cubierta forestal de un lado, y el ciclo hídrico y el suelo de otro, ha estado presente en la ciencia, formación y ejercicio profesional forestal desde sus primeros pasos, especialmente en países montañosos con potencial torrencial. Los dos ejemplos más próximos son el Catálogo de Montes de Utilidad Pública justificado precisamente por la insustituible función regulatoria de los bosques de montaña o la denominación de la formación equivalente a la Ingeniería de Montes en Francia: Ingénieurs des Eaux et Fôrets.

Hasta el arranque de la industrialización, la urbanización, el establecimiento de la red de ferrocarril y la intensificación de la agricultura, el crecimiento demográfico llevaba inexorablemente como contrapartida la ampliación territorial de la agricultura y, por tanto, la deforestación con importantes efectos hidrológicos y sobre el suelo, especialmente en zonas de montaña o de sustratos sueltos como arenales. La Europa del siglo XVIII, y en el caso de España también de buena parte del XIX por las convulsiones internas que retrasaron la industrialización, mostraba un alto grado de deforestación y graves problemas hidro-geológicos hoy difícilmente imaginables. Los arenales de las Landas, Norte de Alemania o al Sur del Duero al haber perdido la sujeción de la vegetación ocasionando importantes daños, las inundaciones y aludes en los Alpes o Pirineos estaban a la orden del día al igual que deslizamientos de ladera o barrancadas (Bosch, 1866; Pemán y Pérez Soba, 2013).

Todo el esfuerzo en las primeras décadas de los servicios forestales de los países mediterráneos y alpinos consistió en frenar la deforestación, regular los aprovechamientos y, sobre todo, restaurar la cubierta forestal complementada con pequeñas y numerosas obras de hidrología forestal centradas en frenar en origen la torrencialidad. Se repoblaron amplias extensiones, especialmente hasta la década de 1960 lo que complementado por la expansión espontánea de los bosques por el abandono de la agricultura de substistencia especialmente intensa en las 
zonas de montaña y las obras hidráulicas frenaron considerablemente este tipo de fenómenos y sus efectos devastadores.

Como ejemplos podríamos citar la repoblación de las Landas, un inmenso arenal de 1.000.000 ha, ejecutado en la segunda mitad del siglo XIX o en España Sierra Espuña, Guardamar del Segura o Empúries (Pemán et al., 2017).

Ante semejante panorama desolador, los forestales ensalzaron la contribución de la cubierta forestal para la regulación del ciclo hídrico y la protección del suelo como su argumento central y sin grandes matizaciones. Una vez el problema más acuciante se había resuelto y quizás sin la suficiente conciencia sobre pasado reciente surgieron enfoques críticos respecto de los efectos de la cubierta arbórea sobre los caudales, especialmente en el caso de los climas semiáridos. De hecho, el caudal medio del Ebro en la desembocadura ha disminuido desde la década de 1960 un 55\% (MITECORD, 2020a) no pudiéndose achacar a menores precipitaciones en la cuenca que no se observan hasta ahora ni enteramente al aumento de la extracción neta debiéndose en una parte importante al aumento y densificación de la cubierta forestal.

En algunos casos, importantes donantes como el Banco Mundial, se hicieron eco de estas reflexiones y despriorizaron la repoblación forestal en climas secos. Sudáfrica estableció hace más de 2 décadas restricciones al establecimiento de cultivos intensivos forestales precisamente en base a su elevado consumo de recursos hídricos (Bennett y Kruger, 2015). Si la defensa de la restauración forestal y sus efectos hidrológicos pecó de poco matizada, no menos la crítica mencionada también.

Afortunadamente, en las últimas décadas va emergiendo una investigación mucho más matizada que aborda cada faceta en la compleja relación bosques-agua permitiendo obtener una imagen mucho más precisa del donde, cuando y como es más deseable una cubierta arbórea y donde menos y que a su vez pueda ser contrastada con otras funciones de los bosques como la mitigación del cambio climático, la lucha contra la despoblación interior, la provisión de biomateriales y bioenergía, el paisaje o la biodiversidad.

\subsection{El nexo bosques-aguas}

La relación entre la cubierta forestal y el ciclo hídrico ésta caracterizada por su complejidad siendo necesario su desglose en los diferentes elementos para poder ser analizada objetivamente. La amplia dispersión de efectos, en algunos casos contradictorios, comporta el riesgo que desde la ciencia se den mensajes también contradictorios por lo segmentado del progreso científico. En la tabla anexa se han recogido solo aquellos efectos relacionados con el ciclo hídrico y la erosión del suelo limitándose los climáticos a gran o pequeña escala a aquellos de relevancia para el balance hídrico directa no incluyéndose los relacionados con el albedo o el cambio climático (balance de $\mathrm{CO}_{2}$ ) de naturaleza indirecta. 
Tabla 4.1. Posible clasificación de los efectos hidrológicos incluido el suelo de la cobertura arbórea

\section{Macroclimáticos}

- Recarga substantiva de humedad atmosférica facilitadora de precipitaciones a larga distancia de mares y océanos

\section{Balance hídrico local (dimensión cuantitativa)}

- Aumento de la intercepción

- Reducción de la escorrentía superficial

- Reducción de la evaporación del suelo

- Favorecimiento de la infiltración y recarga de acuíferos

- Moderación de los flujos

\section{Microclimáticos}

- Aumento de la humedad ambiental y reducción de la temperatura

- Reducción del calentamiento del suelo

- Refuerzo e interceptación de precipitaciones horizontales

Calidad de aguas (dimensión cualitativa)

- Aseguramiento de aguas de alta calidad

Suelos, erosión e infraestructuras

- Prevención de la erosión del suelo

- Moderación de riadas y aludes

- Protección de infraestructuras

- Alargamiento de la vida útil de embalses al reducir los sólidos en suspensión

Fuente: Elaboración propia

Figura 4.1. Ciclo del agua y el rol de la vegetación

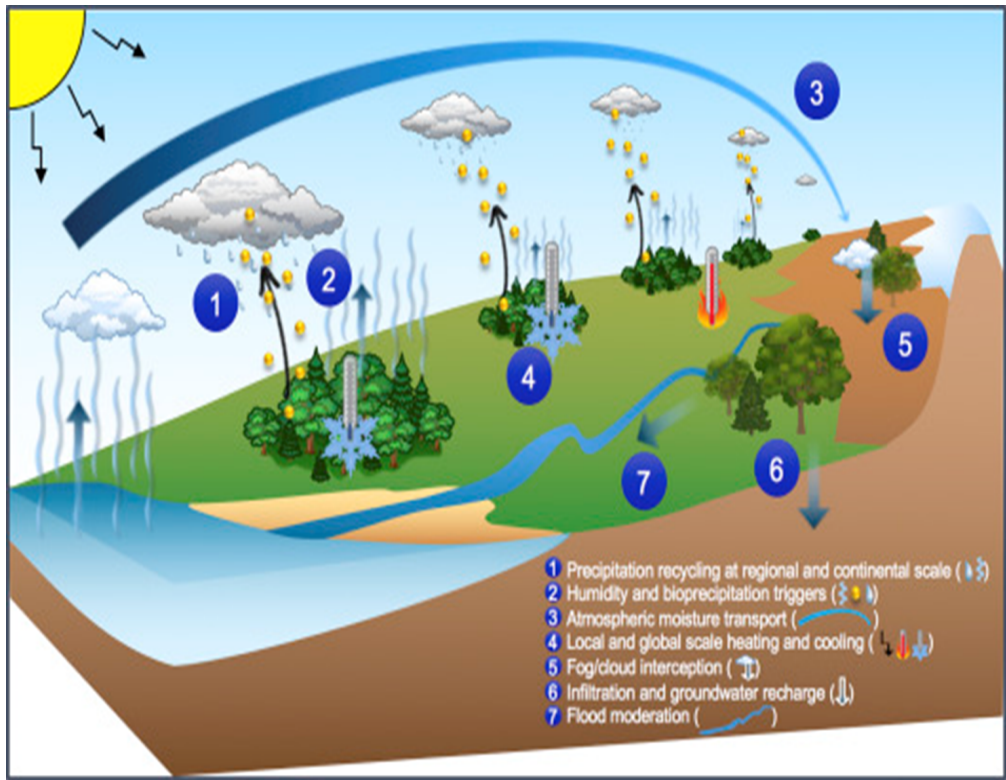

Fuente: Ellison et al, 2017 


\section{a) Macroclimáticos}

Uno de los efectos más mencionado por los forestales para preservar los bosques en el siglo XIX era precisamente su efecto sobre la precipitación basado sobre presunciones meramente empíricas. La ciencia del clima ha atendido esta cuestión en tiempos recientes confirmándola en el caso de extensos bosques continentales cuya evaporación es imprescindible para entender precipitaciones a miles de km de distancia de los mares y océanos destacándose como ejemplos el Amazonas (corriente del Este) o Rusia-Siberia y el Congo (corriente del Oeste) correspondiendo a climas tropicales húmedos, templados o boreales, estos dos últimos limitados al período vegetativo (Myers, 1991). No obstante, no está claro si este fenómeno es significativo en el caso de vegetación semiárida.

\section{b) Microclimáticos}

A escala de parcela, la cubierta arbórea tiene un efecto positivo en la reducción de la temperatura del suelo y con ello de la evaporación de agua del mismo lo que está estrechamente vinculado con el balance hídrico local. Este efecto es mayor cuanto más alta y mayor la fracción de cabida cubierta de la vegetación y mayor en frondosas caducifolias que en el resto, por lo que en el caso de la vegetación mediterránea semiárida es un efecto muy modesto, al menos en el período estival.

También puede reforzar la captación de precipitación horizontal donde confluya una orografía propicia (obstáculos), corrientes cargadas de humedad y grandes árboles con acículas u hojas alargadas en vertical. Un caso paradigmático son los pinares y monte verde canario orientados al NE y en la cota del alisio, especialmente en verano. Una ubicación obviamente estratégica constituyen los pinos en las crestas de las montañas (Braojos, 2015). El rocío es otra forma de precipitación horizontal importante en zonas próximas al mar donde, especialmente en pastizales y bosques abiertos pudiendo explicar la exuberancia de la vegetación forestal en islas áridas como Formentera.

En todo caso, se trata de una precipitación extraordinariamente difícil de medir por su dependencia del viento, orografía a escala meso y micro y la estructura de la cubierta arbórea que requerirá de un mayor esfuerzo investigador en el futuro.

\section{c) Balance hídrico local (dimensión cuantitativa)}

El balance hídrico de una masa arbórea (Del Campo et al., 2019) está determinado por la precipitación y se subdivide en 5 categorías:

- Intercepción: es el agua que queda retenida por las hojas y acículas, tronco y ramas evaporándose directamente a la atmósfera.

- Evaporación del suelo: es el agua que una vez incorporada al suelo se evapora desde el suelo. 
- Transpiración de la vegetación: es el agua que toda la vegetación (arbórea, arbustiva, lianoide, herbácea) evapora.

- Escorrentía: es el agua que llegando al suelo no es absorbida por exceso de intensidad, pendiente o costras y se evacúa por gravedad.

- Infiltración: es el agua que incorporada al suelo y que puede evaporarse, traspirarse o al superar su punto de saturación se incorpora al acuífero por gravedad (recarga de acuíferos).

En primer lugar, cabe señalar que la precipitación puede variar según micro-orografía en el caso de innivación concentrándose en las zonas cóncavas en perjuicio de las convexas, aspecto mucho menor en el caso de cubierta forestal que sirve para anclar el manto de nieve.

De las 5 categorías, el agua interceptada, evaporada o de escorrentía del suelo es hidrológica y productivamente mente inútil, la transpiración se caracteriza por un trade off entre producción/crecimiento e infiltración mientras que la infiltración es el agua finalmente hidrológicamente plenamente útil. Es cierto que la mayor parte del agua de escorrentía puede ser potencialmente útil si bien genera inundaciones y los sólidos que inexorablemente arrastra en una considerable parte aterran embalses.

La intercepción varía mucho con la estructura de la masa, cuando más densa de elementos finos/ha, mayor será. Obviamente también está determinada por los patrones pluviométricos siendo más aguda en casos de frecuentes precipitaciones inferiores a 10-20 mm salvo que sean muy continuadas, pero marginal en el caso de precipitaciones poco numerosas pero intensas. La evaporación del suelo es inversamente proporcional a la cobertura arbórea existiendo por tanto un trade off entre intercepción y evaporación del suelo.

La transpiración de la vegetación en principio y en base a la Ley de Eichhorn (1904) al estar correlacionada con el crecimiento debería ser solo determinada por el grado de cabida cubierta (densidad en proyección) y solo se reduciría significativamente cuando se baje de un determinado umbral (70\%) aumentando la evaporación del suelo.

La escorrentía se ve reforzada por la pendiente, intensidad de lluvia y costras hidrófugas.

Finalmente, la infiltración requiere de episodios de precipitaciones suficientes para llegar al punto de saturación del suelo cosa que en climas mediterráneos pasa con poca frecuencia por debajo de 350-400 mm (González-Sanchis et al, 2019). La infiltración también se ve reforzada positivamente por la vegetación por el mayor contenido de materia orgánica del suelo, la edafogénesis reforzada por las raíces de los árboles y las vías que estas abren en el suelo a la infiltración. También cabe señalar que la infiltración no es igual de valiosa en todas las cuencas al existir freáticos difícilmente aprovechables sea por su proximidad al mar (Serra de Tramuntana) o por su profundidad excesiva (Norte de Castellón).

Otro efecto de la cubierta arbórea es la moderación de los flujos reduciendo y atrasando los flujos punta generadores de inundaciones y moderando los flujos valle aunque en el balance entre cuencas deforestadas y arboladas el balance total sea favorable a las primeras. 


\section{d) Calidad de aguas (dimensión cualitativa)}

La cubierta forestal al reducir la erosión y la escorrentía comporta un efecto clave de calidad de las aguas que en el caso de infiltración suficientemente prolongada en el tiempo permite asegurar también una insuperable calidad bacteriológica. Obviamente, el paso del freático por horizontes salinos y yesosos puede condicionar la calidad química de ese freático concreto.

Figura 4.2. Distribución del agua de precipitación entre las 5 categorías relacionada a la densidad de la cubierta forestal

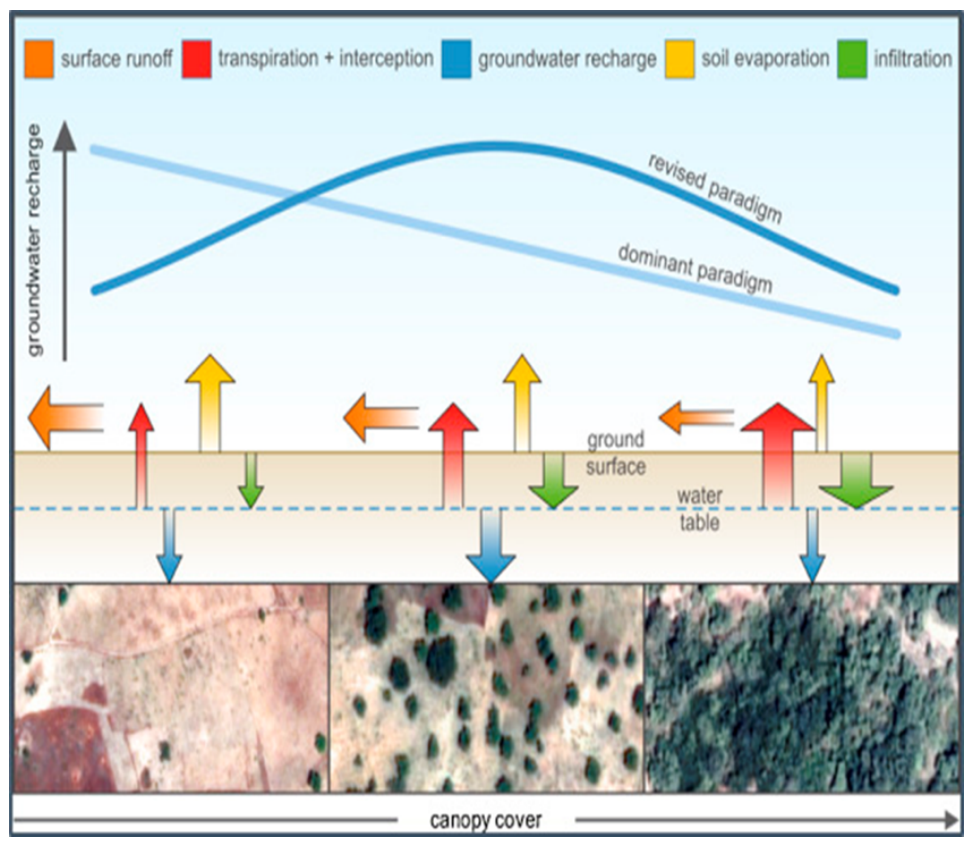

Fuente: Ilstedt et al, 2016

\section{e) Suelos, erosión e infraestructuras}

La cubierta arbórea es la mejor cobertura posible para prevenir la erosión del suelo. Esta función obviamente es más relevante cuando más erosionable sea el sustrato, mayor la pendiente y más intensas las precipitaciones. De hecho, la erosión potencial y real en España difieren considerablemente debido al efecto protector de la cubierta forestal siendo las zonas más erosionadas de naturaleza agrícola como se desprende de la comparativa de los gráficos $4.3 \mathrm{y}$ 4.4 .

Vinculado con la moderación de flujos por prácticamente nula escorrentía y una infiltración más lenta, se reduce el efecto de riadas, el aterramiento de embalses alargando su vida útil al reducir los sólidos en suspensión y los daños a todo tipo de infraestructuras situadas en las zonas bajas, especialmente en zonas próxi- 
mas a ríos y barrancos. Cabe recordar que los embalses son en muchos casos irremplazables por el coste económico, social y político de su réplica además de limitaciones orográficas siendo su aportación a la regulación de inundaciones, suministro de recursos hídricos vitales en períodos de sequía o electricidad modulable y carbono-neutral vitales para el país.

Figura 4.3. Mapa de intensidad de la erosión en España

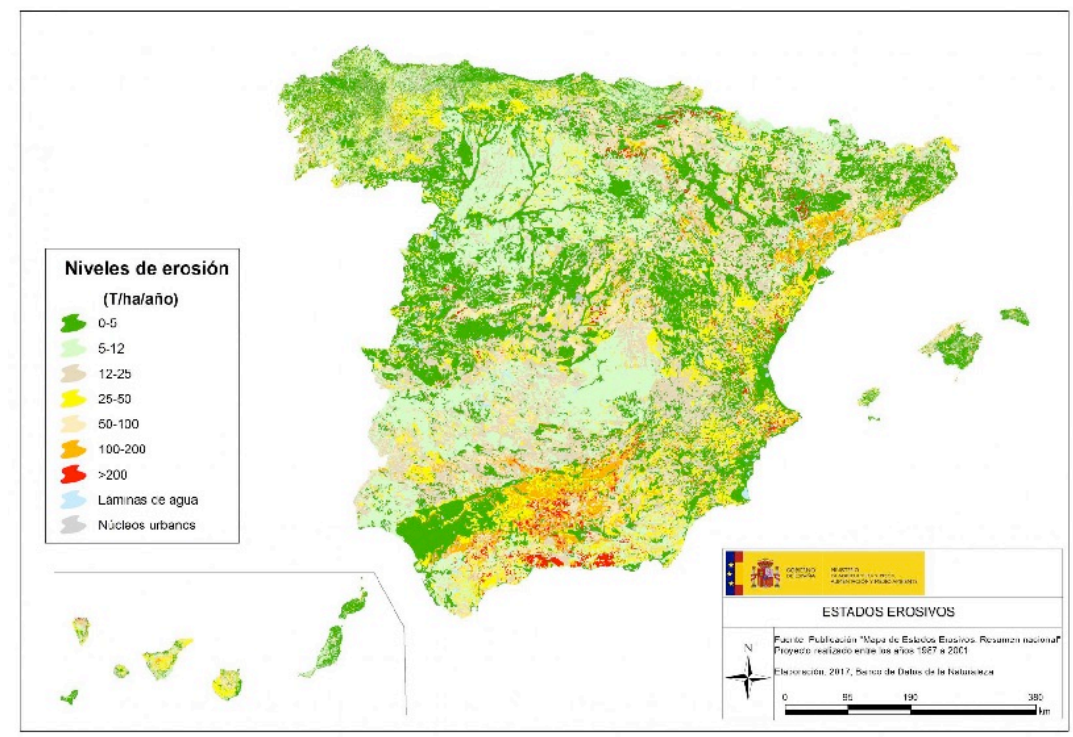

Fuente: MITECORD (2020c)

Figura 4.4.Mapa de superficies forestales arboladas y no arboladas

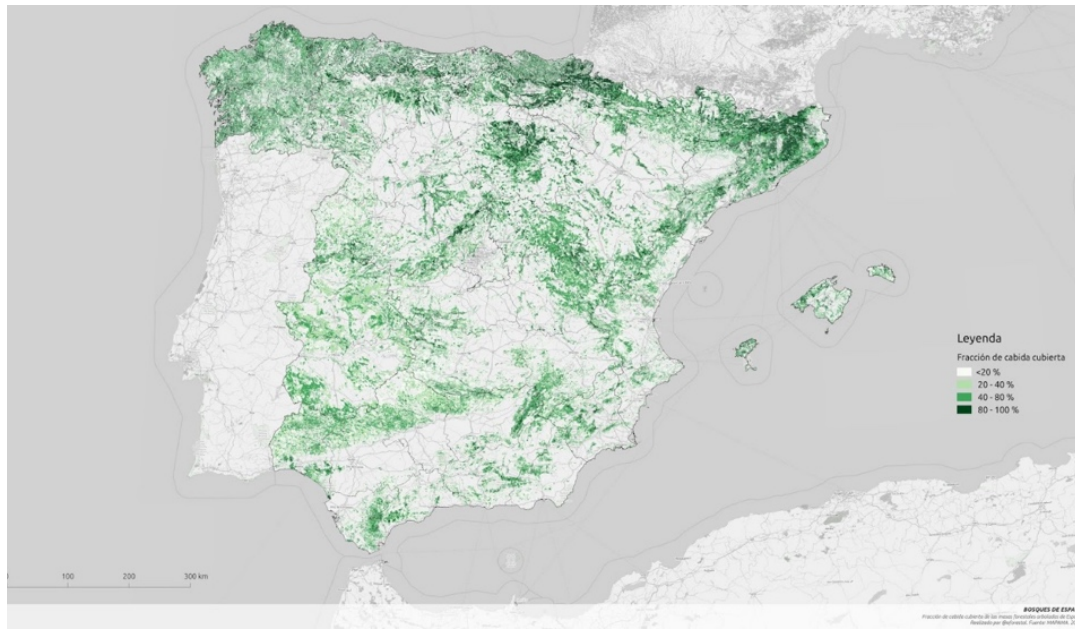


En las zonas de alta montaña, la vegetación arbórea frena el arranque de aludes si bien si estos se producen en cotas mayores o zonas deforestadas no pueden frenar su efecto (Teich et al, 2012).

En conclusión, cabe recordar que los bosques de montaña constituyen los «water towers» por su doble condición de cota - mayor facilidad de gestión por gravedad y generación hidroeléctrica -, mayores precipitaciones y menor temperatura. El $75 \%$ del agua dulce disponible procede de macizos montañosos con importante cobertura forestal (FAO, 2019).

La gestión forestal resulta clave para superar elevadas densidades, sobre todo en climas semiáridos fruto de la silvogénesis tras el abandono rural (Delgado, 2015) para reducir elementos finos y bajando las densidades a un $70 \%$ lo que permite maximizar la reducción de intercepción y transpiración con una aceptable evaporación del suelo sin aumentar la escorrentía maximizando así la infiltración. Todo ello afinado a la pendiente, patrones de precipitación y tipo de suelo.

Obviamente siendo la función hidrológica clave en climas semiáridos no es la única a considerar en la gestión forestal. El tipo de estructuras hidrológicamente deseables en estos climas coinciden en buena medida con las estructuras óptimas desde la perspectiva de adaptación y resiliencia al cambio climático, pero también desde la perspectiva productivo-económica. Reducir pronto las densidades bajando a un 60-80\% de fracción de cabida cubierta concentrando el crecimiento en los mejores árboles reduce la competencia, el estrés en la lucha por los contados recursos hídricos en caso de sequías prolongadas, aumenta la estabilidad de la masa frente a vendavales y nevadas, acelera la producción de semilla y asegura una menor afectación por plagas y enfermedades. La aplicación de clareos y cla-

Figura 4.5. Estructuras altamente consumidoras de agua por intercepción y combustibles frente a otras más eficientes hídricamente así como resilientes ante el fuego

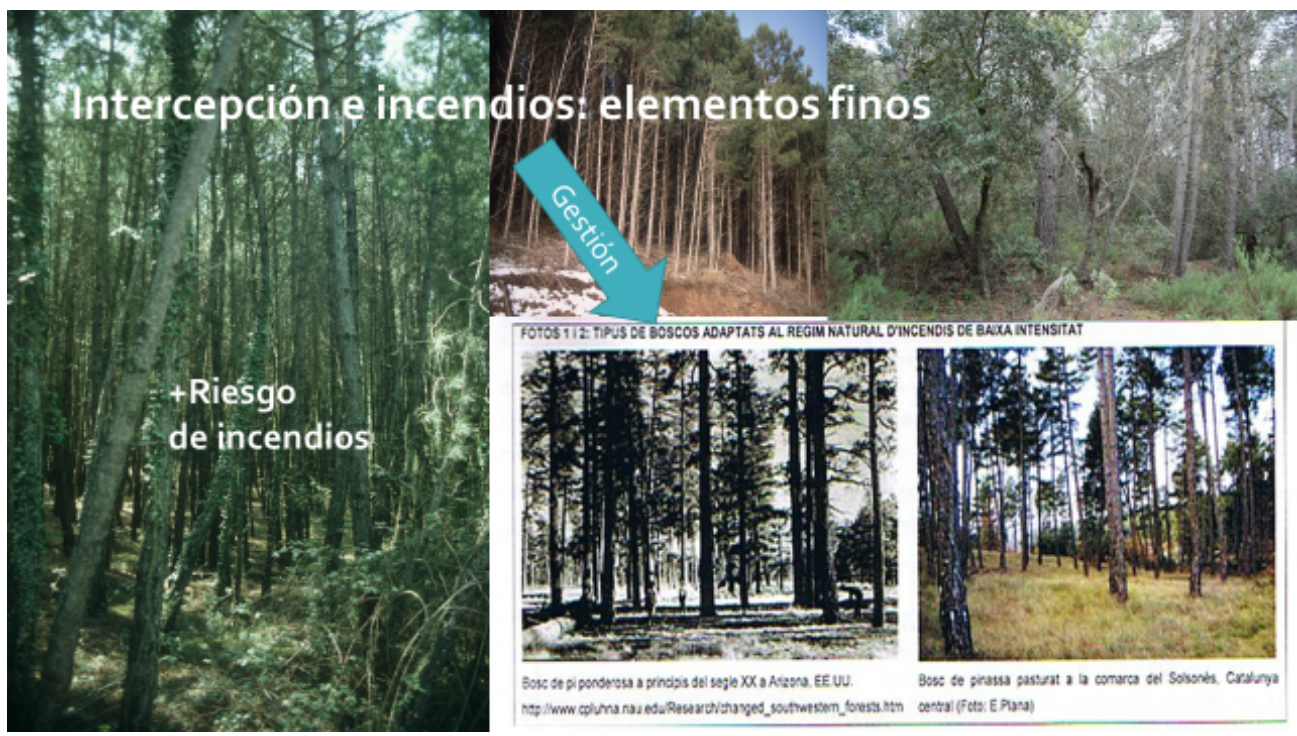

Fuente: Elaboración propia 
Figura 4.6. La agricultura de secano con arbolado disperso y en llano o bancales en condiciones es hidrológicamente muy eficiente además de cortafuegos efectivo

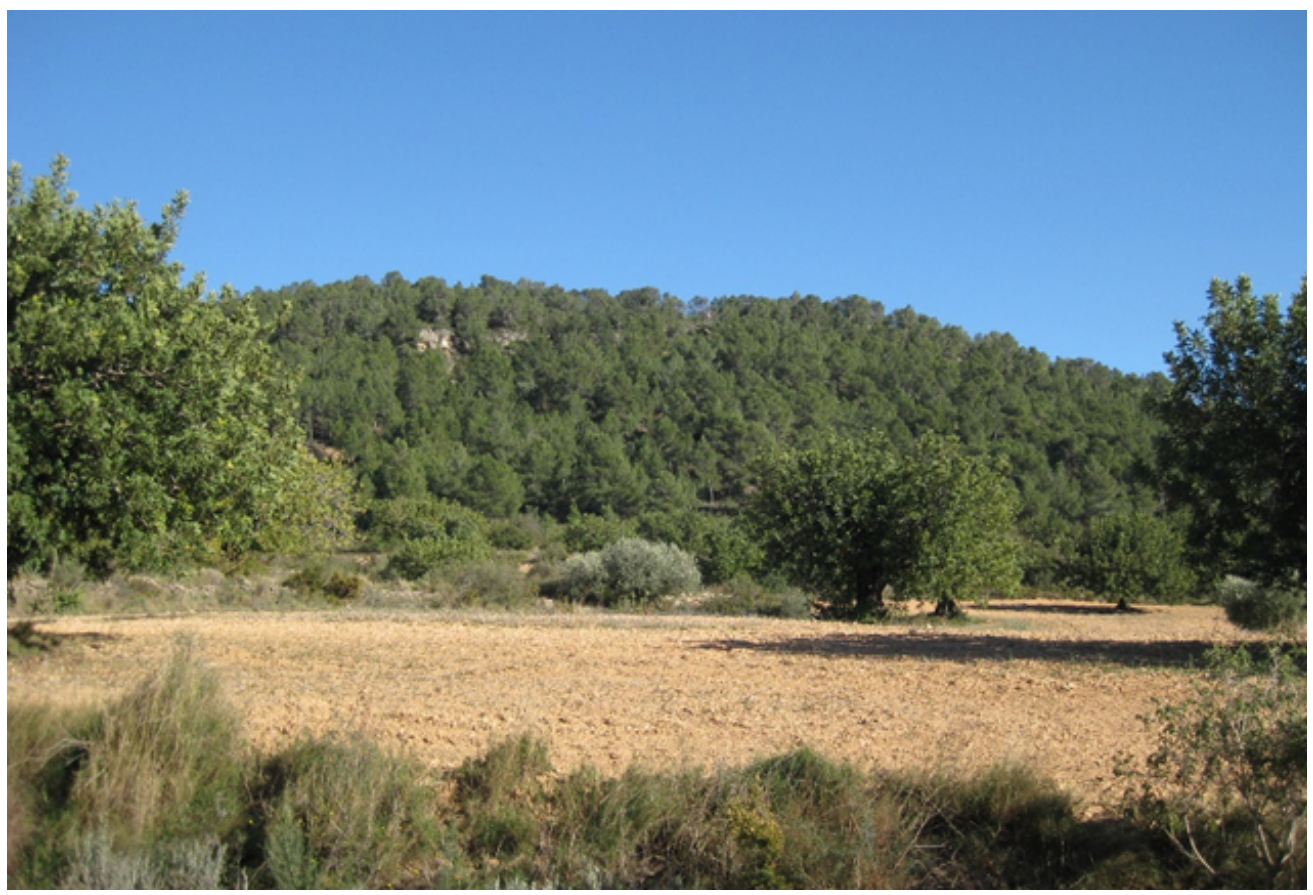

Fuente: Elaboración propia

ras tempranas e intensas tiene un doble efecto hidrológicamente positivo: a) reduce substantivamente la carga de biomasa y con ella de elementos finos/ha y b) de la biomasa restante el porcentaje superior a la dimensión disponible a arder en un incendio (15-20 cm) es mucho menor y además baja más rápidamente con el paso del tiempo. Adicionalmente, las operaciones de la gestión forestal (claras y cortas finales) resultarán más rentables al concentrar más biomasa por actuación y, a medio plazo, obtener árboles más grandes por concentración en los mejores del crecimiento.

Pero también estas estructuras son claramente superiores para la biodiversidad al diversificar más los estratos, permitir vegetación del suelo y la entrada de las aves como indicadores de biodiversidad. Tienen también una mayor productividad pascícola y cinegética. Finalmente, también desde la perspectiva paisajística y recreativa genera bosques mucho más atractivos.

También desde el punto de vista social la recuperación de la gestión forestal y su cadena de valor es clave asegurar empleo rural y luchar contra la despoblación al coincidir las zonas más afectadas por este fenómeno con las más forestales (montaña).

El único trade off existente es el balance de carbono a escala de rodal y a corto plazo. No obstante, este debe de sopesarse con el balance del conjunto de rodales que forman una unidad de gestión (monte, propiedad), la reducción del riesgo 
de incendios, el aumento de sumideros temporales de carbono por el uso de la madera en la construcción y la substitución de materias primas y energías no renovables por madera y biomasa forestal (bioeconomía).

En todo caso, la mayor resiliencia de las masas forestales en el contexto de cambio climático debería ser el criterio final de decisión en esta disyuntiva. También debe analizarse esta cuestión desde la perspectiva territorial siendo conveniente generar también discontinuidades horizontales mediante el mantenimiento y recuperación de agricultura tanto como cortafuegos cultivados como por su función hidrológica en muchos casos superior al bosque, sea en zonas abancaladas en condiciones o de poca pendiente.

\subsection{Evolución reciente de la cubierta forestal en España}

Actualmente España dispone de 18,4 millones de ha de bosques lo que supone un índice de boscosidad del $37 \%$, en la zona media-superior de la UE solo superada por los países escandinavos y alguno alpino. No obstante, un $20 \%$ de esa superficie corresponde a bosques de baja densidad, especialmente dehesas y alta montaña. Un total de 27,6 millones (55\%) de ha son de naturaleza forestal definida en nuestro país como toda aquella superficie que no sea característica de cultivo, pastizales permanentes, zonas urbanizadas, infraestructuras u ocupadas por agua.

En 1970 España disponía de 11,8 M ha (23,5\%) arboladas y de 25 millones de ha forestales. En los pasados 50 años han aumentado los bosques en 6,6 millones de ha (132.000 ha/año o 0,7\% anual) mientras que la superficie forestal 2,5 millones ha en considerable menor medida. Se estiman las primeras repoblaciones en este período a 1,5 millones ha por lo que la mayor parte de esta ganancia (5 millones ha) se debe a expansión espontánea. Las existencias han aumentado extraordinariamente de 512 millones de m3 en 1970 a 1.212 millones de m3 hasta 2015 lo que supone un incremento del $137 \%$ o un $3 \%$ anual.

Aunque resulta complicado reconstruir la cubierta forestal anterior a 1970, en el Plan de Repoblación Forestal (1939; Peman et al. 2017) se estimaban en 5,3 millones ha de monte alto estimándose el monte bajo existente entonces en 2,0-2,5 millones ha lo que darían unos 7,5 millones ha. El incremento hasta 1970 de 4,8 millones ha se explicaría por las 2,5 millones ha de repoblaciones y 1,8 millones de ha de expansión espontánea, fenómeno que se ha acelerado en las últimas décadas.

El punto mínimo de la cobertura arbórea en España se estima hacia la década de 1870 debido a la confluencia de 3 factores: el fin del período convulso que siguió a la invasión napoleónica, especialmente las guerras carlistas que retraso el proceso de urbanización e industrialización del resto de Europa, la plaga de la filoxera y la extensión del ferrocarril que hacía más accesible el carbón mineral. Se estima la superficie de bosques en aquel momento sobre el 12\% (6 millones de ha) que se incrementó hasta la Guerra Civil por repoblaciones 0,5 millones de ha y expansión espontánea 1,0 millones de ha, especialmente en zonas de viñedos en 
Figura 4.7. Evolución de las existencias desde 1970 en los bosques catalanes

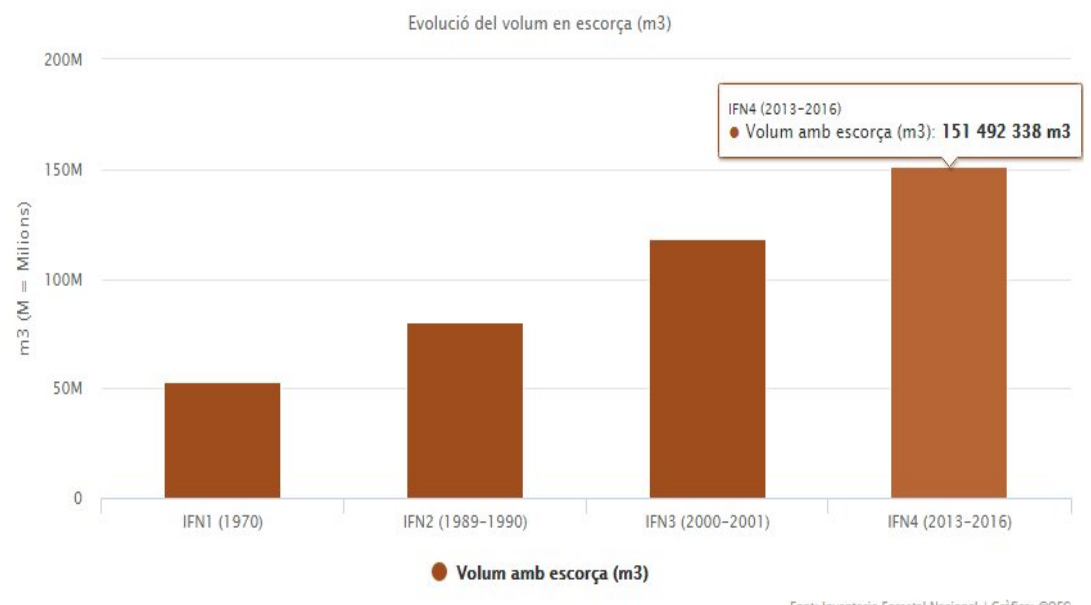

Font: Inventario Forestal Nacional / Gràica: @oFC

Lì Copy

\begin{tabular}{|l|l|l|l|l|}
\hline Inventari & Volum en escorça $\left(\mathrm{m}_{3}\right)$ & Increment & Interval (anys) & Increment anual (m3) \\
\hline IFN1 (1970) & 52726384 & - & - & - \\
\hline IFN2 (1989-1990) & 80.005408 & $34.10 \%$ & 20 & 1363.951 \\
\hline IFN3 (2000-2001) & 118.117 .666 & $32,27 \%$ & 10 & 3811226 \\
\hline IFN4 (2013-2016) & 151.492 .338 & $22,03 \%$ & 15 & 2.224 .978
\end{tabular}

Fuente: MITECORD (2020)

ladera abandonados. De hecho, se dispone de información de importantes incendios a finales de la década de 1920 y la siguiente hasta la Guerra Civil, siendo este hecho siempre indicador de una creciente riqueza forestal.

Los bosques españoles están formados por un 50\% de frondosas y un $50 \%$ de coníferas correspondiendo a cultivos forestales intensivos (choperas y eucaliptos) un $4 \%$ más un $1 \%$ de pino radiata. El resto de los bosques están formados por especies autóctonas o asilvestradas desde hace siglos o milenios.

El crecimiento anual es de $45 \mathrm{~m}^{3} / \mathrm{a}$ de los que se aprovechan 18 Millones de $\mathrm{m}^{3} \mathrm{cc} / \mathrm{a}(40 \%)$ acumulándose el restante -salvo una pequeña proporción perdida por incendios y pudrición- en forma de mayores existencias lo que viene a compensar el 20\% de las emisiones de $\mathrm{CO}_{2}$ de España (Pardos, 2010).

El intenso proceso de recuperación de la cubierta y capital forestal de España es compartido con el resto de los países desarrollados, especialmente Europa, y Japón y Corea del Sur, en menor medida Norteamérica y Australia y Nueva Zelanda. También desde de la década de 1980 Asia ha revertido la tendencia de la deforestación al igual que la región de África del Norte y Cercano Oriente, aunque en este caso sea debido a la extensión de los desiertos, más modesta. La deforestación viene concentrándose en el África Subsahariana y Sudamérica siendo sus causas en el primer caso la degradación forestal causada por la agricultura de 
subsistencia y el abastecimiento de leñas para cocinar una buena parte de la población ( $80 \%$ ) y en el segundo, de deforestación a gran escala debido a la expansión de la agricultura comercial. En los países mediterráneos la más tardía industrialización y urbanización más su montañosidad junto a ambiciosas políticas de repoblación durante el siglo XX explican la intensidad del proceso, especialmente en su ribera norte (FAO 2015 y 2020).

Paradójicamente existe una línea de opinión entre climatólogos que achaca a la pérdida reciente de vegetación forestal la reducción de las precipitaciones estivales en la vertiente mediterránea ibérica (Heraldo de Aragón, 2014) que contrasta con la mínima traspiración de la vegetación mediterránea en esa época y el aumento espectacular de la vegetación forestal constatado por los Inventarios Forestales Nacionales y otras fuentes (imágenes de satélite, fotografías aéreas, comparación de fotografías históricas, etc.).

\subsection{Los retos planteados}

El principal reto identificado en todas las reuniones y expertos reconocidos en este área es el abandono de los montes enmarcado en un proceso más amplio de abandono rural de las zonas de montaña y menos accesibles de España y los incendios forestales como principal perturbación. Entre ambas causas, la primera actúa como causa subyacente de los incendios que devienen mera causa desencadenante. Resulta clave centrarnos en las cusas subyacentes (iceberg) para abordar el problema y no en sus efectos (punta del iceberg) cuyo efecto resultará meramente paliativo.

Mientras en las primeras décadas de lucha contra los incendios desde hace 50 años se centraron en las causas y la extinción, el debate ha ido madurando centrándose en la necesidad de construir paisajes resilientes donde la gestión forestal pero también la recuperación de la ganadería extensiva y de cultivos estratégicos cortafuegos buscando no superar las cargas de combustible que superen la capacidad de extinción.

A su vez, la causa del abandono forestal se explica por la falta de rentabilidad, el minifundio, un excesivo intervencionismo administrativo descoordinado, los marginales recursos públicos destinados a los bosques (a escala europea el $1 \%$ de la PAC, a española el 3\%; MAPA 2020), el cambio climático y la desafección de una sociedad mayoritariamente urbana respecto a la rural.

\subsection{Las respuestas propuestas}

Si bien el diseño de las Confederaciones Hidrográficas es muy avanzado, se han ido perdiendo elementos clave como el original fuerte vínculo con la Administración y política forestal. Ello impide una visión integral del ciclo del agua en toda la cuenca y especialmente de sus cabeceras determinadas por los bosques de montaña y las obras de micro-hidrología tradicionalmente ejecutadas por la Ad- 
ministración forestal en el marco de la restauración hidrológico-forestal centrándose en exceso en las grandes obras hidráulicas e instalaciones. Se hace necesario que las Confederaciones presten más atención a las actividades gestoras del territorio como la agricultura y los espacios forestales y sus complejas relaciones con el ciclo del agua. Mientras la agricultura de regadío es una considerable consumidora de agua, la de secano también es generadora, pudiendo también actuar de aliviadero en casos de inundaciones mientras que los arrozales costeros frenan la intrusión marina. Los bosques son generadores de agua e ideales frenos a la erosión.

El pretexto que ha frenado esta ampliación de enfoque es la cuestión competencial al corresponder el $90 \%$ del territorio a cuentas interautonómicas administradas por la Administración General del Estado y el hecho que la agricultura y la gestión forestal son competencias autonómicas y la gestión responsabilidad de sus titulares.

Igualmente, está pendiente la revisión de su gobernanza y actualización de su funcionamiento, así como mejorando la seguridad jurídica de las partes. No es aceptable que mientras se ha avanzado mucho en el deslinde marítimo-terrestre así como en el de montes públicos, un porcentaje altísimo del dominio público hidráulico se encuentre todavía meramente estimado generando considerables perjuicios (intervención administrativa, cánones aplicados en terrenos que podrían no ser finalmente de dominio público) especialmente a la populicultura a diferencia de la agricultura, lo que reduce las alternativas de desarrollo rural e impide un considerable secuestro de $\mathrm{CO}_{2}$. Entre las buenas prácticas, destaca la integración, simplificación y agilización de los controles administrativos en las zonas de policía en las cuencas internas de Galicia.

En el futuro sería interesante ir avanzando en la integración de diferentes fuentes de financiación vinculando los Planes de Desarrollo Rural (FEADER) con ingresos por tasas ambientales sobre el agua y cambio climático (blending) permitiendo integrar diferentes funciones en las actuaciones forestales que son por definición multifuncional careciendo de sentido pretender disgregarlas por objetivos lo que impediría alcanzar un mayor impacto en su conjunto. Cabe recordar los excelentes ejemplos alcanzados por el Pago por Servicios Ambientales de naturaleza hidrológica en Costa Rica o Nueva York (Calvet Mir et al., 2015).

En este contexto, se hace necesario ir avanzando en la doctrina jurídica de la tenencia de los servicios ambientales, sea titularidad, responsabilidad, valores de referencia, adicionalidad, umbrales mínimos, entre otros. También se hace necesario ampliar el concepto limitado de plena recuperación de costes de la Directiva Marco del Agua (DMA, 2000) a los servicios vitales que aportan los bosques de montaña. La internalización de las externalidades no puede quedar limitada a las negativas y debe ser bidireccional reconociendo que el caso de la gestión sostenible de recurso renovables lo habitual son externalidades positivas que no pueden quedar sin reconocimiento. 


\subsection{Conclusiones}

Con una extensión creciente -actualmente del 55\%-predominante en las zonas de cabecera (montaña), los espacios forestales son esenciales desde un punto de vista hidrológico. En el siguiente gráfico se identifican 6 retos estratégicos para los espacios forestales, dos directamente vinculados con la función hidrológica de los bosques (prevención de riesgos naturales) y los propios recursos hídricos y dos indirectos (incendios y cambio climático).

Todos estos retos están intensamente interrelacionados y requieren para ser abordados con éxito de una actuación integral coherente basadas en estrategias de largo plazo y amplios consensos. A escala operativa, los sistemas de soporte a la decisión (decisión support systems) pueden servir de apoyo a decisiones complejas caracterizadas por sinergias y trade offs.

Tres son las conclusiones claves para el éxito. La primera es reconocer las limitaciones siendo imposible cumplir con todas las expectativas de forma inmediata y al $100 \%$. Compatibilizar demandas potencialmente concurrentes obliga a decisiones pragmáticas que buscan satisfacer a corto-medio plazo las demandas más básicas en todos los campos y progresivamente ir subiendo en el grado de satisfacción de forma armónica manteniendo siempre la visión de conjunto. Si algún factor deba priorizarse, deberá ser la resiliencia de los bosques, base de todas las demás demandas. También es necesario asegurar los recursos precisos para conseguir los objetivos fijados.

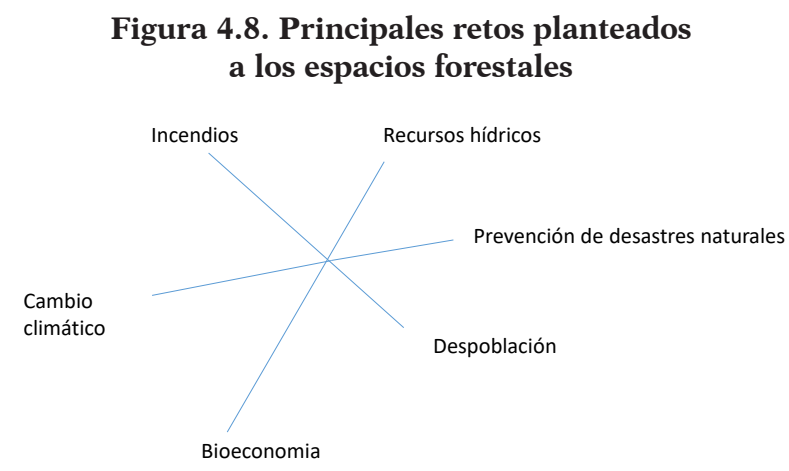

Fuente: Elaboración propia

En segundo lugar, todas las demandas requieren de gestión forestal para satisfacerlas en un plazo de tiempo razonable incluso cuando su aspiración pueda plantear alguna contradicción más filosófica que práctica (biodiversidad). La gestión forestal como la agricultura si requeridas comportan también algunas premisas como la continuidad, un marco propicio y la certidumbre sobre su viabilidad a largo plazo además ciertos umbrales mínimos de mercados y servicios.

Finalmente, gestionar demandas tan dispares con grupos interesados diferentes ubicados en lugares distantes (urbe, ruralidad) requieren de una política de comunicación perseverante, profesional y planificada que permita trasladar los objetivos, actuaciones y retos de este tipo de proyectos a largo plazo. 


\section{Referencias bibliográficas}

Bennett, B y Kruger, F. (2015): Forestry and Water conservation in South Africa. Australian National University Press: 264.

Bosch, M. (1866): Memoria sobre las inundaciones del Júcar en 1864. Ministerio de Fomento.

Braojos, J.J. (2015): La nube, el pino y la otra lluvia: Una metodología para evaluar el potencial de captación de agua de niebla y su aprovechamiento: natural o artificial. Consejo Insular de Aguas de Tenerife.

Calvet-Mir, L. et al. (2015): Payments of forest ecosystem services in the tropics: a closer look at effectiveness and equity. Environmental Sustainability 14: 150162.

Delgado, R. (2015): Análisis de los patrones de evolución de las coberturas forestales en la provincia de Castellón en los últimos 50 años. Tesis Doctoral: Universitat Politècnica de València.

Del Campo, A. et al (2019): Effectiveness of water-oriented thinning in two semiarid forests: The redistribution of increased net rainfall into soil water, drainage and runoff. Forest Ecology and Management (438)163-175.

Eichhorn, F. (1904): Beziehung zwischen Bestandeshöhe und Bestandesmasse. Allg. Forst- u. J.-Ztg. 80: 45-49.

Ellison, D. et al (2017): Trees, forests and water: Cool insights for a hot world. Global Environmental Change 43(51):51 61.

FAO (2015): Forest Resource Assessment.

FAO (2019): Advancing the Forest and Water Nexus - A capacity development facilitation guide.

FAO (2020): Forest Resource Assessment.

González-Sanchis, M. et al (2019): Managing low productive forests at catchment scale: Considering water, biomass and fires risk to achieve economy feasibility. Environmental Management 201: 653-665.

Heraldo de Aragón (2014): La deforestación del Levante reduce las lluvias del Alto Mijares y agrava las gotas frías costeras. 17.2.: 15.

Ilstedt, U., Bargués Tobella, A., Bazié, H.R., Bayala, J., Verbeeten, E., Nyberg, G., Sanou, J., Benegas, L., Murdiyarso, D., Laudon, H., Sheil, D., Malmer, A. (2016): Intermediate tree cover can maximize groundwater recharge in the seasonally dry tropics. Sci. Rep. 6, 21930.

MAPA (2020): Distribución presupuestos de desarrollo rural en España y UE.

MITECORD (2020a): http://www.mma.es/secciones/agua/pdf/informesphnotr/julio_sanchez_choliz.pdf

MITECORD (2020b): Inventario Forestal Nacional.

MITECORD (2020c): Erosión y desertificación en España.

Myers, N. (1990): Tropìcal forests and climate. Climate change. 19 (1-2). 
Pardos, J.A. (2010): Los ecosistemas forestales y el secuestro de carbono ante el calentamiento global. INIA.

Pemán, J. y Pérez Soba, I. (2013): Los Ayerbe. Tres ingenieros de montes altoaragoneses y su aportación a la hidrología forestal española. Lucas Mallada: revista de ciencias, ISSN 0214-8315, Nº 15, 2013, págs. 99-160.

Pemán, J.; Iriarte, I y Lario, F.J. (2017): La restauración forestal de España: 75 años de una ilusión. MAPAMA y SECF.

Teich, M. et al. (2012): Snow Avalanches in Forested Terrain: Influence of Forest Parameters, Topography, and Avalanche Characteristics on Runout Distance. Artic, Antarctic and Alpine Research 44(4): 509-519.

Unión Europea (2000): Directiva 2000/60 Marco del Agua, 12.12. 


\title{
Capítulo 5 \\ Recarga de acuíferos en un contexto de cambio climático
}

\author{
Emilio Custodio Gimena \\ Profesor emérito. Correspondiente de la Real Academia de Ciencias \\ Juan Carlos Santamarta Cerezal \\ Dr. Ingeniero de Montes
}

\subsection{Introducción}

La recarga es una de las variables básicas que determinan el balance de agua y el comportamiento de un sistema acuífero. Esto es objeto de tratamiento detallado en numerosos libros y tratados. Veáse Custodio y Llamas (1976/1983), Custodio et al., (1997) y RAEMIA (2019), donde se aportan numerosas referencias al respecto. Aplicaciones recientes se encuentran en MASE (2015) y SASMIE (2017), también con abundantes referencias. Se han desarrollado diversos métodos de evaluación que se apoyan en balances de agua en el suelo, balance del aporte atmosférico de cloruro (Custodio, 2010, estudios hidrogeoquímicos e isotópicos ambientales y de fluctuaciones freáticas de detalle y a escala amplia, además de métodos empíricos y semi-empíricos, y todo ello con el apoyo de modelación numérica. La aplicación de diversos métodos permite reducir la incertidumbre intrínseca asociada a la naturaleza de los procesos (Alcalá y Custodio, 2014; 2015) y validar razonablemente los modelos conceptuales (Guardiola-Albert et al., 2014; Espinosa-Martínez y Custodio, 2014a; 2014b; Naranjo et al., 2015; Pisani et al., 2017).

La recarga natural en un determinado lugar, además de las condiciones climáticas y sus fluctuaciones y variaciones, depende de las características del suelo y de la vegetación, que evolucionan de forma relacionada (Custodio et al., 1997; REAEMIA, 2019; Berry et al., 2005). Las características del suelo, en especial su capacidad de retención de humedad, y de la vegetación, en especial a través de la profundidad radical y grado en que las hojas recubren el suelo, tiene gran influencia en la recarga que se produce en unas determinadas condiciones climáticas. A mayor retención y profundidad radical, menor es la recarga, a igualdad de las otras condiciones. En clima árido y semiárido, la recarga es una pequeña fracción de la precipitación, tanto menos cuanto más fino sea el suelo. Pero la recarga contiene casi todas las sales depositadas de origen atmosférico y las tomadas del suelo. Así, en clima árido el agua de recarga puede llegar a ser salobre (Custodio, 1992a; 1992b; 1994; Herrera y Custodio, 2003). Esto se manifiesta en los perfiles de salinidad del medio no saturado, como conductividad eléctrica o concentración de cloruros. Las variaciones anuales de la recarga producen cambios de la salini- 
dad en profundidad en torno a un valor medio, si en el periodo de tiempo representado en el perfil no se han producido cambios climáticos o de uso del suelo.

Los cambios de uso del territorio, como la deforestación o la reforestación, la transformación en terreno agrícola del bosque o matorral o la introducción del regadío, producen cambios en la recarga difusa que se traducen en modificaciones del perfil de salinidad, con escalones cuya profundidad depende de la tasa de recarga. Es un tema tratado por muy diversos autores (Adar et al, 1995; Farley et al., 2005; van Lill et al., 1980; Woodward et al., 2014; Zhou et al., 2010), así como el efecto en la recarga de los incendios forestales (Landfortd, 1976; Kuczera, 1987) y en general de los cambios de uso del territorio (Bellot et al., 2001; Calder, 1993; Ibrahim et al., 2014; Zhou et al., 2015). La introducción de regadío también es una causa de salinización de la recarga a través de la infiltración de los retornos de riego (Cabrera y Custodio, 2004; Cruz-Fuentes, 2014a; 2014b; Custodio, 1994; Pulido-Bosch et al., 2018; Jiménez-Martínez et al., 2010). Los efectos hidrológicos se están estudiando en cuencas experimentales bien equipadas, como en Cataluña y la cuenca del Ebro (Gallart y Llorens, 2003; 2013; Latron y Gallart, 2007, Latron et al., 2009; Guasch et al., 2006).

En climas húmedos o moderadamente secos se puede definir una relación lineal entre precipitación y recarga anuales, con un umbral por debajo del cual no se produce recarga significativa. A medida que el clima es más seco, la relación lineal empeora, hasta desaparecer en climas áridos. Las relaciones se modifican cuando la nieve tiene importancia en la recarga. También la relación entre precipitación y recarga se ve modificada por la progresiva mayor importancia de la recarga a partir de la escorrentía de eventos concentrados de precipitación, con gran importancia de los intensos de baja frecuencia, tanto más cuanto mayor sea la aridez. La evaluación de estos efectos requiere conocer bien el funcionamiento de los sistemas hidrogeológicos de montaña-depresión (Capítulo 7 de RAEMIA, 2019).

El clima ha ido cambiando a lo largo de la historia, incluso de la historia relativamente reciente (fluctuaciones climáticas) y eso se refleja en cambios importantes en la recarga media, en especial en áreas semiáridas y áridas. En sistemas acuíferos extensos, con tiempos de renovación de siglos a milenios, las condiciones actuales pueden ser en parte el resultado de condiciones climáticas distintas en épocas anteriores. A lo largo de los milenios, en un determinado ambiente climático medio se han sucedido periodos más húmedos y más secos, de modo que lo que se observa actualmente es el resultado acumulado de circunstancias del pasado. La variación climática natural continúa y es parte de la realidad. Sigue ciclos periódicos, pero con importantes irregularidades, que complican el análisis del pasado y hacen muy incierta la proyección al futuro. A esto se suman los efectos antropogénicos que producen, con mayor o menor importancia relativa, el cambio climático y el cambio global.

En los lugares en que se predice un aumento de temperatura ambiental, cabe esperar un aumento de la evapotranspiración potencial y por tanto una disminución de la recarga, pero la relación es más compleja y puede llegar a ser inversa, ya que en el balance hay que tener en cuenta la evapotranspiración real, que puede diferir notablemente de la potencial. Los efectos pueden estudiarse con los modelos hidrológicos-hidrogeológicos disponibles, una vez que se han definido los escenarios a considerar. Para la aplicación a un acuífero determinado hay que 
adaptar los datos de los modelos climáticos globales a las condiciones locales mediante un proceso de detallado (downscalling).

El cambio global es el debido a las acciones antrópicas que modifican el ambiente natural y humano en un lugar determinado o por acciones que derivan de actuaciones de mayor alcance, como el ascenso actual del nivel del mar, de la disminución de la biodiversidad e introducción de nuevas especies, del talado masivo del bosque, de las grandes acciones de reforestación, de la gran agricultura extensiva, del abandono del medio rural, del descenso generalizado del nivel freático por extracción a gran escala del agua subterránea y de la urbanización de áreas extensas, entre otras situaciones. En general, el cambio global es de mayor alcance a nivel local y regional que el climático, aunque se habla menos del mismo, ya que es más complejo localmente y se carece de muchos de los datos necesarios para crear escenarios futuros probables y de criterios para evaluarlos.

\subsection{Recarga natural difusa y variabilidad climática}

Las condiciones climáticas son cambiantes de un año a otro, con fluctuaciones que determinan periodos secos y periodos húmedos que se repiten con cierta periodicidad, aunque con realizaciones muy irregulares. Hay ciclos del orden de 10 a 11 años y otros más largos que aparecen en las series hidrométricas suficientemente largas. Esta variabilidad climática tiene importantes impactos sociales, económicos y ecológicos. Los más significativos desde el punto de vista de la disponibilidad de recursos de agua son los asociados a las sequías. En áreas áridas y semiáridas, las sequías son un fenómeno natural recurrente. Las sequías importantes duran varios años, con fluctuaciones a lo largo de las mismas, que pueden incluir algunos años húmedos intercalados. Este es un tema especialmente preocupante en España en relación con la Unión Europea. Se tiene una gran sensibilidad en cuanto a las aguas superficiales, modeladas mediante el modelo distribuido precipitación-escorrentía-recarga SIMPA (Estrela y Pérez-Martín, 2012; Capítulo 4 de RAEMIA, 2019), pero mucho menor para las aguas subterráneas, aunque con una fuerte incidencia del uso de reservas (minería del agua subterránea) en diversos lugares y en especial en el sudeste peninsular ibérico y en Canarias (MASE, 2015).

Mientras las fluctuaciones climáticas se refieren a una escala temporal de décadas, la variabilidad climática hace referencia a una escala temporal mucho mayor, de siglos a milenios. El clima ha ido cambiando (variando) notablemente a lo largo de la historia geológica, como se muestra claramente en los sedimentos. Dado que la vida humana es inferior al siglo y que la información histórica instrumental o documentada es sólo un poco más larga, únicamente los cambios climáticos más recientes tienen efectos sociales bien conocidos por los estudios históricos, como la pequeña edad del hielo que se produjo entre el siglo XVI e inicios del XIX, aunque sus efectos en el ámbito español fueron presumiblemente moderados. Durante el Cuaternario se han producido varios periodos glaciares e interglaciares, entre los que la temperatura media puede haber variado entre 4 y $8{ }^{\circ} \mathrm{C}$. Esto no sólo comporta variaciones en la superficie glaciada y nevada, sino de la vegetación (con un notable retraso respecto a la temperatura), de la precipitación 
y de la recarga. La última glaciación tuvo su máximo hace unos 16.000 años y, con algunas fluctuaciones importantes, cesó hace 11.000 años.

Figura 5.1. Evolución simulada de la temperatura media global superficial a lo largo de los últimos 9000 años mediante un conjunto de 5 miembros (en azul) y medias móviles de 25 años y de la irradiación solar total (TSI, total solar irradiance) (en rojo)

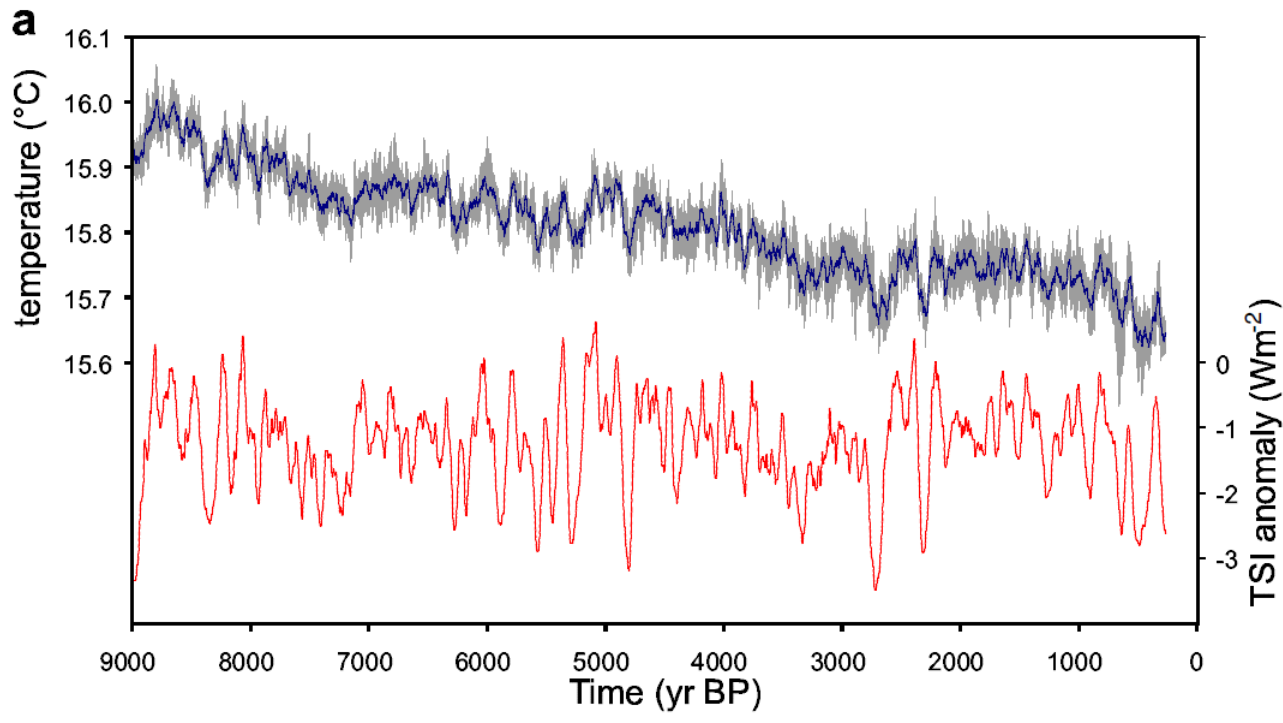

Fuente: Renssen et al (2006a; 2006b)

La Figura 5.1 muestra la evolución simulada de la temperatura media global superficial a lo largo de los últimos 9000 años. La Figura 1.2.2 es un ejemplo de las variaciones en la precipitación y en la cubierta vegetal en el Sahara occidental, que muestra como al avanzar en el actual interglaciar, se ha ido evolucionando hacia una marcada mayor aridez. Esta evolución no es regular y tiene fluctuaciones, como en la región hiperárida de Atacama, en el Norte de Chile (véanse las referencias pertinentes en Herrera y Custodio, 2014; Herrera et al., 2017).

En la Figura 5.3 se muestran dos reconstrucciones de los cambios de la temperatura en el hemisferio norte durante el último milenio. Tras la gran bonanza medieval se produjo una época intermedia seguida de los mínimos de la «pequeña edad del hielo» en los siglos XVI a XIX, seguida de una recuperación y un calentamiento reciente.

Según Luterbacher et al. (2004), el final del siglo XX y principios del XXI han sido en Europa, y en general en el hemisferio norte, $0,5^{\circ} \mathrm{C}$ más cálidos que cualquier periodo desde el año 1500. Sin embargo, tal afirmación queda menos clara al considerar el tiempo hasta el presente (2019). No hay evoluciones cíclicas bien definidas a escala secular y las variaciones de la energía solar por razones astronómicas son también irregulares al ser la suma de varios ciclos (ciclos de Milankovitch) de periodo variable milenariamente (Bassinot et al., 1994). No obstante, se pueden establecer algunas correlaciones históricas, como la que se muestran en la Figura 5.4. 
Figura 5.2. Evolución simulada de la precipitación media en los últimos 9000 años en periodos de 10 años, como consecuencia de cambios en la insolación del mes de junio en el hemisferio norte, en la región occidental del Sahara, con indicación del cambio progresivo de la vegetación, desde abundante a desértica. Se representa la insolación, en $\mathrm{W} / \mathbf{m}^{2}$, la diferencia térmica mar-océano en julio como media móvil de 500 años, en ${ }^{\circ} \mathrm{C}$, la precipitación decenal, en $\mathrm{mm} / \mathbf{a n ̃ o}$ y la fracción de cobertura vegetal
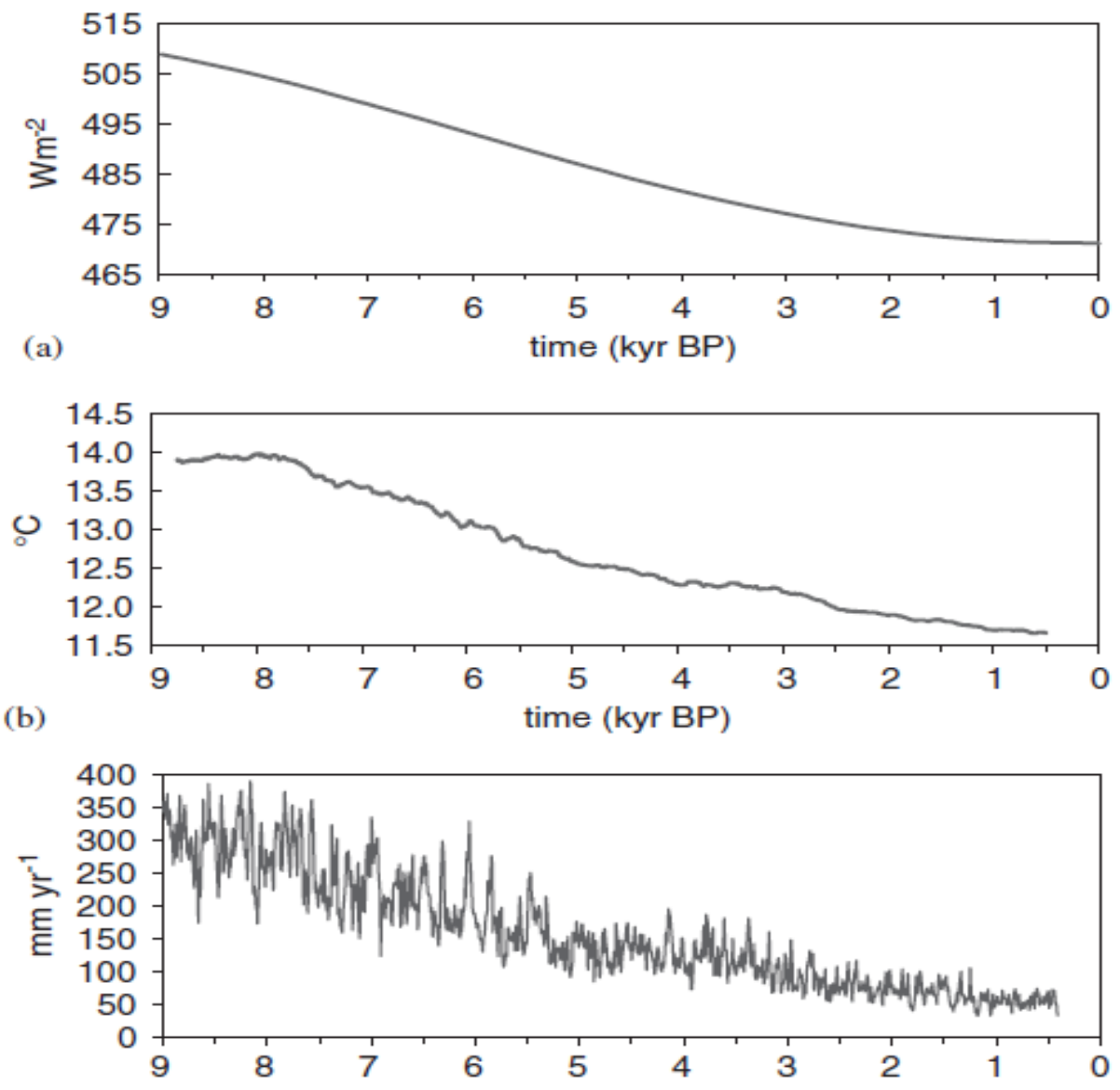

(c)

time (kyr BP)

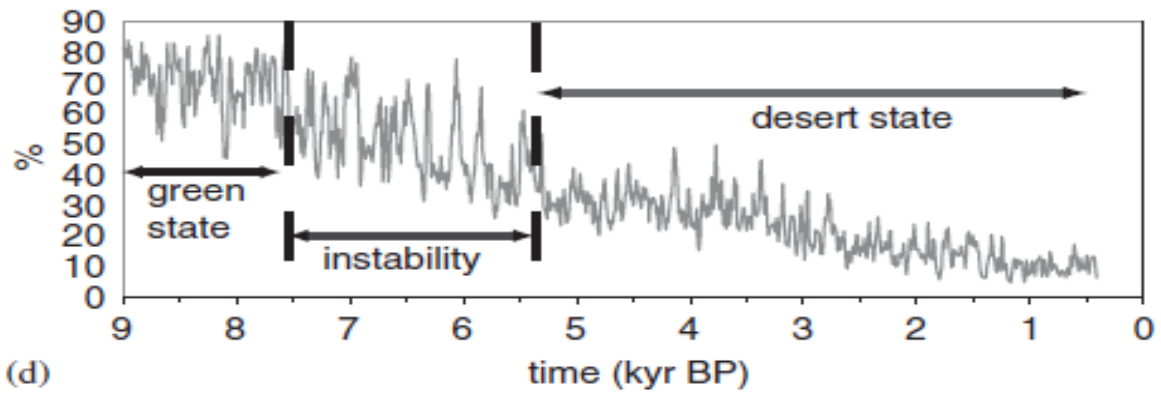

Fuente: Renssen et al (2006a; 2006b) 
Figura 5.3 Dos reconstrucciones de los cambios de la temperatura en el hemisferio norte

durante el último milenio, con los límites de incertidumbre. Tras la gran bonanza medieval se produjo una época intermedia seguida de los mínimos de la "pequeña edad del hielo» en los siglos XVII y XVIII y después una recuperación desde la primera mitad del siglo XIX, con calentamiento actual

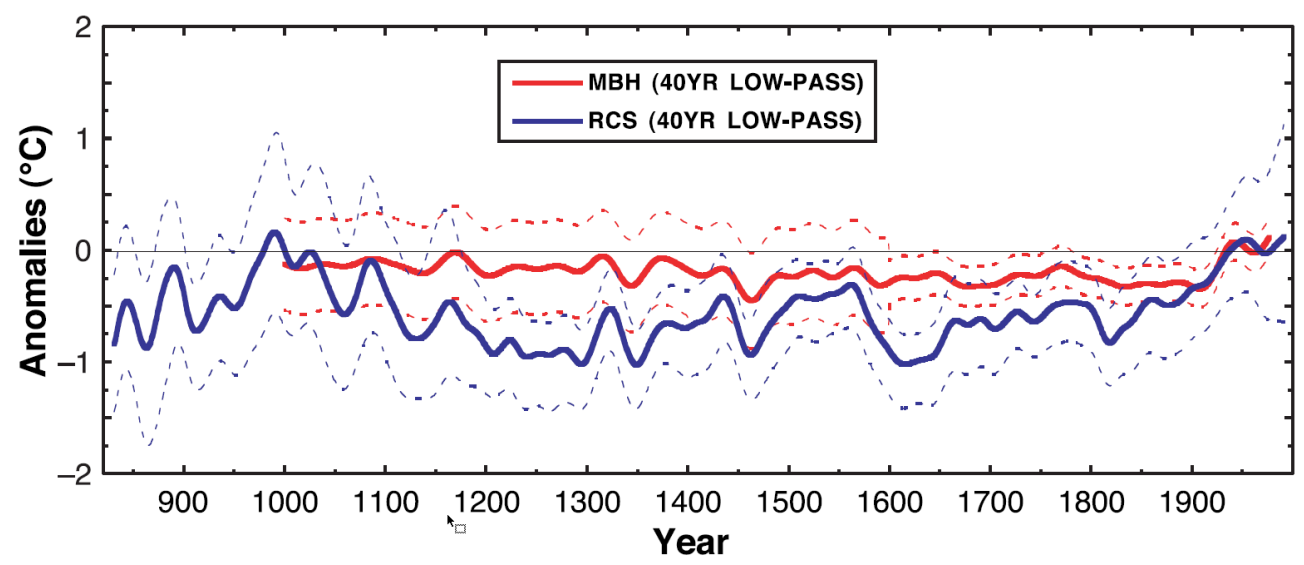

Fuente: Esper et al., 2002

Figura 5.4. Evolución de la temperatura según ciclos observados a lo largo de la historia. Arriba, bonanza romana entre la época fría galaica y su final con las invasiones bárbaras; en medio, bonanza medieval entre el final de la época visigótica y la reciente edad del hielo de los siglos XVI y principios del siglo XIX; abajo: posible evolución actual por causas naturales, con evolución hacia el calentamiento progresivo

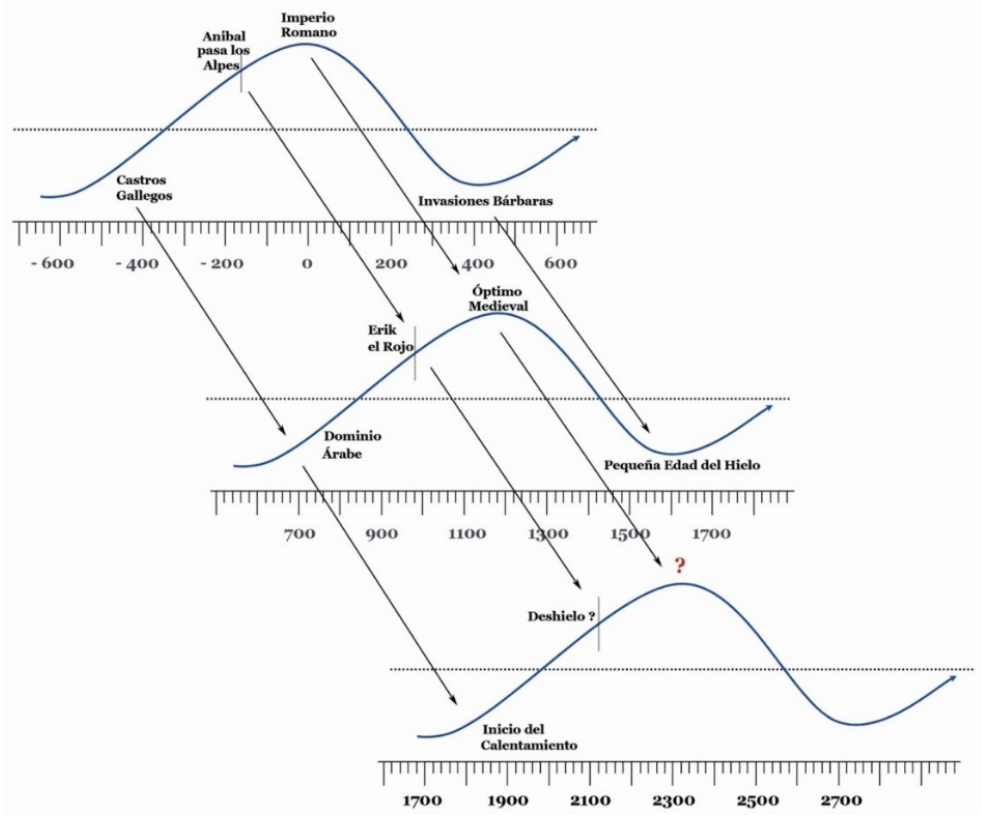

Fuente: Bassinot et al., 1994 


\subsection{Recarga y cambio climático}

La variación climática natural sigue produciéndose y afectará al futuro, siguiendo ciclos con periodicidades que van acompañadas de irregularidades, lo que hace muy incierta la proyección al futuro. A esto se suman los efectos climáticos antropogénicos y de cambio global.

El cambio climático es el debido a la introducción en la atmósfera de gases de efecto invernadero, que favorecen un calentamiento. Se superpone a la evolución natural y un aumento del vapor de agua en la base de la estratosfera y también del polvo ambiental, con efecto de enfriamiento. Esto es considerado en los modelos globales de proyección del clima en las décadas futuras, con mayor fiabilidad en cuanto al incremento relativo de temperatura, pero hay diferencias entre los distintos modelos debido a las necesarias simplificaciones y a que no todos los procesos están incorporados o son conocidos o tienen un efecto relativo no está calibrado Es un asunto estudiado en detalle por numerosos grupos de investigación y que es objeto de consideración mundial a través de los sucesivos informes de síntesis y de las bases científicas del Grupo Intergubernamental de Cambio Climático (IPCC, Intergovernmental Pannel on Climate Change).

La bonanza climática actual se ve alterada por efectos antrópicos que afectan a toda la Tierra y que tienden a producir un calentamiento, denominado cambio climático. Este cambio se superpone a la evolución natural, que es mal conocida en signo y magnitud. El efecto sobre la precipitación y la recarga es mucho menos conocido. De hecho, los 150 años de datos históricos de algunas estaciones no muestran un cambio significativo claro. La previsión más frecuente en el área mediterránea española y en las Islas Canarias es una disminución de la precipitación, pero con mayores fluctuaciones, o sea posibles mayores sequías y más persistentes. No obstante, esto es incierto y el efecto de mayor irregularidad puede estar exagerado a causa de las imperfecciones de las herramientas de predicción, que acumulan los errores inherentes a los métodos. Eso hace aún más incierto la estimación de cómo afectará el cambio climático a la recarga a los acuíferos, en especial en el área mediterránea (Boithias et al., 2014).

Aunque no sean perfectas, las mejores herramientas disponibles actualmente para entender la dinámica y evolución del clima terrestre son los modelos de circulación global (GCM). Estos modelos se basan en leyes físicas, como las de conservación de masa, energía y momento, y los procesos considerados se derivan de una gran cantidad de observaciones. Estos modelos son capaces de simular los aspectos más relevantes del clima a nivel global y de reproducir lo sucedido en el pasado próximo, aunque no tanto si se consideran siglos. Los diferentes modelos disponibles son cada vez más coherentes entre sí a una escala igual o mayor que $200 \mathrm{~km}$. Esta escala es aún demasiado grosera para tratar procesos hidrológicos, como la lluvia, de modo que se producen errores, que se manifiestan, tal como se ha dicho anteriormente, como situaciones extremas más frecuentes e intensas y mayor variabilidad a diferentes escalas temporales (Ehret et al., 2012).

Una reducción de escala de la modelación (detallado, downscalling) permite mejorar las simulaciones si se acompaña con una adecuada información local 
(relieve, vegetación, uso del suelo) y de las apropiadas condiciones de contorno derivadas de los GCM. Para la reducción de escala se pueden aplicar métodos estadísticos y métodos dinámicos. Desde el punto de vista conceptual, el detallado dinámico es el mejor método y permite obtener modelos de circulación regional (RCM) a la escala de $10-50 \mathrm{~km}$, que se adapta mejor a la evaluación de la precipitación. La realidad es que, a pesar del progreso que se ha logrado en la modelación del clima, existen errores sistemáticos (sesgos) que impiden la interpretación directa o la aplicación para simulación y predicción con modelos hidrológicos. Para superar este problema, se han ideado y estandarizado técnicas para corregir los resultados de los GCM y/o los RCM (Figura 5.5) para que se asemejen a las observaciones (Teutschbein et al., 2011; Ehret et al., 2012). Pero la corrección del sesgo altera de forma significativa los resultados de los modelos

Figura 5.5 Diferentes estrategias usadas (i.e. «Direct», «Delta Change» $\mathrm{y}$ «Bias Correction») para filtrar, en las proyecciones a futuro, las tendencias que presentan las variables climáticas simuladas por los GCM respecto a las mismas variables en el periodo histórico

Direct

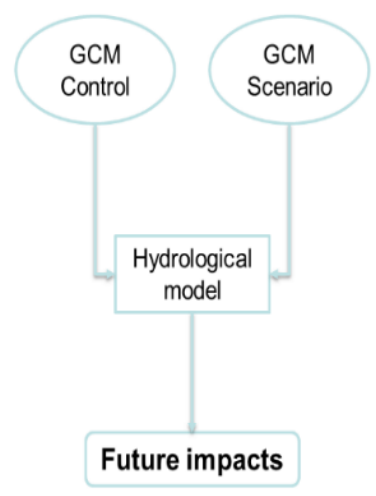

Delta change

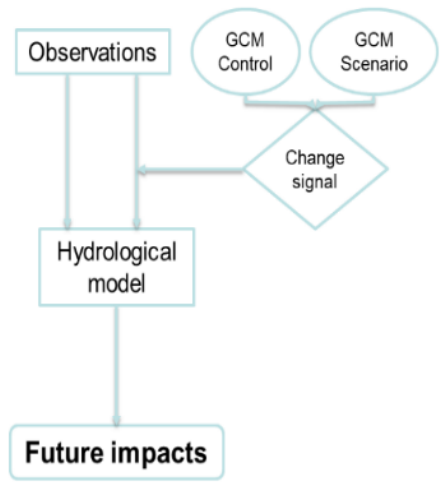

Bias correction

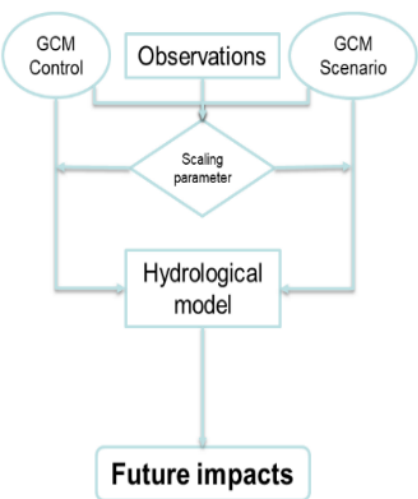

Fuente: Teutschbein et al., 2011; Ehret et al., 2012

El sesgo consiste en la diferencia entre los valores medios predichos y los observados durante un cierto tiempo en un determinado lugar. Las causas principales de sesgo en las salidas de los modelos son la imperfecta representación de la física atmosférica, los valores iniciales incorrectos y los errores en la cadena de parametrización. Los principales errores en los RCM son debidos a un cierre incorrecto del balance de energía y su realimentación a la capa límite convectiva y estable de la atmósfera y a la formación de nubes y precipitación que resulta. En cuanto a la precipitación, el sesgo total depende de una combinación de efectos variables en el tiempo (Ehret et al., 2012). También los GMC y RCM se parametrizan a partir de series temporales relativamente cortas, que no representan bien la variabilidad. Se modifican los modelos para reproducir caudales, pero estos valores pueden tener sesgo si están suavizados o consisten en pocos datos. Una conse- 
cuencia en el NW de Europa es que la precipitación invernal es demasiado grande (Christensen et al., 2008; Dosio y Paruolo, 2011). Para algunas regiones, la influencia de la corrección de sesgo en el cambio climático puede ser mayor que la propia señal (Rojas et al., 2011).

Para reducir el sesgo hay que mejorar los modelos, pero eso depende de cómo progrese el conocimiento. Actualmente se aplican correcciones al final, considerando las medias y momentos de la distribución de mayor grado, por ejemplo, en la radiación, humedad atmosférica y viento. El efecto de las correcciones es mayor en la precipitación que en la temperatura. Se supone que las relaciones y realimentaciones entre estados y flujos meteorológicos, como humedad atmosférica, precipitación y evapotranspiración, no son importantes, de forma que los campos resultantes se pueden corregir después de la modelación de los procesos relacionados. A partir de las salidas de los sistemas GCM/RCM, sólo se evalúan y se corrigen por sesgo los campos que interesan directamente en cuanto son entradas para otros modelos, como los hidrológicos. Tales son la lluvia, temperatura, humedad relativa, viento y radiación, entre otros. Pero las fluctuaciones a diferentes escalas debidas a mecanismos físicos muy diferentes pueden entremezclase y llevar a comportamientos no esperables y no deseados en las series temporales corregidas, de forma que se desdibuja la interpretación con vistas a correcciones de escenarios futuros (Haerter et al., 2011). Es difícil saber si el impacto de la corrección de sesgo en la señal de cambio climático lleva o no a una señal más realista.

Los conjuntos de varios modelos son útiles para atribuir la incertidumbre a los diferentes componentes de la cadena de modelación y a la variabilidad natural. Los proyectos europeos GRAPES (Acreman et al., 2000), ENSEMBLES y PRUDENCE (Christensen y Christensen, 2007; PRUDENCE, 2001) han buscado la cuantificación de la incertidumbre. Los modelos predicen aumentos de la temperatura media, variables de un lugar a otro de la Tierra. Algunos expertos creen que, en realidad, el aumento aún podría ser mayor si mejorasen los modelos (Sciemeyer, 2010), aunque otros minoran ese efecto. Los estudios de Willmott et al. (2017) apuntan a que los modelos climáticos y otros modelos en realidad pueden ser más precisos que lo que se les atribuye. Cook et al. (2013) realizaron un estudio sobre el consenso actual sobre las tendencias del cambio climático entre los diferentes expertos e instituciones.

Debido al aumento de la temperatura ambiental, cabe esperar un aumento de la evapotranspiración y por tanto una disminución de la recarga, aunque el efecto hay que modificarlo según el viento y por la lenta a muy lenta evolución de la vegetación para irse adaptando a las nuevas circunstancias. La simulación de los efectos del cambio climático puede hacerse con los modelos hidrológicos-hidrogeológicos disponibles, una vez que se han definidos los escenarios a considerar (Pulido-Velázquez, 2018) y los efectos a considerar (Sapriza-Azuri et al., 2015a; 2015b. La Figura 5.6 es un ejemplo de predicción de la precipitación en la parte española de la Península Ibérica y las islas Baleares. La transformación de esta predicción en la de recursos disponibles, requiere añadir el cambio de ETR y demanda por el cambio de temperatura y otras condiciones meteorológicas y de vegetación natural y cultivada. 
Figura 5.6. Predicción de la distribución mensual de la variación porcentual de la precipitación en la parte española de la Península Ibérica y en las islas Baleares en el periodo 2071-2100 respecto al de referencia de 1961-1990, según el modelo global HadAM3H, regionalizado con el método de análogos, en el escenario de emisión A2

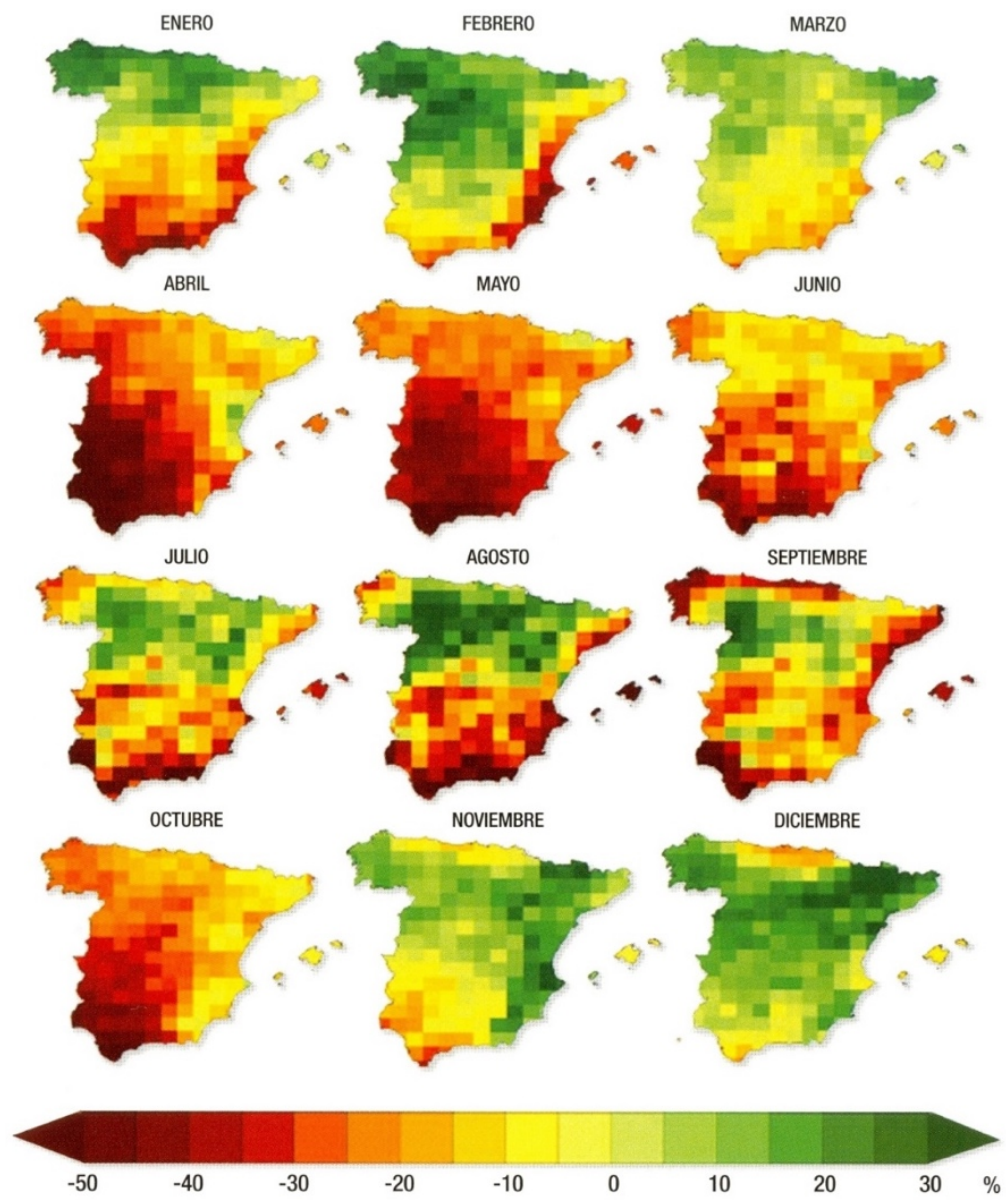

Fuente: Instituto Español de Meteorología (INM-2007)

Para la aplicación hidrológica y para estudiar el efecto sobre un acuífero determinado, como se ha dicho anteriormente, hay que transformar los datos de los modelos climáticos globales a las condiciones locales mediante el proceso de detallado (downscalling), tanto estadístico como dinámico. El detallado incrementa las incertidumbres, que resultan mayores que las del modelo general (Holman et al., 2009). Las proyecciones hacia atrás, para tratar de reproducir la evolución climática observada, además de la incertidumbre de ese conocimiento requiere que se corrija el sesgo de las series de datos de las simulaciones climáticas, o bien que se trabaje con el mismo y la comparación se haga indirectamente.

Mayor precipitación media anual no necesariamente significa mayor recarga media anual a los acuíferos, y viceversa, ya que las intensidades puntuales y la 
distribución tienen gran peso, en un proceso que es altamente no lineal (Green et al. 2011; Taylor et al., 2013). Se han realizado numerosos estudios de cómo posibles escenarios climáticos futuros pueden afectar a la recarga a los acuíferos (Treidel et al. 2011; Jyrkama y Sykes, 2007; Meixner et al., 2016), a los servicios ecosistémicos relacionados (Kløve et al., 2014) y al efecto de los bosques en la generación de escorrentía y recarga (Jones et al., 2014). En general, se trata de aplicaciones de las series de datos diarios o agregados por meses de la precipita-

Figura 5.7. Cambios relativos respecto la diferencia entre el promedio para el periodo

histórico en la respuesta del sistema hidrológico y la respuesta obtenida para la proyección GCM-RCP85 del modelo climático en el año 2100. La línea gris representa el cambio relativo medio anual

(a) Soil Moisture

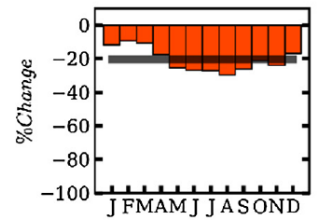

(e) GW-SW Exchange

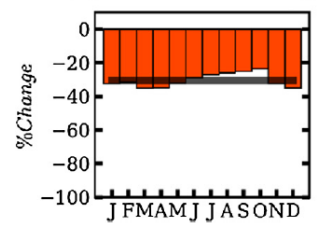

(b) AET

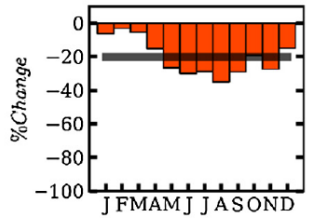

(f) Wetlands

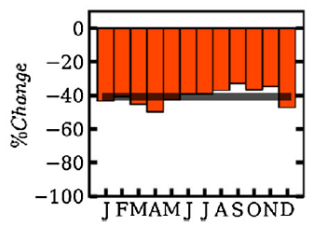

(c) Runoff Generation

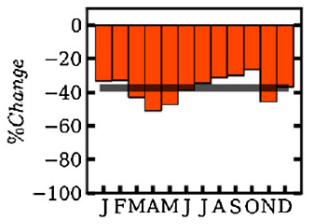

(g) River Runoff

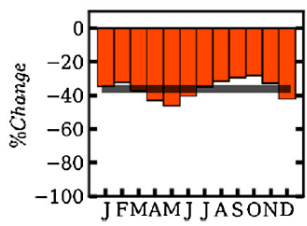

(d) Recharge

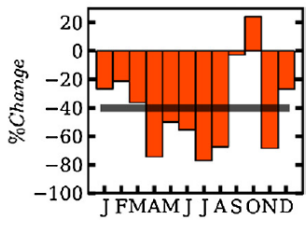

(h) GW Storage

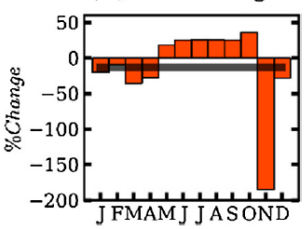

Fuente: Sapriza et al., 2015

Figura 5.8. Cambios relativos en la diferencia promedio para el periodo histórico en la respuesta del sistema hidrológico en condiciones naturales (sin bombeos) y la respuesta hidrogeológica del sistema a causa del bombeo de aguas subterráneas. La línea gris representa el cambio relativo medio anual

(a) Soil Moisture

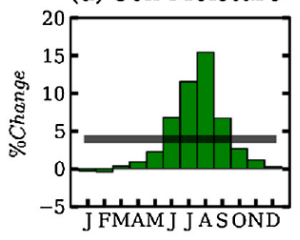

(e) GW-SW Exchange

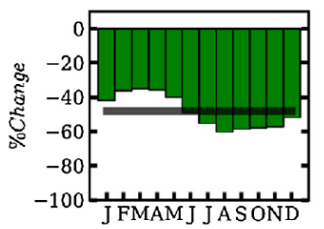

(b) AET

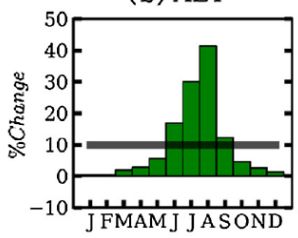

(f) Wetlands

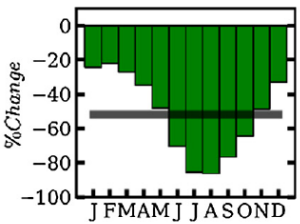

(c) Runoff Generation

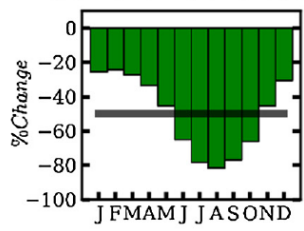

(g) River Runoff

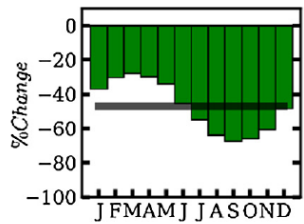

(d) Recharge

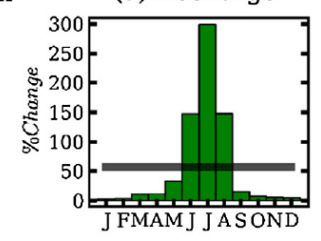

(h) GW Storage

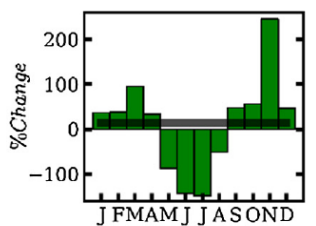

Fuente: Sapriza et al., 2015 
ción y variables meteorológicas proyectadas hasta 2099, o de una parte del periodo, según los distintos modelos existentes, bajo distintos escenarios, en especial los elegidos internacionalmente para poder comparar resultados. Esas series son las funciones de entrada y los resultados obtenidos son simplemente la respuesta a los mismos. No son proyecciones reales y deben interpretarse como tales. Es decir, si sucediere lo que se impone como entrada, dentro de las incertidumbres de la modelación de la recarga y de los recursos de agua, cabe esperar lo simulado en cuanto a los parámetros estadísticos de las series de datos, pero no en el detalle diario, mensual o anual.

Los posibles cambios futuros, tanto naturales como los afectados por la acción antrópica, pueden afectar a las relaciones agua dulce-agua salada en las áreas costeras y a la profundidad del nivel freático (Bloomfield et al., 2003) en cuanto a las posibles afecciones a humedales y cripto-humedales costeros. Con el apoyo del Código Visual-BALAN (Samper et al., 2007; Capítulo 4 de RAEMIA, 2019) se han realizado diversas elaboraciones para analizar el efecto sobre algunos acuíferos en Mallorca y en Cataluña, en especial con vistas a la agricultura (Candela et al., 2009; 2012; 2016), en el NE español (Castaño et al., 2013), en el SE español (Pulido-Velázquez et al., 2015; Aguilera y Murillo, 2009; Hartmann et al., 2014; Molina et al., 2013) y en el área Mediterránea (Stigter et al., 2014; SASMIE, 2017; MASE, 2015). Holman et al. (2012) aportan recomendaciones de cómo mejorar las evaluaciones, aunque con un aumento del coste de cálculo. Sapriza et al. (2015) han evaluado el efecto combinado que producen esas acciones en la dinámica del sistema hidrológico del Alto Guadiana, tanto el cambio climático (Figura 5.7) como el bombeo de aguas subterráneas (Figura 5.8),

Las futuras variaciones climáticas naturales y de origen antrópico pueden ser más acusadas allí donde el clima es el resultado de varias influencias marinas que dependen de las intensidades de la circulación atmosférica. Tal sucede en Oriente Próximo en cuanto a las influencias del Mediterráneo y del Índico (Leguy et al., 1983), en el Mediterráneo occidental (Jalut et al., 2000) y en el área árida sudamericana tropical del Pacífico Sur.

\subsection{Recarga y cambio global}

Como se dicho anteriormente, el cambio global es el debido a las acciones antrópicas que modifican el ambiente natural y humano en un lugar determinado o por acciones que se derivan de actuaciones de mayor alcance, como el ascenso actual del nivel del mar (SASMIE, 2017), de la disminución de la biodiversidad e introducción de nuevas especies, del talado masivo del bosque, de las grandes acciones de reforestación, de la gran agricultura extensiva, del abandono del medio rural, del descenso generalizado del nivel freático por extracción a gran escala del agua subterránea y de la urbanización de áreas extensas, entre otras situaciones (RAEMIA, 2019). En general, el cambio global es de mayor alcance a nivel local y regional que el cambio climático, aunque se habla menos del mismo, ya que es más complejo localmente, se carece de muchos de los datos para crear escenarios futuros y es menos mediático. Recientemente se han publicado las 
actas de un Congreso en Granada centrado en esta temática (Calvache et al., 2017).

El cambio global considera los efectos de las actividades humanas directas o por abandono de actividades seculares, que pueden afectar al clima local. Tales son los cambios territoriales por urbanización, agricultura, estado de forestación (incluyendo manejo del bosque y el matorral) y contaminación, por una población cada vez más numerosa, más longeva y con mayor nivel de vida. Esto comporta cada vez mayor consumo de alimentos, energía y bienes y, por ahora, con escaso grado de reciclado y poca propensión a lo que se viene llamando socio-economía circular, aunque la situación se puede estar actualmente modificando significativamente.

El cambio global puede suponer una mayor presión sobre los recursos de agua y por tanto también sobre los recursos de agua subterránea. Esto se hace en competencia con el agua que necesitan los ecosistemas para su funcionamiento y para mantener los servicios que proporcionan al ser humano. Esta presión puede ser importante localmente en cuanto a la cantidad, aunque a nivel general no hay escasez, pero es y lo será más en cuanto a la calidad. Esto supone reconsiderar el uso del agua, para que sea eficiente en términos globales, así como las actividades económicas y la utilización apropiada del almacenamiento subterráneo dentro de una gestión integrada de los recursos de agua que internalice la variabilidad climática. El proyecto europeo LIFE denominado Water Change, realizado por CETAQUA (Centro Tecnológico del Agua, SUEZ-España) y la UPC (Universidad Politécnica de Cataluña), ha abordado los efectos del cambio global en la cuenca del

Figura 5.9. Posible déficit mensual de agua en $\mathrm{hm}^{3} / \mathrm{mes}$ en la cuenca del río Llobregat (Barcelona) en el siglo XXI como consecuencia de distintos supuestos de cambio climático. Se dan los valores medios y los percentiles $10 \%$ y $90 \%$

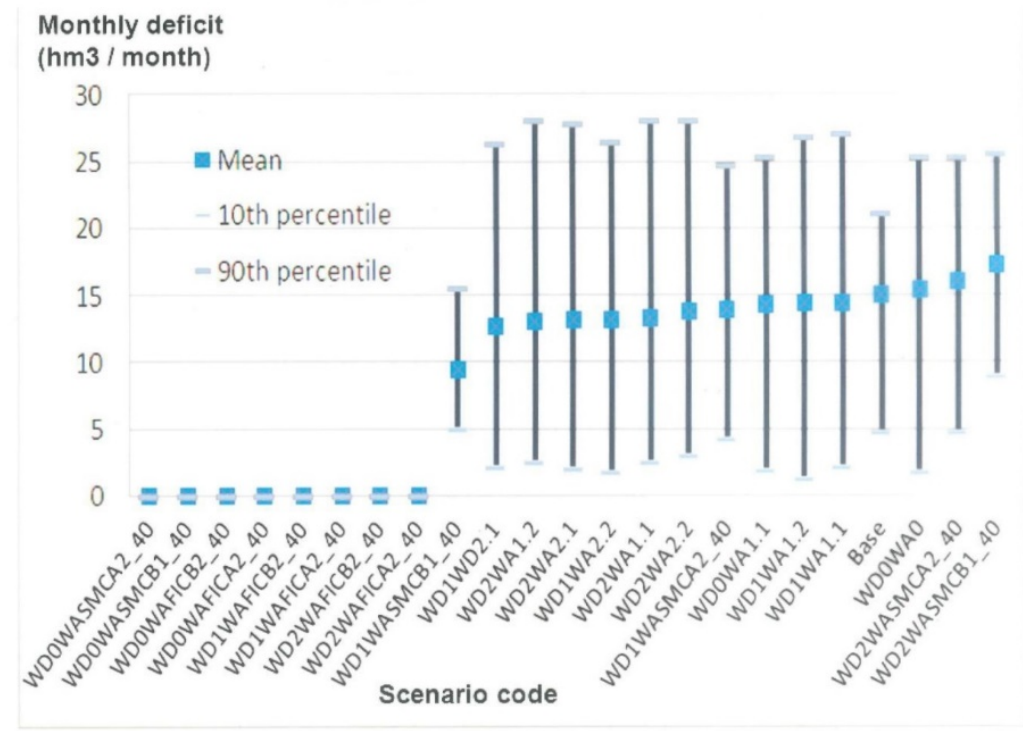

Fuente: Proyecto Water Change (LIFE-CETAQUA) 
río Llobregat con orientación al abastecimiento de agua al área Metropolitana de Barcelona (Pouget et al., 2014; Versini et al., 2016). En la Figura 5.9 se muestran los resultados obtenidos en cuanto al posible déficit mensual de agua.

En diversos ríos españoles se constata una progresiva reducción del caudal en las estaciones de aforo con largos periodos de registro, como ya se muestra en el Libro Blanco del Agua (MIMAM, 2000). Cada vez se añaden nuevos ejemplos en que el descenso se mantiene después de corregir el aumento de usos de agua en la cuenca y de tener en cuenta la mayor ETR por la tendencia al aumento de la tem-

Tabla 5.1. Cambio medio del caudal en los ríos catalanes La Muga, Ter, Llobregat y Siurana en la entrada de embalses en los mismos, en\%/año, después de corregir por los usos conocidos del agua en las respectivas cuencas

\begin{tabular}{|c|c|c|c|c|}
\hline \multicolumn{5}{|c|}{ Cambio medio del caudal en los embalses en \%/a } \\
\hline Río & La Muga & Ter & Llobregat & Siurana \\
\hline Observado & -0.07 & $-0,98$ & $-1,02$ & $-3,35$ \\
\hline Climático & 0,37 & 0,05 & 0,18 & 0,08 \\
\hline Otros & $-1,14$ & $-0,66$ & 0,66 & -2.17 \\
\hline
\end{tabular}

Fuente: J. Armengol

Figura 5.10. Evolución del caudal anual de entrada en el embalse de Sau, en la cabecera del río Ter (Girona), en valores relativos a la capacidad del embalse en el periodo 1960 a 2010. En la cuenca vertiente no hay cambios de uso del territorio, excepto que en el $30 \%$ de su superficie que corresponde a bosque, este se ha densificado, con gran aumento del sotobosque

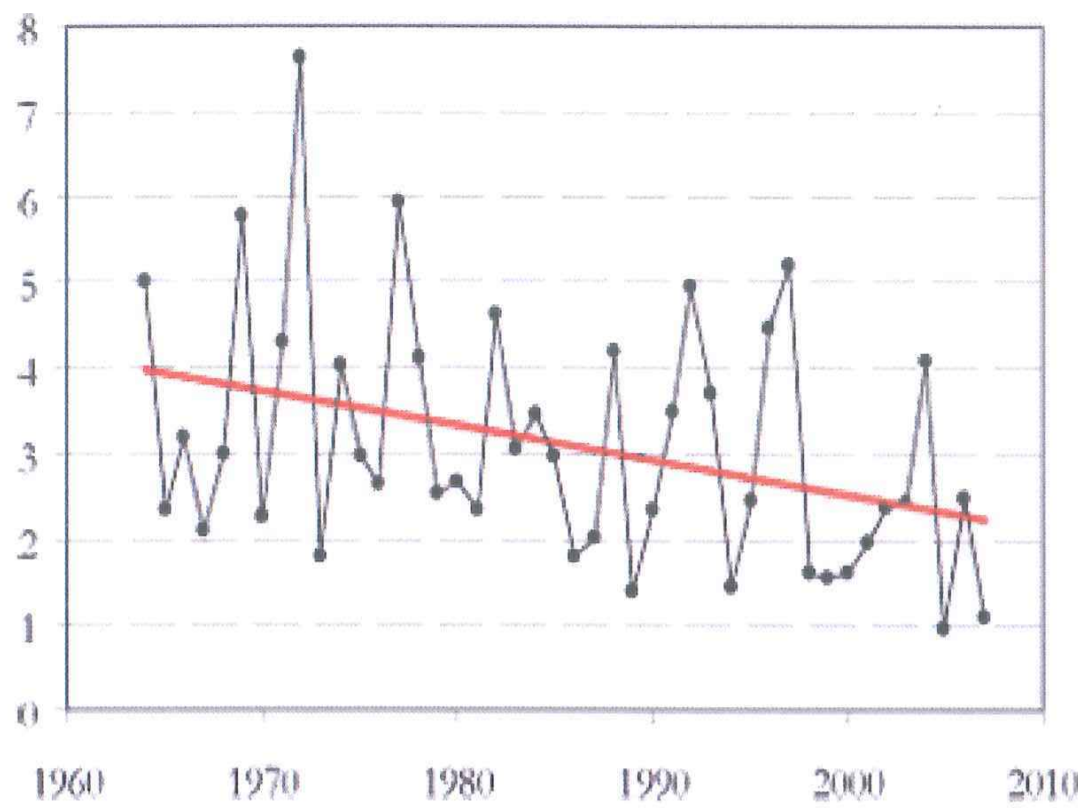

Fuente: F. Gallart y J. Armengol 
peratura. El residuo no está bien explicado y hay que relacionarlo con el cambio global más que con el cambio climático, ya que no se aprecia variación significativa de la precipitación ni de la ocupación del territorio. Una posible causa, verosímil pero no cuantificada aún, es la extensión del bosque por abandono de cultivos y de los aterrazamientos del territorio que favorecen la recarga, y en especial el cambio de uso del bosque. Los tradicionales aprovechamientos forestales controlados con eliminación del sotobosque y masa vegetal muerta contrastan con la actual casi ausencia humana que ha favorecido un gran desarrollo del sotobosque, que aumenta la evapotranspiración. La Figura 5.10 es un ejemplo en la cabecera del río Ter (Girona). En la Tabla 5.1 se da el cambio medio de caudal en tres ríos catalanes. En la Tabla 5.2 se muestran las variaciones simuladas en la cuenca del Ebro hasta Tortosa.

Tabla 5.2. Cambios hidrológicos en la cuenca del Ebro simulados con el programa GIS-BALAN, aplicando al siglo XXI las series de datos del modelo climático global acoplado CGCM3 con los escenarios del IPCC AiB, A2, B1 y Commit

\begin{tabular}{|c|c|c|c|}
\hline Variable & $\mathbf{2 0 1 0 - 2 0 3 9}$ & $\mathbf{2 0 4 0 - 2 0 6 9}$ & $\mathbf{2 0 7 0 - 2 0 9 9}$ \\
\hline Temperatura, $\Delta \mathbf{T}^{\mathbf{}} \mathbf{C}$ & 1,25 & 2.23 & 2,28 \\
\hline Precipitación, $\Delta \mathbf{P} \mathbf{~ m m} / \mathbf{a}$ & $-7(-1,2 \%)$ & $-51(-8,6 \%)$ & $-47(-7,9 \%)$ \\
\hline Escorrentía superficial, $\Delta \mathbf{E S}$ & & & $-2,2 \%$ \\
\hline Escorrentía subterránea, $\Delta \mathbf{A S}$ & $-11,3 \%$ & $-24,2 \%$ & $-22 \%$ \\
\hline ETR, $\Delta \mathbf{E T R}$ & & & Pequeño \\
\hline Caudal total, $\Delta \mathbf{Q}$ & $-9,4 \%$ & $-22 \%$ & $-20.2 \%$ \\
\hline
\end{tabular}

Fuente: Alvares, 2010

El cambio global también tiene una componente que relaciona la explotación del agua subterránea con la climatología local, por evaporación en los regadíos y en terrenos no ocupados por la población y, en clima árido y semiárido, por el descenso de la evapotranspiración al descender el nivel freático (Scheihing y Tröeger, 2018; Miguez-Macho, 2007; Fan et al., 2007). Uno de los aspectos con mayor impacto en el cambio global, que con frecuencia es obviado y que requiere más investigación y experiencia, es el del efecto de los cambios de la cubierta vegetal, como los cambios en el bosque y su manejo, incluyendo el estado vegetativo y del sotobosque (López Rodríguez, 1997; Ventura de Oliveira et al., 2018; Salama et al., 1999; Walker et al., 2002), como también se ha expuesto anteriormente.

La mitigación de los efectos del cambio global y del posible cambio climático es objeto de numerosos trabajos, que se han compilado en Chen et al. (2017). El agua subterránea y el buen manejo de los acuíferos constituyen uno de los grandes e importantes medios para la mitigación de los efectos del cambio climático y cambio global (Pulido-Velázquez, 2018) a través de la inercia que proporcionan sus grandes reservas, a condición de una gestión apropiada y adecuada gobernanza, lo que incluye una legislación efectiva que lo tenga en cuenta y que garantice el suficiente buen funcionamiento de los ecosistemas (Stitger et al., 2014). 
El papel de las aguas subterráneas en la disponibilidad de agua ante un eventual aumento de la irregularidad pluviométrica, tanto si afecta positiva o negativamente a la recarga a los acuíferos, se obtiene valorando la resiliencia de los acuíferos a estos cambios, por ejemplo y analizando el comportamiento de los trazadores naturales químicos e isotópicos ambientales (Lapworth et al., 2013).

La solución a buena parte de los problemas futuros, o por lo menos su mitigación, pasa por una buena gestión y gobernanza de las aguas subterráneas. Esto requiere, además de herramientas legales, administrativas y sociales, un buen y suficiente conocimiento de las aguas subterráneas (Custodio, 2018). La recarga, la evaluación de su incertidumbre y su aplicación a los aspectos prácticos es uno de los componentes esenciales. El buen uso de las aguas subterráneas, junto con la adecuada protección del medio ambiente, requiere una identificación del estado de escasez (Pedro-Monzonís et al., 2015; McKee et al., 1993; McNab y Karl, 1999), con antelación suficiente.

Nota: Este capítulo es una síntesis de las Secciones 8.6 y 8,7, del Capítulo 8 del Informe RAEMIA (RAEMIA, 2019), escritas por E. Custodio (Grupo de Hidrología Subterránea, DECA-UPC) con aportaciones de J. Jódar (IGME-Zaragoza),y modificaciones y adiciones procedentes de otras partes del libro, realizada por E. Custodio y J. C. Santamarta. El libro electrónico RAEMIA (2019) es de libre acceso (hdl.handle.net/2117/182282) y ha sido editado por la Universidad Politécnica de Cataluña (UPC), Barcelona, con el apoyo de SUEZ-España y CETAQUA (Centro Tecnilógico del Agua, Barcelona y Málaga).

\section{Referencias bibliográficas}

Acreman, M., Almagro, J., Álvarez Rodríguez, J., Bouraqui, F., Bradford, R., Bromley, J., Croke, B., Crooks, S., Cruces, J., Dolz, J., Dunbar, M., Estrela, T., Fernández-Carrasco, P., Fornés, J., Gustard, A., Haverkamp, R., Hera, A. de la, Hernández-Mora, N., Llamas, M.R.,Martínez Cortina, L., Papamastorakis, J., Ragab, R.,Sánchez Juny, M., Vardavas, I. y Webb, T. 2000. Technical Report to the European Union ENV4-CT95- 0186. Groundwater and River Resources Action Programme on a European Scale (GRAPES). Institute of Hydrology, Wallingford: 1-248.

Adar, E.M.; Gev, I.; Berliner, P.; Issar, A.S. 1995. The effect of forestation on a shallow groundwater reservoir in an arid sand dune terrain. J. Arid Studies, 55: 259-262.

Aguilera, H., Murillo, J.M. 2009. The effect of possible climate change on natural groundwater recharge based on a simple model: a study of four karstic aquifers in SE Spain. Environ. Geol., 57: 963-974.

Alcalá, F.J.; Custodio, E. 2014. Spatial average recharge through atmospheric chloride mass balance and its uncertainty in continental Spain. Hydrol. Processes, 28: 218-236. 
Alcalá, F.J.; Custodio, E. 2015. Natural uncertainty of spatial average aquifer recharge through atmospheric chloride mass balance in continental Spain. Journal of Hydrology, 524: 642-661.

Álvares, D., Samper, J., García Vera, M.A. 2009. Evaluación del efecto del cambio climático en los recursos hídricos de la cuenca hidrográfica del Ebro mediante modelos hidrológicos. Evaluación de los recursos hídricos de la cuenca hidrográfica del Ebro mediante GISBALAN. En: IX Jornadas de Zona no Saturada, ZNS'09, Barcelona, Vol.IX: 499-506 y 491-498.

Alvares, D. 2010. Acoplamiento de modelos hidrológicos semidistribuidos y GIS: aplicación a la evolución de los efectos de cambio climático. Tesis doctoral. Universidade de A Coruña.

Bassinot, F.C., Labeyrie, L.D., Vincent, E., Quidelleur, X., Shackleton, N.J., Lancelot, Y. 1994. The astronomical theory of climate and age of the Brunes-Matuyama magnetic reversal. Earth Planet Scie. Lett., 126: 91-108.

Bellot, J., Bonet, A., Sánchez, J.R., Chirino, E. 2001. Likely effects of land use changes on the runoff and aquifer recharge in a semiarid landscape using a hydrological model. Landsc. Urban Plan, 55: 41-53.

Berry, S.L., Farquhar, G.D., Roderick, M.L. 2005. Co-evolution of climate, soil and vegetation. In: M., Anderson (ed.), Encyclopaedia of Hydrological Sciences. John Wiley \& Sons, Indianapolis.

Bloomfield, J.P., Gaus, I., Wade, S.D. 2003. A method for investigating the potential impacts of climate change scenarios on annual minimum groundwater levels. Water Environ. J., 17: 86-91.

Boithias, L., Acuña, V., Vergoñós, L., Ziv, G., Marcé, R., Sabater, S. 2014. Assessment of the water supply: demand ratios in a Mediterranean basin under different global change scenarios and mitigation alternatives. Science of the Total Environment, 470-471: 567-577.

Cabrera, M.C.; Custodio, E. 2004. Groundwater flow in a volcanic-sedimentary coastal aquifer: Telde area, Gran Canaria, Canary Islands, Spain. Hydrogeology Journal, 12: 305-320.

Calvache, M.L., Duque, C., Pulido-Velázquez, D. (eds.). 2017. Impacts of global change on western Mediterranean aquifers. International Congress on Groundwater and Global Change in the Western Mediterranean, Granada, International Association of Hydrogeologists-Spanish Chapter. Universidad de Granada: $1-412$.

Calder, I.R. 1993. Hydrologic effects of land-use change. In D.R. Maidment (ed.), Handbook of Hydrology, McGraw Hill, Sydney.

Candela, L., von Igel, W., Javier Elorza, F., Aronica, G. 2009. Impact assessment of combined climate and management scenarios on groundwater resources and associated wetland (Mallorca, Spain). J Hydrol.; 376: 510-527.

Candela, L., Elorza, F.J., Jiménez-Martínez, J., Wolf von Igel, W. 2012. Global change and agricultural management options for groundwater sustainability. Computers and Electronics in Agriculture, 86: 120-130. 
Candela, L., Tamoh, K., Olivares, G., Gómez, M. 2016. Climate and Land Use Changes on Streamflow and Subsurface Recharge in the Fluvià Basin, Spain. Water, 8, 228; doi:10.3390/w8060228.

Chen, W-Y., Suzuki, T., Lackner, M. (eds). 2017. Handbook of climate change mitigation and adaptation, 2nd. Edition. Springer: 1-3331.

Christensen, J.H., Christensen, O.B. 2007. A summary of the PRUDENCE model projections of changes in European climate by the end of this century. Climatic Change, 81, 7-30.

Christensen, J.H., Boberg, F., Christensen, O.B., Lucas-Picher, P. 2008. On the need for bias correction of regional climate change projections of temperature and precipitation. Geophys. Res. Lett., 35, L20 709, doi: 10.1029/2008GL035694, 7864.

Cook, J. Nuccitelli, D., Green, S.A., Richardson, M., Winkler, B., Painting, R., Way, R., Jacobs, P., Skuce, A. 2013. Quantifying the consensus on anthropogenic global warming in the scientific literature. Environ. Res. Lett. 8 (2013) 024024 (7pp).

Cruz-Fuentes, T.; Heredia, J.; Cabrera, M.C.; Custodio, E. 2014a. Behaviour of a small sedimentary volcanic aquifer receiving irrigation return flows: La Aldea, Gran Canaria, Canary Islands (Spain). Hydrogeology Journal, 22: 865-882.

Cruz-Fuentes, T., Cabrera, M.C., Heredia, J., Custodio, E. 2014b. Groundwater salinity and hydrochemical processes in the volcano-sedimentary aquifer of La Aldea, Gran Canaria, Canary Islands, Spain. Science of the Total Environment, 484: 154-166.

Custodio, E.1990. Saline groundwater in the Canary Islands (Spain) resulting from aridity. In: Greenhouse Effect, Sea Level and Drought. NATO ASI Series C: Mathematical and Physical Sciencies. Vol. 325. Kluver Publ Co. Dordrecht: 593-618.

Custodio, E. 1992. Coastal aquifer salinization as a consequence of aridity: the case of Amurga phonolitic massif, Gran Canaria Island. Study and Modelling of Saltwater Intrusion into Aquifers. CIMNE-UPC. Barcelona: 81-98.

Custodio, E. 1994. Endurecimiento del agua del Valle Bajo del Llobregat por cambios en los procesos de recarga. Análisis y Evolución de la Contaminación de las Aguas Subterráneas. Alcalá de Henares. Asociación Internacional de Hidrogeólogos: Grupo Español. II: 123-140.

Custodio, E. 2010. Estimation of aquifer recharge by means of atmospheric chloride deposition balance in the soil. Contributions to Science, 6(1): 81-97.

Custodio, E. 2018. Las aguas subterráneas en la regulación y atenuación de las sequías a corto y largo plazo. En: A. Embid (ed.), Sequía e Inundaciones como Fenómenos Hidrológicos Extremos, XXII Jornadas de Derecho de Aguas. Universidad de Zaragoza.

Custodio,E, Llamas, M.R. 1976/1983. Hidrología subterránea. Ediciones Omega. Barcelona. 2 vol.:1-2350. 
Custodio, E.; Llamas, M.R.; Samper, J. (eds.) 1997. La evaluación de la recarga a los acuíferos en la planificación hidrológica. AIH-GE/IGME. Madrid: 1-455.

Dosio, A. Paruolo, P. 2011. Bias correction of the ENSEMBLES high-resolution climate change projections for use by impact models: Evaluation on the present climate. Geophys. Res.Atmos., 116, D16106, doi:10.1029/2011jd015934.

Ehret, U., Zehe, E., Wulfmeyer, V., Warrach-Sagi, K.W., Liebert, J. 2012. Should we apply bias correction to global and regional climate model data? Hydrol. Earth Syst. Sci., 16, 3391-3404.

Esper, J., Cook, E.R., Schweingruber, F.H. 2002. Low-frequency signals in long tree-ring chronologies for reconstructing past temperature variability. Science, 295(5563): 2250-2253.

Espinosa Martínez, S., Custodio, E. 2014. Comparación de la recarga natural estimada con el balance de agua en el suelo y con el balance de la deposición atmosférica de cloruro en un sistema carbonatado en el área del Baix Ebre, Cataluña, España. Ingeniería del Agua; 20: 135-155

Espinosa Martínez, S.; Custodio, E. 2016. Estimación de la escorrentía superficial para el cálculo de la recarga a los acuíferos del macizo kárstico de los Ports de Beseit (Tarragona, España) combinando balance de agua en el suelo y análisis de hidrogramas de caudales. Estudios Geológicos, 72(1):

Estrela, T., Pérez-Martin, M.A., Vargas, E. 2012. Impacts of climate change on water resources in Spain. Hydrological Sciences Journal 57 (6), 1154-1167.

Fan, F., Gonzalo Miguez-Macho, G., Weaver, C.P., Walko, R., Robock, A. 2007. Incorporating water table dynamics in climate modeling: 1 . Water table observations and equilibrium water table simulations. Journal of Geophysical Research, 112, D10125, doi:10.1029/2006JD008111.

Farley, K. A., Jobbagy, E.G., Jackson, R.B. 2005. Effects of afforestation on water yield: a global synthesis with implications for policy. Global Change Biology, $11,1565-1576$.

Gallart, F., Llorens, P. 2003. Catchment management under environmental change: impact of land cover change on water resources. Water International, 28(3):334340.

Gallart, F., Llorens, P. 2013. Water resources and environmental change in Spain. A key issue for sustainable integrated catchment management. Cuadernos de Investigación Geografica, 27:7-16.

Green, T. R., Taniguchi, M., Kooi, H., Gurdak, J.J., Allen, D.M., Hiscock, K.M., Treidel, H., Aureli, A. 2011. Beneath the surface of global change: Impacts of climate change on groundwater. J. Hydrol., 405(3-4): 532-560.

Guasch, F.S.H., Armengol, E.M.J., Sabater, S. 2006. The Ter: a Mediterranean river case-study in Spain. River and Stream Ecosystems of the World: With a New Introduction: 419.

Guardiola-Albert, C., Martos-Rosillo, S., Pardo-Igúzquiza, E., Durán Valsero, J.J., Antonio Pedrera, A., Jiménez-Gavilán, P., Liñán Baena, C. 2014. Comparison 
of recharge estimation methods during a wet period in a karst aquifer. Groundwater, doi:10.11117gwat.12310.

Haerter, J.O., Hagemann, S., Moseley, C., Piani, C. 2011. Climate model bias correction and the role of timescales. Hydrol. Earth Syst. Sci., 15, 1065-1079.

Hartmann, A., Mudarra, M., Andreo, B., Marín, A., Wagener, T., J. Lange, J. 2014. Modeling spatiotemporal impacts of hydroclimatic extremes on groundwater recharge at a Mediterranean karst aquifer. Water Resour. Res., 50: 6507-6521.

Herrera, C., Custodio, E. 2003. Hipótesis sobre el origen de la salinidad de las aguas subterráneas en las islas de Fuerteventura. Archipiélago de Canarias, España. Boletín Geológico Minero. 114(4): 433-452.

Herrera, C., Custodio, E. 2014. Origin of waters from small springs located at the northern coast of Chile, in the vicinity of Antofagasta. Geology, 41(2): 314-341.

Herrera, C., Gamboa, C., Custodio, E., Jordan, T., Godfrey, L., Jódar, J., Luque, J.A., Vargas, J., Sáez, A. 2017. Groundwater origin and recharge in the hyperarid Cordillera de la Costa, Atacama Desert, northern Chile. Sci Total Environ., 624: 114-132.

Holman, I.P., Tascone, D., Hess, T.M. 2009. A comparison of stochastic and deterministic downscaling methods for modelling potential groundwater recharge under climate change in East Anglia, UK: implications for groundwater resource management. Hydrogeology Journal, 17: 1629-1641.

Holman, I.P., Allen, D.M., Cuthbert, M.O., Goderniaux, P. 2012. Towards best practice for assessing the impacts of climate change on groundwater. Hydrogeology Journal, 20: 1-4.

Ibrahim, M., Favreau, G., Scanlon, B.R., Seidel, J.L., Mathieu Le Coz, M., Demarty, J., Cappelaere, B. 2014. Long-term increase in diffuse groundwater recharge following expansion of rainfed cultivation in the Sahel, West Africa. Hydrogeology Journal, 22: 1293-1305.

Jalut, G.; Amat, A.E.; Bonnet, L.; Gauguelin, Th.; Fontugne, M. 2000. Holocene climatic changes in the western Mediterranean, from south-east France to south-east Spain. Palaeogeography, Palaeoclimatology, Palaeoecology, 160: 255290.

Jiménez-Martínez, J., Candela, L., Molinero, J., Tamoh, K., 2010. Groundwater recharge in irrigated semi-arid areas: quantitative hydrological modelling and sensitivity analysis. Hydrogeol. J. 18, 1811-1824.

Jones, J.A., Creed, I.F., Spargo, A., Buttle, J.M., Adams, M., Beall, F.D., Booth, E., Campbell, J.L., Clow, D.W., Elder, K. et al. 2014. Changing forest water yields in response to climate warming: Results from long-term experimental watershed sites across North America. Glob. Chang. Biol., 20: 3191-3208.

Jyrkama, M.L. Sykes, J.F. 2007a. The impact of climate change on groundwater. In: J.W. Delleur (ed.), The Handbook of Groundwater Engineering, 2nd ed.: 281/28-42. 
Jyrkama, M.S., Sykes, J.F. 2007b. The impact of climate change on partially varying groundwater recharge in the Grand River watershed (Ontario). Journal of Hydrology, 338: 237-250.

Kløve, B., Ala-Aho, P., Bertrand, G., Gurdak, J. J., Kupfersberger, H., Kværner, J. Pulido-Velazquez, M. 2014. Climate change impacts on groundwater and dependent ecosystems. J. Hydrol, 518: 250-266.

Kuczera, G. 1987. Prediction of water yield reductions following a bushfire in ashmixed species eucalypt forest. Journal of Hydrolology, 94: 215-236.

Langford, K.J. 1976. Change in yield of water following a bushfire in a forest of Eucalyptus regnans. Journal of Hydrology, 29: 87-114.

Lapworth, D.J., MacDonald, M., Tijani, M.N., Darling, W.G., Gooddy, D.C., Bonsor, H.C., Araguás-Araguás, L.J. 2013. Residence times of shallow groundwater in West Africa: implications for hydrogeology and resilience to future changes in climate. Hydrogeology Journal, 21: 673-686.

Latron, J., Gallart, F. 2007. Seasonal dynamics of runoff-contributing areas in a small mediterranean research catchment (Vallcebre, Eastern Pyrenees). Journal of Hydrology, 335(1-2): 194-206.

Latron, J., Llorens, P., Gallart, F. 2009. The hydrology of Mediterranean mountain areas. Geography Compass, 3(6): 2045-2064.

Leguy, C.; Rindsberger, M.; Zangwil, A.; Issar, A.; Gat, J.R. 1983. The relation between the oxygen-18 and deuterium contents of rainwater in the Negev Desert and air mass trajectories. Isotope Geosciences 1: 205-218.

López Rodríguez, J.J. 1997. Evaluación de la modificación de la recarga por cambios en la cobertera vegetal. En: E. Custodio, M.R. Llamas y J. Samper (eds.), La Evaluación de la Recarga a los Acuíferos en la Planificación Hidrológica. AIH-GE/IGME. Madrid: 209-228.

Luterbacher, J., Dietrich, D., Xoplaki, E., Grosjean, M., Wanner,H. 2004. European seasonal and annual temperature variability, trends and extremes since 1500 AD. Science, 303, 1499-1503.

MASE 2015. Aspectos hidrológicos, ambientales, económicos, sociales y éticos del consumo de reservas de agua subterránea en España. Preparado por E. Custodio para UPC and AQUALOGY-CETAQUA. Barcelona. UPC e-books: 1-487. http://hdl.handle.net/2117/111272

McKee, T.B.,,Doesken, N.J., Kleist, J. 1993. The relationship of drought frequency and duration of time scales. Eighth Conference on Applied Climatology, Anaheim, California. 179-186.

McNab, A.L., Karl, T.R. 1989. Climate and droughts. US Geological Survey, Water-Supply Paper 2375: 89-95

Meixner, T., Manning, A.H., Stonestrom, D.A., Allen, D.M., Ajami, H., Blasch, K.W., Brookfield, A.E., Castro, C.L., Clark, J.F., Gochis, D.J., Flint, A.L., Neff, K.L., Niraula, R., Rodell, M., Scanlon, B.R., Singha, K., Walvoord, M.A., 2016. Implications of projected climate change for groundwater recharge in the Western United States. Journal of Hydrology, 534: 124-138. 
Miguez-Macho, G., Fan, Y., Weaver, C.P., Walko, R., Robock. A. 2007. Incorporating water table dynamics in climate modeling: 2. Formulation, validation, and soil moisture simulation. J. Geophysical Research, 112, D13108, doi:10.1029/ 2006JD008112.

MIMAM 2000. Libro blanco del agua en España. Ministerio de Medio Ambiente, Secretaría de Agua y Costas, Dirección General de Obras Hidráulicas y Calidad del Agua, Madrid: 1- 637.

Molina, J.L., Pulido-Velázquez, D., García-Aróstegui, J.L., Pulido-Velázquez, M. 2013. Dynamic bayesian networks as a decision support tool for assessing climate change impacts on highly stressed groundwater systems. J. Hydrol., 479: 113-129.

Naranjo, G.; Cruz-Fuentes, T.; Cabrera, M.C.; Custodio, E. 2015. Estimating natural recharge by means of chloride mass balance in a volcanic aquifer: Northeastern Gran Canaria (Canary Islands, Spain). Water: 7(6): 2555-2574; doi: 10.3390/w7062555.

Pedro-Monzonís, M., Solera, A., Ferrer, J., Estrela, T., Paredes-Arquiola, J. 2015. $A$ review of water scarcity and drought indexes in water resources planning and management. Journal of Hydrology, 527: 482-493.

Pisani, B., Samper, J., Espinha Marques, J. 2017. Climate change impact on groundwater resources of a hard rock mountain region (Serra da Estrela, Central Portugal). Sustainable Water Resour. Manag. DOI 10.1007/s40899-017-01290.

Pouget, L.; Velasco, M.; Cabello, A.; McEnnis, S.; Escaler, I.; Guiu, R.; Massana, J.; Custodio, E. 2014. Estrategias de adaptación al cambio global en la gestión de los recursos hídricos de la cuenca del Llobregat. TecnoAqua, 9: 2-9.

PRUDENCE, 2001. Prediction of Regional scenarios and Uncertainties for Defining EuropeaN Climate change risks and Effects. Project EVK2-CT2001-00132 in the EU 5th Framework program for Energy, environment and sustainable development. Web: http://prudence.dmi.dk/.

Pulido-Velázquez, D., Collados-Lara, A.J., Alcalá, F.J. 2018. Assessing impacts of future potential climate change scenarios on aquifer recharge in continental Spain. Journal of Hydrology, 567: 803-819.

Pulido-Bosch, A. Rigol-Sanchez, J.P., Vallejos, A., Andreu, M., Ceron, J.C., Molina-Sanchez, L. Sola, F. 2018. Impacts of agricultural irrigation on groundwater salinity. Environmental Earth Sciences, 77.

Pulido-Velázquez, D., García-Aróstegui, J., Molina, J.L., Pulido-Velázquez, M. 2015. Assessment of future groundwater recharge in semi-arid regions under climate change scenarios (Serral-Salinas aquifer, SE Spain). Could increased rainfall variability increase the recharge rate? Hydrological Processes; 29: 828-844.

RAEMIA 2019. Recarga natural a los acuíferos, metodología y soporte de la isotopía del agua. Aplicación a la planificación hidrológica y conocimiento de las aguas subterráneas en España. Preparado por E. Custodio, con revisión de J. Jódar y aportaciones específicas de J.V. Giráldez y A. Sahuquillo, para UPC, Suez-España y Cetaqua, Barcelona: 1-1206. http://hdl.handle.net/2117/182282. 
Renssen, H., Goosse, H., Muscheler, R. 2006a. Coupled climate model simulation of Holocene cooling events: oceanic feedback amplifies solar forcing. Climate of the Past, European Geosciences Union (EGU), 2(2): 79-90.

Renssen, H., Brovkin, V., Fichefet, T., Goose, H. 2006b. Simulation of the Holocene climate evolution in Northern Africa: The termination of the African Humid Period. Quaternary International, 150(1): 95-102.

Rojas, R., Feyen, L., Dosio, A., Bavera, D. 2011. Improving pan-European hydrological simulation of extreme events through statistical bias correction of RCM-driven climate simulations. Hydrol. Earth Syst. Sci., 15, 2599-2620.

Salama, R., Hatton, T., Dawes, W. 1999. Predicting land use impacts on regional scale groundwater recharge and discharge. J. Environ. Qual.; 28: 446-460.

Samper, J., Pisani, B., Álvares, D., García Vera, M.A. 2007c Evaluación del efecto del cambio climático en la cuenca hidrográfica del Ebro mediante modelos hidrológicos y Sistemas de Información Geográfica, En: J.V. Giráldez y F.J. Jiménez (eds.), VIII Jornadas de Zona no Saturada, ZNS'07, Córdoba: 347-353.

Sapriza-Azuri, G., Jódar, J., Navarro, V., Slooten, L.J., Carrera, J., Gupta H.V. 2015a. Impacts of rainfall spatial variability on hydrogeological response. Water Resources Research, https://doi.org/10.1002/2014WR016168

Sapriza-Azuri, G., Jódar, J., Gupta, H.V., Carrera, J. 2015. Toward a comprehensive assessment of the combined impacts of climate change and groundwater pumping on catchment dynamics. Journal of Hydrology, 529: 1701-1712.

SASMIE 2017. Salinización de las aguas subterráneas en los acuíferos costeros mediterráneos e insulares españoles. Preparado por E. Custodio, para UPC y Suez Solutions-CETAQUA, Barcelona. UPC e-books. Barcelona: 1-852. http:// hdl.handle.net/2117/111515.

Scheihing, K, Tröger, U. 2018. Local climate change induced by groundwater overexploitation in a high Andean arid watershed, Laguna Lagunillas basin, northern Chile. Hydrogeol. J., 26: 705-719.

Sciermeier, Q. 2010. The real holes in climate science. Nature 463: 284-287.

Stigter, T.Y., Nunes, J.P., Pisani, B., Fakir, Y., Hugman, R., Li, Y., Tomé, S., Ribeiro, L., Samper, J., Oliveira, R., Monteiro, J.P., Silva, A., Tavares, P.C.F., Shapouri, M., Cancela da Fonseca, L., El Himer, H. 2014. Comparative assessment of climate change impacts on coastal groundwater resources and dependent ecosystems in the Mediterranean. Regional Environmental Change, DOI 10.1007/ s10113-012-0377-3.

Taylor, R.G., Scanlon, B., Döll, P., et al. 2013. Ground water and climate change. Nature Climate Change, 3 April 2013. www.nature.com/natureclimatechange.

Teutschbein, C., Wetterhall, F., Seibert, J. 2011. Evaluation of different downscaling techniques for hydrological climate-change impact studies at the catchment scale. Climate Dynamics, 37(9-10): 2087-2105.

Treidel, H., Martin-Bordes, J. L., Gurdak, J. J. 2011. Climate change effects on groundwater resources: A global synthesis of findings and recommendations. CRC Press Taylor \& Francis Group. 
Van Lill, W.S., Kruger, F.J., Van Wyk, D.B. 1980. The effect of afforestation with Eucalyptus-grandis Hill ex Maiden and Pinuspatula Schlecht et Cham on streamflow from experimental catchments at Mokobulaan, Transvaal. J. Hydrol., 48, 107-118.

Ventura de Oliveira, V., da Silva Ferreira, D.B., Sahoo, P.K., Conceição Sodré, G.R., Barreiros de Souza, E., Barbosa Queiroz, J.C. 2018. Differences in precipitation and evapotranspiration between forested and deforested areas in the Amazon rainforest using remote sensing data. Environmental Earth Sciences, 77.

Versini, P.-A.; Pouget, L.; Mc Ennis, S.; Custodio, E.; Escaler, I. 2016. Climate change impact on water resources availability - Case study of the Llobregat River basin (Spain). Hydrological Sciences Journal, 61(14): 2496-2508.

von Igel Grisar, W.F. 2006. Impactos del cambio climático y escenarios de gestión en la Unidad Hidrogeológica de Inca-Sa Pobla (Mallorca, España). Tesis de Master en Hidrología Subterránea. Departament d'Enginyeria del Terreny i Cartogràfica. UPC. Barcelona.

Walker, G.R., Zhang, L., Ellis, T.W., Hatton, T.H. Petheram, C. 2002. Estimating impacts of changed land use on recharge: review of modelling and other approaches appropriate for management of dryland salinity. Hydrogeology Journal 10: 68-90.

Willmott, C.J., Roberson, S.M., Matsuura, E. 2017. Climate and other models may be more accurate than reported. EOS, 98(9) (21 June 2017), 4 pp.

Woodward, C., Shulmeister, J., Larsen, J., Jacobsen, G.E., Zawadski, A. 2014. The hydrologic legacy of deforestation on global wetlands. Science, 346: 844-847.

Zhou, G., Wei, X., Luo, Y., Zhang, M., Qiao, Y., Liu, H., Wang, C. 2010. Forest recovery and river discharge at the regional scale of Guangdong Province, China. Water Resources Research, 46, W09503, doi:10.1029/2009WR008829.

Zhou, G.; Wei, X.; Chen, X.; Zhou, P.; Liu, X.; Xiao, Y.; Sun, G.; Scott, D.F.; Zhou, S.; Han, L.; et al. 2015. Global pattern for the effect of climate and land cover on water yield. Nat. Commun., 6, 5918. 


\section{BLOQUE II}

\section{Planes Hidrológicos}





\title{
Capítulo 6 \\ Retos de la planificación hidrológica española ante el $3^{\text {er }}$ ciclo de la Directiva Marco del Agua
}

\author{
Luis Martínez CoRTina \\ Doctor Ingeniero de Caminos, Canales y Puertos
}

\subsection{La planificación hidrológica en España. Contexto y objetivos}

La planificación hidrológica en España, como en el resto de Estados miembro de la Unión Europea, se establece bajo los principios de la Directiva 2000/60/CE Marco del Agua, en adelante DMA (Unión Europea, 2000), vigente desde diciembre de 2000 y transpuesta a la legislación nacional.

La Directiva tiene un marcado carácter medioambiental, siendo su objetivo central alcanzar el buen estado de las masas de agua y de los ecosistemas y otras zonas protegidas asociadas, y respetando en todo caso el principio fundamental de no deterioro.

Algunos de los principios sobre los que se basa la DMA son: la gestión basada en la cuenca hidrográfica (algo en lo que España ya era pionera en la primera mitad del siglo XX), la integración de todas las masas de agua en la demarcación hidrográfica (que supone en España incorporar a las aguas continentales -superficiales y subterráneas- las aguas de transición y costeras), la recuperación de los costes de los servicios relacionados con el agua (aplicando el principio de quien contamina paga y con una contribución adecuada de los diversos usos del agua), la importancia de los procesos de participación pública, o la necesidad de designar en cada demarcación hidrográfica a las autoridades competentes para la adecuada aplicación de la Directiva.

La transposición de la DMA a la legislación estatal supuso incorporar sus objetivos a la Ley de Aguas. Se integraron así con uno de los objetivos tradicionalmente considerado como esencial en la planificación hidrológica española: la atención de las demandas correspondientes a los diferentes usos del agua. En ocasiones, esta atención de las demandas conlleva medidas que, en el contexto de la DMA, suponen presiones para las masas de agua. Dado que esta atención de las demandas está estrechamente relacionada con el desarrollo social y económico de diversos sectores, no siempre es fácil resolver de forma satisfactoria las expectativas existentes sin poner en riesgo el objetivo principal de la DMA: alcanzar el buen estado de todas las masas de agua y de los ecosistemas asociados. 
Figura 6.1. Demarcaciones hidrográficas en España

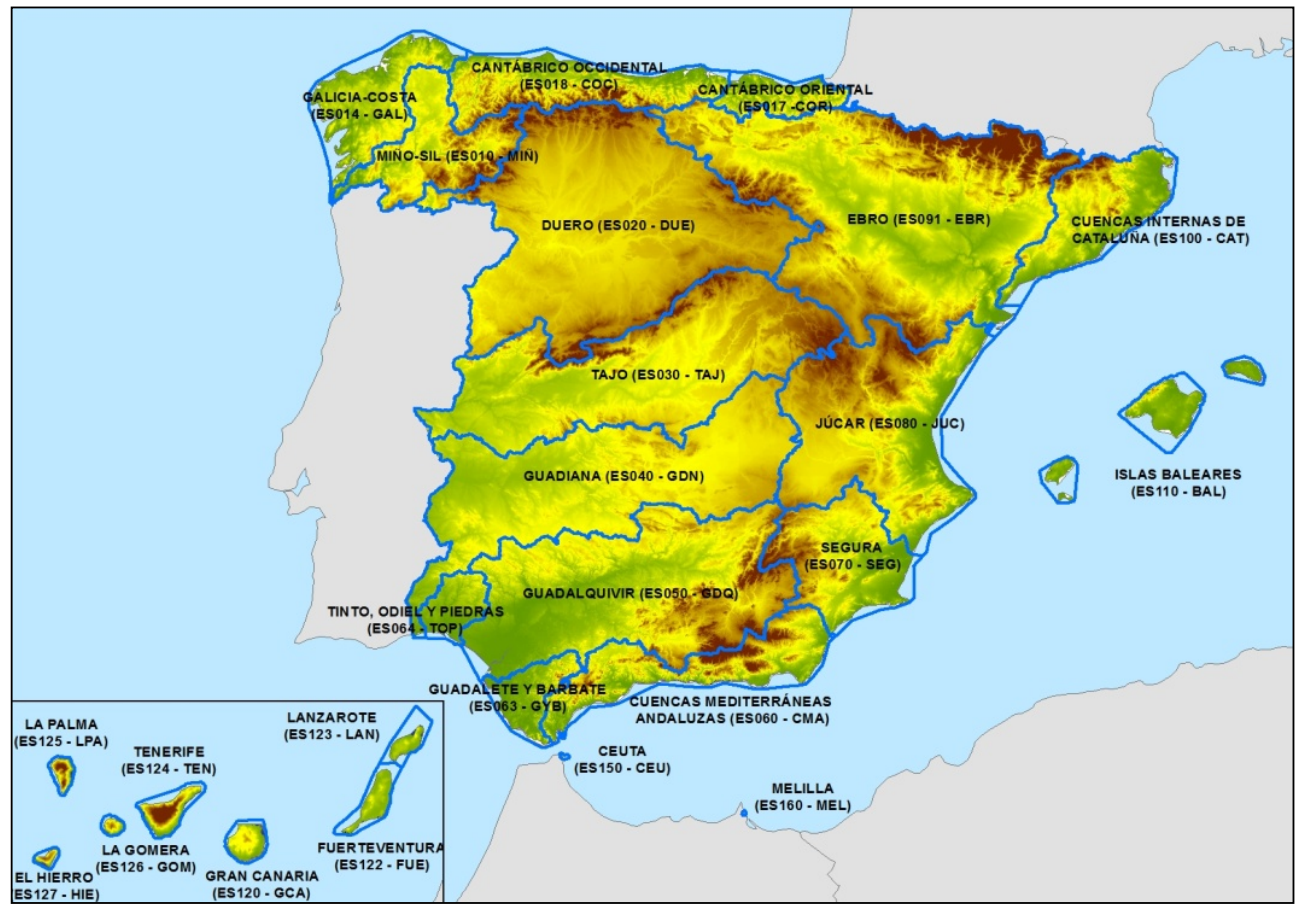

Fuente: MITECO

Con la entrada en vigor de la DMA, se establecieron en España 25 demarcaciones hidrográficas (Figura 6.1). Respondiendo a la distribución competencial posibilitada por la Constitución, existen 11 demarcaciones intercomunitarias (cuyas aguas discurren por más de una Comunidad Autónoma), en las que básicamente ejerce la competencia la Administración General del Estado a través de las Confederaciones Hidrográficas; 13 demarcaciones intracomunitarias (con cuencas comprendidas íntegramente en el territorio de una Comunidad Autónoma), que tienen transferidas las competencias de la Administración del Agua a la Comunidad Autónoma (Galicia, Cataluña, Baleares, 3 en Andalucía y 7 en las Islas Canarias); y por último una demarcación -la del Cantábrico Oriental- que tiene dos ámbitos de planificación: uno correspondiente a las cuencas internas del País Vasco, gestionado a través de la Agencia Vasca del Agua, y otro de carácter intercomunitario, gestionado por la Confederación Hidrográfica del Cantábrico. En este caso existe un órgano de coordinación de los trabajos desarrollados en uno y otro ámbito, que finalmente lleva a la adopción de un único plan hidrológico para la demarcación del Cantábrico Oriental. 


\subsection{El proceso de planificación hidrológica para el tercer ciclo}

De acuerdo con la DMA, la planificación hidrológica se articula en ciclos de seis años, durante los cuales se realiza un seguimiento del plan vigente, y se va produciendo la revisión del mismo a través de unas etapas regladas que conducen a la aprobación definitiva de un nuevo plan al final del ciclo, que sustituirá al anterior.

En este momento están vigentes los 25 planes hidrológicos correspondientes al segundo ciclo de la DMA (2016-2021)1 (MITECO, 2018), y por tanto están en curso los trabajos de seguimiento y revisión de dichos planes y de la consiguiente elaboración de los planes del tercer ciclo, que tendrán que ser definitivamente aprobados antes del final del año 2021 y estarían vigentes durante el sexenio 2022-2027.

De las tres principales etapas documentales en la elaboración de los nuevos planes se ha completado la primera, correspondiente a los documentos iniciales ${ }^{2}$ (que en general comprenden el programa y calendario de trabajos, el estudio general de la demarcación -que entre otras cuestiones de importancia incluye el estudio de presiones e impactos- y una descripción de la forma en que se va a desarrollar la participación pública).

La segunda etapa -clave dentro del proceso de elaboración de los planes hidrológicos- la constituyen los Esquemas de Temas Importantes (ETI) de cada demarcación hidrográfica, que exponen y analizan los principales temas que en cada cuenca ponen en riesgo el cumplimiento de los objetivos establecidos por la planificación hidrológica. Su principal objetivo es plantear, para su discusión, las alternativas existentes para la resolución de los problemas y esbozar las posibles soluciones que se desarrollarán posteriormente en la tercera y última etapa, de elaboración del plan hidrológico propiamente dicho.

Desde el pasado 25 de enero se encuentran en consulta pública (hasta el 24 de julio) los Esquemas provisionales de Temas Importantes (EpTI) de las demarcaciones hidrográficas intercomunitarias (también lo están ya la mayor parte de las intracomunitarias) ${ }^{3}$. Dentro de ese plazo de consulta pública se podrán formular las aportaciones, observaciones y sugerencias que se estimen convenientes, dirigidas al organismo de cuenca.

Durante esos seis meses las Confederaciones Hidrográficas organizarán también talleres y reuniones para debatir el contenido de los EpTI, con el fin de promover la participación activa de aquellos sectores interesados y del público en general. El documento consolidado tras el proceso de participación se someterá a informe del Consejo del Agua de la demarcación, pasando a ser el ETI definitivo.

${ }^{1}$ Disponibles en: https://www.miteco.gob.es/es/agua/temas/planificacion-hidrologica/planificacion-hidrologica/planes-cuenca/default.aspx

${ }^{2}$ Disponibles en: https://www.miteco.gob.es/es/agua/temas/planificacion-hidrologica/planificacion-hidrologica/cpdocsini.aspx

${ }^{3}$ Disponibles en: https:/www.miteco.gob.es/es/agua/temas/planificacion-hidrologica/planificacion-hidrologica/ETI_tercer_ciclo.aspx 


\subsection{Principales retos de la planificación hidrológica para el tercer ciclo}

La valoración que de los planes hidrológicos españoles del segundo ciclo realizó la Comisión Europea (CE) (Comisión Europea, 2019) fue bastante más positiva que la correspondiente a los planes del primer ciclo. Los servicios técnicos de la $\mathrm{CE}$ reconocieron mejoras evidentes en la mayor parte de las cuestiones puestas de manifiesto en informes previos.

Sin embargo, como reconoce la CE en su informe conjunto para todos los Estados miembro ${ }^{4}$, aún queda mucho para alcanzar los objetivos que la DMA pretendía.

La puesta en consulta pública de los Esquemas provisionales de Temas Importantes del tercer ciclo de planificación, que han tenido en cuenta estos informes de valoración de la $\mathrm{CE}$ a la hora de determinar los problemas más importantes de cada demarcación, es un buen momento para analizar cuáles son, de forma general, los principales retos que tiene planteados la planificación hidrológica española de cara al tercer ciclo.

Los siguientes subapartados no tratan de establecer ningún orden de importancia ni de formar una lista exhaustiva, pero reúnen algunos de los principales retos a los que se enfrenta el tercer ciclo de planificación. Los problemas no son siempre comunes -ni en su existencia, ni en su importancia- en las diferentes demarcaciones hidrográficas españolas, pero la mayor parte de ellos puede considerarse que, en mayor o menor medida, constituyen un reto bastante generalizado.

\subsubsection{Mitigación y adaptación al cambio climático}

Aunque se indicaba anteriormente que no se pretendía establecer orden alguno, el problema del cambio climático se ha incluido deliberadamente en primer lugar, pues establece un condicionante general que ha de marcar la gestión asociada a cualquier política sectorial, y en particular la gestión de los recursos hídricos, con tanta repercusión en dichas políticas sectoriales.

De acuerdo con la Instrucción de Planificación Hidrológica (IPH) (España, 2008), los planes hidrológicos evalúan el efecto del cambio climático sobre los recursos hídricos naturales aplicando porcentajes de reducción de la aportación natural para un horizonte temporal 12 años posterior al año de finalización del periodo de vigencia del plan.

Esta consideración cuantitativa de los escenarios futuros de cambio climático y su aplicación en los balances hídricos es fundamental a la hora de adoptar decisiones en el horizonte de aplicación del plan. Para los planes del tercer ciclo se utilizarán los resultados obtenidos en los últimos trabajos desarrollados por el CEDEX para la Oficina Española de Cambio Climático (CEDEX-OECC, 2017)

\footnotetext{
${ }^{4}$ Disponible en: https://ec.europa.eu/environment/water/water-framework/impl_reports.htm
} 
relativos a la evaluación del impacto del cambio climático en los recursos hídricos y las sequías en España. No obstante, esta no es la única consideración en la que la mitigación y la adaptación al cambio climático deben ser incorporadas en los planes.

La mitigación y la adaptación al cambio climático han de desarrollarse mediante estrategias a largo plazo y transversales a todas las políticas sectoriales. En la actualidad se están desarrollando el anteproyecto de Ley de Cambio Climático y Transición Energética, por parte del Ministerio para la Transición Ecológica y el Reto Demográfico, y la Estrategia de Adaptación al Cambio Climático de la Costa Española ${ }^{5}$, aprobada por la Dirección General de la Sostenibilidad de la Costa y del Mar. Los planes hidrológicos han de estar necesariamente alineados con estas estrategias de largo plazo, debiendo adecuarse a las directrices y medidas que se desarrollen.

En consecuencia, sería importante elaborar unos planes de adaptación al cambio climático a escala de las demarcaciones hidrográficas, que recopilaran y analizaran los escenarios climáticos e hidrológicos, incorporando la variabilidad espacial y la distribución temporal. Estos planes deberían identificar y analizar el nivel de exposición y la vulnerabilidad de las actividades socioeconómicas y de los ecosistemas para los distintos escenarios, así como establecer medidas de adaptación que disminuyan esa exposición y vulnerabilidad, considerando su potencial para adaptarse a nuevas situaciones, en el marco de una evaluación de riesgo.

Todos los EpTI de las demarcaciones hidrográficas intercomunitarias incluyen el cambio climático como uno de los Temas Importantes de la demarcación, destacando su relación transversal con todos los demás Temas Importantes. La implicación de todas las autoridades competentes, que representan a sectores diversos, y el desarrollo de un proceso de participación pública integrador y eficaz, son elementos fundamentales en esta etapa de elaboración del ETI. Es importante una adecuada consideración de los principios estratégicos de adaptación y mejora de la resiliencia del recurso y de los usos frente al cambio climático, en la identificación, evaluación y selección de actuaciones a considerar en los planes hidrológicos, aspectos que constituyen objetivos esenciales de los ETI.

En cualquier caso, no debe olvidarse que los planes hidrológicos son instrumentos de gestión para aplicar en periodos de seis años, que se revisan y actualizan para disponer de un nuevo plan en el sexenio siguiente. Esto hace que cada seis años pueden incorporarse al plan los nuevos conocimientos existentes, realizando los ajustes que sean necesarios para el siguiente ciclo de planificación.

\subsubsection{Depuración de vertidos urbanos}

La importancia de este problema se pone de manifiesto en el hecho de que actualmente España está pagando una importante multa por mala aplicación de la Directiva 91/271/CEE (Unión Europea, 1991a), sobre el tratamiento de las

${ }^{5}$ Disponible en: https://www.miteco.gob.es/es/costas/temas/proteccion-costa/estrategia-adaptacion-cambio-climatico/default.aspx 
aguas residuales urbanas. En concreto, la sentencia C 343/2010 del Tribunal de Justicia de la Unión Europea, de 14 de abril de 2011, se refería al incumplimiento en un total de 38 aglomeraciones urbanas de más de 15.000 habitantes equivalentes que vierten sus aguas residuales a zonas normales. La cuantía definitiva de la sanción se estableció en sentencia del 25 de julio de 2018, por la que se condenó a España a pagar un tanto alzado de 12 millones de euros, más una multa coercitiva semestral de otros 10,95 millones de euros por las 38 aglomeraciones desde la fecha del 14 de abril de 2011 (con reducción proporcional en la medida que se fueran solucionando los incumplimientos). En julio de 2018 continuaba el incumplimiento en 14 de las 38 aglomeraciones. En la actualidad el incumplimiento se ha reducido a 9 (7 en Andalucía, una en Asturias y una en Canarias).

Los problemas no son solo exclusivos de las aglomeraciones de más de 15.000 habitantes que vierten a zonas normales. También los hay en las que vierten a zonas sensibles, o en las de menos de 15.000 habitantes equivalentes. Desde el punto de vista del cumplimiento de la DMA, también la falta de depuración en muchas pequeñas aglomeraciones de menos de 2.000 habitantes equivalentes impide en bastantes masas de agua alcanzar los objetivos ambientales establecidos.

Aunque en varios casos existen problemáticas particulares asociadas a la falta de construcción de las depuradoras, hay algunas cuestiones generales que se pueden destacar. La competencia en la materia recae en la administración local y subsidiariamente en la autonómica, salvo que exista una declaración de interés general, en cuyo caso la administración estatal se hace cargo de la ejecución de la infraestructura. Aunque se han realizado esfuerzos significativos en la recogida y tratamiento de las aguas residuales urbanas, los problemas económicos, especialmente relevantes a partir de 2008, no han ayudado a que se pudieran ejecutar todas las infraestructuras necesarias. Estos problemas se agravan en pequeños municipios, que en ocasiones añaden al problema de la construcción, la falta de capacidad para gestionar las infraestructuras una vez recibidas tras su ejecución. En cualquier caso, la asunción de competencias por parte de cada administración y la coordinación administrativa son requisitos imprescindibles en la resolución de este problema.

La situación existente hizo que en los programas de medidas de los planes hidrológicos de segundo ciclo, las actuaciones en materia de saneamiento y depuración destacaran por su relevancia, tanto en su número como en su cuantía económica (unas 3.500 actuaciones, con un presupuesto superior a los 6.500 millones de euros para el periodo 2016-2021). Pero no todas estas actuaciones han contado finalmente con el compromiso o la capacidad de ejecución por parte de la administración competente. Así, pasado el ecuador del periodo de vigencia de los planes, el grado de ejecución está bastante por debajo del ritmo previsto (MITECO, 2019).

Actualmente se está elaborando, por parte del Ministerio para la Transición Ecológica y el Reto Demográfico, el Plan Nacional de Depuración, Saneamiento, Eficiencia, Ahorro y Reutilización (Plan DSEAR) ${ }^{6}$, con el objetivo de revisar las

${ }^{6}$ Disponible en: https://www.miteco.gob.es/es/agua/temas/planificacion-hidrologica/planificacion-hidrologica/planes-programas-relacionados/ 
estrategias de intervención definidas en los actuales planes hidrológicos de segundo ciclo, y de cara a la preparación de los planes del tercer ciclo. Este Plan se configura como complementario al proceso general de planificación hidrológica, en el sentido expresado por la DMA. Se trata de avanzar en la resolución de problemas estratégicos detectados tras dos ciclos de planificación, dando cumplimiento a la DMA, atendiendo sin mayores demoras las obligaciones jurídicas en el ámbito comunitario, y estableciendo unos programas de medidas para el tercer ciclo realistas, claros, priorizados y completos respecto a las materias señaladas, y asumidos en cuanto a su cumplimiento por parte de todas las administraciones implicadas.

\subsubsection{Contaminación difusa de origen agrario}

Los análisis de presiones e impactos sobre las masas de agua, tanto superficial como subterránea, muestran la especial incidencia de las presiones difusas, debidas principalmente a los excedentes de la fertilización química de origen agrícola y al aporte de elementos nitrogenados en forma de estiércol.

Como puede verse en la Figura 6.2, las presiones significativas de fuente difusa son las que más afectan a las masas de agua subterránea (aproximadamente al $55 \%$ de las mismas). En el caso de las masas de agua superficial son más relevantes las alteraciones hidromorfológicas, pero aun así las difusas afectan a más del $40 \%$ de las masas.

Estas presiones significativas se traducen en impactos muy generalizados de contaminación por nutrientes, principalmente nitratos. Aunque este problema comenzó a generalizarse en los años 80 del siglo pasado, y dio lugar a la Directiva 91/676 relativa a la protección de las aguas contra la contaminación producida por nitratos utilizados en la agricultura (Unión Europea, 1991b), lo cierto es que las medidas hasta ahora consideradas no han producido el efecto esperado, y este problema de la contaminación por nitratos es probablemente el más generalizado en toda Europa.

España tiene actualmente abierto un procedimiento sancionador (aún en sus primeras fases) por parte de la Comisión Europea, relativo a la Directiva 91/676. Los requerimientos de la Comisión obedecen a aspectos como: deficiencias en la comunicación de los programas de control, retrasos en la modificación o ampliación de las zonas vulnerables designadas y del consiguiente establecimiento de programas de acción, o adopción de medidas adicionales para la consecución de los objetivos.

Pero como cuestión de fondo el hecho más preocupante es que las concentraciones de nitratos no bajan. Aunque en los últimos años parecen haberse estabilizado, es necesario invertir esta tendencia.

El reparto competencial en esta materia también es complejo. La Administración General del Estado tiene competencias en la declaración de aguas afectadas y en el control y seguimiento de la calidad de las aguas, mientras que las Comunidades Autónomas, generalmente a través de las Consejerías de Agricultura, son 
Figura 6.2. Porcentaje de masas de agua subterránea y superficial afectadas por los distintos tipos de presiones significativas

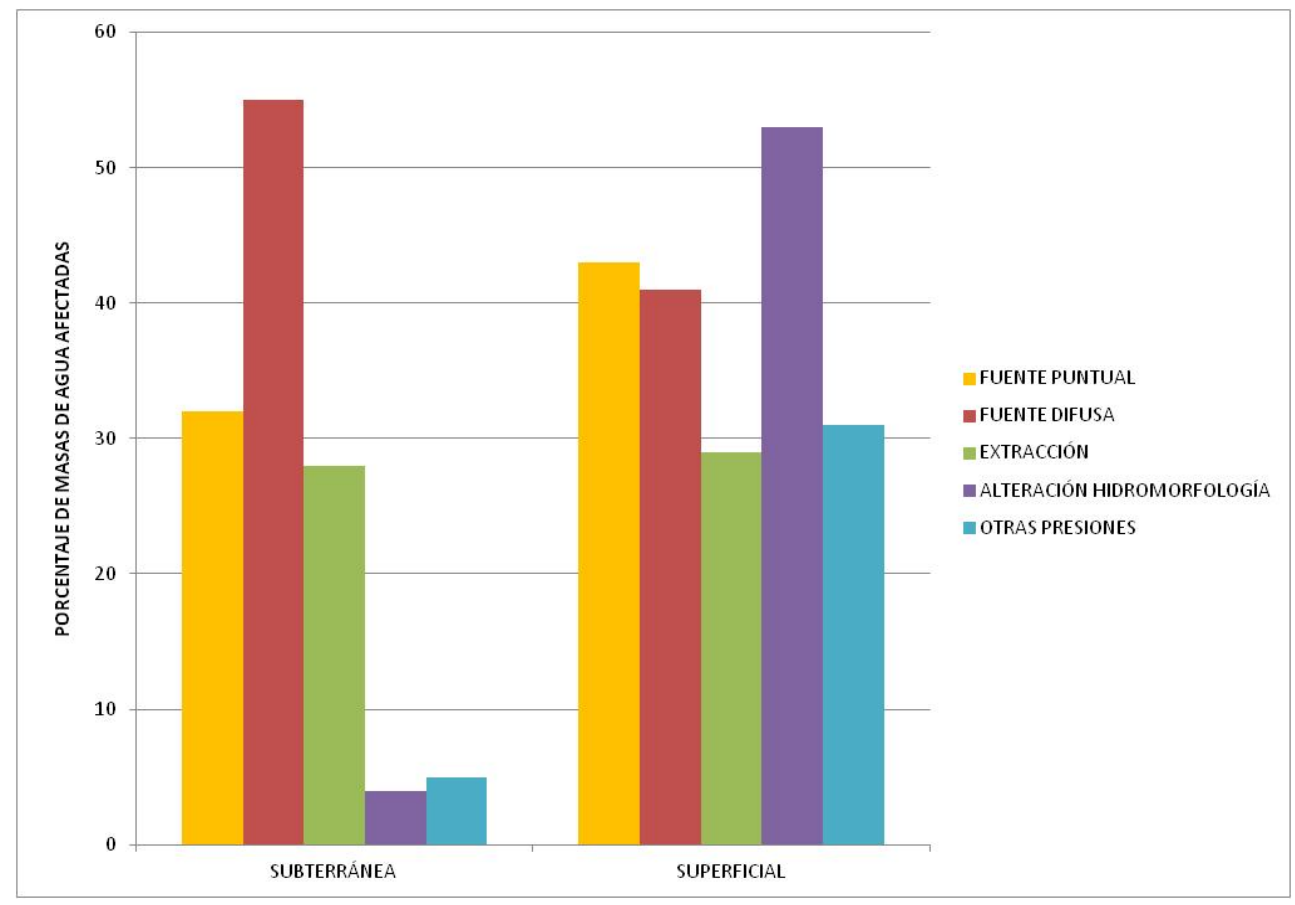

Fuente: MITECO

competentes en la designación de zonas vulnerables, en la elaboración de códigos de buenas prácticas agrarias y en el establecimiento de programas de actuación en zonas vulnerables. Estos aspectos son críticos para avanzar en la resolución del problema, por lo que la implicación de las Comunidades Autónomas y la coordinación entre administraciones resulta esencial.

La magnitud del problema en algunos casos es tal, que aunque se dejaran de aportar fertilizantes nitrogenados a los cultivos, el contenido ya acumulado tardaría años en eliminarse, debido a las lentas tasas de renovación de las aguas subterráneas. En el ámbito europeo es muy valorada la utilización en España de modelos de simulación del contenido de nitratos, que permiten definir los escenarios futuros de acuerdo con las medidas planteadas, lo que facilita la adecuada consideración de objetivos y exenciones (buen estado, prórroga por condiciones naturales, objetivos menos rigurosos) en el marco de la elaboración de los planes hidrológicos.

Pero además es necesario avanzar en la difícil resolución del problema impulsando medidas como: diseñar programas de control más ambiciosos, fijar tasas de aplicación de fertilizantes en función del estado de las masas de agua, declarar masas de agua subterránea en riesgo adoptando las medidas cautelares de protección que sean necesarias, condicionar cualquier ayuda económica a buenas prácticas agrarias y ambientales, agilizar los procedimientos sancionadores en caso 
de malas prácticas, y -cuestión fundamental- mejorar la coordinación entre las administraciones del agua y de la agricultura, entre otras.

\subsubsection{Alteraciones hidromorfológicas}

El contexto en el que se desarrolló la planificación hidrológica española durante el pasado siglo, marcado por la necesidad de incrementar la oferta del recurso, basándose generalmente en la construcción de infraestructuras, ha permitido una disponibilidad y una garantía del recurso hídrico muy superior a la que existiría en una situación cercana a la natural. Como efecto ambiental negativo esto ha producido importantes alteraciones en la hidromorfología de nuestros ríos.

Como podía verse en la Figura 6.2, las presiones hidromorfológicas son las que más afectan en España a las masas de agua superficial. Estas presiones están relacionadas con las extracciones de agua (la derivación del caudal para su utilización), y con las alteraciones físicas producidas en los cauces de los ríos y en sus márgenes. Existe, por ejemplo, una gran cantidad de canalizaciones, protecciones de márgenes que alteran el comportamiento hídrico de las masas de agua, y modificación de la vegetación de ribera.

Desde un punto de vista metodológico para una adecuada aplicación de la DMA, se añade la problemática de la dificultad de encontrar indicadores biológicos que respondan a las presiones hidromorfológicas. Teóricamente los indicadores de fauna piscícola deberían ser los adecuados, pero en general hay muchos problemas para que estos indicadores respondan de manera adecuada.

De cara al tercer ciclo de planificación se ha elaborado un protocolo de caracterización hidromorfológica ${ }^{7}$, que será fundamental a la hora de evaluar la situación de las masas de agua al respecto.

Pero el reto de futuro pasa por mejorar el estado hidromorfológico de muchas masas de agua. Una mejoría importante pasaría por el impulso decidido de la Estrategia Nacional de Restauración de Ríos, que se vio frenada de manera importante por la crisis económica que afectó a España desde 2008. Las actuaciones en esta materia son a menudo costosas, por lo que la priorización de medidas de restauración y recuperación ambiental con criterios adecuados para la consecución de los objetivos ambientales es muy necesaria.

\subsubsection{Caudales ecológicos}

La definición e implementación de caudales ecológicos es uno de los contenidos obligatorios de los Planes Hidrológicos establecido por nuestra legislación.

${ }^{7}$ Disponible en: https://www.miteco.gob.es/es/agua/temas/estado-y-calidad-de-las-aguas/ aguas-superficiales/programas-seguimiento/Protocolos-caracterizacion-y-calculo-metricas-en-hidromorfologia.aspx 
No es, estrictamente, una imposición explícita de la Directiva Marco del Agua, pero su inclusión en la normativa nacional es conveniente en la medida que resulta necesaria para la consecución del buen estado de las masas de agua.

En particular, la componente del caudal mínimo debería ser establecida en todas las masas de agua de la categoría río, especialmente en cuencas tan presionadas por la escasez como las españolas. Es necesario fijar restricciones ambientales a la modificación artificial del régimen de corrientes para no imposibilitar el logro de los objetivos ambientales. De esta forma se objetiva la limitación al aprovechamiento del agua, ya sea por extracción o por alteración del régimen hidrológico. El resto de componentes del régimen de caudales ecológicos parece necesario en la medida que su implementación lo es para alcanzar los objetivos ambientales.

De cara al tercer ciclo, el reto relacionado con los caudales ecológicos podría establecerse en un doble sentido: por una parte el problema de falta de definición de la componente de mínimos del caudal ecológico en muchos ríos. Tras los notables avances al respecto producidos en los planes del segundo ciclo de las demarcaciones intercomunitarias, este problema afecta solo a las demarcaciones del Ebro y Tajo.

En segundo lugar, y en este caso de forma más generalizada, es necesario avanzar de forma importante en el seguimiento, control y cumplimiento de los caudales ecológicos. Los planes vigentes prevén actuaciones como la instalación de órganos de desagüe en presas para regular el caudal ecológico en la masa de aguas abajo, o sistemas de aforo del caudal ecológico. Como se indicaba anteriormente, el grado de ejecución de las medidas es bastante bajo, lo que repercute lógicamente en la consecución de los objetivos previstos (MITECO, 2019).

Una estrategia necesaria de futuro pasa por realizar un seguimiento adaptativo del régimen de caudales ecológicos que permita ir mejorando su definición para que sean verdaderamente funcionales, es decir, que respondan al objetivo que con ellos se pretende. Existen ciertas dificultades para establecer una relación directa entre los caudales y sus indicadores, puesto que las metodologías empleadas son insuficientes para reflejar las funciones y estructura del sistema fluvial.

También será necesario de cara al tercer ciclo avanzar en la definición de otras componentes del régimen de caudales ecológicos en las masas de agua que lo requieran para el cumplimiento de los objetivos ambientales, y tener en cuenta de forma específica las previsiones de incidencia del cambio climático en esos regímenes de caudales ecológicos.

\subsubsection{Medición de extracciones y asignación de recursos}

La necesidad de un mayor y mejor control de los recursos utilizados ha sido un requerimiento constante en los informes de valoración de los planes hidrológicos españoles elaborados por la Comisión Europea. El control es normalmente muy elevado en recursos de origen superficial, y también en los casos de la reuti- 
lización y la desalinización, pero suele presentar mayores problemas en el caso de los recursos subterráneos.

Algunos de estos casos coinciden con las zonas que presentan mayores problemas de stress hídrico (suele darse el caso de que los derechos reconocidos superan a los recursos disponibles) y de impactos negativos sobre ecosistemas asociados de gran riqueza, acrecentados en ocasiones por la utilización ilegal de recursos y la resistencia social al control de las extracciones. Basta citar los ejemplos emblemáticos de Doñana o las Tablas de Daimiel. El control de las extracciones de agua subterránea por parte de la Administración es más difícil dada la propia esencia de su utilización, caracterizada por la existencia de miles de captaciones individuales, y con dificultades, incluso de tipo técnico, para la instalación de caudalímetros.

Los planes de cuenca contienen medidas para avanzar en el control de los usos del agua (implantación, seguimiento y control de contadores, actuaciones de teledetección para mejorar el seguimiento y control de regadíos, estricto cumplimiento del sistema sancionador) pero el ritmo de implementación de las mismas, y en ocasiones la dificultad social de establecerlas, no parece suficiente para alcanzar en el plazo requerido el conocimiento necesario, por lo que los planes del tercer ciclo deberán intensificar estas medidas.

Es fundamental una apuesta decidida desde la administración por solucionar este problema de ordenación y control del dominio público hidráulico, que debería llevar asociada una inversión de cierta importancia en medios técnicos y humanos.

Uno de los temas al que debería dársele un impulso definitivo es el del Registro de Aguas y la Base Central del Agua. El completado adecuado de los trabajos relativos al Registro de Aguas electrónico, y el mantenimiento de ese Registro de manera automática mediante el vínculo con los procedimientos administrativos de la sede electrónica, han de desempeñar un papel fundamental en cuestiones de tanta importancia como la revisión de las concesiones existentes cuando así lo exija su adecuación a las asignaciones formuladas por los planes hidrológicos.

\subsubsection{Gestión y uso sostenible de aguas subterráneas}

Lograr una gestión sostenible de las aguas subterráneas es fundamental para la consecución de los objetivos de la planificación hidrológica, y de hecho está en mayor o menor medida relacionada con casi todas las problemáticas mencionados en el resto de subapartados. Esto es debido a la gran importancia que las aguas subterráneas tienen a la hora de atender demandas, como recurso estratégico en situaciones de sequía y escasez, a la hora de mantener los caudales base de los ríos, o de alimentar ecosistemas y zonas húmedas de gran riqueza ecológica.

El uso intensivo que de las aguas subterráneas se ha realizado en muchas zonas de España, principalmente para regadío, ha supuesto un importante desarrollo socioeconómico en muchas comarcas. Sin embargo, también ha originado impactos negativos, principalmente medioambientales, por su afección a las corrientes superficiales y a los ecosistemas terrestres asociados. 
En el segundo ciclo de planificación, un 36\% de las masas de agua subterránea estaban sometidas a presiones significativas por extracción. Por su parte, el $24 \%$ de las masas estaban en mal estado cuantitativo, que refleja también el impacto producido sobre las corrientes superficiales o los ecosistemas asociados.

Entre las medidas incluidas al respecto en los planes de segundo ciclo las hay de sustitución de recursos subterráneos por superficiales o por recursos no convencionales, de ordenación de las extracciones asociadas a la declaración de masas en riesgo, y algunas de las contempladas en subapartados anteriores (por ejemplo en el 6.3.6) que también tienen un indudable efecto positivo para la resolución de este problema.

La dificultad administrativa, social y económica de implantar algunas de estas medidas, unido a la inercia de los acuíferos y a su dependencia de la secuencia meteorológica, hace que las recuperaciones no sean lo rápidas que a veces se programan y esperan. Esta inercia de las aguas subterráneas ha hecho que desde la aprobación de los planes hidrológicos vigentes no se haya producido, estadísticamente, una mejoría en cuanto al número de masas de agua subterránea en buen estado, al contrario de lo que ha sucedido con las masas de agua superficial.

Por ello es un reto importante para el tercer ciclo, no solo la implementación estricta de las medidas planteadas, sino una intensificación de las mismas que permita alcanzar los objetivos planteados para las masas de agua subterránea. En la gestión de las aguas subterráneas han de tener especial importancia algunas medidas relacionadas con la gobernanza del agua: la consideración de los costes ambientales, el desarrollo de las declaraciones de masas en riesgo, la co-responsabilidad en la gestión de las comunidades de usuarios, etc.

\subsubsection{Objetivos en Zonas Protegidas}

Aunque existen oportunidades de mejora evidentes respecto a otros tipos de zonas protegidas, el reto más importante en este ámbito de cara al tercer ciclo puede considerarse el de los objetivos de las zonas protegidas pertenecientes a Red Natura 2000.

Durante el segundo ciclo hubo una mejoría bastante importante en el tratamiento dado por los planes hidrológicos a estas zonas, por ejemplo en la identificación de los tipos de hábitats y especies ligados al agua, la vinculación entre las masas de agua de la Directiva Marco y los mencionados elementos de interés que dependen del agua, o el análisis de los Planes de Gestión de los espacios protegidos de Red Natura 2000 desde el punto de vista de los requerimientos hídricos, pero aún existe mucho por mejorar.

Una de las mayores dificultades que se ha puesto de manifiesto en los planes anteriores es la relativa a la imprescindible aplicación conjunta y coordinada de las Directivas relacionadas directamente con la biodiversidad y de la Directiva Marco del Agua. La Red Natura 2000 designa sus zonas de conservación en virtud de la Directiva Hábitats (que protege especies y tipos de hábitats de interés comunitario) (Unión Europea, 1992), y de la Directiva Aves (que protege especies de 
aves) (Unión Europea, 2009). Por tanto, el ámbito de protección y aplicación de estas Directivas no coincide con el de la DMA. Y tampoco son coincidentes las unidades de gestión respecto a las que se evalúan los objetivos. Mientras que en la DMA es la masa de agua, en las Directivas de biodiversidad se evalúan los elementos (especies y hábitats) a nivel de región biogeográfica en cada Estado miembro.

De acuerdo con los objetivos de la DMA, las necesidades relacionadas con el medio hídrico de los hábitats y especies de Red Natura 2000, deben ser incorporadas como requerimientos adicionales para las masas de agua implicadas. Pero los planes de gestión desarrollados para los espacios de Red Natura 2000 (que han sido en general analizados en los planes del segundo ciclo), no incluyen, normalmente, necesidades específicas que puedan ser trasladadas a modo de requerimientos adicionales a las masas de agua de la DMA.

Es importante señalar que los objetivos de buen estado de las masas de agua contribuyen claramente al estado favorable de conservación de hábitats y especies, y que los estudios que en su momento establecieron las condiciones de referencia de los tipos de masas se hicieron teniendo en cuenta las tipologías de hábitats relacionadas. Esto hace que en la mayoría de los casos los objetivos de la DMA sean suficientes para lograr también los objetivos de las Directivas de biodiversidad desde el punto de vista de las necesidades relacionadas con el medio hídrico. Sin embargo en algunos casos son necesarios estudios específicos que permitan determinar requerimientos más exigentes.

En España, muchas de las competencias en materia medioambiental, y en concreto la de la gestión de los espacios de Red Natura 2000 recaen en las Comunidades Autónomas, responsables por tanto de determinar las necesidades y objetivos de hábitats y especies, así como de la evaluación de su estado de conservación. Por tanto es imprescindible una coordinación adecuada con las administraciones responsables del agua (la administración central en el caso de las demarcaciones intercomunitarias). La administración autonómica debe analizar y determinar los requisitos y actuaciones que son necesarios respecto del medio hídrico (parámetros específicos de algún indicador, valor de algún componente del régimen de caudales ecológicos, actuaciones específicas necesarias respecto al medio hídrico), de manera que estas puedan ser incorporadas al plan hidrológico en forma de requerimientos adicionales para la consecución de objetivos en las masas de agua concernidas, o bien como medidas a incluir en el plan.

\subsubsection{Recuperación de costes}

Uno de los requerimientos que la Comisión Europea viene realizando a España desde los primeros planes hidrológicos elaborados en el contexto de la Directiva Marco del Agua, es la aplicación correcta de su artículo 9, que obliga a tener en cuenta el principio de recuperación de los costes de los servicios relacionados con el agua, incluidos los costes ambientales y del recurso. Esto implica una política de precios que proporcione incentivos para una utilización eficiente del recurso, así como una contribución adecuada de los diversos usos del agua. 
En los planes de segundo ciclo ha habido mejoras metodológicas importantes en los estudios de recuperación de costes y en aspectos como la estimación de los costes ambientales, así reconocidas en los informes de evaluación de la Comisión Europea.

Sin embargo hay problemas importantes que se siguen evidenciando. Es clara la ausencia (o insuficiencia) de instrumentos de recuperación de costes para algunos tipos de medidas. Un aspecto muy concreto, pero especialmente relevante, es la inexistencia de un instrumento para la recuperación de los costes ambientales y del recurso que tenga en cuenta las presiones causadas, por ejemplo, por las extracciones y captaciones de aguas subterráneas, por las captaciones directas de aguas superficiales, o por la contaminación difusa.

Una de las claves -aunque no la única- del bajo grado de ejecución de los Programas de Medidas de los planes, es la falta de capacidad financiera para afrontar dichas medidas. Las actuaciones ante determinadas medidas que responden a costes ambientales no gravados con instrumentos específicos, se afrontan con los limitados presupuestos públicos disponibles, lo que pone en riesgo la consecución de los objetivos ambientales. A este problema se le añade la falta de capacidad financiera de los organismos de cuenca para atender sus obligaciones de protección, gestión y control del dominio público hidráulico o el mantenimiento del importante patrimonio hidráulico asignado.

Son problemas que trascienden a los planes hidrológicos, puesto que parte de su resolución pasa por reformas del vigente régimen económico-financiero, es decir, reformas legales que deben ser consensuadas en el Parlamento, y que a veces incluyen medidas que pueden resultar impopulares.

Respecto a la fiscalidad ambiental, un aspecto que debería plantearse es requerir las obligación de que los ingresos derivados de las distintas figuras impositivas (tarifas, cánones, tasas) derivados de la gestión del agua, se destinara a actuaciones en el ámbito de la planificación y gestión del agua.

\subsubsection{Mejora de la Gobernanza y Coordinación administrativa}

La gobernanza del agua, entendida de un modo amplio, se refiere a todo lo que atañe al marco político, económico, social y administrativo que condiciona su gestión. Este marco determina, por ejemplo, quién, dónde, cuándo y bajo qué condiciones tiene acceso al agua y se beneficia de su uso, o cómo se reparten los costes de los servicios relacionados con el agua.

Son múltiples los aspectos en los que cabe plantear retos y mejoras relacionados con la gobernanza del agua en España. El Ministerio para la Transición Ecológica y el Reto Demográfico viene desarrollando un Libro Verde de la Gobernanza del Agua en España ${ }^{8}$ que plantea y desarrolla muchos de estos retos.

Los problemas de gobernanza atañen principalmente a todas las administraciones públicas implicadas. La gestión de los recursos hídricos tiene un carácter

${ }^{8}$ Disponible en: http://www.librogobernanzagua.es/ 
muy transversal, por lo que todas las administraciones con competencias en materia de aguas y sectoriales se ven afectadas, de forma más o menos directa, por las medidas previstas para solucionar los problemas existentes. Esto implica a la Administración General del Estado, en varios Ministerios con múltiples Direcciones y Subdirecciones Generales (relacionadas con Agua, Costas, Biodiversidad, Evaluación ambiental, Cambio climático, Sanidad, Regadíos, etc.); a las Comunidades Autónomas (muy directamente a Consejerías como las de Medio Ambiente, Agricultura, Sanidad o Fomento); y a la Administración local.

A lo largo de muchos de los apartados anteriores se ha puesto en evidencia que detrás de muchos de los principales problemas existentes hay asociada una compleja distribución competencial entre las tres administraciones mencionadas. Por ello, la efectividad en la coordinación administrativa es uno de los ejes centrales de una adecuada planificación de los recursos hídricos.

En el marco de la planificación hidrológica existe, en cada demarcación hidrográfica, la figura del Comité de Autoridades Competentes (CAC), en el que están representados diversos organismos de la Administración General del Estado, los distintos gobiernos autonómicos con territorio en la demarcación, y representantes de las entidades locales. Es preciso conseguir que estos CAC funcionen de forma efectiva para conseguir la necesaria coordinación administrativa, y no solo como un órgano que se reúne para dar el visto bueno a los documentos finales de cada etapa del proceso de planificación.

Es fundamental que cada administración asuma las competencias que le otorga la legislación y comprenda que alcanzar los objetivos de la planificación de los recursos hídricos es un tema que no solo compete al organismo de cuenca responsable de la elaboración del plan. La gestión, el desarrollo de los planes hidrológicos, y en particular los programas de medidas y su ejecución, se ven a menudo afectados por una insuficiente colaboración y coordinación entre las distintas administraciones competentes.

\subsection{El cumplimiento de la DMA ante el hito de 2027}

La incorporación de la Directiva Marco del Agua (DMA) a nuestra legislación ha sido muy positiva para cambiar los planteamientos relacionados con la gestión de los recursos hídricos en España. Uno de los preceptos fundamentales de la DMA es el principio de no deterioro, y este ha sido asumido de forma bastante clara y generalizada. Respecto al objetivo de alcanzar el buen estado de las masas de agua, se han producido mejorías importantes, pero el ritmo no ha sido el previsto y se está muy lejos aún de cumplir las previsiones establecidas para el año 2027.

Sin restar importancia a este incumplimiento de las previsiones, debe valorarse el hecho de que a veces las mejorías en el control y en las exigencias (incorporación de nuevos elementos de calidad, mayor seguimiento, parámetros más exigentes) producen empeoramientos en los resultados que no suponen un deterioro real del estado de las masas, sino un mejor conocimiento y una mayor ambición 
en los objetivos. Tampoco hay que olvidar que, de acuerdo con el principio del one out-all out, el estado de una masa queda determinado por el elemento de calidad en peor estado. Pueden producirse mejoras importantes en algunos de los elementos de calidad que no queden reflejadas en las estadísticas generales de cumplimiento.

En el apartado anterior se ha establecido una relación de 10 de los principales retos a los que la gestión de los recursos hídricos se enfrenta de cara al tercer ciclo (2022-2027). Pero este tercer ciclo de planificación no es uno más en el contexto de la DMA. Hay que recordar que el objetivo de la DMA era alcanzar el buen estado de todas las masas de agua en el año 2015. La Directiva establecía exenciones a este cumplimiento, que debían ser adecuadamente justificadas. Estas exenciones eran, básicamente, prórrogas por inviabilidad técnica, por costes desproporcionados, o por condiciones naturales; o bien establecimiento justificado de objetivos menos rigurosos ante la imposibilidad de alcanzar los requeridos por la DMA. Pero las exenciones por prórrogas (salvo para el caso de condiciones naturales) se extendían un máximo de dos ciclos de planificación, es decir, 2016-2021 y 2022-2027. Por tanto en 2027 todas las masas de agua tendrían que alcanzar el buen estado (salvo prórroga por condiciones naturales o definición de objetivos menos rigurosos).

Por tanto, por encima de los retos que suponen todos los problemas planteados en el anterior apartado, se plantea un reto global con el propio cumplimiento de la DMA. La posibilidad de alcanzar los objetivos ambientales más allá de 2027 por condiciones naturales es adecuada cuando la inercia de los sistemas hidrológicos hace que las condiciones de buen estado tarden más años en alcanzarse (puede ser el caso de la disminución de nitratos en las masas de agua subterránea, en las que se requiere un plazo más largo para llegar a los valores exigidos), pero en todo caso exige que todas las medidas necesarias estén en el plan del tercer ciclo, y en marcha antes de 2024. Por el contrario, el establecimiento de objetivos menos rigurosos supone renunciar a la ambición marcada por la DMA, y ser menos exigentes en alguno de los objetivos de la masa.

En opinión de quien escribe, debería hacerse una apuesta decidida en el tercer ciclo para avanzar de forma importante hacia la consecución de los objetivos ambientales, lo que ineludiblemente pasa por un programa de medidas muy ambicioso, pero con garantías de cumplimiento en su ejecución (lo que obliga a un esfuerzo importante, tanto económico como de gobernanza), y con priorización casi absoluta en las medidas de consecución del buen estado. No parece posible, ni en España ni en el resto de Europa, que se alcance el buen estado de todas las masas en 2027, pero parece más adecuado demostrar un avance real y decidido hacia la resolución de los problemas, que rebajar la ambición de los objetivos establecidos por la Directiva Marco del Agua. 


\section{Referencias bibliográficas}

CEDEX-OECC (2017). Evaluación del Impacto del Cambio Climático en los Recursos Hídricos y Sequías en España. Encomienda de la Oficina Española de Cambio Climático al CEDEX. Centro de Estudios Hidrográficos del CEDEX. Disponible en:

http://adaptecca.es/recursos/buscador/evaluacion-del-impacto-del-cambio-climatico-en-los-recursos-hidricos-y-sequias-en

Comisión Europea (2019). Report from the Commission to the European Parliament and the Council on the implementation of the Water Framework Directive (2000/60/EC) and the Floods Directive (2007/60/EC). Second River Basin Management Plans. Member State: Spain. 206 págs. Disponible en:

https://www.miteco.gob.es/es/agua/temas/planificacion-hidrologica/informevaloracionplanes2ciclospain_tcm30-496534.pdf

España (2008). Orden ARM/2656/2008, de 10 de septiembre, por la que se aprueba la Instrucción de Planificación Hidrológica. Publicado en: «BOE» núm. 229, de 22/09/2008. Disponible en:

https://www.boe.es/eli/es/o/2008/09/10/arm2656/con

MITECO (2018). Síntesis de los planes hidrológicos españoles. Segundo ciclo de la DMA (2015-2021). Ministerio para la Transición Ecológica. 171 págs. Disponible en:

https://www.miteco.gob.es/es/agua/temas/planificacion-hidrologica/libro_sintesis_pphh_web_tcm30-482083.pdf

MITECO (2019). Informe de Seguimiento de los Planes Hidrológicos de cuenca y de los Recursos Hídricos en España. Año 2018. Avance diciembre de 2019. 175 págs. y 25 Apéndices. Disponibles en:

https://www.miteco.gob.es/es/agua/temas/planificacion-hidrologica/planificacion-hidrologica/seguimientoplanes.aspx

Unión Europea (1991a). Directiva 91/271/CEE del Consejo, de 21 de mayo de 1991, sobre el tratamiento de las aguas residuales urbanas. Publicado en: «DOCE» núm. 135, de 30 de mayo de 1991, págs. 40 a 52. Disponible en:

https://www.boe.es/buscar/doc.php?id=DOUE-L-1991-80646

Unión Europea (1991b). Directiva 91/676/CEE del Consejo, de 12 de diciembre de 1991, relativa a la protección de las aguas contra la contaminación producida por nitratos utilizados en la agricultura. Publicado en: «DOCE» núm. 375, de 31 de diciembre de 1991, 8 págs. Disponible en:

https://www.boe.es/buscar/doc.php?id=DOUE-L-1991-82066

Unión Europea (1992). Directiva 92/43/CEE del Consejo, de 21 de mayo de 1992, relativa a la conservación de los hábitats naturales y de la fauna y flora silvestres. Publicado en: «DOCE» núm. 206, de 22 de julio de 1992: págs. 7 a 50. Disponible en:

https://www.boe.es/buscar/doc.php?id=DOUE-L-1992-81200 
Unión Europea (2000). Directiva 2000/60/CE del Parlamento Europeo y del Consejo, de 23 de octubre de 2000, por la que se establece un marco comunitario de actuación en el ámbito de la política de aguas. Publicado en: «DOCE» núm. 327, de 22 de diciembre de 2000, 73 págs. Disponible en:

https://www.boe.es/buscar/doc.php?id=DOUE-L-2000-82524

Unión Europea (2009). Directiva 2009/147/CE del Parlamento Europeo y del Consejo, de 30 de noviembre de 2009 relativa a la conservación de las aves silvestres. Disponible en:

https://www.boe.es/doue/2010/020/L00007-00025.pdf 


\title{
Capítulo 7
}

\section{Transición hidrológica y nueva gobernanza del agua en España $(*)$}

\author{
Alberto Fraguas Herrero \\ Biólogo
}

\subsection{Introducción}

El agua es esencial para la vida, y el uso que hacemos de ella debe adecuarse por tanto a la nueva realidad de un cambio climático que está modificando las condiciones de vida del Planeta.

En el caso de nuestro país, especialmente vulnerable a los impactos de un clima que se va tornando cada vez más seco, esto provoca una creciente presión sobre los recursos hídricos de todo el territorio que se traduce ya, entre otros efectos, en una notable merma del agua disponible tanto en cantidad como en calidad, lo que conlleva graves déficits ecológicos que generan desequilibrios territoriales y desigualdades sociales. Los datos de la propia Agencia Española de Meteorología indican que esta es ya la realidad de nuestro territorio pues en los últimos años el descenso de precipitaciones ha sido de un $18 \%$ en la España Peninsular con respecto a la media hídrica 1980-2010, con realidades que superan incluso las modelizaciones predictivas.

Esta nueva realidad exige una respuesta urgente a través de dos vectores de alcance sistémico; la energía y el agua. La obligada sustitución de los actuales patrones energéticos alimentados por fuentes fósiles, debe venir acompañada de una indispensable reorientación de la actual política de agua mediante la transición hidrológica hacia modelos de gestión y planificación con capacidad resiliente, territorialmente equilibradores, y solidarios en clave intergeneracional, incluyendo la revalorización del potencial cultural y económico del agua en términos de sostenibilidad: y tanto en el regadío como en otras actividades turísticas, deportivas, de naturaleza..., que podrían incentivar el desarrollo y la creación de empleo en territorios en claro proceso de despoblación.

El Estado debe preservar seguridades vitales, garantizando una equilibrada disponibilidad y calidad de los recursos naturales y su sostenibilidad en el tiempo, y el agua es el recurso natural por excelencia, soporte ecológico de un desarrollo económico socialmente justo. En tanto que se trata de un Derecho Humano, tal y como refrendó Naciones Unidas en 2010, el Estado viene obligado a blindar el

(*) Síntesis del «Documento de Bases de la estrategia del agua para la Transición Ecológica» del Ministerio de Transición Ecológica y Reto Demográfico. 
carácter de bien público del agua, a procurar su uso sostenible y a garantizar el acceso al mismo, evitando situaciones de exclusión social.

Las medidas de carácter excepcional aplicadas para paliar los efectos de las sequías han pasado a ser recurrentes, apuntando así a la carencia de políticas estructurales encaminadas a asegurar su disponibilidad, dando pie a un modelo de gestión insostenible que, en el actual escenario de cambio climático, podría desembocar en una situación en la que ya no hubiese recurso al que apelar y todo ello con el añadido de que la consolidación en el tiempo del uso de medidas excepcionales, convirtiéndolas en método de gestión ordinaria, se traduce en continuas licitaciones de nuevas infraestructuras al margen de criterios de planificación racional, o bien en una progresiva mercantilización del agua mediante la cesión de derechos concesionales con la justificación de una provisionalidad que transmuta en indefinida, generando desigualdades e inequidades.

Se precisa, por tanto, una política del agua para el siglo XXI donde España además fortalezca su papel como líder a escala internacional en las tecnologías asociadas a la obtención, el tratamiento y el uso eficiente del agua. Nuestras empresas y nuestros profesionales están hoy día presentes en todos los continentes, contribuyendo a dar respuesta a uno de los desafíos globales más importantes contemplados en la Agenda 2030 de Naciones Unidas: el acceso universal al agua potable y al saneamiento, imprescindible para garantizar la salud, la alimentación, el progreso... en este sentido la misma ley de Aguas de 1985 fue pionera en cuanto a la gestión integrada de las cuencas hidrográficas y a la consideración del agua como bien público, en una estructura basada en la corresponsabilidad entre administraciones.

A pesar de todo, la política del agua en España no se ha adaptado todavía al cambio de paradigma propiciado, a partir del año 2000, por la Directiva marco europea sobre el agua (DMA), que exige alcanzar el buen estado ecológico de todas las masas de agua, la gestión integrada de las aguas superficiales, subterráneas y costeras, desde la perspectiva de la gestión de la demanda, la repercusión de los costes asociados al consumo del agua, así como la participación pública y la transparencia en la correspondiente toma de decisiones.

La situación catalizada por el Cambio Climático, implica necesariamente el revisar la política de aguas hasta ahora emprendida y transicionar hacia nuevas formas de analizar y de gestionar; nuevos paradigmas que inicien por la lógica de que es preciso conocer integralmente la realidad para comprender, y comprender para tomar decisiones adecuadas, sostenibles en el tiempo y con el entorno. Una transición que se apoye en dos aspectos centrales como son la autosuficiencia territorial en materia de usos y recursos (por ese orden) y en la aplicación del principio de soluciones basadas en la naturaleza más que en infraestructuras hídricas con importantes incertidumbres en la utilidad para el recurso agua por lo que fueron construidas. Se trata de una transición necesaria para reducir esas dudas, esas incertidumbres, aportando garantías de suministro para agua de boca y para la economía y seguridad global al sistema socioecológico.

En suma, lograr la seguridad hídrica para las personas y el planeta, salvaguardando el interés general. 
La transición hidrológica es un proceso deliberado de transformación política e institucional orientado a mejorar nuestra capacidad de respuesta y de adaptación al nuevo escenario de cambio climático y como antes se indicó para conseguir la seguridad hídrica de las personas, sus actividades económicas y el medio ambiente. El nuevo escenario requiere un planteamiento estratégico y una hoja de ruta para la transformación de la gestión del agua en España de manera que podamos abordar de manera gradual los múltiples desafíos preexistentes de la gestión del agua considerando los cambios climáticos y ambientales en el contexto de las importantes transformaciones sociales e institucionales que han ocurrido en los últimos años en la gestión del agua.

La transición hidrológica se justifica por la dificultad de abordar los retos del cambio climático con el marco institucional con los instrumentos de política en que se ha sustentado la gestión del agua y el desarrollo hidrológico en España hasta el momento, además de las dificultades inherentes a las llamadas alternativas tradicionales, basadas en las obras hidráulicas y la expansión de la oferta de agua. Estas respuestas, en un país como España que ya ha aprovechado buena parte de su potencial hidrológico, están asociadas a costes crecientes, rendimientos decrecientes, impactos añadidos sobre el medio ambiente y mayor resistencia política y mayores barreras para su aceptación social. Además de ello, estas respuestas carecen de la capacidad de adaptación que exige el nuevo escenario de cambio climático y sus efectos sobre las disponibilidades futuras de agua en cada punto del territorio nacional.

La crisis climática viene acompañada de nuevos retos y de nuevas circunstancias en las que será necesario encontrar respuesta a los viejos desafíos de la gestión del agua. Todo ello exige nuevas respuestas. Frente a un futuro incierto, estas nuevas respuestas serán mejores en cuanto mayor sea su capacidad de adaptarse a la disponibilidad de agua futura. Por ese motivo, las alternativas con el mayor potencial de responder bien cualesquiera que sean las circunstancias futuras deben ir más allá de las opciones tradicionales que responden a unas circunstancias hidrológicas hasta ahora consideradas como normales.

Las respuestas convencionales a la escasez y el deterioro de la calidad del agua aportan menos seguridad que alternativas adaptables tales como el desarrollo de fuentes no convencionales de agua, la flexibilización del sistema de oferta existente, la protección o restauración de las fuentes, las infraestructuras verdes (medidas basadas en la naturaleza) o las concesiones y precios contingentes y otros instrumentos de gestión de la demanda de servicios del agua .

Por todo lo anterior, reconocer el cambio climático exige reconocer la seguridad hídrica como uno de los principales desafíos de la política y la gestión del agua. El principal reto de la gobernanza del agua consistirá en asegurar el agua para las personas, para los activos y las actividades económicas que dependen de ella, pero de igual manera para los ecosistemas que regulan el ciclo hidrológico y nos aportan múltiples servicios.

En síntesis, la transición hidrológica es una apuesta por una gestión integral de los recursos hídricos que garantice la seguridad hídrica mediante la respuesta 
y la adaptación al cambio climático para lograr un desarrollo económico, social y ambientalmente sostenible y justo.

Esta gestión integral exige cambios en la gestión y gobernanza del agua ${ }^{1}$ en al menos las cuatro dimensiones siguientes:

a) La coordinación de las políticas sectoriales de manera que estas se ajusten y sirvan a los objetivos de la política y gestión del agua.

b) La coherencia entre los distintos niveles de la administración pública que conviertan el ciclo del agua y su gestión en un conjunto unitario de responsabilidades institucionales y decisiones que contribuyan efectivamente a objetivos comunes.

c) La cooperación del mayor número posible de usuarios y agentes sociales que asuman sus responsabilidades compartidas con una administración que involucre y se relacione de una manera diferente con los ciudadanos.

d) Una nueva forma de construir, diseñar y ejecutar las decisiones políticas basada en el conocimiento y en sistemas de información y apoyo a la gestión que permitan el seguimiento, la evaluación continua y la evaluación de resultados con criterios transparentes de efectividad, eficiencia, equidad y sostenibilidad que, a diferencia de criterios normativos y de procedimiento, hasta el momento, no han ocupado un papel destacado en la política y gestión del agua.

\subsection{Situación Actual}

\subsubsection{Usos}

La complejidad de la gestión del agua en España, especialmente en aquellas zonas con una utilización intensiva del recurso, hace difícil ofrecer datos cuantitativos absolutos que se expliquen por sí mismos y no requieran de matices desde el punto de vista de la gestión. Sin embargo, a pesar de la dificultad para presentar en España datos globales homogéneos de todas las demarcaciones hidrográficas españolas, la puesta en común de estos datos permite extraer las siguientes consideraciones.

En los planes hidrológicos de segundo ciclo, la previsión de la demanda estimada en España para el año 2021 es del orden de los 32.000 hm³/año. El principal uso del agua es el de regadíos y usos agrarios, que suponía aproximadamente el $80 \%$ de esta demanda, representando el abastecimiento urbano apenas el $16 \%$ y el 4,0\% las industrias no conectadas a redes urbanas.

Un aspecto clave en cuanto a las necesidades de agua de los usos actuales y futuros es la asignación y reservas de recursos hídricos. En este sentido, las reservas establecidas deberán inscribirse en el Registro de Aguas a nombre del orga-

${ }^{1}$ Libro Verde de Nueva Gobernanza del Agua. Josefina Maestu. MITECO. 2019 
nismo de cuenca, el cual procederá a su cancelación parcial a medida que se vayan otorgando las correspondientes concesiones.

En el caso de las reservas establecidas y de su materialización a lo largo del ciclo de planificación, el tratamiento dado por los planes hidrológicos es muy diferente entre sí. Por todo ello, no es posible plantear una comparativa homogénea que además de la asignación de recursos a 2021 para los distintos usos, indique la parte de esa asignación que corresponde a reserva y la evolución de lo que se va concediendo o materializando.

En el planteamiento de fondo de la problemática respecto a asignaciones y reservas desempeña un papel fundamental el Registro de Aguas y la Base Central del Agua. El completado adecuado de los trabajos relativos al Registro de Aguas electrónico, y el mantenimiento de ese Registro de manera automática mediante el vínculo con los procedimientos administrativos de la sede electrónica supone un reto futuro esencial para poder aplicar adecuadamente criterios planteados en este tema, de tanta importancia como, por ejemplo, la revisión de las concesiones existentes cuando así lo exija su adecuación a las asignaciones formuladas por los Planes Hidrológicos de cuenca (artículo 91.2 del RDPH).

Con los datos de los recursos disponibles y asignaciones se estiman distintos índices de explotación en las distintas demarcaciones hidrográficas. Las cuencas cantábricas, con menor peso específico del regadío que otras cuencas españolas, ofrecen los valores más bajos de los índices de explotación, tanto anuales como mensuales. Las grandes cuencas (Duero, Tajo, Guadiana, Guadalquivir y Ebro) ofrecen valores muy altos en los índices mensuales especialmente en los meses estivales. Las cuencas mediterráneas del levante español (Segura y Júcar) muestran los mayores valores anuales del índice de explotación, sin embargo no son las que evidencian un mayor desequilibrio mensual porque la demanda es menos estacional que en otras zonas de España.

Por todo ello, los anteriores datos confirman los necesarios retos a abordar en la gestión del agua, en concreto de los usos y demandas, ante futuros escenarios de escasez hídrica. Es necesario abordar la necesaria gestión de la demanda, especialmente la demanda agraria, la disposición de inventarios de regadíos actualizados, la mayor incorporación de recursos no convencionales y el control estricto de las captaciones de agua, asignaciones y reservas.

Asimismo, el análisis de los datos globales también refleja la necesidad de abordar acciones diferenciadas por demarcaciones especialmente aquellas en las que existe un mayor índice de explotación, en las que la proporción entre agua extraída y agua existente son mayores.

\subsubsection{Recursos}

El seguimiento de los recursos hídricos tras la elaboración de los planes hidrológicos de segundo ciclo en base a la información relativa a precipitaciones, caudales registrados en estaciones de aforo, niveles piezométricos, volumen almacenado en embalses, así como datos relativos a recursos hídricos no conven- 
cionales y a recursos hídricos externos refleja una tendencia, a pesar de la variabilidad interanual, marcada por la progresiva menor disponibilidad del recurso.

Los datos de los últimos años reflejan importantes reducciones de las precipitaciones medias en los últimos años, una notable reducción de las aportaciones en prácticamente todas las demarcaciones, un descenso generalizado en los niveles piezométricos, niveles de agua embalsada en descenso, especialmente en el año hidrológico 2016/2017 que terminó con un volumen almacenado del 34.5\% respecto de la capacidad máxima.

Sin embargo, en relación con el uso de los recursos llamados no convencionales no parece que haya existido un incremento significativo de los volúmenes suministrados para reutilización. Teniendo en cuenta que los niveles de ejecución de las medidas destinadas a reutilización de los planes del segundo ciclo presentan un escaso nivel de ejecución (apenas alcanzan el $20-25 \%$ ) y que el incremento de uso de agua reutilizada se revela como esencial de cara a la planificación y gestión del recurso en los años venideros, el Miteco ha abordado la elaboración del Plan dSEAR. Así, la Dirección General del Agua fomenta el Plan Nacional de Depuración, Saneamiento, Eficiencia, Ahorro y Reutilización (Plan dSEAR), con el objetivo de revisar las estrategias de intervención definidas en los actuales planes hidrológicos de segundo ciclo, y de cara a la preparación de los planes del tercer ciclo.

Por su parte, a pesar del alto grado de incertidumbre en los datos, sí se puede concluir que ha producido un, aún leve, incremento del volumen de agua utilizada procedente de desalinización, que se ha situado por encima de los $530 \mathrm{hm}^{3} /$ año, debido a la incorporación de nuevos recursos en cuencas del levante español, principalmente en la demarcación del Segura, que reúne más del $40 \%$ de los recursos de desalinización suministrados en España. No obstante, esta tecnología y este recurso presentan aún un amplio margen hasta alcanzar su capacidad potencial máxima.

Tras la aprobación de los planes hidrológicos de segundo ciclo, es destacable el año hidrológico 2016/17 pues tuvo un carácter marcadamente seco en casi toda España, especialmente en todo el noroeste peninsular y zonas de la cuenca del Duero, así como en diversas áreas de Asturias, Cantabria, Extremadura, Andalucía y Canarias. El valor medio global de la precipitación fue de $502 \mathrm{~mm}$, un $20 \%$ por debajo del valor medio de referencia. Este carácter seco se reflejó en los datos de caudales en ríos, niveles piezométricos y almacenamiento en embalses.

De cara al tercer ciclo de planificación, las series utilizadas en el inventario de recursos hídricos han de ampliarse en seis años, los correspondientes al periodo 2012/13 a 2017/18. Además, el Centro de Estudios Hidrográficos del CEDEX está llevando a cabo una mejora y actualización del modelo SIMPA de estimación de los recursos hídricos en régimen natural.

Desde el punto de vista de la situación de la sequía hidrológica, ya el año 2016/17 fue complicado, debido a su carácter muy seco y al hecho de venir ya de dos años secos. Tres demarcaciones hidrográficas (Duero, Segura y Júcar) tuvieron vigentes sendos Reales Decretos por los que se declaraba la situación de sequía prolongada y se adoptaban medidas excepcionales para la gestión de sus 
recursos hídricos, pero también otras tuvieron problemas en algunas zonas (Miño-Sil, Galicia Costa, Guadiana, Guadalquivir o cabeceras de Ebro y Tajo). En general, no se registraron restricciones importantes relacionadas con el abastecimiento urbano, salvo algunos problemas puntuales, generalmente en pequeñas localidades. La campaña de riego sí se desarrolló con restricciones en varias zonas de las demarcaciones afectadas.

Es de destacar que, en este año, se produce esta complicada situación de sequía y, tal y como los datos de anteriores apartados reflejan en relación con los usos, los valores de utilización del agua son más bajos de las demandas que se recogían en los planes de segundo ciclo para el momento de elaboración del plan y para la estimación del año 2021.

Todo ello insiste en la necesidad de revisar los usos del agua, atendiendo a las nuevas disponibilidades del recurso, otorgando una prioridad efectiva a los abastecimientos de población, configurando una gestión integrada de todas las fuentes de agua disponible entre las que se incluyan recursos convencionales y no convencionales y buscando la adaptación de los sectores productivos a futuros escenarios de menor disponibilidad de recursos.

Asimismo, existe aún mucho margen en la necesidad de mejorar la gestión de la sequía con objeto de incorporar en la planificación hidrológica la incertidumbre climática e integrar los previsibles efectos del cambio climático en la planificación de los recursos hídricos de manera adecuada.

\subsubsection{Estado Ecológico de Masas de Agua}

\section{Áreas y Especies protegidas}

Las zonas húmedas protegidas están sometidas a presión por sobreexplotación de los recursos hídricos de los que dependen. El incremento en el uso del agua tiene un reflejo directo en la reducción o distribución temporal de los caudales circulantes en estos medios o la extensión de la lámina de agua en el caso de los humedales o lagos.

Sin embargo, excepto en contadas ocasiones, no existen reservas específicas de agua en los Planes Hidrológicos para las zonas protegidas, salvo que en ellas se haya definido un punto con propuesta de caudales ecológicos. Los Planes de Ordenación de los Recursos Naturales, competencia de las Comunidades Autónomas, raramente incluyen las necesidades de agua para los espacios protegidos. Excepciones a esta regla son por ejemplo la Albufera de Valencia, el Delta del Ebro y Las Tablas de Daimiel, que si tienen definidas las demandas ambientales., aunque globales.

Los espacios dependientes del agua subterránea son los que más han sufrido en la última década, a causa de que la extracción ha aumentado un 35\%, al tiempo que se ha mantenido los niveles de contaminantes en las zonas en riesgo de la Directiva de Nitratos (acuíferos que los alimentan).

Tal como se verá más adelante, la calidad del agua, principalmente por los nutrientes generados por la actividad agraria y ganadera intensiva y la contami- 
nación puntual ha afectado al tamaño de las poblaciones de especies acuáticas y la expansión de las especies invasoras (peces exóticas, camalote).

Por otra parte, en la planificación hidrológica faltan indicadores específicos para peces y para eficacia de los caudales ecológicos, así como otros elementos significativos en relación con el bosque de ribera. Por tanto, aunque los indicadores hidrológicos pueden estimar el estado de las aguas, el estado ecológico basado en los elementos de ecosistema no es completo ni mucho menos para poder definir el estado de conservación del ecosistema y las especies indicadoras. En el protocolo de seguimiento tan solo incluye el epígrafe para la valoración del estado «estado de conservación». No se señalan los indicadores utilizados para la evaluación del estado. Se aportan indicadores sobe el estado del procedimiento de seguimiento. Pero no otro. En definitiva, no hay fondos para hacer el seguimiento de la cobertura total.

En relación con las especies invasoras de ecosistemas acuáticos, la mayor parte de los casos, las estrategias no están operando adecuadamente, ya que las especies invasoras siguen avanzando (por ejemplo, cabe citar el caso del visón americano o los peces invasores en general, se han expandido enormemente). Sería necesario revisar las estrategias y actualizarlas. Además, el número de estrategias aprobadas resulta muy poco ambicioso, teniendo en cuenta que sólo tienen estrategia un $2 \%$ de las especies catalogadas.

\section{Calidad de las Aguas}

La estimación global del estado de las masas de agua para determinar la evolución registrada desde la aprobación de los planes hidrológicos de segundo ciclo ha dado como resultado que, de las 5.238 masas de agua identificadas de agua superficial, solo están en buen estado el $58 \%$, aún bastante lejos de los objetivos planteados por los planes para el año 2021, que son del 72,6\%.

En lo que respecta a las masas de agua subterránea, la situación es más negativa. En general, las variaciones son a peor, lo que en parte refleja la inercia que las aguas subterráneas tienen, necesitando en general bastantes años para que las medidas puestas en marcha surtan efecto. Se produce un descenso en el número de masas de agua subterránea en buen estado (del 55,8\% en 2013-14, al 52,4\% en 2017, con un objetivo parcial para 2021 del 66,5\%). Este descenso de masas en buen estado en ciertos años que por su carácter muy seco se caracterizó por una recarga muy baja y una mayor utilización de los acuíferos.

El descenso de calidad de acuíferos se produce, de forma casi exclusiva, por los valores de las demarcaciones del Segura y principalmente del Guadalquivir.

\section{Caudales ecológicos}

El establecimiento de los regímenes de caudales ecológicos en ríos y en aguas de transición constituye uno de los contenidos obligatorios de los planes hidrológicos de demarcación. 
En general, los planes hidrológicos contienen medidas necesarias para poder garantizar el cumplimiento de los caudales ecológicos que se deberán implantar a lo largo del tiempo, pero no existe un avance en este aspecto, como sería la traslación de los caudales ecológicos a la realidad de las concesiones de agua actualmente existentes.

Aunque en el segundo ciclo de planificación se avanzó de forma importante en la definición del régimen de caudales ecológicos en casi todas las demarcaciones hidrográficas, los datos ofrecidos por los organismos de cuenca y administraciones del agua de las Comunidades Autónomas muestran bastantes problemas con el control y el cumplimiento de dichos caudales.

En todo caso, llama la atención que en un $44 \%$ de las masas controladas se haya producido algún tipo de incumplimiento de los caudales ecológicos a lo largo del año. Un factor general que explica parte de estos incumplimientos es el grado de ejecución, todavía relativamente bajo, de los Programas de Medidas de los planes hidrológicos, que suelen incluir determinadas actuaciones en infraestructuras, necesarias para poder garantizar el cumplimiento de los caudales ecológicos.

Por otra parte, se han mantenido a la baja en ocasiones los caudales mínimos, como es el caos de la demarcación del Ebro, en el que persisten valores de caudales ambientales significativamente inferiores a los propuestos en los estudios científico-técnicos.

\subsection{Diagnóstico: Contexto para la Transición}

\subsubsection{Previsiones en función del Cambio Climático}

Los informes a este nivel corresponden a las investigaciones realizadas por el CEDEX en 2010 y 2012 y su revisión en 2017/18. Asimismo, a nivel de la UE son muy relevantes los Informes del «Joint Research Centre (JRC)» y del propio Panel de Expertos internacionales de NNUU (IPCC). En ellos y sobre los escenarios marcados en el IPCC, se establecen proyecciones climáticas y las consiguientes simulaciones hidrológicas de impactos sobre los recursos hídricos en sus distintos vectores: evapotranspiración real, humedad del suelo, recarga subterránea y escorrentía especialmente.

Existe una clara incertidumbre si bien hay también una tendencia general a una reducción de recursos hídricos: reducción de las precipitaciones, aumento de la ETP y fuertes reducciones de escorrentías. Las reducciones son mayores conforme avanza el siglo XXI.

Se estiman mayoritariamente descensos de precipitación, siendo mayores estos descensos en el cuadrante SO de la Península y en los archipiélagos. Para el conjunto de España, la media de los cambios son respectivamente del - $2 \%$ y $-4 \%$ para $2010-2040,-6 \%$ y $-8 \%$ para $2040-2070$ y $-7 \%$ y $-14 \%$ para $2070-2100$.

Por otro lado, también se pronostica un cambio en el régimen de sequías. La mayoría de las proyecciones climáticas muestran un futuro en el que las sequías 
serían más frecuentes, acusándose ese efecto cuanto más nos alejamos en el siglo XXI. Estas sequías serán mayores a lo largo del siglo. Territorialmente las Demarcaciones del Duero, Tajo y Guadiana, dan resultados similares, un régimen más propenso a sequías que en el Norte. La del Guadalquivir es representativa de las del sur de la Península. El impacto de las sequias es de mayor frecuencia que en las cuencas anteriores.

Para el SE de España, en concreto para la del Segura, los resultados del impacto son y frecuencia de sequías son más o menos como las del Tajo. Casi todas las proyecciones siguen la tónica general de una mayor frecuencia de sequías conforme avanza el siglo XXI.

La Demarcación del Ebro presenta características similares a las del norte de España, con sequías menos frecuentes que en el resto de ámbitos.

Los estudios de evaluación del impacto del cambio climático sobre los recursos hídricos, tanto a nivel nacional (CEDEX), de la Unión Europea (JRC, 2018) y a nivel global (IPCC) coinciden en señalar dos tipos de resultados. En primer lugar, que las consecuencias del cambio climático diferirán notablemente entre países y regiones. En segundo lugar, el cambio climático afectará negativamente la disponibilidad de recursos hídricos en algunas regiones específicas dentro de las que se encuentra España y particularmente las cuencas mediterráneas del país.

Según el CEDEX (2017), si se producen los escenarios de incumplimiento de los acuerdos de París, se prevé una reducción de caudales medios de los ríos, desde 2010 a finales de siglo, , del orden del $24 \%$, que podría situarse entre el 30 y el $40 \%$ en las zonas más sensibles; mala infiltración que alimenta los acuíferos disminuirá en proporciones similares CEDEX (2017).

En relación a la distribución espacial, en general hay una reducción más intensa hacia el suroeste peninsular y en Canarias, y menor reducción, o incluso aumento de escorrentía, en algunas zonas del este peninsular.

El impacto del cambio climático en el régimen de sequías, se ha reflejado como cambio en el periodo de retorno de las sequías en cada uno de los periodos de impacto con respecto al periodo de control.

A partir de los resultados obtenidos se pronostica que, en general, las sequías en España se harán más frecuentes conforme avance el siglo XXI, con el consecuente aumento de la escasez de agua en España debido a la reducción de los recursos hídricos.

Casi todas las proyecciones siguen la tónica general de una mayor frecuencia de sequías conforme avanza el siglo XXI. Se aprecian escasas diferencias entre los resultados aportados por ambos escenarios de emisiones.

Por otra parte, de acuerdo con las conclusiones del JCR (UE):

- Los flujos de aguas superficiales incrementarán en la Unión Europea, a lo largo de las cuatro estaciones, pero se reducirán (también en todas las estaciones) en las cuencas mediterráneas.

- Como consecuencia del cambio climático, los picos de descargas aumentarían, incluso en las zonas mediterráneas, con contadas excepciones es- 
pecialmente en zonas costeras, con el consecuente aumento del riesgo de inundaciones.

- Los eventos de sequía se harán más frecuentes y podrían ser más severos especialmente en la región Mediterránea en España, Grecia y Portugal. Considerando los usos del agua de referencia (correspondientes al año 2006), las proyecciones de cambio climático conllevan un aumento en el número de días que los caudales de los ríos mediterráneos se encuentren por debajo de niveles críticos y se presentarán problemas para mantener los caudales ambientales (especialmente en los ríos españoles).

La principal referencia sobre las previsiones de pluviometría, escorrentía superficial e infiltración a los acuíferos en España, la ofrecen los estudios del CEDEX.

En definitiva, todas las simulaciones y previsiones apuntan, de forma consistente, a notables incrementos de la temperatura media, que dependen del nivel de emisiones que se produzca en el futuro.

Fruto de ese aumento de temperaturas, especialmente en primavera-verano, crecerá fuertemente la evapotranspiración de las masas vegetales, generando una recesión de escorrentías.

Las precipitaciones, aunque los diversos modelos de simulación ofrecen mayor incertidumbre, las expectativas en espacios mediterráneos prevén una importante tendencia recesiva, que se acentúa en horizontes de finales de siglo y en escenarios pesimistas, en los que se incumplen los acuerdos de París.

Los caudales fluviales y los niveles de infiltración en los acuíferos, por aumento de evapotranspiración de las masas vegetales y menor precipitación, obligan a asumir escenarios con menos recursos disponibles.

Esta situación repercutirá muy especialmente en la agricultura. En efecto el «stress» hídrico, que puede reducir los rendimientos de los aprovechamientos agrícolas, aumentará especialmente en las cuencas mediterráneas, lo que comprometerá la viabilidad de la agricultura de secano y aumentará la demanda social de transformación a regadío a lo largo de toda la geografía española, aumentando la brecha entre demanda y oferta de agua.

En la agricultura, fuertemente vinculada a la vertebración del medio rural, los impactos de las sequías son directos, sobre todo en el secano, que supone el $80 \%$ de la superficie cultivada. Por ello, más allá de su valor socio-económico, el secano tiene una importancia decisiva sobre la gestión del territorio. Las estrategias de protección del secano, como riegos de apoyo, puede ser clave en las estrategias de adaptación pero deben diseñarse de modo que no aumente las presiones sobre los recursos ni agraven la exposición a la sequía.

Por otra parte, las olas de calor combinadas con la reducción de caudales circulantes podrían tener un impacto significativo en la demanda de agua para refrigeración de plantas industriales y centrales de generación. Si esto se acompaña del previsible aumento de la demanda de energía, para regular temperatura, se puede observar que el cambio climático supondrá un desafío para las tecnologías convencionales de generación de energía, especialmente las plantas térmicas y nucleares. 


\subsubsection{Contexto Hidrico}

En suma, como ampliamente se ha insistido, la crisis climática obliga a replantear la Planificación y la Gestión del Agua. Asimismo, los paradigmas previos cambian lo que exige una nueva construcción de instrumentos para la Seguridad global hídrica, una seguridad que debe aunar criterios socioeconómicos con los ecosistémicos.

En todo caso esta «nueva normalidad» hidrológica está basada en incertidumbres con menos determinismos y tendrá impactos evidentes en cuanto al agua disponible:

- Mayor Temperatura/Mayor evapotranspiración (hasta duplicarse) y menores escorrentías.

- Previsibles caudales inferiores en $24-40 \%$ y otro tanto aporte a acuíferos.

Esta realidad se caracterizará por considerar:

- Desajustes Oferta/Demanda y por tanto la insuficiencia del modelo de Oferta.

- Mayor vulnerabilidad a la sequía.

- Mayor vulnerabilidad a inundaciones.

- Mayor desertización general.

- Necesidad de optimizar nexo agua y energía.

- Necesidad de optimizar ciclo de depuración y regeneración.

- Nuevo contexto regulador y del marco competencial.

- Afrontar Disrupción Tecnológica y el papel de las TICs.

- Gestión Participativa con presencia creciente de la ciudadanía en los procesos de gestión.

Específicamente en el entorno natural los riesgos serán:

- Desecación de Hábitats de interés ecológico.

- Afección a los «Servicios ecosistémicos».

- Disminución de potencial autodepurador.

- Implicaciones en riesgos (afección llanuras de inundación).

- Implicaciones económicas (pesca).

- Alteración del proceso Erosión/Sedimentación:

- Colmatación de embalses.

- Aumento desertización: Incendios.

- Descenso general de la calidad del agua. 
Todo ello precisará de una adecuada gestión de masas forestales ligado íntimamente a las políticas hídricas.

El Cambio Climático tendrá impactos negativos en las actividades económicas que se benefician de los servicios del agua y de los ecosistemas hídricos.

Por todo ello, en los próximos años debemos estar preparados para enfrentar:

- Una reducción del rendimiento de la agricultura de secano, el $80 \%$ de la superficie cultivada española, con importantes efectos sobre la economía rural aumentando el riesgo de despoblación, desertificación y abandono del patrimonio histórico.

- El aumento de los requerimientos de agua de los cultivos de regadío, añadiendo a la reducción de disponibilidades de agua aumentos de la demanda que solo pueden resultar en mayor escasez tensiones asociadas al agua.

- Un aumento de la demanda de agua de refrigeración como efecto del aumento de las temperaturas que sumado a la mayor demanda de energía para climatización y a la reducción de caudales puede resultar en desafíos para las tecnologías convencionales de generación de energía, especialmente para las plantas térmicas y nucleares.

\subsection{La Necesaria Transición Hidrológica ${ }^{2}$}

\subsubsection{Bases para la Transición}

La situación exige un cambio, una transición hacia un nuevo modelo de gestión.

La transición hidrológica es un proceso deliberado de transformación política e institucional orientado a mejorar nuestra capacidad de respuesta y de adaptación al nuevo escenario de cambio climático y a conseguir la seguridad hídrica de las personas, sus actividades económicas y el medio ambiente.

Las alternativas tradicionales, basadas en las obras hidráulicas y la expansión de la oferta de agua, en un país como España que ya ha aprovechado buena parte de su potencial hidrológico, están asociadas a costes crecientes, rendimientos decrecientes, mayor resistencia política, impactos agravados sobre el medio ambiente y mayores barreras para su aceptación social.

Esta gestión integral exige cambios en la planificación y en la gobernanza del agua por lo menos en las cuatro dimensiones siguientes:

- La mejora de la coordinación de las políticas sectoriales de manera que se ajusten y sirvan a los objetivos de la política y gestión del agua y se garantice que los avances sectoriales o regionales no entren en contradicción con los objetivos conjuntos y nacionales.

\footnotetext{
${ }^{2}$ Bases de Transición Hidrológica. MITECO. 2019.
} 
- El restablecimiento de la coherencia entre los distintos niveles de la administración pública que conviertan el ciclo del agua y su gestión en un conjunto unitario de responsabilidades institucionales, en el que la administración central, las administraciones autonómicas, provinciales y municipales se coordinan mediante decisiones que contribuyen efectivamente a objetivos comunes.

- La participación comprometida del mayor número posible de usuarios y agentes sociales que, además de demandar y controlar la acción pública, asuman responsabilidades compartidas.

- Una nueva forma de construir, diseñar y ejecutar las decisiones políticas basada en el conocimiento y en sistemas de información y apoyo a la gestión, el seguimiento y la evaluación de resultados de la gestión pública y privada con criterios transparentes de efectividad, eficiencia, equidad y sostenibilidad.

A continuación se sintetizan los Principios, Objetivos y Metas concretas para conseguir esta transición hidrológica.

\section{Objetivos}

- Objetivo General

Adaptarnos al cambio climático para lograr la seguridad hídrica reduciendo la brecha entre los recursos realmente disponibles y la demanda de servicios del agua, y protegiendo y mejorando el estado de conservación del patrimonio natural y la biodiversidad, aportando capacidad adaptativa al cambio climático para así garantizar nuestro bienestar presente y futuro.

- Tres objetivos interrelacionados:

- Seguridad Hídrica.

- Protección de los ecosistemas y de la biodiversidad.

- Adaptación al Cambio Climático.

\section{Principios}

- El agua no es un bien mercantil sino un bien público que debe ser protegido, defendido y tratado como tal.

- El agua es, por tanto, parte del dominio público hidráulico, cuyo aprovechamiento debe estar subordinado y condicionado al interés general.

- El acceso a los servicios básicos de agua de boca y saneamiento son derechos humanos esenciales para el pleno disfrute de la vida y para el cumplimiento de otros derechos humanos.

- La falta de certeza sobre los posibles impactos de las actividades humanas sobre el medio acuático no debe utilizarse como argumento para evitar la 
acción o para no tomar las medidas necesarias para evitar dichos daños (Principio de Precaución).

- Se debe prevenir cualquier deterioro adicional del estado de los ecosistemas acuáticos y los ecosistemas terrestres que dependan de estos (Principio de no deterioro).

- La gestión y uso del agua debe tener en cuenta la integridad de la cuenca hidrográfica que se considera indivisible (de acuerdo con el Principio de unidad de cuenca).

\section{Metas de la Seguridad Hídrica}

- Salvaguardar y promover la salud pública y asegurar el acceso adecuado a los servicios a un precio asequible para todos.

- Desacoplamiento de la actividad económica y gestionar el agua desde la gestión del territorio.

- Mejorar la resiliencia ante eventos extremos reduciendo la exposición y la vulnerabilidad.

- Alcanzar el buen estado de las masas de agua y asegurar la disponibilidad sostenible.

Metas de Adaptación al Cambio Climático

- Anticipación. Gestión sostenible y la capacidad de adaptación frente al cambio climático.

- Disminución de la exposición.

- Gestión de riesgos para reducir los impactos negativos de eventos adversos.

- Reducción de la vulnerabilidad y aumentar la resiliencia. Respuesta del sistema frente al cambio.

- Gobernanza adaptativa y colaborativa. Modelo de gestión flexible y adaptativo.

Metas de Protección de los ecosistemas y mejora de la biodiversidad

- Puesta en valor de los servicios prestados por los ecosistemas.

- Papel funcional de la biodiversidad en los ecosistemas.

- A través de:

- Mejora de la estabilidad ecológica caudales ambientales y calidad.

- Gestión integrada del territorio mediante soluciones naturales.

- Mejorar los sistemas naturales para la gestión del riesgo ante fenómenos extremos. 


\subsubsection{Proceso de implantación}

La puesta en marcha de una nueva política de transición hídrica implicará en actuar en muy diversos frentes y con orden prelativo diverso. Se precisará, en síntesis, actuar sobre:

- Planificación:

- Revisión Planes de Cuenca III Ciclo.

- Revisión Plan DSEAR.

- Planes de Desarrollo Rural y Urbanístico.

- Estrategia de Restauración de ríos.

- Marco Regulatorio:

- Nueva Ley Marco del Agua.

- Marco Herramientas (Instrucción Técnica de Planificación).

- Nueva Ley Ciclo Urbano.

- Regularización de pozos.

- Gobernanza:

- Gestión DPH.

- Clarificación Obras Interés General.

- Regularización Concesiones.

- Aumento capacidad de Desalación.

- Mesas de Coordinación

- AGE

AGE/CCAA

AGE/FEMP

\subsection{Nueva Gobernanza del Agua}

\subsubsection{Participación ciudadana y gobernanza hídrica en España}

De acuerdo con Hernández Mora (2016) en el contexto de crisis de legitimidad de la esfera pública, han surgido, desde la sociedad civil infinidad de iniciativas, movimientos, redes más o menos estructuradas o formalizadas, que precisamente buscan involucrarse tanto en el seguimiento y la evaluación de las políticas públicas, como en la exigencia de mayores niveles de transparencia y rendición de cuentas de las administraciones públicas hacia la sociedad.

En el caso de la gestión del agua, la involucración social es particularmente importante al tratarse de sistemas socioecológicos complejos, con altos niveles de incertidumbre asociados, grandes intereses en juego y donde coexisten múltiples visiones de la realidad frecuentemente contrapuestas e igualmente legítimas (Pita et al., 2014). 
Los problemas del agua son problemas profundamente políticos. Ya no se trata únicamente de ofrecer las mejores soluciones desde una perspectiva científico-técnica o económica. Mientras que estas perspectivas son fundamentales en el diseño de políticas públicas, la legitimidad de las decisiones sobre la esfera pública también depende en gran medida del grado de confianza de los ciudadanos en las instituciones y de la implicación de la sociedad y las partes interesadas en los procesos de toma de decisiones. En el caso de España esta confianza se ha erosionado como consecuencia de los múltiples casos de corrupción, malversación de fondos públicos y opacidad en la toma de decisiones. Con demasiada frecuencia se percibe que las decisiones se diseñan para favorecer los intereses de unos pocos en detrimento del interés de todos. La nueva gobernanza del agua debe tener muy en cuenta estos procesos participativos.

La actual situación de partida que requiere ser cambiada se caracteriza por:

- La gobernanza debe interpretarse como un elemento de seguimiento y control de la Gestión Integrada de los recursos hídricos. Esta gobernanza tiene que ver con las propias instituciones que afectan a las decisiones: transparencia, participación y rendición de cuentas.

- Es necesario establecer la relación apropiada entre el recurso hídrico y el territorio por el que transcurre. Las prácticas internacionales reconocen la gestión por cuenca, ecosistema, hábitat o demarcación hidrográfica como método idóneo para integrar las fronteras políticas y administrativas.

- El sistema español no ha interiorizado suficientemente los principios conformadores de la gobernanza no habiendo superado la división de las fronteras político-administrativas, sino que, en cambio, ha dotado a las cuencas de una dimensión política. Este diseño impide la interacción de la realidad física y política que estructura el ámbito escogido para la gestión. En dicho contexto, se dificulta la gestión integrada, lo cual implica una mayor coordinación y por ello la dotación de nuevos instrumentos que coadyuven a esta.

- El diseño del sistema español está pensando más en términos de oferta y demanda que en términos de calidad de agua y, por ello, la obra hidráulica forma una parte sustancial de él. Aunque este sistema ofrece servicios con un "alto nivel tecnológico y de innovación", no potencia (como hace la DMA) los principios de adecuación ecológica y de participación y transparencia, básicos para el ejercicio de la gobernanza, así como el de autosuficiencia en la gestión en un equilibrio Oferta/Demanda.

- El hecho de que el sistema español de gestión del agua haya presentado históricamente una dualidad entre las funciones soberanas en materia de agua y las facultades relativas a la obra hidráulica ha condicionado la estructura de los órganos institucionales.

- En España no se ha implantado una verdadera gobernanza del agua que tenga en cuenta las relaciones entre el Estado y los ciudadanos, así como las continuas transformaciones que se llevan a cabo en la sociedad. 
- Los Organismos de cuenca constituidos a partir de 1985 no han liderado aún el cambio de una política hidráulica entendida de forma monolítica y homogénea a una política de aguas integradora de los distintos niveles de gobierno.

- Actualmente se cumplen las condiciones necesarias para instaurar una gobernanza participativa en España. La sociedad está suficientemente capacitada y organizada para tomar parte en la gestión del agua y ofrecer soluciones a los problemas que la acucian. La instauración en España de procesos de gobernanza del agua es un reto ineludible que requiere un cambio de paradigma en el sistema hídrico.

\subsubsection{Paradigmas de la Transición para la nueva gobernanza ${ }^{3}$}

Las bases orientativas de una nueva gobernanza son:

- La resiliencia ante el cambio climático implica reorientar la planificación hidrológica (Tercer ciclo) y sus decisiones especialmente en las referentes a ejecución de nuevas infraestructuras.

- Sobre esta base debe orientarse una cohesión social y territorial sostenida en el tiempo y sostenible en lo ambiental, aportando la necesaria seguridad en ambos aspectos.

- Esta situación hace que debamos adaptarnos a los principios marcados por la naturaleza, acoplando y armonizando nuestros objetivos a sus ciclos integrales de renovación. En suma, buscar en materia de agua la autosuficiencia en la relación uso/recurso y revisar la política de nueva construcción de infraestructuras, fomentando la inversión en infraestructuras "verdes" que coadyuven en esta política de transición hídrica, entre ellas actuaciones ligadas a restauración de riberas e hidrológicoforestales y de drenaje sostenible.

- Deberá priorizarse el agua de consumo humano en cantidad y calidad garantizándose en todos sus términos sin afección o riesgo alguno obviamente sobre la salud. La deficiente calidad existente de las aguas sea por mala gestión del territorio y los ecosistemas o la falta de depuración debe ser un reto ineludible.

- Se hace urgente revisar la información existente en cuanto a calibrar los usos y presiones sobre el medio hídrico utilizando para ello todas las nuevas tecnologías disponibles que hayan mostrado eficacia.

- Auditar así la situación existente en cuanto a usos existentes (concesiones, aguas subterráneas) y su operatividad y eficiencia debe ser un punto de partida esencial. Asimismo, se hace imprescindible conocer en mayor nivel de detalle la estructura de costes de los servicios ligados al agua (in- 
cluidos los servicios ecológicos) para posteriormente definir políticas de tasas y tarifas que incentiven el uso eficiente del agua.

- Para todo ello, es imprescindible avanzar en el desarrollo de nuevas tecnologías aplicadas al ciclo del agua en sus distintos estudios: desde la incentivación de la regeneración, reutilización, desalación, control de calidad, teledetección, TICs para optimización de gestión y control de concesiones, etc...

- La coordinación entre planificaciones sectoriales (energética, agraria, territorial, ...) con la hidrológica, se revela como un aspecto central en el nuevo escenario.

- La nueva gobernanza implica por una parte mejorar la coordinación administrativa a los tres niveles (AGE, Autonómico y Local) pero también integrar más decididamente la participación ciudadana y por tanto la transparencia y rendición de cuentas en las decisiones. La reestructuración administrativa a nivel de AGE debe partir de una redefinición de las Demarcaciones Hidrográficas como centrales de seguimiento desvinculándolas del carácter inversor.

- El uso de energías renovables en la gestión del agua (desalación, regeneración, bombeos, etc...) es otro elemento básico para abaratar costes de gestión y minimizar el cambio climático.

- La regularización de la actual gestión debe estar basado en un nuevo marco normativo global y específicamente del ciclo urbano del agua que garantice el derecho humano y establezca criterios e indicadores claros de gestión.

\subsubsection{Estructura de la nueva gobernanza}

La gobernanza del agua se refiere al sistema político, social, económico y administrativo que determina el uso del agua y su gestión».

Según la OCDE:

«La Gobernanza del Agua se refiere a una serie de procesos políticos, institucionales y administrativos por los cuales las partes implicadas (stakeholders) articulan sus intereses, preocupaciones y necesidades, con el fin de tomar e implementar decisiones responsables del desarrollo y de la gestión de los recursos y servicios de agua».

Los elementos clave de esta nueva gobernanza del agua son:

\section{Funciones}

- Desarrollo de objetivos, prioridades y políticas del agua.

- Generación y mantenimiento de conocimientos.

- Movilización de recursos. 
- Desarrollo de normas/reglas.

- Implementación de políticas, evaluación y seguimiento.

- Resolución de conflictos.

- Son elementos estructurales los siguientes:

- Actores (institucionales, asociaciones, organizaciones de prestaciones servicios, otros).

- Estructuras de colaboración y coordinación.

- Procesos políticos.

- Normas/Leyes.

Principios

- La participación pública, involucración de los ciudadanos y co-responsabilidad

- Los principios de integridad, transparencia y rendición de cuentas

- Los principios de coherencia y coordinación entre niveles de la administración y ámbitos de actuación política

- Aplicación de los principios de recuperación de costes y de contaminador-pagador

- Evaluación y acción eficaz con criterios objetivos y seguimiento.

\section{Criterios}

- Adaptabilidad del marco institucional a una realidad cambiante e incierta, sobre la que tenemos conocimiento limitado.

- Flexibilidad de las estructuras institucionales y los sistemas de gestión para que sean capaces de dar respuesta a los nuevos retos, incluyendo los fenómenos extremos.

- Integración del conocimiento científico y de los conocimientos locales en la gestión para reforzar la efectividad, legitimidad y viabilidad de las políticas del agua.

- Hacer operativa la coordinación vertical y horizontal de las políticas públicas en torno al agua para poder dar respuestas rápidas y coordinadas.

- Empoderamiento de la sociedad y potenciación del aprendizaje y las capacidades sociales (co-responsabilidad) de manera que los ciudadanos sean capaces de ser parte del sistema de información y gestión.

- Potenciar la adopción de las nuevas herramientas TIC para mejorar la capacidad de optimización del sistema actual de gestión del agua y la capacidad rápida de respuesta. 


\subsubsection{Actuaciones específicas de la Nueva Gobernanza del Agua}

Reorganización y Fortalecimiento de la Administración del Agua.

- En el ámbito de la Administración general del Estado (MITECO y Confederaciones hidrográficas) y en lo relativo a la acción de España en las relaciones con la Unión Europea.

Coordinación y Coherencia de la Administración del Agua.

- Fortalecer -y en ocasiones reformar o crear nuevos- mecanismos de coordinación y cooperación efectiva en diversos ámbitos con:

- CCAA.

- Entes Locales.

Financiación de la Gestión del Agua.

Las necesidades de financiación de las inversiones y gestión del ciclo del agua requieren desarrollar instrumentos de financiación para que las administraciones del agua dispongan de los medios necesarios para realizar su labor.

Es importante que el sistema de financiación genere una fuente estable de financiación de actuaciones de la política de aguas, clarificando las competencias en la promoción y ejecución de infraestructuras hidráulicas y arbitrar las fórmulas necesarias para asegurar la transparencia, participación social y rendición de cuentas de las inversiones y mecanismos de financiación.

Fiscalidad del Agua.

- Es necesario desarrollar una política de precios del agua en el sentido de la Directiva Marco del Agua.

- Armonizar y simplificar el sistema actual de tasas y tarifas impuestas sobre el ciclo del agua, de manera que exista coherencia entre la estructura tarifaria.

Reforma del régimen concesional.

- Revisar la efectividad y agilizar los procesos de revisión concesional.

- Completar y mantener actualizado el registro de usos del agua.

- Clarificar la situación de los regadíos históricos y de las zonas regables del estado que operan con títulos distintos de la concesión administrativa.

- Reformar algunos aspectos del régimen concesional de las aguas subterráneas. 
Tecnologías de la Información y el Conocimiento (TIC).

- Fortalecimiento de la administración electrónica; la potenciación de sistemas de información para la gestión del recurso integrados e interoperativos entre las distintas administraciones competentes y con las comunidades de usuarios.

Fomento de la corresponsabilidad social en la gestión del agua.

- Prestación de servicios de forma colaborativa y contribuyan a una mejora de la gestión del agua y el bienestar de las personas y a una mayor legitimidad y eficacia de la acción pública (Observatorios Ciudadanos del Agua).

Mejorar el marco regulador del Ciclo Integral del Agua Urbana.

- Mejora de los servicios del abastecimiento y el saneamiento de acuerdo con las nuevas exigencias legales, teniéndose en cuenta el conjunto del ciclo urbano del agua, incluyendo las aguas de lluvia, el drenaje, las aguas regeneradas y los procesos de recirculación.

- Regulación y garantía del derecho humano al agua.

- Establecimiento de una estructura tarifaria armonizada que permita la recuperación de costes de los servicios incluyendo los gastos operativos, de mantenimiento y reposición.

Reforzar la capacidad de gestión del Ciclo Integral del Agua en pequeños municipios.

- Garantizando la autonomía municipal desde una financiación suficiente y razonable que permita desarrollar una gestión pública, eficaz, transparente y participativa de los servicios de agua y saneamiento para toda la población, facilitando el papel de Diputaciones, cabildos o comunidades autónomas como impulsoras de estos mecanismos.

\subsection{Conclusiones: Paradigmas de la Transición Hidrológica y la Nueva Gobernanza}

Sintetizando todo lo planteado:

- La resiliencia ante el cambio climático implica reorientar la planificación hidrológica (Tercer ciclo) y sus decisiones especialmente en las referentes a ejecución de nuevas infraestructuras. 
- Sobre esta base debe orientarse una cohesión social y territorial sostenida en el tiempo y sostenible en lo ambiental, aportando la necesaria seguridad en ambos aspectos.

- Esta situación hace que debamos adaptarnos a los principios marcados por la naturaleza, acoplando y armonizando nuestros objetivos a sus ciclos integrales de renovación. En suma, buscar en materia de agua la autosuficiencia en la relación uso/recurso y revisar la política de nueva construcción de infraestructuras, fomentando la inversión en infraestructuras "verdes" que coadyuven en esta política de transición hídrica, entre ellas actuaciones ligadas a restauración de riberas e hidrológico forestales y de drenaje sostenible.

- Deberá priorizarse el agua de consumo humano en cantidad y calidad garantizándose en todos sus términos sin afección o riesgo alguno obviamente sobre la salud. La deficiente calidad existente de las aguas sea por mala gestión del territorio y los ecosistemas o la falta de depuración debe ser un reto ineludible.

- Se hace urgente revisar la información existente en cuanto a calibrar los usos y presiones sobre el medio hídrico utilizando para ello todas las nuevas tecnologías disponibles que hayan mostrado eficacia.

- Auditar así la situación existente en cuanto a usos existentes (concesiones, aguas subterráneas) y su operatividad y eficiencia debe ser un punto de partida esencial. Asimismo, se hace imprescindible conocer en mayor nivel de detalle la estructura de costes de los servicios ligados al agua (incluidos los servicios ecológicos) para posteriormente definir políticas de tasas y tarifas que incentiven el uso eficiente del agua.

- Para todo ello, es imprescindible avanzar en el desarrollo de nuevas tecnologías aplicadas al ciclo del agua en sus distintos estudios: desde la incentivación de la regeneración, reutilización, desalación, control de calidad, teledetección, TICs para optimización de gestión y control de concesiones, etc...

- La coordinación entre planificaciones sectoriales (energética, agraria, territorial, ...) con la hidrológica, se revela como un aspecto central en el nuevo escenario.

- La nueva gobernanza implica por una parte mejorar la coordinación administrativa a los tres niveles (AGE, Autonómico y Local) pero también integrar más decididamente la participación ciudadana y por tanto la transparencia y rendición de cuentas en las decisiones. La reestructuración administrativa a nivel de AGE debe partir de una redefinición de las Demarcaciones Hidrográficas como centrales de seguimiento desvinculándolas del carácter inversor.

- El uso de energías renovables en la gestión del agua (desalación, regeneración, bombeos, etc...) es otro elemento básico para abaratar costes de gestión y minimizar el cambio climático. 
- La regularización de la actual gestión debe estar basado en un nuevo marco normativo global y específicamente del ciclo urbano del agua que garantice el derecho humano y establezca criterios e indicadores claros de gestión.

\section{Referencias bibliográficas}

Comisión Europea (2016): WFD Reporting Guidance 2016. Final draft 6.0.6. Abril de 2016. Comisión Europea. En: http://cdr.eionet.europa.eu/help/WFD/ WFD_521_2016

Consejo de la Unión Europea (2016): Sustainable water management - Council conclusions. (17 October 2016). En: http://data.consilium.europa.eu/doc/document/ST-13342-2016- INIT/en/pdf

Ministerio de Medio Ambiente y Medio Rural y Marino (2007): Plan Nacional de Calidad de las Aguas: Saneamiento y Depuración (2007-2015). Dirección General del Agua. En: https://www.mapama.gob.es/es/agua/planes-y-estrategias/

Ministerio de Medio Ambiente y Medio Rural y Marino (2010): Plan Nacional de Reutilización de Aguas. Dirección General del Agua. Versión preliminar de diciembre de 2010. En: https://www.mapama.gob.es/es/calidad-y-evaluacion-ambiental/participacion- publica/PP_2009P006.aspx.

Ministerio para la Transición Ecológica (2018a): Informe de seguimiento de los planes hidrológicos de cuenca y de los recursos hídricos en España (Año 2017). Dirección General del Agua. En: https://www.miteco.gob.es/es/agua/ temas/planificacion-hidrologica/planificacion- hidrologica/seguimientoplanes.asp

Ministerio para la Transición Ecológica (2018b): Síntesis de los planes hidrológicos españoles. Segundo ciclo de la DMA (2015-2021). Dirección General del Agua y Centro de Estudios Hidrográficos del CEDEX. Edita Ministerio para la Transición Ecológica. Secretaría General Técnica. Centro de Publicaciones. NIPO: 013-18-124-7.

Naciones Unidas (2015): Transforming our world: the 2030 Agenda for Sustainable Development. En: https://sustainabledevelopment.un.org/post2015/transformingourworld 


\title{
Capítulo 8 \\ La participación activa en el tercer ciclo de planificación hidrológica
}

\author{
Henar Hercilla Ventura \\ Licenciada en Ciencias Ambientales
}

\subsection{Introducción a la participación activa}

En 1998, la Comisión Económica de las Naciones Unidas para Europa promovió el Convenio sobre el acceso a la información, la participación del público en la toma de decisiones y el acceso a la justicia en materia de medio ambiente, conocido como el Convenio de Aarhus.

Dicho convenio se adaptó al reglamento europeo mediante dos directivas, la Directiva 2003/4 relativa al acceso del público a la información medioambiental y la Directiva 2003/35 por la que se establecen medidas para la participación del

Figura 8.1. Esquema temporal de las disposiciones legales en materia de participación pública

Convenio de Aarhus

\section{8}

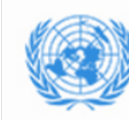

Directiva acceso a la información

Directiva participación público planes y programas

2003

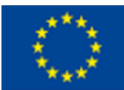

Ley 27/2006, sobre información, participación y justicia en medio ambiente 
público en la elaboración de determinados planes y programas relacionados con el medio ambiente.

Posteriormente sendas directivas fueron traspuestas al ordenamiento español en una única norma, la Ley 27/2006, de 18 de julio, por la que se regulan los derechos de acceso a la información, de participación pública y de acceso a la justicia en materia de medio ambiente.

El Convenio de Aarhus, y por ende, todas las normas que le siguieron, se basa en 3 pilares:

- el derecho al acceso a la información,

- el derecho a la participación y

- el derecho a la justicia.

De estos 3 pilares, los relativos a la participación son «el derecho a la información» y «el derecho a la participación».

\subsubsection{El derecho a la información}

El derecho a la información hace referencia a la potestad de acceder a información medioambiental por el público o las partes interesadas sin distinción, es decir, sin interés determinado o porque pueden ser afectados por alguna actividad, mediante una petición expresa a la administración competente pero también a recibir información ambientalmente relevante sin que medie una petición previa.

La administración debe facilitar la información que se requiera en el formato solicitado cuando no sea fácilmente accesible de otra manera, siendo potestad de la administración determinar si el solicitante debe pagar por ella.

El derecho de recibir información ambientalmente relevante se puede entender como una obligación para la administración, si bien no se determina legalmente que se considera relevante.

\subsubsection{El derecho a la participación}

El derecho a la participación establece que los ciudadanos puedan participar de manera efectiva y real en la elaboración, modificación y revisión de planes, programas y otras disposiciones. Esto implica que se deben habilitar los mecanismos necesarios para que puedan colaborar cuando todas las opciones estén todavía abiertas y que el resultado de los debates se hagan públicos.

\subsection{La participación en la planificación hidrológica}

La reglamentación de carácter general en materia del acceso a la información ambiental y el derecho a la participación, tuvo su reflejo evidentemente en la normativa de aguas tanto a nivel europeo como nacional. 
Así la Directiva Marco del Agua (DMA) recoge en su artículo 14 los principios de la información y consulta pública; y el Título II, sección $2^{\mathrm{a}}$ del Reglamento de la Planificación Hidrológica detalla cómo se debe organizar la participación.

\section{Artículo 14- Información y consulta públicas}

1. Los Estados miembros fomentarán la participación activa de todas las partes interesadas en la aplicación de la presente Directiva, en particular en la elaboración, revisión y actualización de los planes hidrológicos de cuenca. Los Estados miembros velarán por que, respecto de cada demarcación hidrográfica, se publiquen y se pongan a disposición del público, incluidos los usuarios, a fin de recabar sus observaciones, los documentos siguientes:

a) un calendario y un programa de trabajo sobre la elaboración del plan, con inclusión de una declaración de las medidas de consulta que habrán de ser adoptadas, al menos tres años antes del inicio del período a que se refiera el plan;

b) un esquema provisional de los temas importantes que se plantean en la cuenca hidrográfica en materia de gestión de aguas, al menos dos años antes del inicio del período a que se refiera el plan;

c) ejemplares del proyecto de plan hidrológico de cuenca, al menos un año antes del inicio del período a que se refiera el plan.

Previa solicitud, se permitirá el acceso a los documentos y a la información de referencia utilizados para elaborar el plan hidrológico de cuenca.

2. Los Estados miembros concederán un plazo mínimo de seis meses para la presentación de observaciones por escrito sobre esos documentos con objeto de permitir una participación y consulta activas.

3. Los apartados 1 y 2 serán igualmente aplicables a las actualizaciones de los planes hidrológicos de cuenca.

Extracto de la Directiva, de 23 de octubre de 2000, por la que se establece un marco comunitario de actuación en el ámbito de la política de aguas

\section{Sección 2. ${ }^{a}$ Participación pública}

Artículo 72. Organización y procedimiento para hacer efectiva la participación pública.

1. Los organismos de cuenca formularán el proyecto de organización y procedimiento a seguir para hacer efectiva la participación pública en el proceso de planificación.

2. El citado proyecto incluirá, al menos, los siguientes contenidos:

a) Organización y cronogramas de los procedimientos de información pública, consulta pública y participación activa del plan hidrológico según lo indicado en el presente reglamento.

b) Coordinación del proceso de evaluación ambiental estratégica del plan hidrológico y su relación con los procedimientos anteriores.

c) Descripción de los métodos y técnicas de participación a emplear en las distintas fases del proceso.

Artículo 73. Información pública.

1. El proceso de elaboración de los planes incorporará los requerimientos establecidos en la Ley 27/2006, de 18 de julio, en particular aquellos referentes al 
suministro activo de información sustantiva para el proceso de planificación y que resulte adicional a la enumerada en el presente reglamento.

2. Esta información deberá estar accesible en papel y en formato digital en las páginas electrónicas del Ministerio de Medio Ambiente y en las de las respectivas demarcaciones hidrográficas.

Artículo 74. Consulta pública.

1. La consulta pública se realizará sobre los documentos referidos en los artículos 77 a 80, ambos inclusive, a los que podrán añadirse otros documentos, de carácter divulgativo, que faciliten este proceso.

2. Estos documentos deberán estar accesibles en papel y en formato digital en las páginas electrónicas del Ministerio de Medio Ambiente y en las de las respectivas demarcaciones hidrográficas.

3. La duración del proceso de consulta pública de cada documento será como mínimo de seis meses. Las aportaciones de la consulta pública se integrarán en informes que formarán parte del proceso de planificación y que se recogerán en un anexo del plan.

Artículo 75. Participación activa.

1. Los organismos de cuenca fomentarán la participación activa de las partes interesadas en el proceso de planificación, extendiendo dicha participación al público en general.

2. También podrán constituir foros o grupos de trabajo en los que participen, además de las partes interesadas, personas de reconocido prestigio y experiencia en materia de aguas que asesoren en el proceso de elaboración de los planes hidrológicos.

Extracto del Real Decreto 907/2007, de 6 de julio, por el que se aprueba el Reglamento de la Planificación Hidrológica.

Dicho de otra manera la participación activa puede resumirse en los siguientes hitos:

- Dar a conocer el proceso y su alcance.

- Fomentar el intercambio de diferentes puntos de vista entre diferentes actores.

- Recoger y analizar las propuestas, observaciones y sugerencias recibidas.

\subsection{La participación en el tercer ciclo de planificación}

A pesar de que la larga tradición en la planificación y gestión del agua en España y tras dos ciclos de planificación hidrológica de acuerdo con la DMA, en los que la calidad técnica de los estudios y documentos no dejó de incrementarse, se detectó que una de las observaciones más frecuentes recibidas durante las diferentes fases de consulta pública era la necesidad de mejorar y facilitar la participación activa de las partes interesadas y el público en general. 
Con estas premisas, desde el Ministerio para la Transición Ecológica y el Reto Demográfico en estrecha coordinación con las Autoridades de Cuenca, se está impulsando la participación activa durante el tercer ciclo de planificación mediante las acciones que se describen a continuación.

\subsubsection{Favorecer la información pública}

Aunque la información siempre ha estado disponible tanto para el público en general como para las partes interesadas, se ha hecho un esfuerzo adicional para dar a conocer el proceso de planificación hidrológica al público no sensibilizado mediante la generación de vídeos divulgativos, la publicación de contenido en las redes sociales y la publicación de contenido impreso o digital que resume el contenido de la profusa documentación que se genera tanto en los Documentos Iniciales como en el Esquema provisional de Temas Importantes. Este mismo esfuerzo se realizará para la Propuesta de Plan Hidrológico.

Figura 8.2.Fotograma del video de SuperGota para los Documentos Iniciales

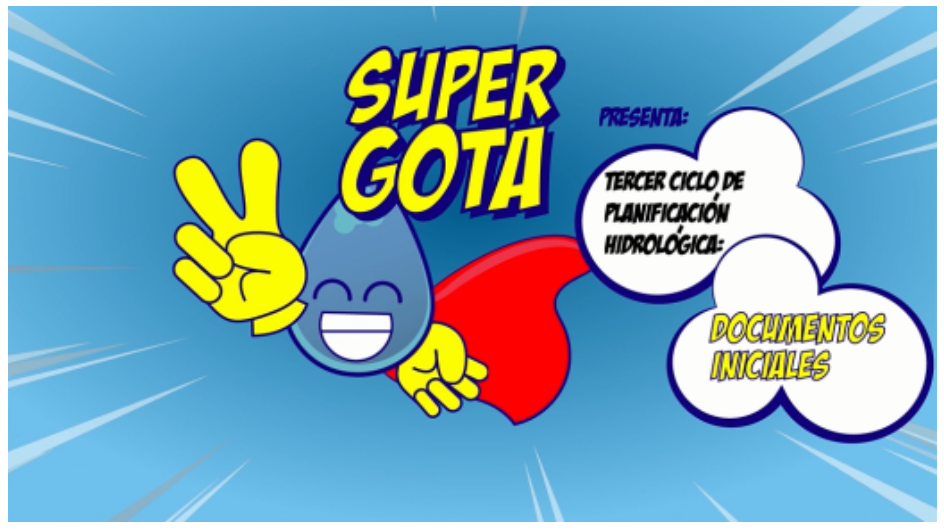

Fuente: MITECO

Figura 8.3.Fotograma del video de SuperGota para el Esquema de Temas Importantes

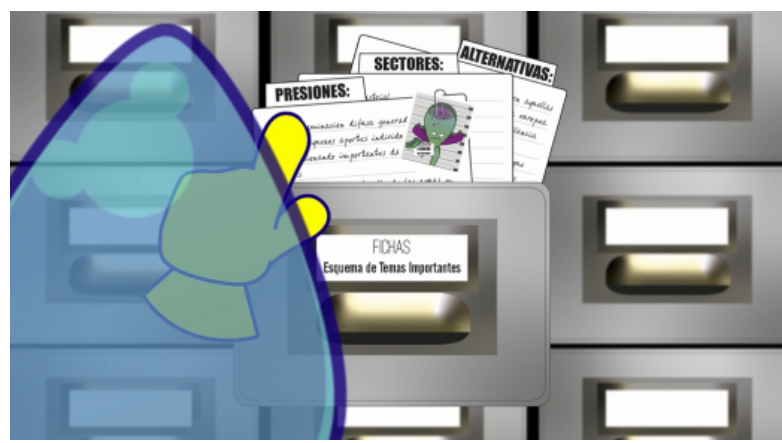

Fuente: MITECO 
Figura 8.4. Ejemplo de mensaje publicado en Twitter

Confederación Hidrográfica del Guadiana @CH_Guadiana

¿\#SabíasQue con una precipitación media anual de $650 \mathrm{~mm}$ España es uno de los países más secos de Europa? La \#PlanificaciónHidrológica permite poder atender las demandas de agua garantizando la protección del medio ambiente

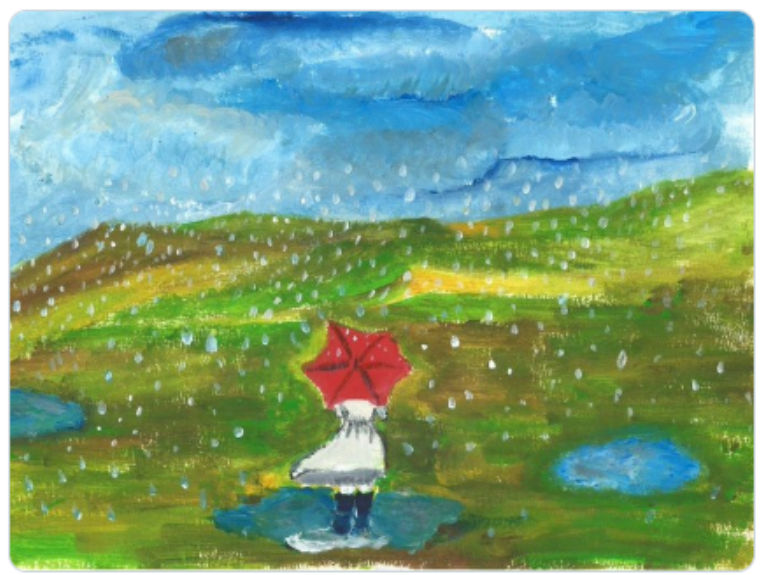

Fuente: MITECO

Figura 8.5. Página interior de un Folleto explicativo sobre los Documentos Iniciales de la demarcación del Duero

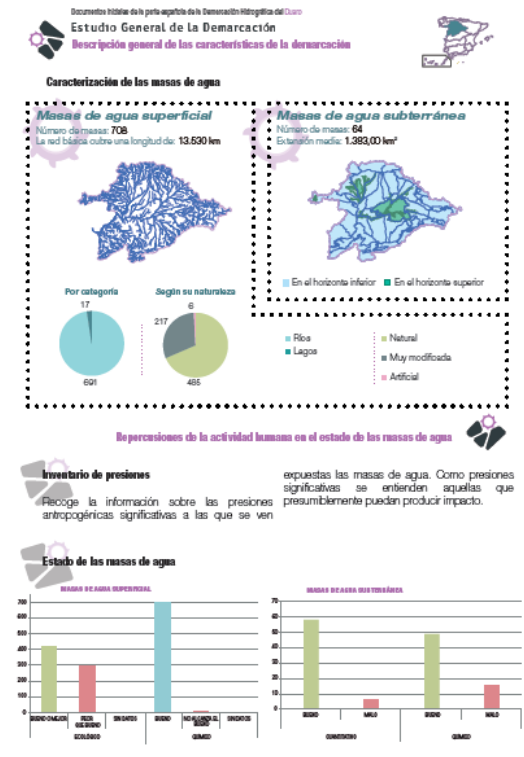

Fuente: MITECO 
Figura 8.6. Cartel explicativo del proceso de planificación

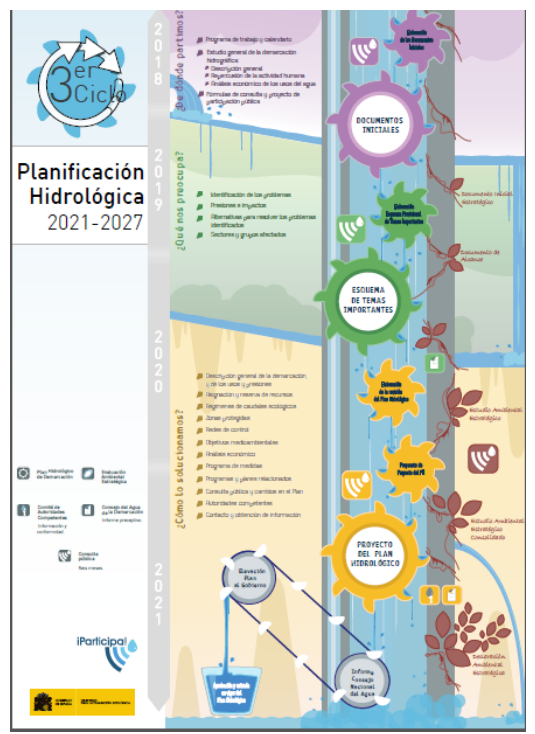

Fuente: MITECO

Figura 8.7. Contraportada del díptico sobre el Esquema de Temas Importantes del Guadiana

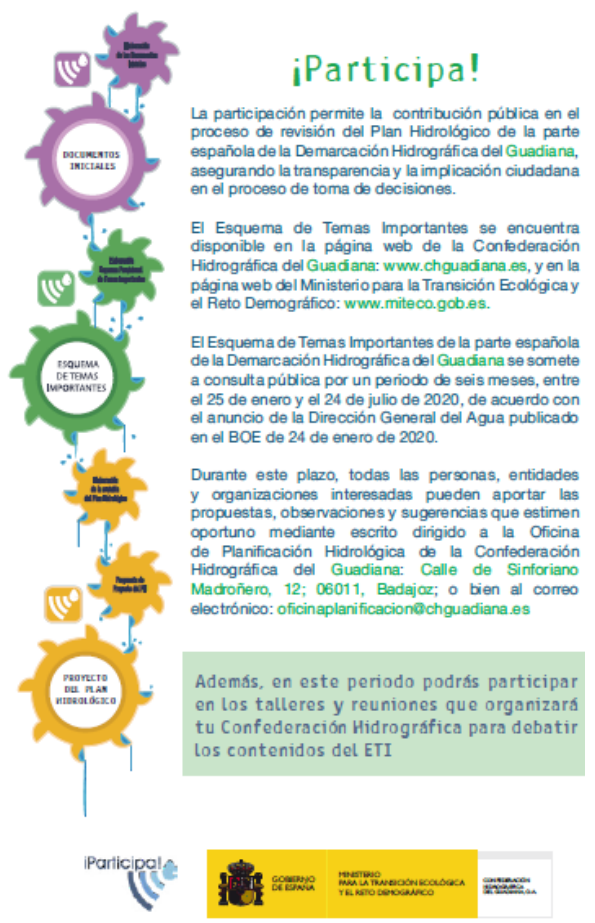




\subsubsection{Favorecer la participación activa}

Con el objetivo de favorecer la participación activa durante el proceso de consulta pública del Esquema provisional de Temas Importantes, se ha impulsado en esta etapa de la planificación hidrológica el desarrollo de talleres participativos en los que se empleen dinámicas de trabajo que centren los esfuerzos, no en dar información por parte de la Administración, sino en que los participantes aporten ideas coincidentes o no con las temáticas identificadas y alternativas propuestas en cada uno de los temas importantes.

Figura 8.8. Fotografía de un taller participativo de la Confederación Hidrográfica del Júcar

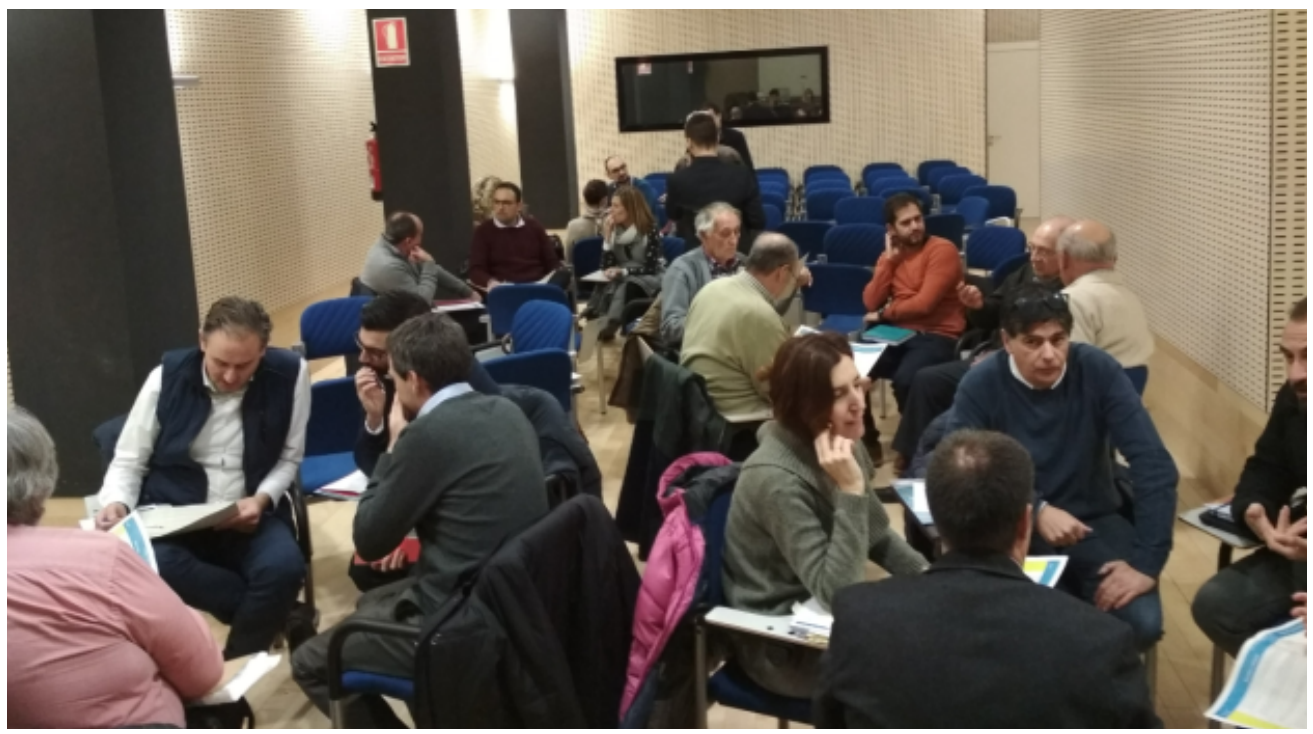

Fuente: MITECO

Expresado de otra manera, la atención en esta etapa de la planificación debe trasladarse del análisis de la realidad (normalmente realizada en los Documentos Iniciales) a los escenarios de futuro. Los participantes deben imaginar qué futuro desean y cómo lograrlo.

Para alcanzar estos objetivos, es vital crear un clima de colaboración y creatividad, para lo cual se considera imprescindible contar con equipo mediador o dinamizador especializado. Este equipo desde una postura de imparcialidad y de fomento de escucha, favorece la creación de ese clima de colaboración y creatividad, además de reconducir los debates si se pierde el foco en los asuntos previamente marcados como objetivos de trabajo.

Se ha previsto la realización de más de 40 talleres participativos en la fase de Esquema provisional de Temas Importantes y un número similar para la fase de consulta de la Propuesta del Plan Hidrológico en las demarcaciones intercomunitarias. 


\title{
Capítulo 9 \\ SSD en el marco de la DMA. Experiencia en España y aplicación en otros países
}

\author{
Jesús Mora Colmenar \\ Ingeniero de Caminos, Canales y Puertos \\ Álvaro Rodríguez García \\ Ingeniero de Caminos Canales y Puertos \\ María Alcaraz Boscá \\ Ingeniera de Caminos, Canales y Puertos \\ Antonio Benítez González \\ Ingeniero Técnico de Obras Públicas
}

\subsection{Introducción}

La Directiva 2000/60/CE del Parlamento Europeo y del Consejo de 23 de octubre de 2000 por el que se establece un marco comunitario de actuación en el ámbito de la política de aguas (denominada Directiva Marco del Agua, DMA) traspuesta a la legislación española mediante la Ley 62/2003, de 30 de diciembre, de medidas fiscales, administrativas y del orden social, establece entre sus objetivos los siguientes: prevenir el deterioro y mejorar el estado de los ecosistemas acuáticos y promover el uso sostenible del agua.

La citada DMA establece en su artículo 13 la necesidad de elaborar un plan hidrológico para cada demarcación hidrográfica, que debe ser revisado cada seis años. Los planes hidrológicos españoles deben atender no sólo a los requerimientos de la DMA, sino a la propia legislación española, que establece en el artículo 40 del TRLA que son también objetivos de la planificación «la satisfacción de las demandas de agua, el equilibrio y armonización del desarrollo regional y sectorial, incrementando las disponibilidades del recurso», por lo que los planes hidrológicos españoles presentan en la asignación y reservas de los recursos una de sus partes fundamentales además de aquellas necesarias para cumplir con la DMA, como es el análisis de presiones impactos, estado, objetivos y medidas para alcanzar los objetivos medioambientales.

Para que se alcancen los objetivos de la Directiva es necesario establecer y desarrollar un Programa de Medidas que pretenda contribuir a alcanzar el objetivo del buen estado ecológico que la Directiva Marco del Agua propugna para el año 2015, así como cumplir otras Directivas anteriores, caso de la Directiva 91/271.

\subsection{La necesidad de empleo de SSD}

El contenido de los planes viene recogido en el Real Decreto 907/2007, de 6 de julio, por el que se aprueba el Reglamento de la Planificación Hidrológica y se muestra en la figura siguiente: 
Figura 9.1 Contenido de los planes hidrológicos conforme a la DMA y la legislación española

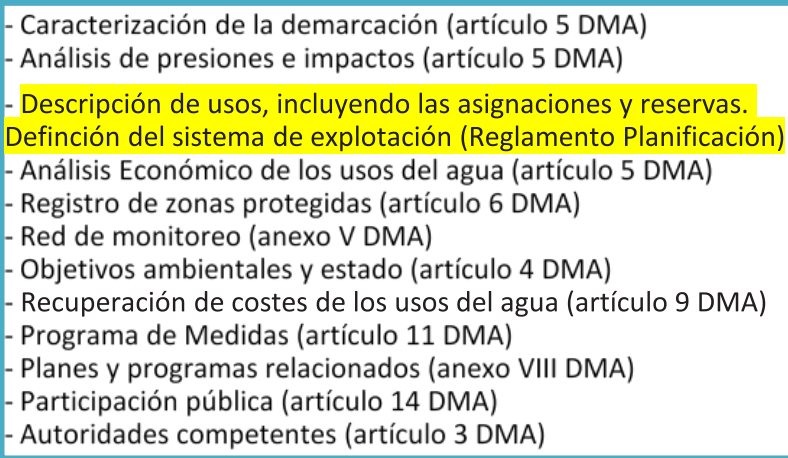

Fuente: Elaboración propia

Tal y como se ha expuesto anteriormente, los planes hidrológicos españoles no sólo necesitan cumplir con los objetivos medioambientales de la DMA, sino que presentan también como objeto de planificación «la satisfacción a las demandas, [...] incrementando las disponibilidades del recurso, protegiendo su calidad, economizando su empleo y racionalizando sus usos en armonía con el medio ambiente» (art 40 TRLA). Esta doble vertiente de los planes españoles ha sido a veces considerada como un problema de cierta «bicefalia» por parte de los técnicos de la Comisión Europea.

Para la fijación de las asignaciones y reservas en los planes hidrológicos, la Instrucción de Planificación Hidrológica, publicada por la Orden ARM/2656/2008, de 10 de septiembre, establece la necesidad de establecer sistemas de explotación que puedan ser simulados mediante herramientas matemáticas. La complejidad de los sistemas de explotación, la mezcla de recursos de distintos orígenes, las diferentes variables y reglas de gestión hacen inviable un análisis de asignaciones y reservas sin acudir a este tipo de herramientas matemáticas.

Figura 9.2 Objetivo del empleo de los SSD en el proceso de planificación

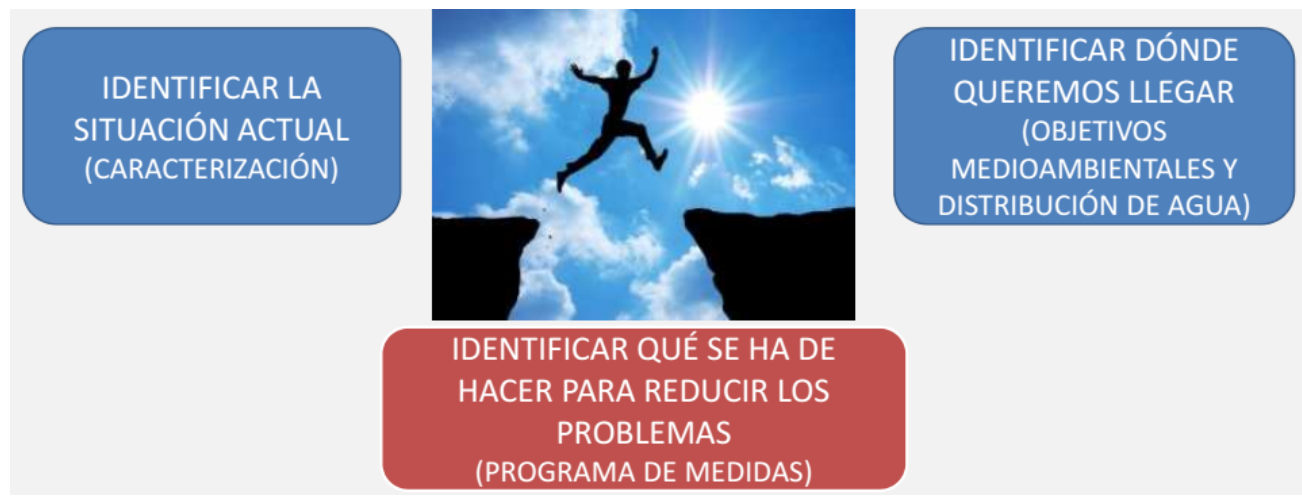

Fuente: Elaboración propia 
Por otro lado, para que se alcancen los objetivos de la Directiva es necesario establecer y desarrollar un Programa de Medidas que pretendan contribuir a alcanzar el objetivo del buen estado ecológico que la Directiva Marco del Agua propugna para el año 2015, así como cumplir otras Directivas anteriores, caso de la Directiva 91/271.

Figura 9.3. Principales aspectos del plan hidrológico en los que es necesario el empleo de SSD

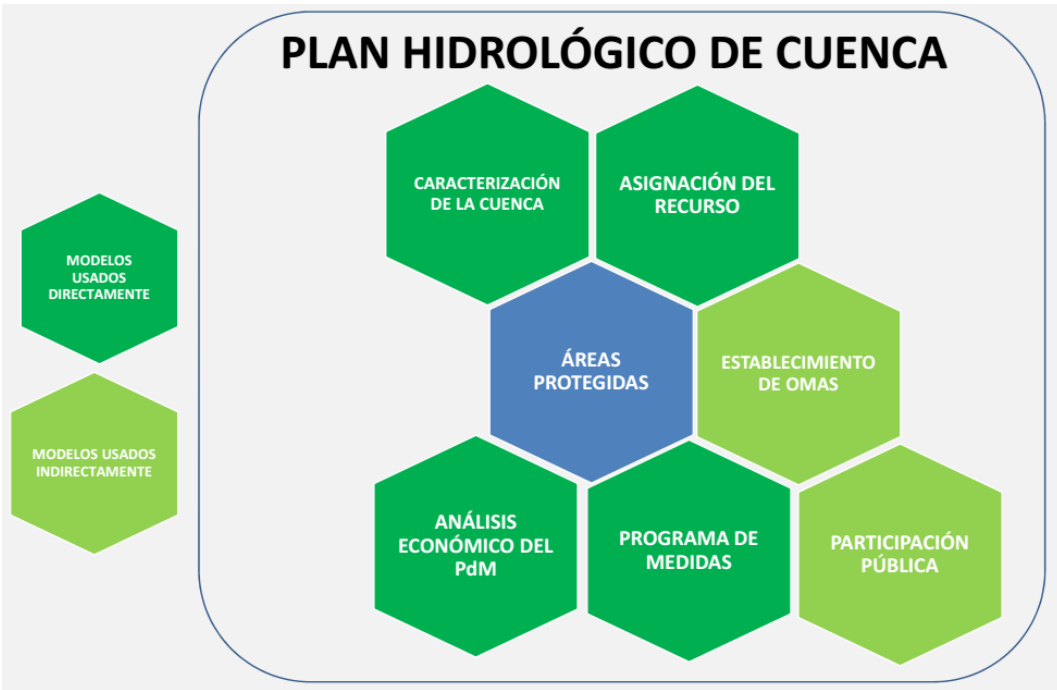

Fuente: Elaboración propia

Para un correcto establecimiento del Programa de medidas, es necesario modelizar la cantidad y calidad del agua evaluando el estado fisicoquímico de las masas de agua esperable tras la aplicación de una batería de medidas y analizar la eficiencia de las mismas propuestas para alcanzar el buen estado fisicoquímico en aquellas masas de agua que no lo alcancen. Las herramientas matemáticas se consideran la mejor opción para abordar estas tareas ya que permiten reproducir el comportamiento de un sistema hídrico en función de distintas expresiones matemáticas y sus parámetros para representar distintas alternativas de medidas.

En síntesis, las herramientas matemáticas nos permiten caracterizar la situación actual donde no hay información, asignar el recurso y ayudar a evaluar la eficacia del Programa de medidas.

\subsection{SSD más empleados - AQUATOL}

De todas las herramientas matemáticas disponibles, el entorno AQUATOOL es el Sistema de Soporte a la Decisión (SSD) más ampliamente empleado en España 
y ha sido desarrollado por el Departamento de Ingeniería Hidráulica y Medio Ambiente de la Universidad Politécnica de Valencia (https://aquatool.webs.upv.es/ aqt/). El SSD AQUATOOL dispone de varios módulos, de entre los cuales se han empleado más profusamente los siguientes:

- Módulo EVALHID (EVALuación de los recursos HíDricos) que permite el desarrollo de Modelos Precipitación-Escorrentía en cuencas complejas

- Módulo SIMGES de simulación de la gestión de cuencas, con el que se pueden simular sistemas de explotación complejos, en los que se incluyan elementos de regulación, transporte, demandas, acuíferos, reglas de explotación, etc.

- Módulo OPTIGES de optimización del reparto de recurso conociendo los recursos futuros. No incluye al sistema subterráneo. Empleado en Planes del año 1998 (Segura) y Plan Hidrológico Nacional, pero no en los planes bajo la DMA.

- Módulo GESCAL de evaluación de la calidad del agua a nivel de cuenca.

La mayor ventaja en el empleo del SSD-AQUATOOL la constituye su amplia experiencia de más de 30 años de aplicación a demarcaciones hidrográficas en casos reales de planificación en cuencas españolas (Júcar, Segura, Duero, Tajo, etc.), mediterráneas (Marruecos, Argelia, Bosnia, Italia y Turquía) e iberoamericanas (Argentina, Brasil, México, Chile, Ecuador, Perú, etc.), gracias a la robustez de los modelos y su flexibilidad para implementarse en muy diferentes demarcaciones.

Figura 9.4. Principales modelos del SSD Aquatool empleados en el proceso de planificación

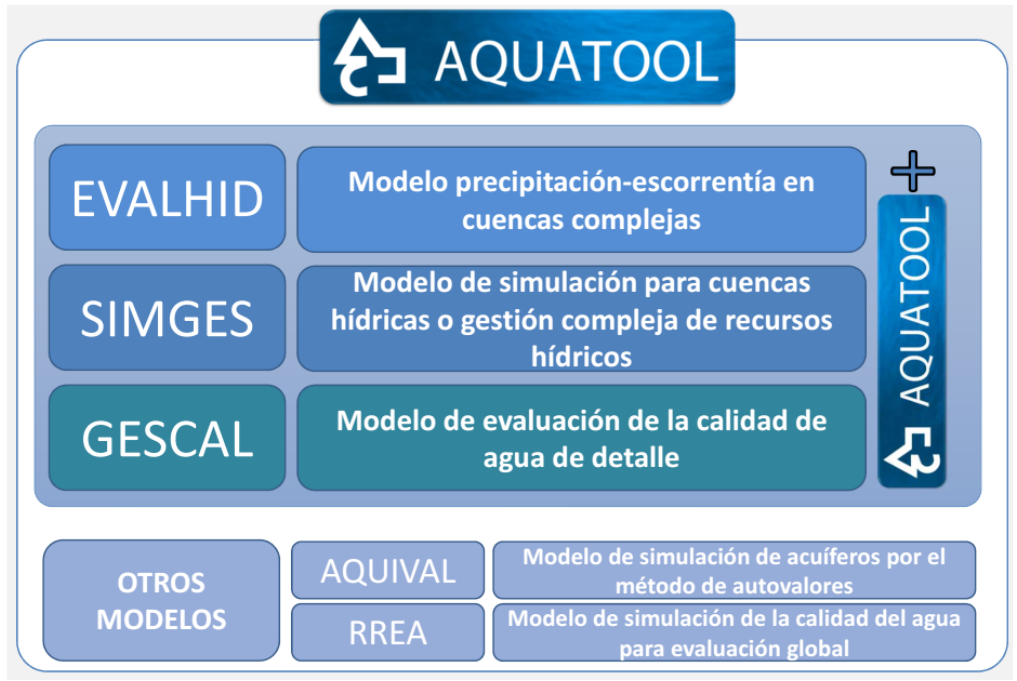

Fuente: Elaboración propia 
Además del SSD AQUATOOL es necesario reseñar la importancia en España del «Sistema Integrado de Modelación Precipitación Aportación» SIMPA (Cabezas et al., 1999; Ruiz, 1998; Estrela y Quintas, 1996), modelo de precipitación-escorrentía que reproduce los procesos esenciales de transporte de agua que tienen lugar en las diferentes fases del ciclo hidrológico y ampliamente usado en el proceso de planificación para evaluar los recursos en régimen natural en España (Libro Blanco del Agua, Plan Hidrológico Nacional, planes hidrológicos del I y II ciclo).

Por último, el modelo «Precipitación Aportación en Tramos de Red Integrados con Calidad del Agua», PATRICAL (Pérez, 2005) permite construir modelos del ciclo hidrológico y calidad de las aguas distribuidos espacialmente, con paso de tiempo de simulación mensual, ha sido desarrollado por el Departamento de Ingeniería Hidráulica y Medio Ambiente de la Universidad Politécnica de Valencia y ha sido empleado en los procesos de planificación españoles en la simulación del contenido de nitratos en las masas de agua subterránea.

\subsection{Ejemplos de simulaciones de cantidad - SIMGES}

El modelo SIMGES es un modelo de simulación de la gestión de sistemas de agua complejos, incluyendo acuíferos y está basado en la optimización de una red de flujo más las reglas de gestión definidas por el usuario. La simulación y gestión del subsistema de superficie son simulados simultáneamente mediante un algoritmo de optimización de red de flujo de tipo conservativo. Los usos que presenta el modelo son:

- Modelos de balance hídrico: garantía de las demandas y establecimiento de asignaciones y reservas

- Análisis de sequías

- Dimensionamiento de infraestructuras

- Impacto del cambio climático

- Impacto de caudales ambientales

Los requerimientos de la Instrucción de Planificación en lo referente a la simulación de sistemas de explotación (apartado 3.5.1.2.) han hecho que la práctica totalidad de las demarcaciones hidrográficas españolas hayan empleado SIMGES para simularlos, tanto en el marco de los planes hidrológicos como en el de los Planes Especiales de Sequía, revisados por la Orden TEC/1399/2018, de 28 de noviembre.

De entre los modelos desarrollados en los distintos planes hidrológicos, es destacable el caso del sistema de explotación único de la cuenca del Segura, en el que se simulan hasta 6 orígenes de recurso diferentes para una única unidad de demanda, lo que muestra el extremo de complejidad que se alcanza en la simulación de estos sistemas. 
Figura 9.5. Principales datos de entra y salida del modelo SIMGES

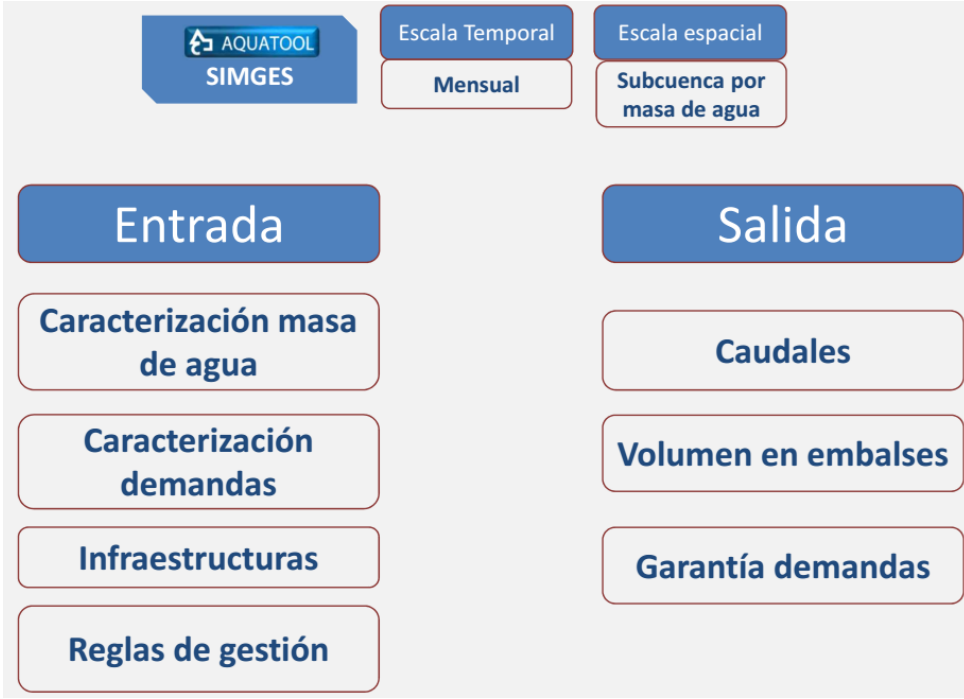

Fuente: Elaboración propia

Figura 9.6 Detalle del modelo del sistema de explotación del Segura

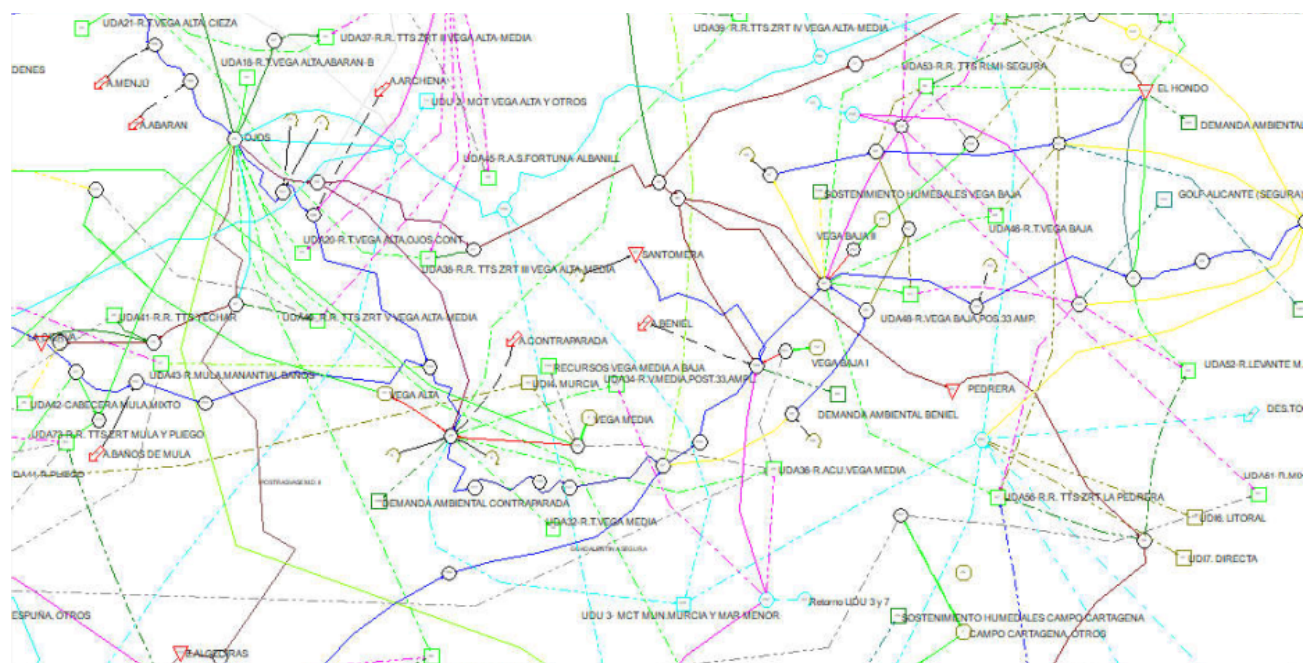

Fuente: OPH de la CHS (2016)

En otros sistemas de explotación, caso de las cuencas mesetarias, es el gran número de elementos a simular (942 conducciones, 97 embalses, 565 demandas consuntivas y 143 centrales hidroeléctricas en el caso del Duero) la principal causa de que sólo con el empleo de SSD se pueda abordar el análisis de los sistemas. 
Figura 9.7. Modelo de simulación de la demarcación del Duero

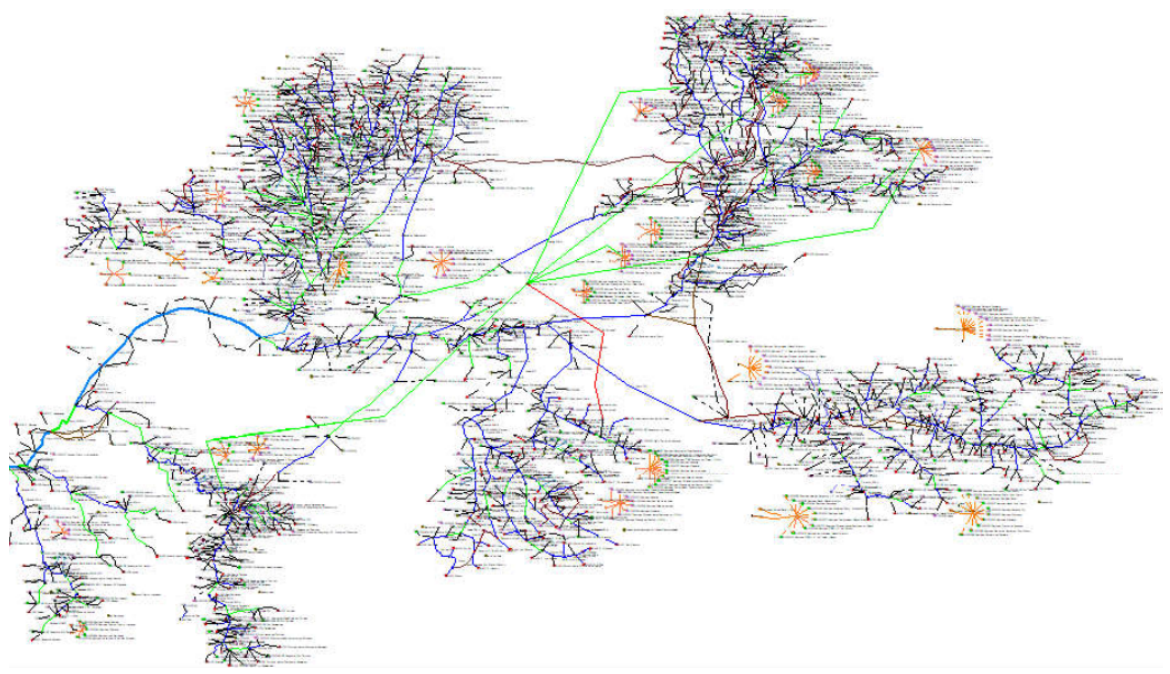

Fuente: OPH de la CHD (2016)

Una de las últimas aplicaciones en las demarcaciones españolas del modelo SIMGES ha sido la fijación de umbrales de escasez en los Planes especiales de sequía revisados en 2018. A título de ejemplo, en la demarcación del Guadiana y para sistemas con regulación y uso mixto (abastecimiento y regadío) se ha empleado el modelo SIMGES para aplicar los criterios expuestos en la tabla siguiente.

Figura 9.8 Criterios para el establecimiento de umbrales en situación de escasez y resultado de los umbrales en la UTE 20 Valuego-Brovales

\begin{tabular}{|c|c|c|c|c|c|c|}
\hline & \multicolumn{6}{|c|}{ SISTEMAS MIXTOS } \\
\hline & $\begin{array}{c}\text { PERIODO } \\
\text { CONSIDERADO }\end{array}$ & $\begin{array}{l}\text { SERIE } \\
\text { APORTACIONES } \\
\text { CONSIDERADA }\end{array}$ & $\begin{array}{c}\text { ATENCIÓN } \\
\text { DEMANDAS } \\
\text { ABASTECIMIENTO }\end{array}$ & $\begin{array}{c}\text { ATENCIÓN } \\
\text { DEMANDAS RIEGO }\end{array}$ & $\begin{array}{l}\text { ATENCIÓN } \\
\text { OTRAS } \\
\text { DEMANDAS }\end{array}$ & $\begin{array}{l}\text { CUMPLIMIENTO } \\
\text { REQUERIMIENTOS } \\
\text { AMBIENTALES }\end{array}$ \\
\hline PREALERTA & 3 años & \begin{tabular}{|c|} 
años más \\
secos 1980/81- \\
$2011 / 12$
\end{tabular} & 3 años $100 \%$ & $\begin{array}{l}2 \text { años } 100 \% \text { y el } \\
\text { tercero riegos } \\
\text { permanentes* }\end{array}$ & $\begin{array}{l}3 \text { años } \\
100 \%\end{array}$ & $100 \%$ \\
\hline ALERTA & 2 aก̃os & \begin{tabular}{|c|}
2 años más \\
secos $1980 / 81-$ \\
$2011 / 12$ \\
\end{tabular} & 2 años $100 \%$ & $\begin{array}{l}\text { Primer año } 100 \% \text { y el } \\
\text { segundo riegos } \\
\text { permanentes* }\end{array}$ & $\begin{array}{l}2 \text { años } \\
100 \%\end{array}$ & $100 \%$ \\
\hline EMERGENCIA & 2 años & \begin{tabular}{|c|}
2 años más \\
secos $1980 / 81-$ \\
$2011 / 12$
\end{tabular} & 2 aก̃os $100 \%$ & $\begin{array}{l}\text { Primer año } 50 \% \text { y el } \\
\text { segundo riegos } \\
\text { permanentes* }\end{array}$ & $\begin{array}{l}2 \text { años } \\
100 \%\end{array}$ & $100 \%$ \\
\hline
\end{tabular}
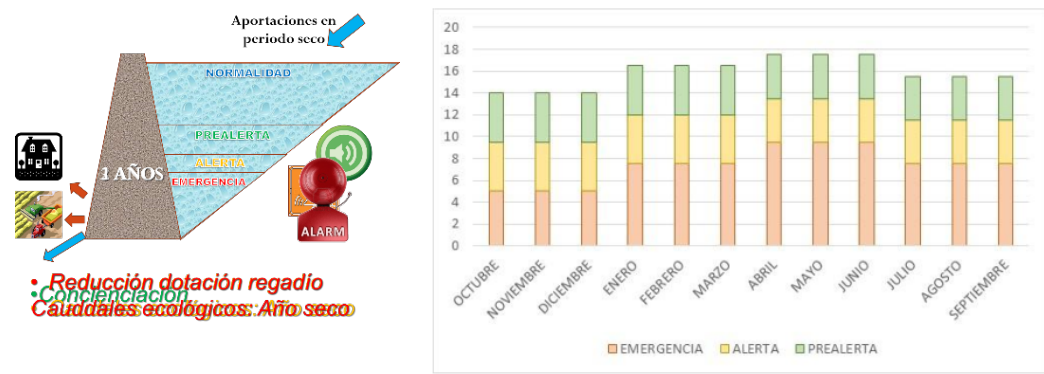

Fuente: PES de la demarcación del Guadiana (2018) 
El módulo SIMGES puede ampliarse con otros módulos como el CAUDECO y ECOWIN. El módulo CAUDECO permite la estimación de las Series Temporales de Hábitat (STH) y de las Curvas de Duración de Hábitat (CDH) para diferentes etapas vitales de diversas especies piscícolas en varias masas de agua, conocidos los caudales circulantes por las mismas. De esta forma puede analizarse de forma conjunta el hábitat de las especies piscícolas y la afección a los usuarios que presentan los caudales circulantes, para su empleo en el establecimiento de los caudales ambientales. Este módulo ha sido empleado a escala de cuenca en la demarcación del Duero.

El módulo ECOWIN permite la valoración económica de los recursos asignados por SIMGES a las distintas demandas para cada escenario y permite establecer el Coste Marginal de Oportunidad del Recurso (CMOR) en los embalses del sistema. Este coste de oportunidad puede emplearse como una aproximación al coste del recurso, tal y como se describe en la Guía WATECO de Análisis Económico en la DMA. El módulo ECOWIN ha sido implementado a nivel de cuenca en la demarcación del Segura y en la cuenca del Serpis.

\subsection{Ejemplos de simulaciones de calidad- GESCAL}

La herramienta GESCAL ha sido utilizada para la modelación de la calidad del agua a escala de cuenca en diversas demarcaciones, como por ejemplo Segura, Júcar, Tajo y Duero. Esta herramienta permite la representación esquematizada de las principales infraestructuras de la realidad del sistema a modelar con sus características de funcionamiento al que se le añade información referente a la calidad de las aguas que se pretende simular, así como de los vertidos existentes. No pretende representar la evolución de la calidad del agua frente a eventos puntuales sino, por el contrario, reflejar la evolución espaciotemporal de la calidad del agua en los sistemas modelados, fruto de las diferentes alternativas de gestión, depuración, contaminación y uso del recurso.

También permite la modelación de los constituyentes convencionales con un doble objetivo: por un lado, se busca sencillez a la hora de modelar de una manera coherente con la escala de trabajo y, por otro, se intenta no perder representatividad ni capacidad de modelación.

El modelo de simulación de la calidad de las aguas estima la evolución de una serie de constituyentes fisicoquímicos que serán los utilizados para evaluar el estado de las masas de agua. La herramienta permite seleccionar los constituyentes fisicoquímicos y añadir cualquier otro componente arbitrario considerando un proceso de descomposición modelado mediante una cinética de primer orden y un proceso de sedimentación de la parte particulada, de la forma:

\section{Ecuación 9.1}

$$
\sum W_{i}=-K \cdot\left(\theta^{T-20}\right) \cdot C-\frac{V_{S}}{h} \cdot C
$$

donde $\mathrm{K}$ representa la constante de descomposición a $20^{\circ} \mathrm{C}$ (dia-1), $\theta$ es el coeficiente por corrección de temperatura, Vs es la velocidad de sedimentación del 
constituyente (m/día), h es el calado del río (m) y C es la concentración del contaminante en el río $(\mathrm{mg} / \mathrm{l})$.

Los constituyentes utilizados en las simulaciones realizadas en las demarcaciones españolas han sido generalmente: oxígeno disuelto, demanda biológica de oxígeno (DBO5), amonio, nitratos, conductividad, sólidos en suspensión y fosfatos (como constituyente arbitrario).

En la implementación de este modelo es fundamental disponer de suficientes datos de control para poder realizar una correcta calibración, en primer lugar, de caudales circulantes y en segundo lugar de la propia calibración fisicoquímica. Este proceso consiste en concretar el valor de las distintas constantes que componen la formulación matemática de los distintos parámetros a simular.

Tabla 9.1. Constantes de calibración empleadas en la simulación de la demarcación del Segura

\begin{tabular}{|c|c|c|}
\hline Parámetro & $\begin{array}{l}\text { Constante descomposición } \\
\text { (1/día) }\end{array}$ & $\begin{array}{l}\text { Constante velocidad } \\
\text { sedimentación (m/día) }\end{array}$ \\
\hline Oxígeno Disuelto & $\mathrm{K}_{\mathrm{a}}$ : Reaireación & \\
\hline $\mathrm{DBO}_{5}$ & $\begin{array}{l}\mathrm{K}_{\mathrm{d}} \text { : Descomposición de la } \\
\text { materia orgánica carbonosa }\end{array}$ & $\begin{array}{l}\mathrm{V}_{\mathrm{SL}} \text { : Velocidad de sedimentación } \\
\text { de la materia orgánica carbonosa }\end{array}$ \\
\hline $\begin{array}{l}\text { Nitrógeno Orgánico } \\
\text { (Norg) }\end{array}$ & $\mathrm{K}_{\text {noa }}$ : Hidrólisis del Norg. & $\begin{array}{l}\mathrm{V}_{\mathrm{SNO}}: \text { Velocidad sedimentación } \\
\text { Norg }\end{array}$ \\
\hline Nitratos & $\mathrm{K}_{\mathrm{Nai}}:$ Nitrificación amonio & \\
\hline $\begin{array}{l}\text { Sólidos } \\
\text { Suspendidos (SS) }\end{array}$ & & $\begin{array}{l}\mathrm{V}_{\text {sS }}: \text { Velocidad de sedimentación } \\
\text { SS }\end{array}$ \\
\hline Fosfatos & $\begin{array}{l}\mathrm{K}_{\mathrm{P}} \text { : Descomposición del } \\
\text { fosfato }\end{array}$ & $\begin{array}{l}\mathrm{V}_{\mathrm{p}} \text { : Velocidad sedimentación } \\
\text { fosfato }\end{array}$ \\
\hline
\end{tabular}

Figura 9.9 Oxígeno disuelto observado y simulado en la ICA Embalse de la Fuensanta

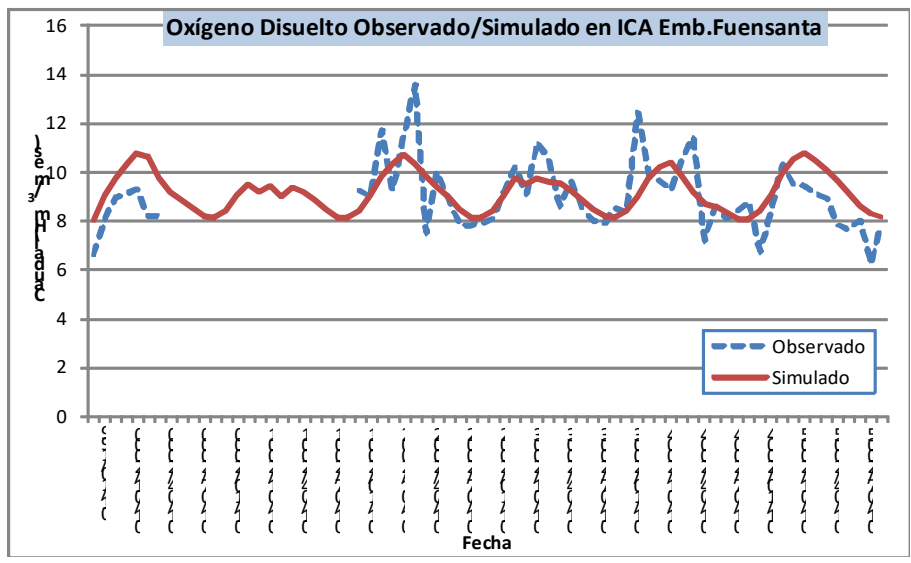


Una vez calibrado el modelo, se pueden crear distintos escenarios de simulación adicionales para comprobar la eficacia de las medidas propuestas en el programa de medidas del plan hidrológico. Para el caso particular de la demarcación del Segura, los escenarios contemplados en el proceso de planificación han sido:

- Escenario Tendencial Base: Se somete al modelo a las condiciones y cargas contaminantes esperadas para el horizonte 2015 de acuerdo con el borrador del Plan Nacional de Calidad y de la información proporcionada por las entidades de gestión de aguas residuales ESAMUR y EPSAR para las provincias de Murcia y Alicante, respectivamente.

- Medida Complementaria sobre vertidos significativos (escenario 1): Al escenario tendencial base anterior se le añade la condición de que todas las EDARs que vierten más de $250.000 \mathrm{~m}^{3}$ /año tengan tratamiento terciario, consistente en una filtración por arena de la totalidad del efluente de las EDARs, y un tratamiento avanzado de eliminación de nutrientes.

- Medida Complementaria sobre vertidos significativos (escenario 2): Esta medida complementa y es adicional a la anterior, de modo que todos los vertidos de estas provincias sean tratados por las estaciones depuradoras de titularidad municipal y gestionadas por ESAMUR y EPSAR, reduciéndose la contaminación en los tramos de río afectados.

Figura 9.10 Resultados finales del escenario de medidas complementarias 2 en el modelo de calidad del Segura

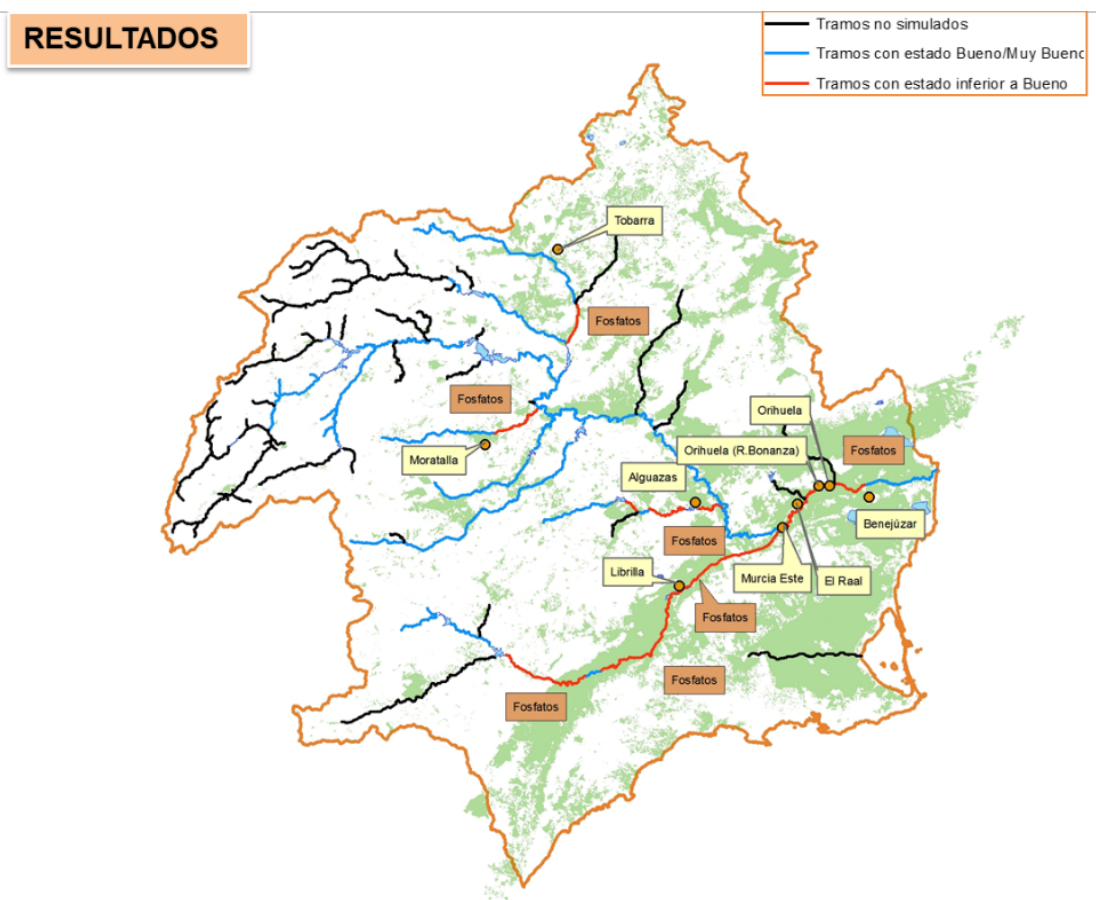

Fuente: OPH de la CHS (2016) 


\subsection{Modelos numéricos aplicados en demarcaciones turcas}

El SSD AQUATOOL ha sido aplicado por el consorcio formado por las empresas españolas Initec Infraestructuras (grupo Técnicas Reunidas) y Tragsatec, junto con la empresa turca Su-Yapı, en el desarrollo exitoso de los primeros planes hidrológicos de cuenca bajo la Directiva Marco del Agua (DMA) en cuatro demarcaciones hidrográficas de Turquía (http://ribamap.ormansu.gov.tr/index). Este proyecto se desarrolló durante el periodo 2014-2018.

Los modelos numéricos fueron empleados durante la Caracterización de la Demarcación y el diseño del Programa de Medidas, siendo uno de los ejes angulares sobre los que se fundamentó el desarrollo del proyecto.

Se implementaron modelos de precipitación-escorrentía, cantidad y calidad mediante el entorno AQUATOOL y modelos específicos de calidad de indicadores biológicos mediante el desarrollo de modelos matemáticos de redes neuronales llamado PUNN (Product Unit Neuronal Network)

El modelo matemático PUNN es una red neuronal cuyo objetivo es obtener fórmulas matemáticas que describan el comportamiento de un determinado parámetro a partir de otros factores, cuyos valores sean conocidos. En este caso se empleó para estimar el valor de indicadores biológicos.

La siguiente figura trata de clarificar el proceso seguido en la caracterización de la demarcación y el papel que los distintos modelos han tenido.

Figura 9.11 Uso de los modelos numéricos en la caracterización de la demarcación

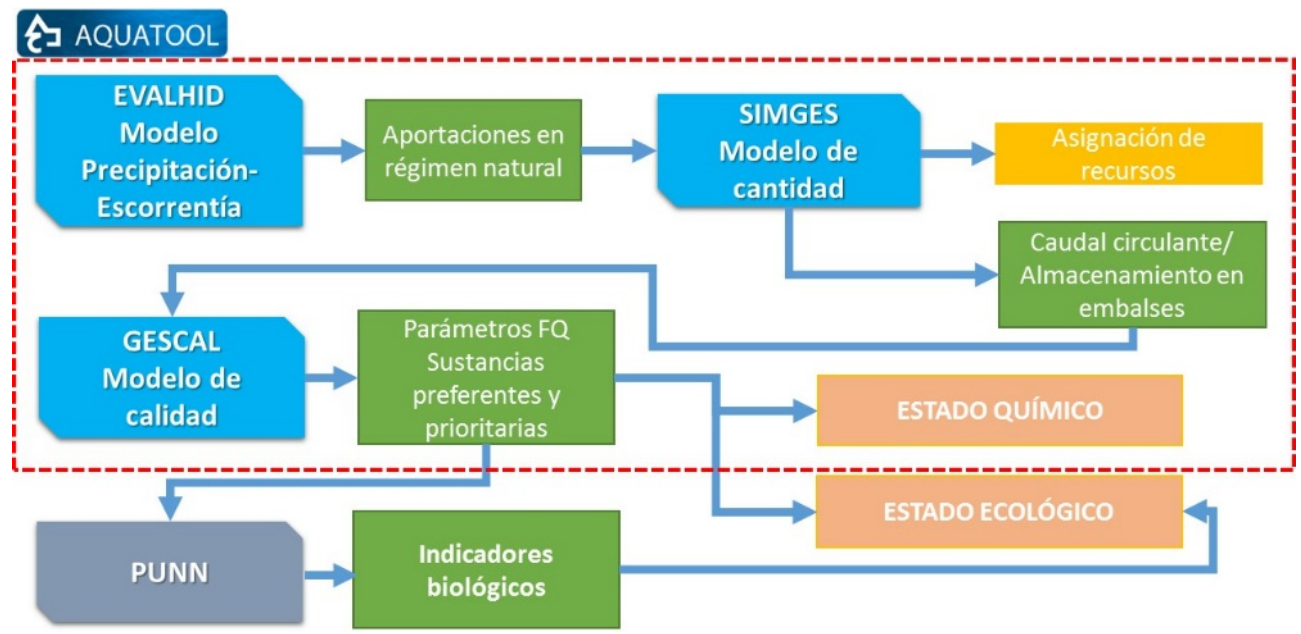

Fuente: Elaboración propia

El módulo EVALHID permite estimar las aportaciones de recursos hídricos en régimen natural y la infiltración de lluvia en una cuenca a partir de datos de precipitación, temperatura del aire, evapotranspiración potencial y superficie de las subcuencas. Para calcular la escorrentía, el módulo EVALHID permite ele- 
gir entre tres modelos de precipitación-escorrentía distintos: Sacramento, HBV y Témez. En este caso, se optó por el modelo HBV.

Los resultados fueron calibrados con datos de estaciones de aforo existentes que reflejaban el régimen natural. Sin embargo, no se disponía de muchas estaciones de aforo válidas, que permitieran una correcta calibración situadas en masas de agua y en zonas sin afecciones antrópicas pues la mayoría de las estaciones de aforo estaban situadas aguas abajo de embalses. No obstante, los valores de las estaciones más antropizadas fueron contrastados con los valores obtenidos en régimen natural para comprobar la alteración de estas.

El módulo SIMGES simula la gestión de recursos hídricos en sistemas hidráulicos complejos. En este caso y a diferencia de los planes hidrológicos españoles, el módulo SIMGES se empleó como un paso previo a la implementación del módulo de calidad GESCAL, pero no constituía un fin en sí mismo ya que la gestión de recursos no forma parte de la DMA. Las aportaciones en régimen natural obtenidas en EVALHID fueron un dato de entrada en el módulo de cantidad SIMGES, y el objetivo de este modelo fue obtener un régimen de caudales similar al régimen alterado, de modo que sirviera de base para la realización del modelo de calidad, realizado con el módulo GESCAL.

Figura 9.12 Esquema del modelo de simulación SIMGES de la cuenca de Konya (izq.) y ejemplo de calibración del modelo EVALHID (der.)

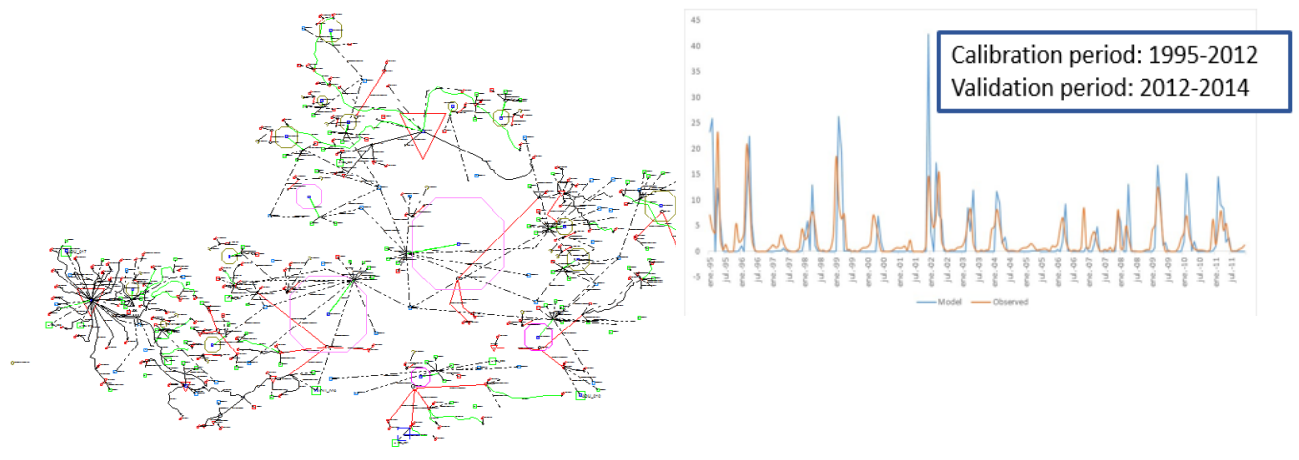

Fuente: Elaboración propia

El siguiente paso consistió en la implementación del módulo de calidad GESCAL que permite estimar la concentración de parámetros fisicoquímicos, así como de sustancias prioritarias y preferentes en las masas de agua superficiales. Este módulo fue empleado tanto en la caracterización de la demarcación, como en el análisis de la eficacia del programa de medidas, tal y como se ha descrito previamente. Los modelos GESCAL fueron calibrados mediante los datos de recogidos durante las campañas de monitoreo.

Finalmente, el modelo de redes neuronales llamado PUNN se empleó para modelizar indicadores biológicos (peces, fitobentos, macrófitos y macroinvertebrados) a partir de los valores fisicoquímicos y otros parámetros, como el caudal 
circulante en cada masa de agua respecto al régimen natural, obtenidos mediante la implementación de modelos AQUATOOL.

Las masas de agua se clasificaron en función de sus características y tipología (lagos, ríos en zonas de cabecera, ríos en zonas bajas, etc.) y se obtuvieron las respectivas fórmulas de indicadores biológicos. Estas fórmulas son útiles para estimar el estado ecológico de las masas de agua superficiales en las que no existan datos de monitoreo.

Figura 9.13 Ejemplo de resultados obtenidos PUNN: Fitobentos en masas de agua situadas en tramos bajos de la cuenca de Susurluk

\section{Slow Flowing Rivers: Phytobenthos}

\section{Susurluk}

\begin{tabular}{|l|l|l|}
\hline \multirow{2}{*}{ EQR (at slow flowing rivers) } & \multicolumn{2}{|l|}{ Training and validation set } \\
\cline { 2 - 3 } & RMSE & coeff. of determ. $\mathbf{R}^{2}$ \\
\hline Phytobenthos & $\mathbf{0 . 1 5 5 8}$ & $\mathbf{0 . 6 3}$ \\
\hline
\end{tabular}

$E Q R_{\text {Phyt.b }}=-0.0588+3.1951 \frac{\operatorname{COD}^{2.0832} \operatorname{Cond}^{1.9280} \text { Tox }^{6.3297} \operatorname{SS}^{1.1353}}{T^{0.3467} N_{\text {tot }}^{0.8659} P_{\text {tot }}^{2.0278} A_{F} R^{12.1427}}$

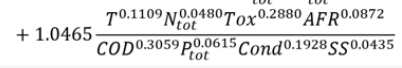

\section{Susurluk}

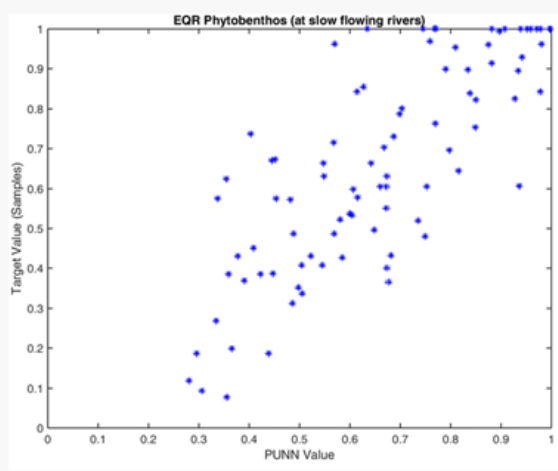

Fuente: Elaboración propia

El proceso seguido para identificar y definir las medidas del PdM se muestra en la figura anterior siguiente. En primer lugar, se identificaron las medidas básicas, en base al cumplimiento de la legislación vigente. Una vez definidas las medidas básicas, se estimó el efecto de estas sobre las masas de agua mediante el uso del modelo de simulación de calidad GESCAL. En aquellas masas en las que con la aplicación de las medidas básicas no era posible alcanzar los OMA, se definieron posibles medidas complementarias.

La elección de las medidas complementarias se realizó mediante un análisis coste-eficacia, analizando la eficiencia de las medidas mediante modelos de simulación y comparando los costes de las distintas alternativas mediante ratios coste-eficacia. Las medidas complementarias con las que se conseguía alcanzar los OMA y que presentaban el mínimo ratio coste-eficacia fueron elegidas para conformar el programa de medidas definitivo.

\subsection{Resultados y conclusiones}

Los procesos de planificación hidrológica en demarcaciones hidrológicas complejas necesitan del empleo de SSD que permitan a los gestores establecer mediante herramientas técnicas y trasparentes las medidas necesarias para al- 
canzar los objetivos de la planificación hidrológica en su doble vertiente, alcanzar el buen estado de las masas de agua conforme a la DMA y una adecuada satisfacción de las demandas conforme a lo expuesto en el artículo 40 de la DMA. Esta necesidad se debe al gran número de masas de agua, demandas y elementos de regulación de las demarcaciones, la complejidad de las presiones que presentan (de tipo cualitativo y cuantitativo) y la concomitancia de estas. Los resultados de los modelos matemáticos puedan emplearse para evaluar la eficacia de cada medida y ver el impacto que presentan las reglas de explotación en las asignaciones y reservas y en el estado de las masas de agua.

El SSD AQUATOOL se han convertido en una de las principales herramientas de trabajo en las Oficinas de Planificación Hidrológica, MITECO y consultores, siendo prácticamente imprescindibles para establecer asignaciones y reservas y analizar los efectos sobre el estado de las masas de agua que presentan los problemas cuantitativos y cualitativos.

Estos SSD, creados para su aplicación en demarcaciones españolas, están siendo objeto de exportación a demarcaciones internacionales, aplicándose recientemente en la elaboración de 4 planes hidrológicos en Turquía por parte de empresas españolas (Tragsatec e Initec Infraestructuras SAU del grupo TÉCNICAS REUNIDAS). Destaca el empleo de modelos de simulación, el desarrollo de redes neuronales para el análisis de indicadores biológicos (aspecto poco desarrollado en España), así como los análisis de coste-eficacia y coste-beneficio llevados a cabo.

\section{Referencias bibliográficas}

Álvarez, E., M. Pulido -Velázquez, J. Andreu, 2006. Estimación del Coste Marginal de Oportunidad del Recurso mediante modelos hidro-económicos a escala de Cuenca. Aplicación al Sistema del río Mijares en España. XXII Congreso Latinoamericano de Hidráulica. Ciudad Guyana, Venezuela.

Andreu, J., J. Capilla y E. Sanchis, 1996. AQUATOOL, a generalized decision support system for water resources planning and management. Journal of Hydrology (177) 269-291.

Andreu, J., Abel Solera, José Capilla, Ferrer Polo, 2004. Modelo SIMGES de Simulación de la Gestión de Recursos Hídricos, incluyendo Utilización Conjunta. Manual de usuario. Servicio Publicaciones, Universidad Politécnica de Valencia, Valencia, España.

Cabezas Calvo-Rubio, F.; Estrada Lorenzo, F. y Estrela Montreal, T., 1999. Algunas contribuciones técnicas del Libro Blanco del Agua en España. Ingeniería Civil, no 115, pp. 79-96.

CEDEX. Ministerio de Fomento, 1996. El Sistema Integrado de Modelización Precipitación Aportación, SIMPA. Revista de Ingeniería Civil, $n^{\circ} 104$, páginas 43-52. 
CHD, 2016. Plan Hidrológico del ciclo 2016/21. Anejo 6: Asignaciones y reservas, http://www.chduero.es/Inicio/Planificaci\%C3\%B3n/Planhidrol\%C3\%B3gico20162021Vigente/PlanHidrol\%C3\%B3gico/tabid/734/Default.aspx

CHS, 2006. Determinación y análisis del coste del recurso de los servicios del agua y de restricciones ambientales en la cuenca del Segura. Estudio realizado para la Confederación Hidrográfica del Segura. INITEC-UPV, Valencia, España.

CHG, 2018. Plan Especial de Sequía, https://www.chguadiana.es/planificacion/ plan-especial-de-sequia/revision-plan-especial-de-sequia/propuesta-final-de-revision-del-plan-especial-de-sequia.

CHS, 2016. Plan Hidrológico del ciclo 2016/21. Anejo 6: Asignaciones y reservas y Anejo 10: Programa de Medidas, http://chsegura.es/chs/planificacionydma/ planificacion15-21/index.html

Common Implementation Strategy for the Water Framework Directive (2000/60/ EC). Guidance Document No: 1 - Economics and the Environment. European Commission.

Directiva 2000/60/CE del Parlamento Europeo y del Consejo de 23 de octubre de 2000 por la que se establece un marco comunitario de actuación en el ámbito de la política de aguas.

Directiva del Consejo de 21 de mayo de 1991 sobre el tratamiento de las aguas residuales urbanas $(91 / 271 / \mathrm{CEE})$

Estrela, T. \& Quintas, L, 1996. A distributed hydrological model for water resources assessment in large basins. RIVERTECH 96. 1st International Conference on New/Emerging Concepts for Rivers. IWRA. Sep. 22-26, 1996. Chicago. EE.UU.

IIAMA - Instituto de Ingeniería del Agua y Medio Ambiente de la Universidad Politécnica de Valencia. https://aquatool.webs.upv.es/aqt/

Ley 62/2003, de 30 de diciembre, de medidas fiscales, administrativas y del orden social.

MIMAM, 2002. Plan Hidrológico Nacional

Momblanch A. , Paredes J., Solera A., Andreu J. Módulo CAUDECO de estimación de series temporales de hábitat. Manual del Usuario. Servicio Publicaciones, Universidad Politécnica de Valencia, Valencia, España.

Mora J., Benítez A., Rodríguez A., Almagro J., García J., 2013. Sistemas de modelado matemático de la calidad del agua en sistemas de gestión hídricos. III Jornadas de Ingeniería del Agua. La protección contra los riesgos hídricos. Valencia 2013.

Orden ARM/2656/2008, de 10 de septiembre, por la que se aprueba la instrucción de planificación hidrológica

Orden TEC/1399/2018, de 28 de noviembre, por la que se aprueba la revisión de los planes especiales de sequía correspondientes a las demarcaciones hidrográficas del Cantábrico Occidental, Guadalquivir, Ceuta, Melilla, Segura y Júcar; a la parte española de las demarcaciones hidrográficas del Miño-Sil, Due- 
ro, Tajo, Guadiana y Ebro; y al ámbito de competencias del Estado de la parte española de la demarcación hidrográfica del Cantábrico Oriental.

J. Paredes Arquiola et al. Modelo GESCAL de simulación de calidad de aguas. Manual de usuario v1.0. Editorial Universidad Politécnica de Valencia.

J. Paredes Arquiola et al. Modelación de la calidad del agua a escala de cuenca. Editorial Universidad Politécnica de Valencia.

Pérez, M. A. 2005 Modelo distribuido de simulación del ciclo hidrológico y calidad del agua, integrado en sistemas de información geográfica, para grandes cuencas. Aportación al análisis de presiones e impactos de la Directiva Marco del Agua.

Real Decreto Legislativo 1/2001, de 20 de julio, por el que se aprueba el texto refundido de la Ley de Aguas y sus modificaciones posteriores.

Real Decreto 907/2007, de 6 de julio, por el que se aprueba el Reglamento de la Planificación Hidrológica

RIBAMAP, 2018. Technical assistance for the conversion of river basin action plans into river basin management plans (TR2011/0327.21-05-01-001), http:// ribamap.ormansu.gov.tr/index

Ruiz García J.M. 1998. Desarrollo de un Modelo Hidrológico Distribuido de Simulación Continua Integrado con un Sistema de Información Geográfica. Mayo 1998.

Tragsatec S.A. y Universidad Politécnica de Valencia. 2009. «Definición de la concentración objetivo de nitrato en las masas de agua subterráneas de las cuencas intercomunitarias». (Borrador v.2 de 14 de mayo de 2009) 


\section{BLOQUE III}

\section{Gestión de los recursos hídricos en las islas}





\title{
Capítulo 10 \\ El ejercicio de la planificación hidrológica en las Islas Canarias
}

\author{
Marta Robledo Jiménez \\ Ingeniera Agrónoma
}

\subsection{Consideraciones}

La Directiva Marco del Agua (Directiva 2000/60/CE del Parlamento Europeo y del Consejo, de 23 de octubre de 2000-DMA) establece un marco de actuación comunitario en el ámbito de la política de aguas y pretende la protección de las aguas por Demarcación Hidrográfica.

Esta misma Directiva (artículo 13.7) establece ciclos de planificación de seis años, considerándose la aprobación y entrega a la Comisión Europea del primer ciclo en el año 2009, ejecutándose aquello planificado durante el periodo 20092015. Al final de este primer ciclo, se debe revisar, reelaborar y planificar el siguiente ciclo, siendo aprobado en 2015.

En el caso de las Demarcaciones Hidrográficas de Canarias la fecha de entrega de los documentos de los Planes Hidrológicos se realizó con retraso, de forma que el primer ciclo fue aprobado y entregado en 2015. Esto supuso un gran retraso en la ejecución y revisión del segundo ciclo. Y supuso un procedimiento de infracción por este incumplimiento. Todos los planes fueron aprobados durante 2019 y primeros de 2020, por lo que actualmente se está ejecutando lo planificado en este segundo en los tres años que quedan de ciclo, hasta el 2021. En la reunión de Comisarios Europeos de noviembre de 2019 dicho procedimiento fue cerrado.

Se debe tener en cuenta que la Comisión Europea coordina y revisa la elaboración de dichos planes, por lo que, tras la aprobación del primer ciclo, recomienda a los Estados Miembros en matices y obligaciones condicionados por el articulado de la Directiva. Las recomendaciones que hizo la Comisión para las Demarcaciones Hidrográficas Canarias del primer ciclo se tuvieron en cuenta a la hora de elaborar los Planes Hidrológicos en el segundo ciclo de planificación.

Actualmente, se está ejecutando el segundo ciclo y revisándose, conforme los plazos que norma la Directiva para este tercer ciclo, habiéndose consolidado los Documentos Iniciales y estando en proceso de consolidar también el Esquema provisional de Temas Importantes. Ambos han estado en participación pública en 6 meses (artículo 14). 
Otro procedimiento de infracción en el que está inmersa la Comunidad Autónoma de Canarias es en relación a la Directiva de Inundaciones (Directiva 2007/60/CE, del Parlamento Europeo y del Consejo, de 23 de octubre de 2007, relativa a la evaluación y gestión de los riesgos de inundación). En este caso el primer ciclo de planificación debiera estar aprobado en el 2015 y el segundo ciclo (revisión del primero) en 2021. Sin embargo, a día de hoy, febrero 2020, no hay ninguna Demarcación Hidrográfica Canaria que tenga aprobado Plan de Gestión de Riesgo de Inundaciones. Sin embargo, se ha trabajado también en la revisión de la Evaluación Preliminar de Riesgo de Inundaciones (EPRIS) y, posteriormente en los mapas, habiéndose consolidado los EPRIS y estando en proceso de consolidar también los mapas.

Finalmente, en relación a la tercera Directiva en materias de protección de las aguas en Canarias es la Directiva Marco de Estrategia Marina (Directiva 2008/56/ CE del Parlamento Europeo y del Consejo de 17 de junio de 2008 por la que se establece un marco de acción comunitaria para la política del medio marino DMEM). Acaba de finalizar el plazo de información pública de la revisión del primer ciclo. La misma tiene el objeto de proteger las aguas de las Demarcaciones Marinas. En el caso que nos ocupa, la Demarcación Canaria.

\subsection{Directiva Marco del Agua en Canarias}

En este apartado se refleja el esfuerzo realizado en los dos últimos años con respecto a la aprobación de los Planes Hidrológicos del segundo ciclo. Por comenzar por el final, la aprobación definitiva de los Planes Hidrológicos de las Demarcaciones Hidrográficas de Canarias por parte del Gobierno de Canarias (Ley 12/1990, de 26 de julio, de Aguas- Comunidad Autónoma de Canarias «BOC» núm. 94, de 27 de julio de 1990 «BOE» núm. 224, de 18 de septiembre de 1990 Referencia: BOE-A-1990-23087) y su publicación en el Boletín Oficial de Canarias se realizó entre 2018 y principios de 2019.

Como ya se ha comentado anteriormente, la Demarcación Hidrográfica es la unidad de cuenca en la que se tiene que garantizar la protección de las aguas. En el caso de Canarias hay siete Demarcaciones Hidrográficas (ordenadas por su localización geográfica de este a oeste): Lanzarote, Fuerteventura, Gran Canaria, Tenerife, La Gomera, La Palma y El Hierro. Este hecho ya implica que la elaboración, por cada Consejo Insular de Aguas, de cada plan implica 7 documentos de cada tipo así como 7 bases de datos de reporting al portal de la Comisión Europea. Este mismo hecho ocurre con los procedimientos de tramitación, por ejemplo, es necesaria la emisión de 7 Declaraciones Estratégicas.

El ámbito administrativo en la Comunidad Autónoma de Canarias, tal como dice la ley de Aguas de canaria, en su artículo 6:

"Las competencias y funciones administrativas de la Comunidad Autónoma de Canarias en materia de aguas serán ejercidas por:

a) El Gobierno de Canarias. 
Figura 10.1. Demarcaciones Hidrográficas Canarias

1

ES123

LANZAROTE

ES125

LA PALMA
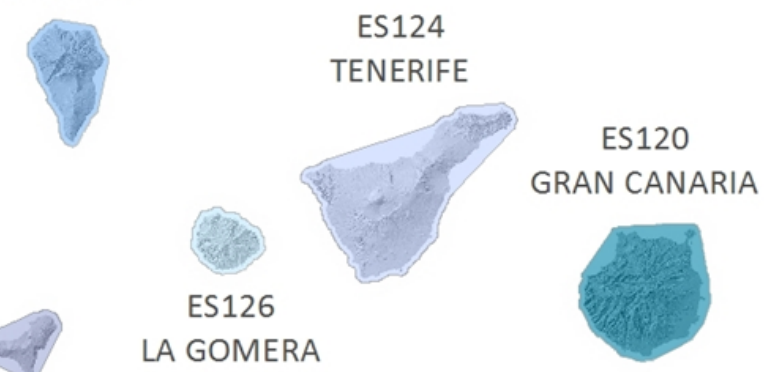

ES124

TENERIFE

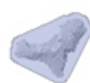

LA GOMERA

ES127

EL HIERRO

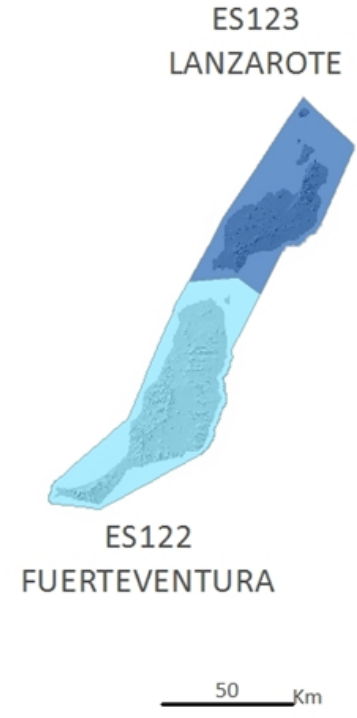

Fuente: Elaboración propia

b) La Consejería competente del Gobierno.

c) Los Cabildos Insulares, en cuanto entidad a la que quedan adscritos administrativamente los Consejos Insulares de Aguas.

d) Los Consejos Insulares de Aguas, que ejercerán en cada isla las funciones que la legislación general confía a los organismos de cuenca y las competencias que les otorga la presente Ley.»

El ordenamiento jurídico canario tiene además el Decreto 165/2015, de 3 de julio, por el que se aprueba la Instrucción de Planificación Hidrológica para las Demarcaciones Hidrográficas Intracomunitarias de la Comunidad Autónoma de Canarias. Esta Instrucción ha servido de base para la redacción de la Memoria de los Planes Hidrológicos del segundo ciclo.

También es de reseñar la reciente Ley Orgánica 1/2018, de 5 de noviembre, de reforma del Estatuto de Autonomía de Canarias.

La Comisión Europea evalúa todos los planes hidrológicos una vez aprobados. En el caso de los del primer ciclo de las Demarcaciones Hidrográficas de Canarias se tuvieron en cuenta estas recomendaciones en la elaboración de los segundos ciclos. Las más significativas fueron las siguientes:

- No se clarifica si existen masas de agua continentales superficiales: en cada plan hidrológico se justificó la no existencia de masas de agua tipo río natural, río muy modificado -embalses- y lagos, así como cuencas con posible escorrentía.

- Lagunas en los programas de medida de las aguas subterráneas y enfoques metodológicos específicos para determinar el estado de las masas de agua 
subterráneas son heterogéneos...en particular sobre su interrelación con ecosistemas dependientes: Se revisaron las redes de control subterráneas, recomendando a los Consejos Insulares de Aguas una nueva red en el caso de masas de aguas subterráneas con mayor densidad en algunos casos. Así mismo se evaluaron el estado de las masas de agua subterráneas conforme la Guía técnica elaborada en la Estrategia Común de Implantación número 18 (guía sobre el estado de las aguas subterráneas y la evaluación de tendencias) con los 5 text, incluyendo la evaluación de los ecosistemas terrestres dependientes.

- No se hizo una evaluación preliminar de las masas de agua superficiales costeras muy modificadas: Se revisaron, con las Autoridades Portuarias, todos los puertos del Estado, siguiendo los 10 pasos que indican la Guía técnica elaborada en la Estrategia Común de Implantación número 4 (Identification and Designation of Heavily Modified and artificial Water Bodies)guía de masas de agua muy modificadas, llegándose a las siguientes conclusiones (tabla 10.1):

Tabla 10.1. Conclusiones sobre el estado de las masas de agua superficiales en Canarias

\begin{tabular}{|c|c|c|c|}
\hline Demarcación & Actuación & Masa de Agua Afectada & Conclusión \\
\hline \multirow{2}{*}{ Gran Canaria } & Puerto de Las Palmas & Puerto de Las Palmas & Muy modificada \\
\hline & Puerto de Arinaga & Puerto de Arinaga & Muy modificada \\
\hline Fuerteventura & Puerto del Rosario & Puerto del Rosario & Muy modificada \\
\hline \multirow[t]{2}{*}{ Lanzarote } & Puerto de Arrecife & Puerto de Arrecife & Muy modificada \\
\hline & $\begin{array}{l}\text { Puerto de Santa Cruz de } \\
\text { Tenerife }\end{array}$ & $\begin{array}{l}\text { Puerto de Santa Cruz de } \\
\text { Tenerife }\end{array}$ & Muy modificada \\
\hline \multirow[t]{2}{*}{ Tenerife } & $\begin{array}{l}\text { Puerto de Los Cristia- } \\
\text { nos }\end{array}$ & $\begin{array}{l}\text { Montaña Pelada-Ba- } \\
\text { rranco Seco }\end{array}$ & Natural \\
\hline & Puerto de Granadilla & Puerto de Granadilla & Muy modificada \\
\hline La Palma & $\begin{array}{l}\text { Puerto de Santa Cruz de } \\
\text { La Palma }\end{array}$ & Santa Cruz-El Socorro & Natural \\
\hline La Gomera & $\begin{array}{l}\text { Puerto de Santa Sebas- } \\
\text { tián de La Gomera }\end{array}$ & Salinas-Corralito & Natural \\
\hline El Hierro & Puerto de La Estaca & $\begin{array}{l}\text { Roque del Barbudo-Pun- } \\
\text { ta de los Saltos }\end{array}$ & Natural \\
\hline
\end{tabular}

Fuente: Elaboración propia

Además de estas recomendaciones, la elaboración de los planes hidrológicos canarios se revisaron/redactaron lo siguiente: 
- El artículo 4.7 de la Directiva marco del agua obliga a avisar de posibles nuevas modificaciones de las características físicas de una masa de agua (tanto superficiales como subterráneas). En el caso del segundo ciclo, se revisaron, como indica dicho artículo:

Tabla 10.2. Masas de agua en Canarias modificaciones de las características físicas revisadas en el $2^{\circ}$ ciclo de planificación

\begin{tabular}{lll}
\hline Demarcación & \multicolumn{1}{c}{ Actuación } & \multicolumn{1}{c}{ Masa de Agua Afectada } \\
\hline Gran Canaria & Ampliación del Puerto de Agaete & Costera Noroeste \\
\hline \multirow{2}{*}{ Tenerife } & $\begin{array}{l}\text { Construcción del Puerto de Puer- } \\
\text { to de la Cruz }\end{array}$ & Punta de Teno-Punta del Roquete \\
\cline { 2 - 3 } & $\begin{array}{l}\text { Construcción del Puerto de Fonsa- } \\
\text { lía }\end{array}$ & Montaña Pelada-Barranco Seco \\
\hline Lanzarote & $\begin{array}{l}\text { Ampliación del Puerto de Playa } \\
\text { Blanca }\end{array}$ & Sur de Lanzarote \\
\hline
\end{tabular}

Fuente: Elaboración propia

- Los Consejos Insulares de Aguas y las Autoridades Portuarias, en numerosas reuniones, hicieron notar la deficiencia de las condiciones de referencia para las aguas superficiales. Por ello, en cada Programa de Medidas de cada Plan Hidrológico, se ha previsto una medida cuyo fin sea la determinación de las mismas por tipología de masa de agua a ejecutar en este segundo ciclo de planificación.

- Así mismo se realizó un muestreo, en el año 2018, en la red de control superficial y subterránea en las siete Demarcaciones Hidrográficas. Este muestreo ha servido como revisión de la red correspondiente, verificar el estado de eutrofización de las zonas sensibles según la Directiva 91/271 de aguas residuales y para determinar los índices ya establecidos de las masas de aguas superficiales (no se han incluido las fanerógamas marinas). Es de destacar que se han determinado casi 50 taxones que no están incluidos en el índice M-AMBI para fauna bentónica de invertebrados (https://ambi.azti.es/es/).

- Se han revisado y homogeneizado (conforme a las guías aportadas por el MITECO) de los instrumentos de recuperación de costes.

Además de han elaborado, puesto en información pública durante seis meses y consolidado los documentos correspondientes a las dos primeras «fases» de planificación: los documentos iniciales y fórmulas de consulta y los Esquemas de Temas Importantes junto con los Documentos Iniciales Estratégicos de cada Demarcación Hidrológica. 


\subsection{Directiva de Inundaciones en Canarias}

En el caso de las Demarcaciones Canarias, no todos los Planes de Gestión de Riesgos de inundaciones tienen aprobados el primer ciclo de planificación según la Directiva 2007/60/CE, del Parlamento Europeo y del Consejo, de 23 de octubre de 2007, relativa a la evaluación y gestión de los riesgos de inundación. Este hecho no ha limitado la consecución y revisión del segundo ciclo, teniendo en cuenta el proceso de infracción.

La revisión de la Evaluación Preliminar de Riesgo de Inundaciones (EPRIS) fue consolidado en este segundo ciclo y, posteriormente en los Mapas de Peligrosidad (excepto la Demarcación Hidrográfica de Lanzarote que se puso en información pública la última en la web del Consejo Insular de Aguas de Lanzarote). Además, cada consolidación ha ido sido reportada también a la Comisión Europea.

Finalmente, comentar que, siguiendo la Ley 21/2013, de 9 de diciembre, de evaluación ambiental, se ha redactado el Documento Inicial Estratégico conjunto del Plan Hidrológico y Plan de Gestión del Riesgo.

\subsection{Directiva de Estrategia Marina en Canarias}

La Demarcación marina canaria se solapa geográficamente con las Demarcaciones Hidrográficas canarias: las aguas costeras interiores más las aguas que distan hasta una milla náutica son coincidentes en ambas Demarcaciones. Por ello, también parte de la evaluación y protección de las mismas es la misma.

Figura 10.2. Demarcación Marina Canaria

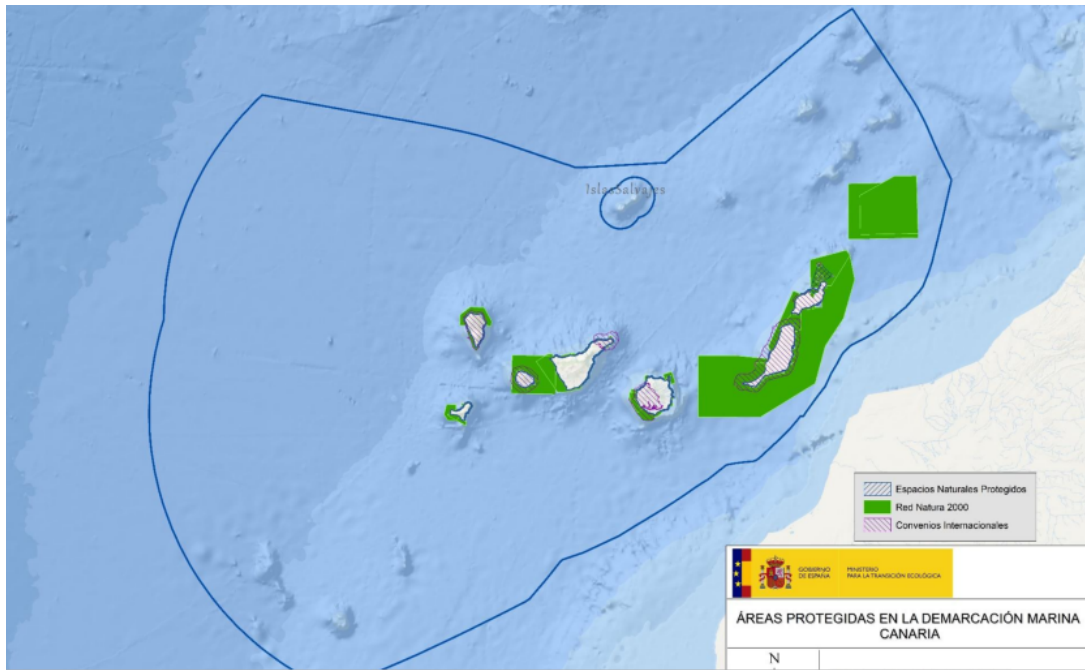

Fuente: MITECO 
Existe, por ello, solapamiento en parámetros de evaluación (la Decisión 2017/848 establece explícitamente que en las aguas costeras deben medirse los elementos y aplicarse los valores umbral establecidos por la DMA. Los descriptores corresponden son los siguientes:

- D5-Eutrofización.

- D7-Condiciones hidrográficas.

- D8-Contaminantes y sus efectos parcialmente los descriptores de biodiversidad:

- D1-Especies.

- D6-Fondos marinos.

El resto de descriptores no han sido abordados en las aguas costeras por la DMA, por lo que deberá ser cubierto por la DMEM en dicho ámbito geográfico, del mismo modo que en el resto de aguas marinas.

\subsection{Retos/Obligaciones/Mejoras}

Tras estos dos años de elaboración y aprobación del segundo ciclo de planificación hidrológica en Canarias, se presenta un futuro esperanzador en materia de protección de las aguas cuyo objetivo no sólo es el de cumplir plazos, sino de hacer unos buenos Planes que técnicamente aseguren dicha protección. Por ello, a continuación se presentan retos a conseguir en los próximos meses y años:

- Finalizar el procedimiento administrativo, aprobar definitivamente los PGRIS.

- Rediseñar la red de control de referencia de las masas de agua superficiales costeras y definir las condiciones de referencia para cada elemento de calidad y tipología de masa de agua. Definir métrica para fanerógamas marinas.

- Crear y convocar los 7 Comités Sectorial de Aguas Costeras y Zonas Protegidas.

- Continuar con el desarrollo de las condiciones de referencia de EQS (Element Quality Standard) para nuevas sustancias prioritarias (22 diciembre 2018) que constituyen el estado químico de las masas de agua superficiales costeras.

- Verificar el impacto de las presiones SIGNIFICATIVAS tanto en las aguas superficiales como subterráneas.

- Control de la extracción: conocer el consumo de agua a través de contadores dinámicos volumétricos on-line para tener un registro actualizado de la extracción de agua. 
- Reforzar el conocimiento que evalúe los términos del balance hídrico (recarga, salidas al mar, extracciones, etc.) y su incertidumbre hidrogeológicos, modelos conceptuales y/o matemáticos).

- Fomentar estudios para evaluar los niveles de referencia (valor natural que tiene la masa de agua) de los parámetros químicos.

- Incrementar la reutilización de las aguas residuales tratadas desarrollando re-des de distribución específicas, fomentando la economía circular, disminuyen-do los vertidos residuales y mejorando la adaptación al cambio climático.

- Realizar Programas de Medidas REALISTAS, que correspondan con los techos presupuestarios. Incorporar más medidas de adaptación y mitigación al cambio climático.

- Realizar análisis coste-beneficio en las medidas ya planificadas.

- Potenciar las buenas prácticas agrícolas para «debilitar» el contenido de nitratos en las aguas subterráneas.

- Análisis pormenorizado de algunas zonas de riesgo, especialmente costeras.

- Mayor coordinación con las Autoridades Competentes DMA-Directiva Inundaciones y DMEM. 


\title{
Capítulo 11 \\ La gobernanza del agua en las Islas Canarias
}

\author{
Juan Carlos Santamarta Cerezal \\ Doctor Ingeniero de Montes \\ Jesica Rodríguez-Martín \\ Doctora Ingeniera de Caminos, Canales y Puertos \\ Noelia CRuz Pérez \\ Ingeniera Civil
}

\subsection{Introducción}

Las Islas Canarias es un archipiélago formado por 8 islas localizadas en el océano Atlántico, cercano al Sáhara occidental. Forman parte del reino de España. Se dividen en dos provincias; Tenerife y Las Palmas de Gran Canaria. En la provincia de Tenerife se encuentran de mayor a menor extensión de territorio: Tenerife, La Palma, La Gomera y El Hierro. En la provincia de Las Palmas de Gran Canaria, igualmente, de mayor a menor extensión de territorio, se encuentran; Fuerteventura, Gran Canaria, Lanzarote y La Graciosa. La población de la comunidad autónoma supera los 2 millones de habitantes. Es una región donde predomina la industria turística, por lo tanto el sector de los servicios, aunque también el sector primario tiene cierto peso, con una agricultura importante, fundamentalmente de exportación. Sus cultivos relevantes son, el plátano, la papa, el tomate y el viñedo, también el cultivo de flores para exportación es importante. Actualmente se está integrando en la islas el olivo y el aguacate. Existe una pequeña ganadería, sobre todo de porcino y caprino. También, existe una raza bovina canaria pero con muy poca presencia, salvo en las islas capitalinas, para actividades fundamentalmente de exhibición.

Conjuntamente con Cabo Verde, Madeira (Portugal), lslas Salvajes (Portugal) y, el archipiélago de las Azores (Portugal) conforman una región denominada Macaronesia. Esta zona geográfica comparte características comunes, como un origen geológico común por la actividad volcánica. Una flora singular, como la laurisilva y un clima influenciado por los vientos alisios. Estos vientos condicionan de manera notable el ciclo hidrológico de cada isla debido a la humedad que transportan. También forman el característico mar de nubes que se puede observar en algunas islas a ciertas cotas de altitud, más habitual en verano.

Este conjunto de islas comparten características ambientales, económicas y sociales comunes tales como: (i) ecosistemas forestales singulares y especies muy sensibles a pequeñas perturbaciones en los hábitats, (ii) singularidad botánica, (iii) alta presencia del sector primario, (iv) dependencia del turismo como indus- 
tria, (v) alta dependencia energética pero posibilidad de integrar energías renovables y, (vi) elevada densidad de población (Santamarta, 2014).

Los recursos hídricos en las islas de la Macaronesia provienen de dos fuentes. Por un lado, las precipitaciones, condicionadas por la localización y altitud de las islas. Estas precipitaciones son mayores en Azores, y se van reduciendo conforme nos aproximamos al sur de la Macaronesia. Cabo Verde que es la región con menores precipitaciones, por lo tanto dispone de menos recursos hídricos naturales. En el caso particular de Canarias, las islas occidentales disponen de precipitaciones cuantitativamente mayores que las islas orientales. La precipitación media en Canarias se puede considerar cercana a los $400 \mathrm{~mm}$ al año, con grandes diferencias entre islas e, incluso, en cada isla, hay que considerar diferentes zonas (microclimas), como la orientada al sur (sotavento) -con menores precipitaciones-con respecto la orientada al norte (barlovento) con mayores precipitaciones e influenciadas por el efecto comentado de los vientos alisios. Por otro lado, la humedad de los vientos alisios que es aprovechada por las formaciones boscosas mediante la denominada precipitación oculta, horizontal o de niebla.

Comprender el ciclo integral del agua en las Islas Canarias no es fácil. La gestión y aprovechamiento del agua forma parte de la historia y el patrimonio hidráulico de las Islas Canarias, existen unos vínculos históricos, sociales y afectivos en toda la sociedad canaria difíciles de comparar con otro lugar del mundo. La economía y progreso que disfrutan actualmente los habitantes de las Islas no

Figura 11.1. Situación de las Islas Canarias con respecto a la península ibérica, Europa y África

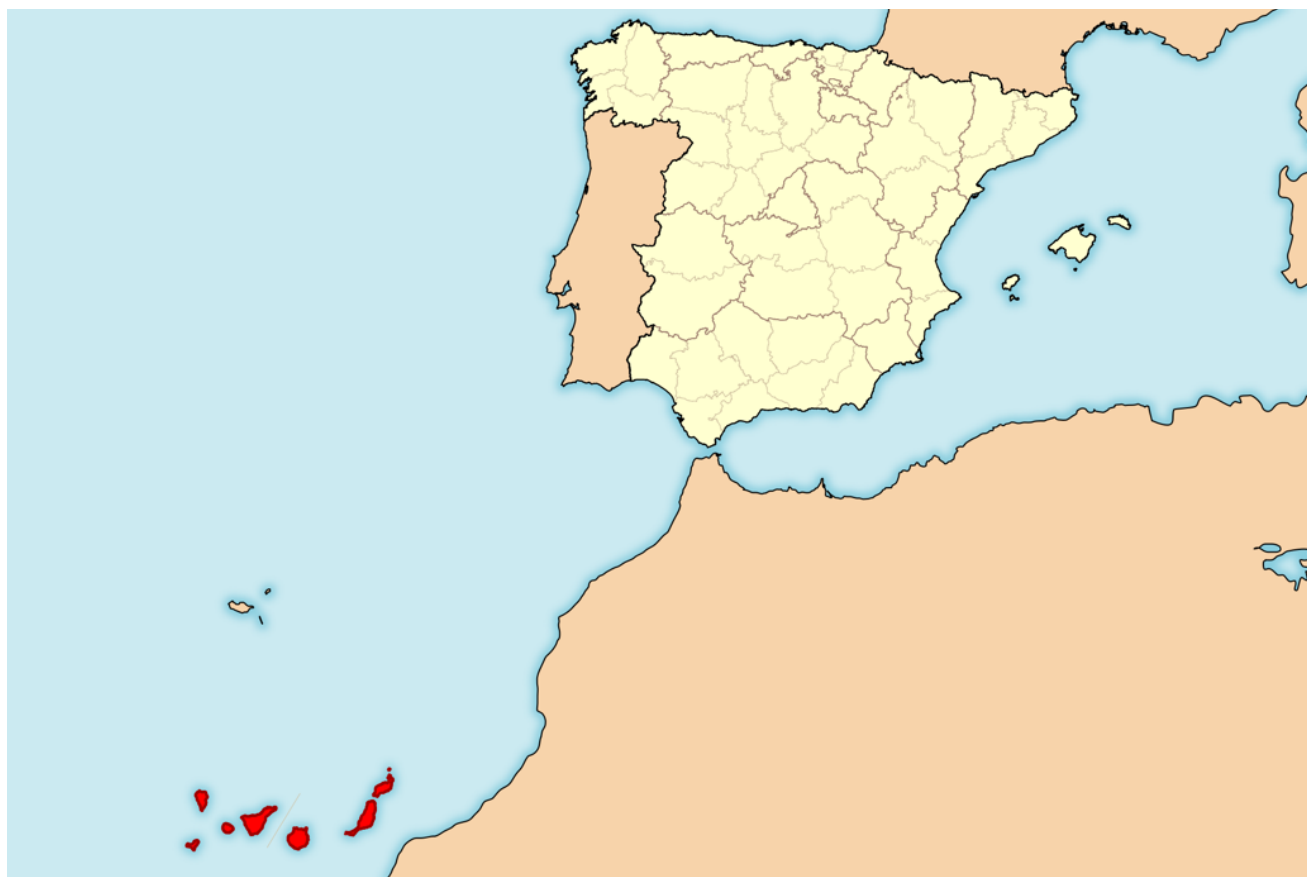

Fuente: Wikipedia 
Figura 11.2. El mar de nubes sobre Frontera, en la isla de El Hierro

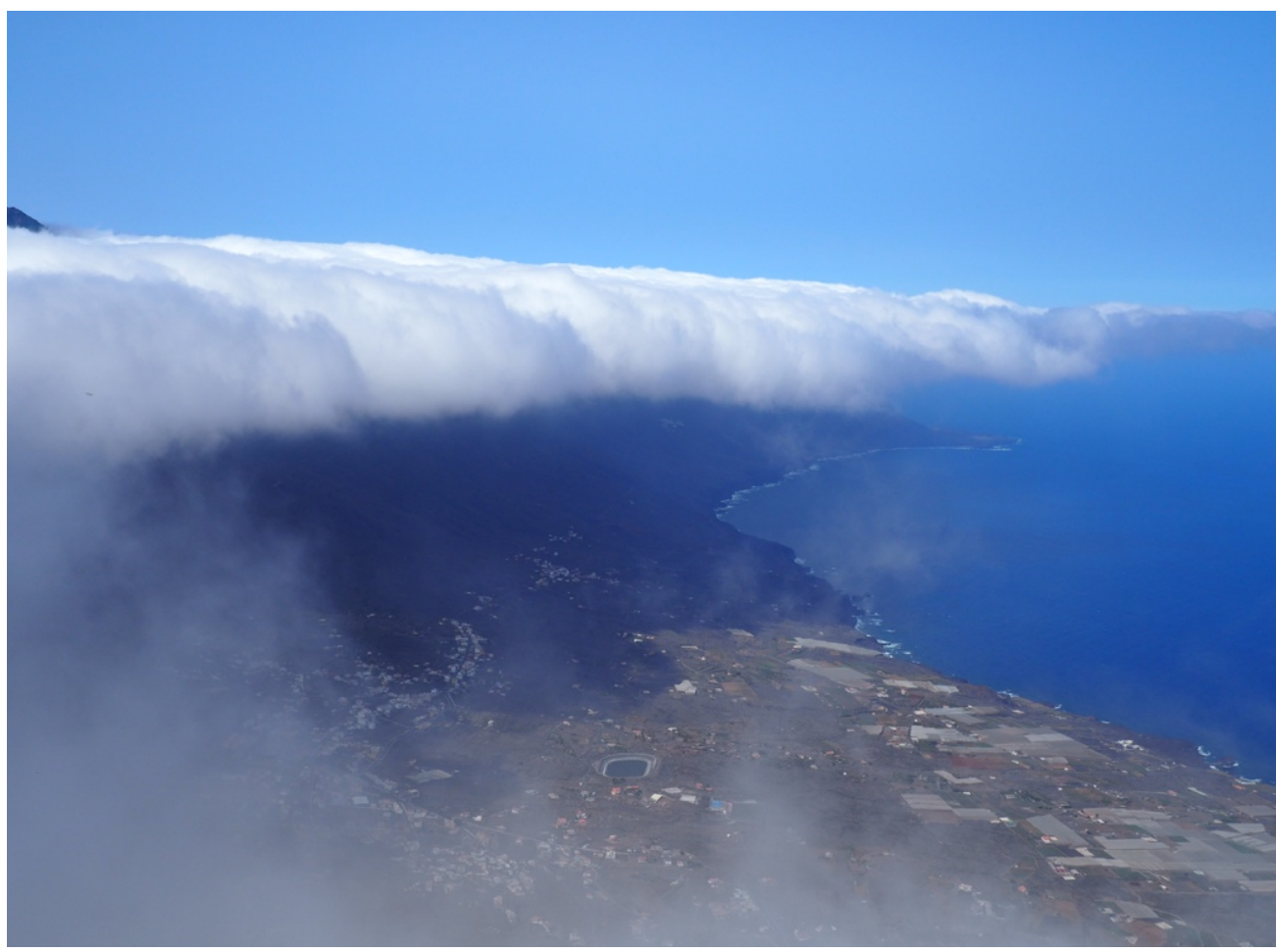

Fuente: Santamarta, J.C.

se podría entender sin el desarrollo de unas técnicas singulares para captar y aprovechar hasta la última gota de agua extraída de las entrañas de la tierra. Esa evolución en el aprovechamiento del agua ha seguido hasta nuestros días, con la producción industrial de agua a través de la desalinización del agua procedente del océano. Donde la tecnología desarrollada en las Islas y sus ingenieros, reconocidos a nivel mundial, han tenido mucho que ver. Sobre todo, en las islas donde los recursos naturales no daban más de sí por un crecimiento (urbano y turístico) y la demanda de recursos hídricos que crecía año tras año.

Actualmente, pese a que en general, se piense que en las Islas Canarias, prácticamente toda el agua utilizada proviene de la desalinización del agua del océano. Es una teoría errónea. Las aguas subterráneas siguen siendo fundamentales, sobre todo en las islas occidentales. Por ejemplo, en la Isla de Tenerife, el $85 \%$ del agua consumida proviene del subsuelo, en La Palma más del $90 \%$. Incluso en Fuerteventura se siguen aprovechando los recursos hídricos subterráneos. También las aguas superficiales son importantes, pero con un papel más secundario y fundamentalmente en la agricultura. En la isla de La Gomera y Gran Canaria, se concentran casi 100 grandes presas para este fin (Santamarta \& González, 2012).

Los principales aprovechamientos y obras hidráulicas que se pueden localizar en Canarias son los siguientes (Santamarta, 2013): 
- Aguas subterráneas.

- Galerías.

- Minas de agua.

- Norias.

- Pozos convencionales.

- Pozos canarios.

- Sondeos.

- Aguas superficiales.

- Tomaderos de barranco.

- Caideros.

- Balsas convencionales.

- Balsas de tierra.

- Presas convencionales.

- Presas de tierra.

- Maretas (figura 11.3).

- Gavias.

- Nateros.

- Conducciones.

- Canales.

- Tuberías.

Figura 11.3. Mareta y aljibe, para el aprovechamiento del agua de lluvia en la isla de El Hierro

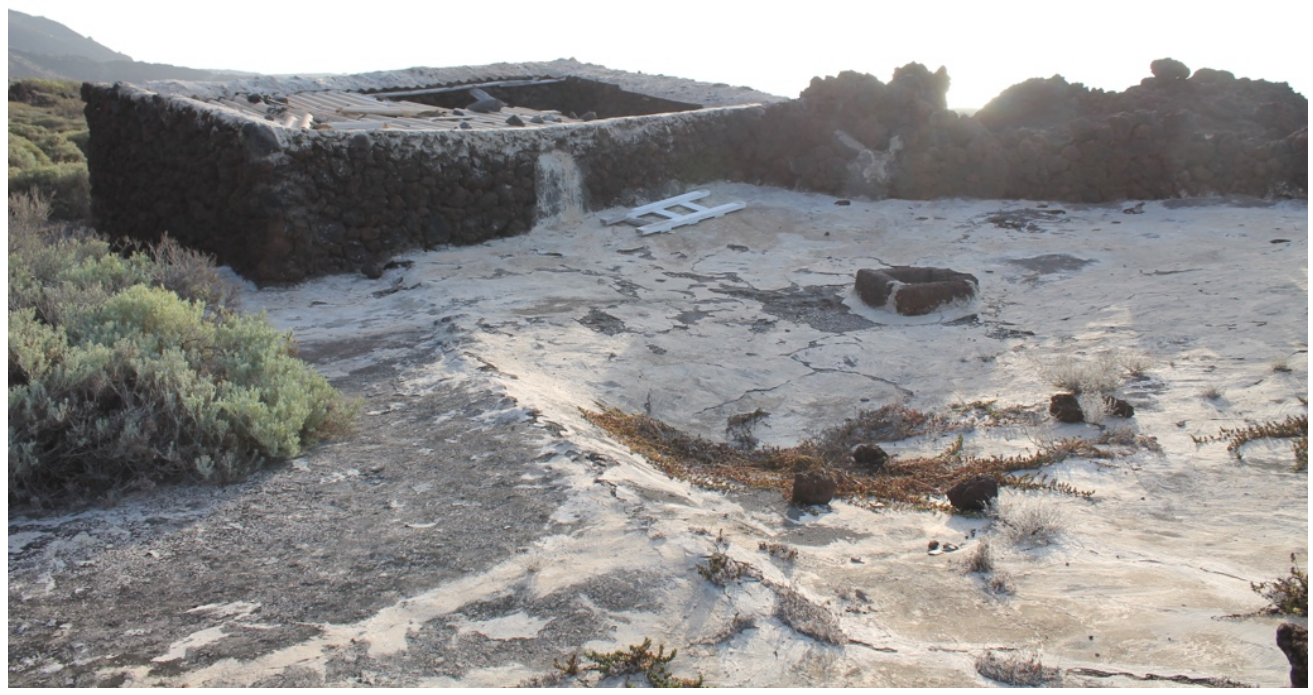

Fuente: Santamarta, J.C. 
Figura 11.4. Barranco de Las Angustias en la isla de La Palma, es de donde se aprovechan la mayoría de los recursos hídricos superficiales en la Isla para riego agrícola

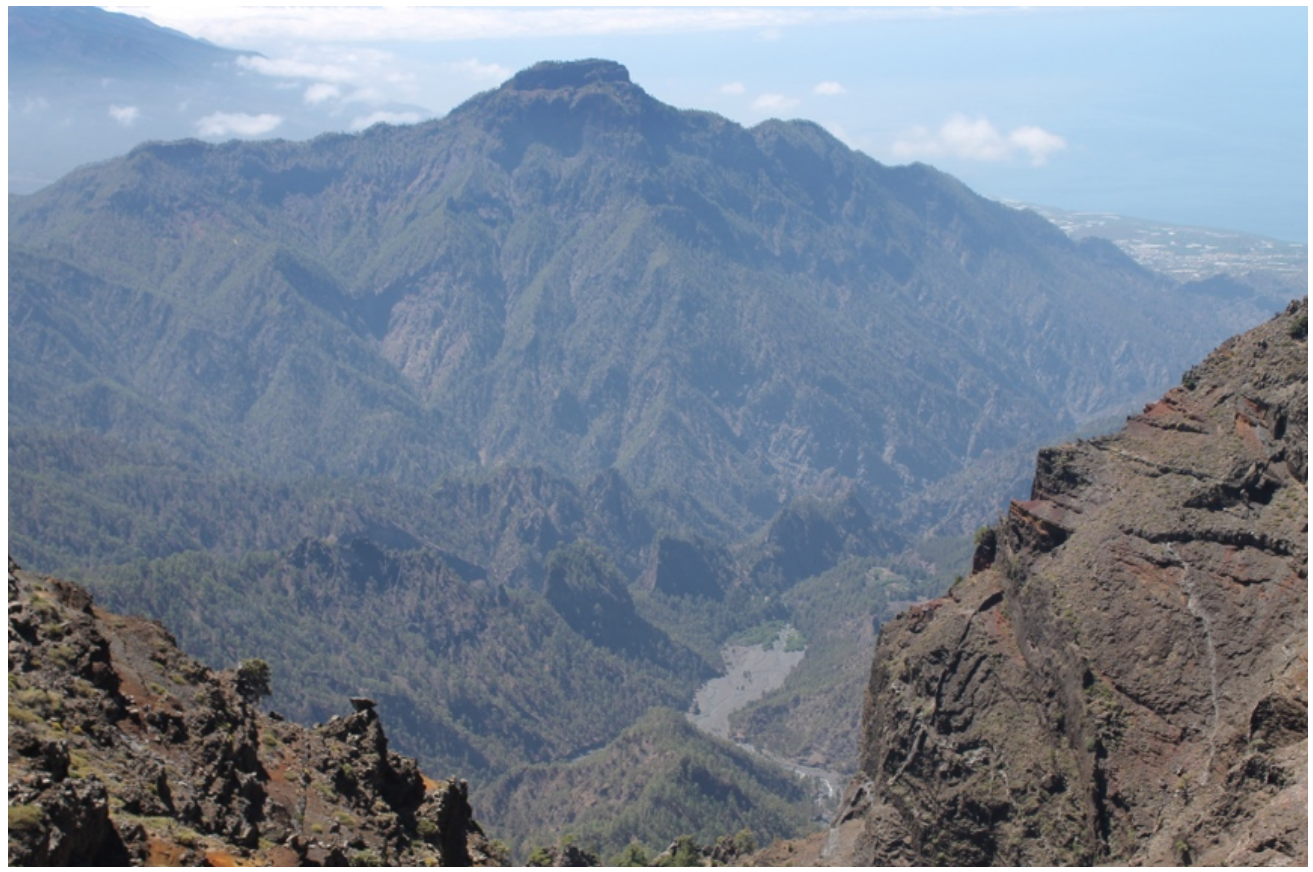

Fuente: Santamarta, J.C.

- Acueductos.

- Cantoneras.

- Elevadores.

- Sifones.

- Producción industrial de agua.

- Plantas desalinizadoras de agua procedente del océano.

- Estaciones Depuradoras de Aguas Residuales (EDAR) para la producción de aguas para su reutilización en agricultura.

En las Islas Canarias, como norma general, los recursos hídricos superficiales son escasos, no suponen más del $10 \%$ en el cómputo global de los recursos disponibles en las islas. No obstante, para aprovechar este recurso, por mínimo que sea, se han realizado grandes esfuerzos económicos y técnicos para poder almacenar y utilizar el agua, debido fundamentalmente, a la escasez general de los recursos hídricos en las Islas y a la gran calidad del recurso procedente por esta vía, con muy poca cantidad de sales. Un ejemplo son las numerosas balsas y presas que existen en la región. Los recursos hídricos superficiales no se utilizan para abastecimiento urbano en las Islas Canarias. 
Inicialmente hablaremos de los recursos hídricos subterráneos y su aprovechamiento.

Para obtener los recursos hídricos subterráneos es necesario que haya suficientes precipitaciones. Posteriormente, que esta lluvia se infiltre y, finalmente que el agua llegue al acuífero contribuyendo a la recarga del mismo. La infiltración se define como la entrada del agua a través de la capa superficial de la corteza terrestre, es decir del suelo. La relación entre el aporte de agua (precipitación, riego, etc.) y la infiltración determina la proporción de la primera que penetra y puede moverse hacia capas más profundas, y la que queda en superficie es la disponible para la escorrentía que suele acabar en los barrancos y, como se ha comentado, en parte es aprovechada, mediante tomaderos de barranco como es el caso del tomadero a Dos Aguas en el barranco de Las Angustias en la isla de La Palma (Santamarta, 2013).

Para el almacenamiento del agua se disponen de depósitos reguladores, como estanques de riego, balsas y presas. En algunos casos este almacenamiento de agua se puede realizar en el propio acuífero mediante embalses subterráneos dispuestos a lo largo de la traza de las galerías mediante el sistema de cierre de diques geológicos (Santamarta et al. 2010). Esta tipología de almacenamiento se ha utilizado en Canarias en las islas de La Palma y El Hierro (Soler, 2012). A nivel mundial, se ha utilizado en Hawái o Japón (Santamarta, 2016).

Figura 11.5. Balsa en la isla de La Palma para riego agrícola

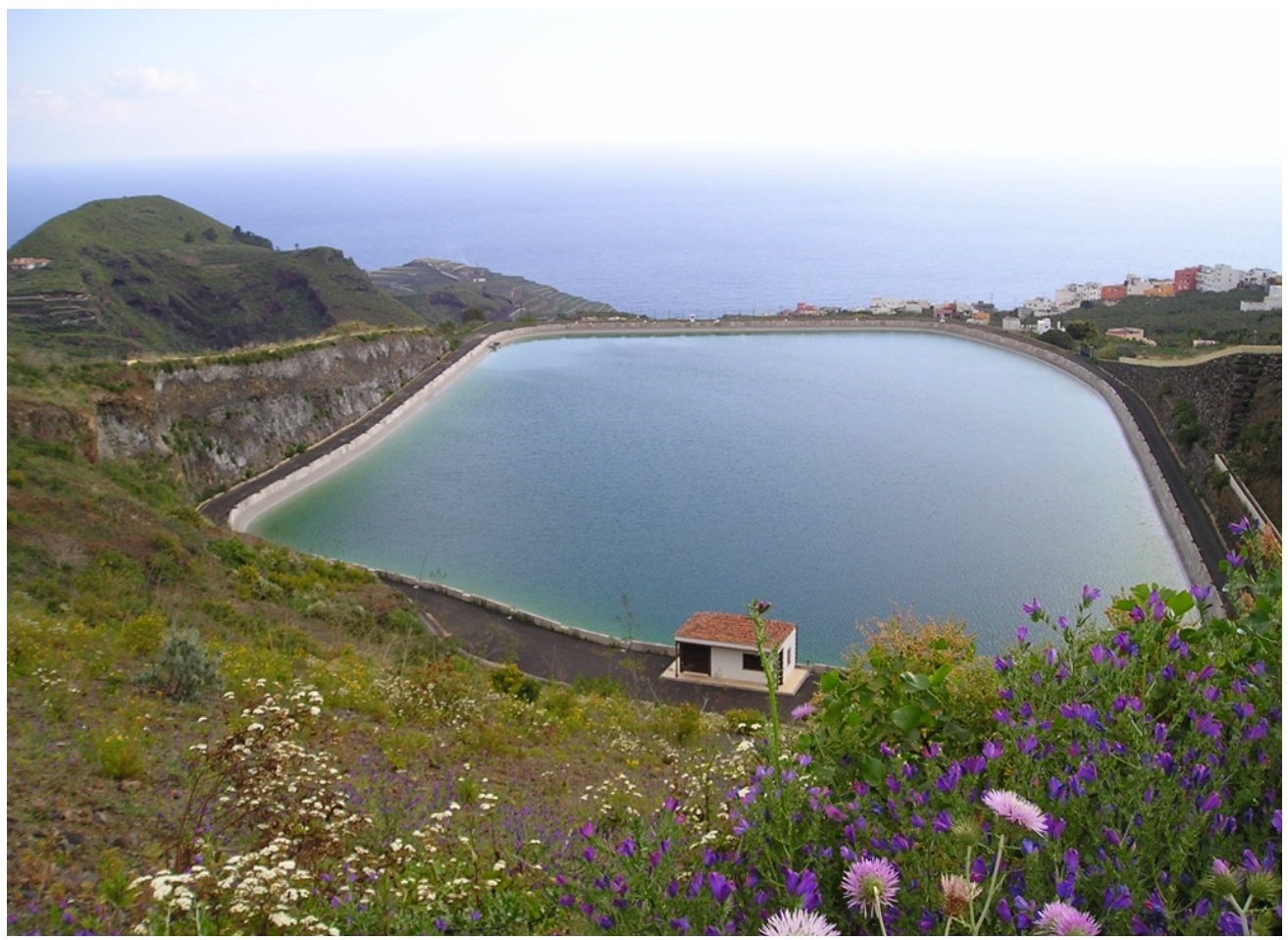

Fuente: Santamarta, J.C. 
Figura 11.6. Presa encajada en un barrando en la isla de La Gomera para riego agrícola

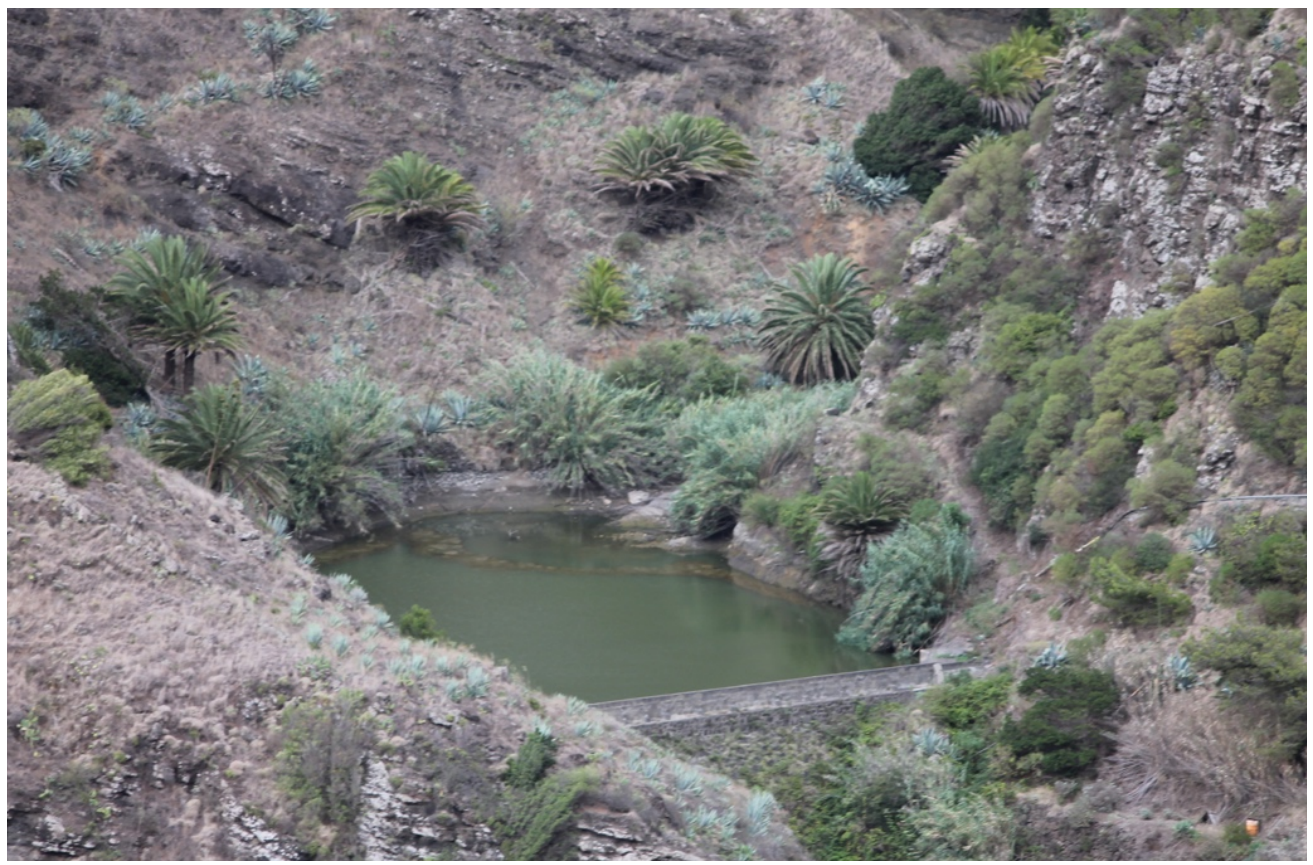

Fuente: Santamarta, J.C.

Para el transporte y la distribución del agua, se disponen de conducciones tipo canal o bien, tuberías convencionales de plástico o metal. En la isla de Tenerife existen más de 4000 kilómetros de conducciones. Sin embargo, esta red de distribución presenta debilidades como las pérdidas reales (fugas) en las conducciones. En algunos casos se superan el 50 o 60\% de las pérdidas de agua (PHI Tenerife, 1 er ciclo).

Las zonas de consumo que, por lo general, suelen estar localizadas en las zonas costeras no suelen coincidir con las zonas de captación de aguas. En el caso de las aguas subterráneas obtenidas por galerías de agua, estas se encuentran en cotas elevadas (300-2000 msnm), por lo que en la mayoría de los casos estos recursos hídricos llegan a las zonas de consumo por gravedad, lo cual es muy positivo desde el punto de vista de la eficiencia energética. En el caso de los pozos, sondeos y plantas desalinizadoras de agua de mar, es necesario bombear agua. Esto genera un fuerte nexo agua y energía lo que supone consumos energéticos importantes vinculados a la gestión del recurso hídrico. Hay que recordar que la producción de energía en las Islas Canarias depende fundamentalmente de los combustibles fósiles. No obstante, desde las diferentes administraciones y por parte de usuarios privados, entre los que se encuentran las cooperativas agrícolas, se realizan importantes esfuerzos económicos y técnicos con el fin de incrementar el uso de energías renovables, fundamentalmente solar y eólica. Hay casos de éxito en la Mancomunidad del Sureste en la isla de Gran Canaria por la integración de la energía eólica en el ámbito rural. 


\subsection{La planificación hidrológica en las Islas Canarias}

El uso, la gestión y la protección del agua en un territorio debe ser planificada. Históricamente en España se han gestionado los recursos hídricos desde el paradigma de aumentar la oferta de agua. El aumento de las extensiones agrícolas unido a las masivas urbanizaciones, sobre todo en zonas costeras, donde además se sumaba la escasez de recursos hídricos, aumentaba una demanda hídrica que era muy compleja de satisfacer. El agua era considerada en definitiva un factor de producción más. Cuando esta no era posible obtenerla de manera natural se recurría a la producción industrial de agua dulce a partir del agua de mar. En el peor de los casos se desalinizaba agua de pozos abandonados por volverse salobres, fundamentalmente pozos costeros, con lo cual se potenciaba el efecto de la intrusión marina.

Desde hace años ha habido un cambio de paradigma en la gestión y planificación del agua. Por un lado, se actúa desde la demanda, esto ha supuesto imponer criterios racionales para ajustar la demanda a la oferta. Por otro lado, se destaca la importancia ambiental del agua y la necesidad de su protección. Finalmente se establece un criterio de recuperación de costes en el uso del agua. Esta planificación no debe ser estática, sino dinámica, por lo que se necesita revisar cada cierto tiempo. En el caso de los planes hidrológicos, el plazo son 6 años.

La Directiva Marco del Agua (DMA) es uno de los mayores avances en materia de gestión de los recursos hídricos a nivel europeo. Esta DMA tiene cuatro pilares: la gestión y planificación en la escala de la demarcación hidrográfica, la racionalidad económica, la recuperación del buen estado de las aguas y, por último, pero no menos importante, la transparencia y la participación social. Desde la DMA se han desarrollado tres ciclos de planificación:

- Primer ciclo de planificación (2009-2015).

- Segundo ciclo de planificación (2015-2021).

- Tercer ciclo de planificación (2021-2027).

Las Islas Canarias cuentan con siete Demarcaciones Hidrográficas formadas por cuencas hidrográficas intracomunitarias (Art. 5 BIS, de la Ley 10/2010, modificación de la Ley 12/1990), competencia de las administraciones hidráulicas de la comunidad autónoma.

Actualmente se está desarrollando la documentación para el tercer ciclo de planificación. En las Islas Canarias, la documentación del segundo ciclo se presentó con retraso, aunque actualmente se está ya trabajando en el tercer ciclo de planificación. En este sentido, cabe volver a resaltar que existen 7 Demarcaciones Hidrográficas, una por cada isla, salvo La Graciosa (incluida en Lanzarote), organizándose mediante los Consejos Insulares de Agua, con competencias en los temas vinculados a los recursos hídricos, incluyendo la planificación hidrológica de los mismos. Si se compara esta organización con la de las Islas Baleares, se observa que, en el caso de las islas mediterráneas, es una demarcación hidrográfica única. Esto supone una mejor organización y gestión de cara a cumplir con los plazos administrativos que exige Europa. Si bien, no es un modelo perfecto, dado 
que es un sistema muy centralista con respecto a la isla principal (Mallorca) donde, según los propios ciudadanos de las islas de menor territorio, en ocasiones adolece de las singularidades y problemas particulares de cada isla.

En el caso canario este es uno de los argumentos de peso para no hacer una demarcación única para todas las Islas Canarias. Pero, por otro lado, es evidente que hay islas con mayores recursos humanos y técnicos que otras para poder asumir los compromisos con Europa, lo cuál se traduce en retrasos y penalizaciones, Hierro (10000 habitantes) versus Tenerife (1.000.000). Esto hace que, en última instancia, sea el Gobierno de Canarias quién titularice esta gestión en colaboración con los diferentes Consejos Insulares de Aguas con el fin de cumplir los plazos requeridos, esto es lo que ha ocurrido con el segundo ciclo de planificación hidrológica.

Fundamentalmente el proceso de planificación hidrológica tiene las siguientes fases:

- Documentos iniciales.

- Caracterización ambiental y económica.

- Registro de zonas protegidas.

- Identificación de presiones.

- Esquema de temas importantes.

- Establecimiento de objetivos.

- Plan hidrológico de la demarcación y programa de medidas.

- Seguimiento y evaluación.

La participación pública se integra en los apartados de los documentos iniciales, en el esquema de temas importantes, en el plan hidrológico y en el programa de medidas.

Se puede considerar el agua como algo estratégico en Europa ya que durante los últimos años, no sólo se ha desarrollado la DMA, si no que existen numerosas normativas vinculadas a los recursos hídricos como por ejemplo:

- Gestión calidad aguas de baño (76/160/EEC) reformada por la 2006/7/CE.

- Lucha contra contaminación nitratos agrícolas (91/676/CEE).

- Tratamiento aguas residuales urbanas (91/271/EEC).

- Directiva agua potable (98/83/EC).

- La comentada, Directiva Marco del Agua (2000/60/CE).

- Directiva aguas subterráneas (2006/118/EEC).

- Directiva inundaciones (2007/60/EC).

\subsection{Desarrollo histórico del agua en las Islas Canarias}

Los primeros habitantes de las Islas Canarias satisfacían sus necesidades en materia de recursos hídricos mediante el aprovechamiento directo del agua que 
corría de manera continua por los barrancos, que funcionaban como auténticos ríos. También hay constancia de que existían numerosos nacientes en todas las islas, incluidas las orientales. Hay que tener en cuenta que la población y necesidades en aquella época dista mucho de la que existe actualmente. En el caso de la isla de El Hierro, la isla más joven geológicamente hablando, es donde existía mayor infiltración del agua procedente de la lluvia. Se potenciaron los aprovechamientos de la precipitación de niebla o lluvia horizontal. Un claro ejemplo de estas estrategias son el árbol Garoé, situado en la zona de San Andrés que captaba el agua del mar de nubes y se almacenaba en unas oquedades excavadas en la ladera cercana que eran impermeabilizadas con arcilla y resina de pino canario (Santamarta \& Seijas, 2010b) y, por otro lado, los troncos huecos que se disponían en diferentes puntos de la isla que se llenaban también de agua gracias a este tipo de precipitación y eran usados por los bimbaches (primeros pobladores de el Hierro).

Figura 11.7. El árbol Garoé y las albercas de almacenamiento de agua de niebla captada impermeabilizadas con resina de pino canario

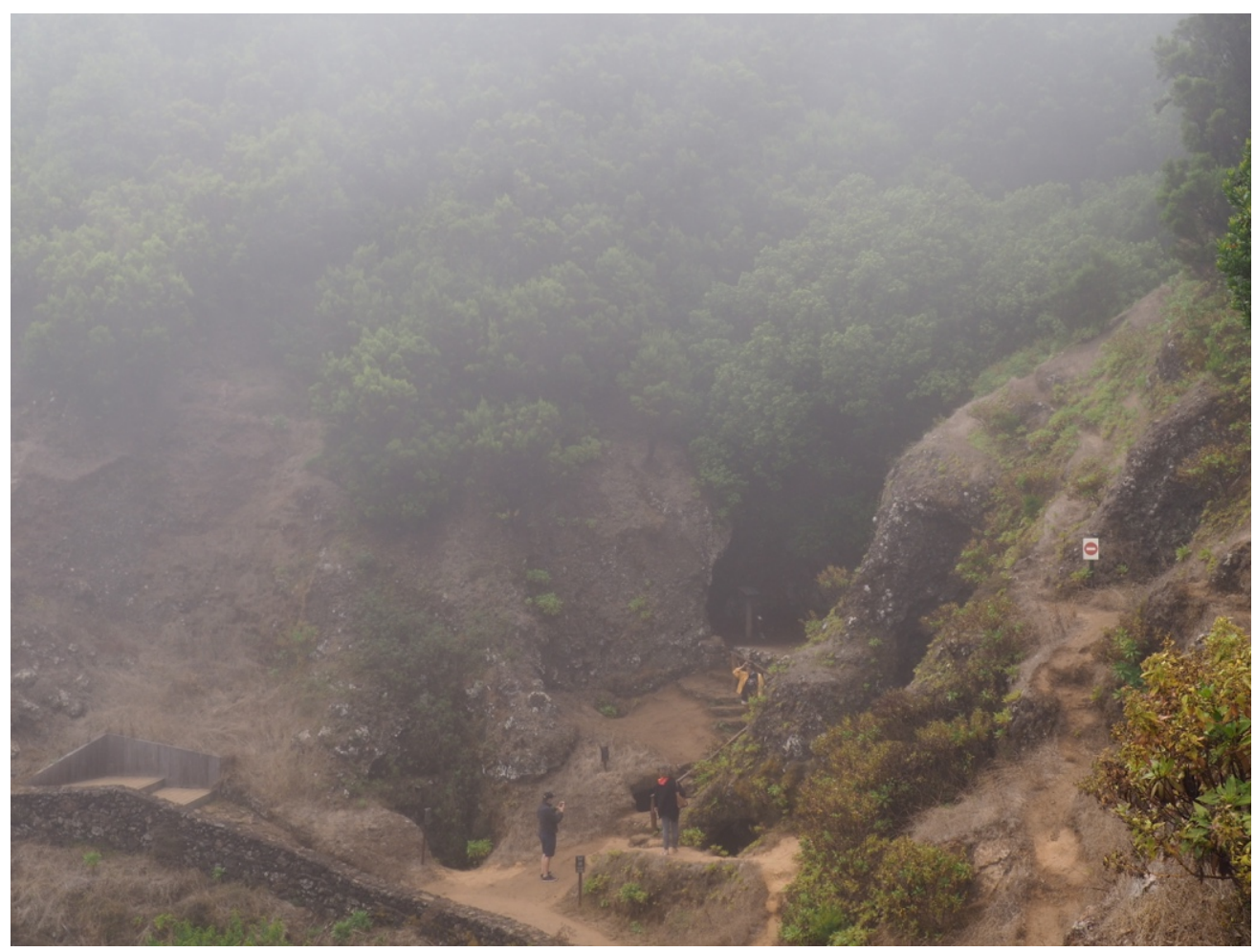

Fuente: Santamarta, J.C.

A nivel de gestión del agua, los aborígenes del archipiélago de Hawái presentan muchas similitudes con los primeros nativos de Canarias. En Hawái se organizaron en un sistema social denominado «Ohana, los jefes de cada tribu (en Ca- 
narias, serían los menceyatos), administraban la tierra y el agua, se crearon infraestructuras de riego, canales y se castigaba con grandes penas el mal uso del agua (McGregor \& MacKenzie, 2013).

A partir del siglo XV, comienza la conquista de las Islas Canarias, la tierra se repartió conjuntamente con el agua superficial procedente de los nacientes y los barrancos, que fluían en continuo y satisfacían las necesidades de los primeros pobladores, como ya se comentó. Los recursos hídricos disponibles se gestionaron en un régimen privado, cuyos propietarios se organizaban en heredades de agua modelo que ha llegado hasta la actualidad. A partir del siglo XIX, se comienza a perforar las galerías y pozos, ya que la Ley de Aguas de 1879, otorgaba la propiedad del agua alumbrada a los propietarios del terreno.

La ley de Aguas de 1879 distinguía en las aguas continentales entre superficiales, estancadas y subterráneas, lejos del concepto actual de ciclo global. Según Díaz Cruz (2017) esta ley diferenciaba entre aguas vivas, de manantiales y corrientes, tratadas en el capítulo II, aguas muertas o estancadas (capítulo III) y aguas subterráneas (capítulo IV), precisando el dominio público o privado en cada caso. Díaz Cruz, concluyó en su estudio de 2017, que «en el Artículo 188 de la Ley de Aguas, es donde se reconocía la concesión a perpetuidad de las solicitudes otorgadas a propietarios de tierras, y por 99 años a las sociedades para riego de tierras ajenas» según el citado autor.

Figura 11.8. Edificio sede de la Comunidad de Aguas, Río y Badajoz en Güimar, Tenerife

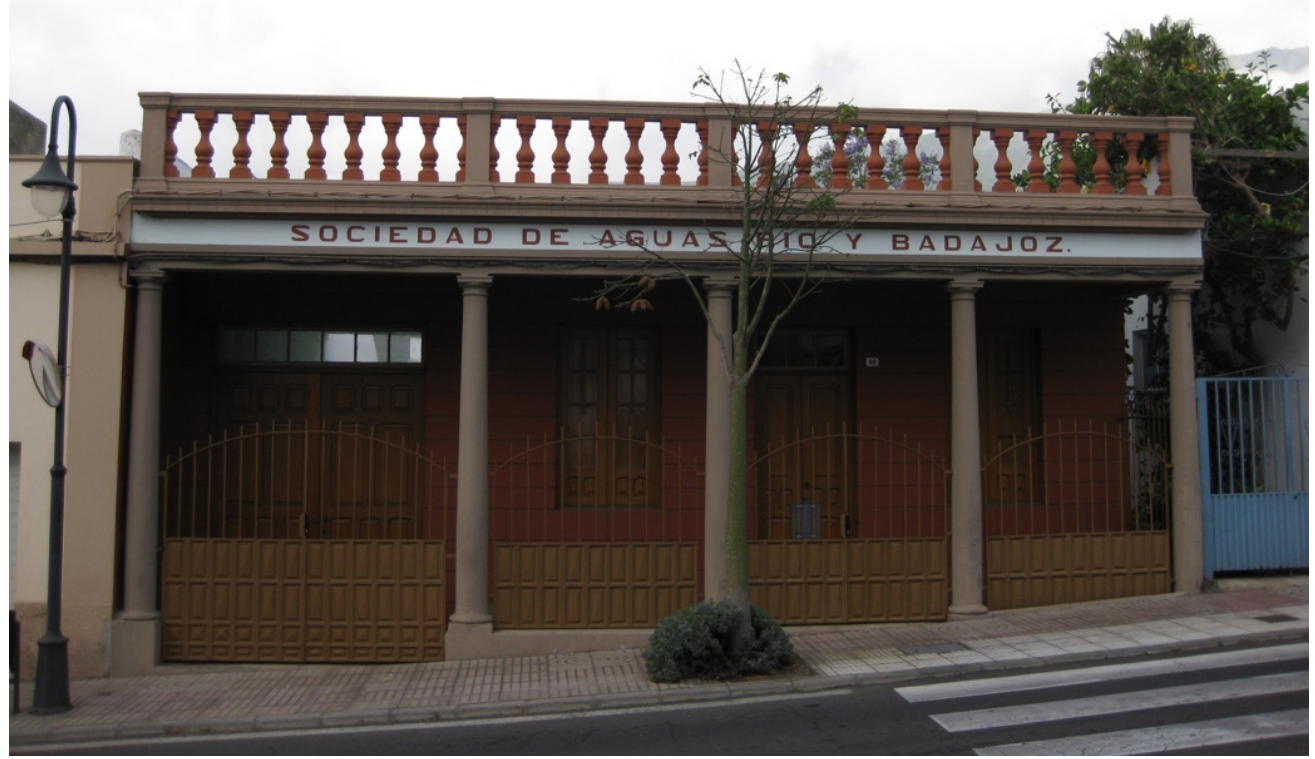

Fuente: Santamarta, J.C.

La población de las islas aumentó, la agricultura se orientó a cultivos singulares, como la caña de azúcar por lo que la demanda de recursos hídricos fue en 
aumento y llegó un momento donde los recursos superficiales no satisfacían suficientemente las necesidades. Se pensó entonces en nuevas estrategias para obtener más agua, y se comenzó a perforar el suelo en busca de nuevos recursos como ya se había hecho en otras regiones vecinas como el ejemplo de la isla de Madeira. Primero se perforaron, mediante explosivos, minas para aumentar los caudales de los nacientes, primer lugar donde por pura observación se sabía que manaba agua procedente del subsuelo. Algunos se secaron y otros drenaron más recursos hídricos. Esta técnica posteriormente se denominó galerías de nacientes (figura 11.9).

Es de justicia reconocer que el desarrollo económico actual de Canarias es en parte debido a la disponibilidad del agua subterránea, en aquella época, para su uso en la agricultura, consumo urbano, industrial y, en menor medida el consumo turístico.

Figura 11.9. Galería de naciente en San Cristóbal de La Laguna, Tenerife

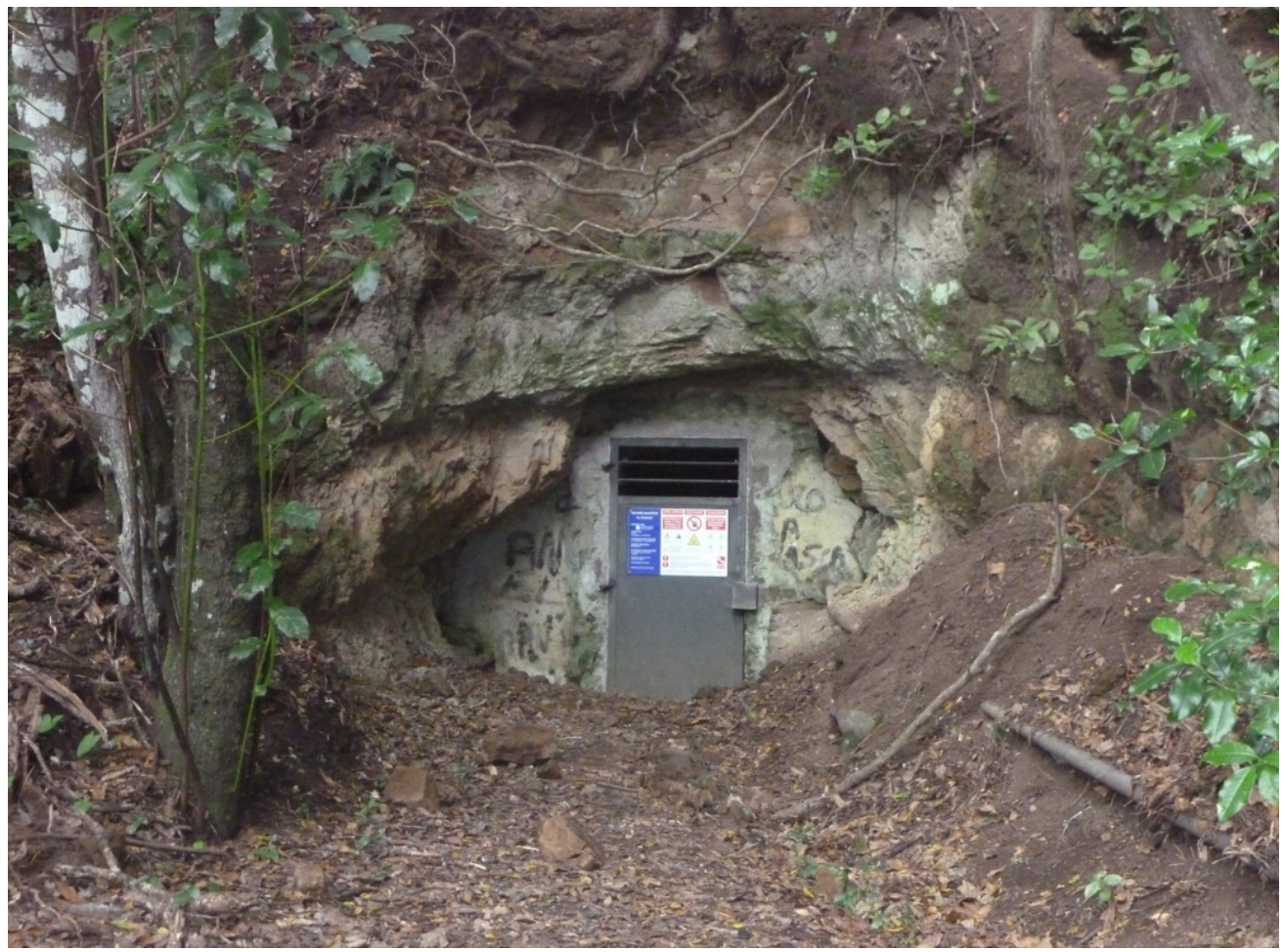

Fuente: Santamarta, J.C.

Destacar que estos recursos subterráneos no fueron obtenidos por la iniciativa pública, si no, por unas inversiones privadas y colectivas (muchas de ellas venían de los propios agricultores), que durante el principio del siglo $\mathrm{XX}$, apostaron sus recursos económicos (escasos en aquella época) en la construcción de las galerías (minas) de agua y pozos, cuando esta no era suficiente para mantener las diferentes sectores económicos de aquella época y habían sido abandonados por el Estado. En unas ocasiones, con menor o mayor acierto, se consiguió aumentar la 
disponibilidad de agua y con ello mejorar las condiciones de unas islas aisladas y que necesitaban depender de ellas mismas para subsistir, otros accionistas de arruinaron y tuvieron que emigrar, principalmente a Venezuela.

Es por ello, que las Comunidades de Agua y sus accionistas han sido uno de los precursores del desarrollo en las islas, mediante la mercantilización de un recurso, el agua. En este sentido existen muchas voces críticas en las islas, manifestando que el mercado del agua subterránea en Canarias adolece de transparencia en su gestión y que tienen en cierta medida culpa del progresivo deterioro en la calidad del agua alumbrada así como, de la sobreexplotación del acuífero. El Tribunal de Cuentas de Canarias (2017) ha detectado numerosas irregularidades en la prestación del servicio de producción y distribución de agua potable en todas las Islas Canarias. Por otro lado, actualmente se ha desarrollado una privatización de los servicios del agua, muchas localidades tienen su abastecimiento urbano en concesión a las grandes multinacionales del agua. Aunque existen modelos mixtos.

Durante los años 70, la UNESCO y el servicio Geológico del antiguo MOPU realizaron el estudio de los recursos hídricos el SPA15 (1974). Se contó con numerosos expertos, investigadores e ingenieros traídos de diferentes regiones. En él, se puso de manifiesto el mal estado de los acuíferos insulares. El siguiente proyecto hidráulico de referencia en las Islas Canarias fue el proyecto MAC-21, que duró casi 20 años, este proyecto supuso la primera planificación del recurso hídrico en las Islas Canarias. A partir de ahí, se comenzaron a redactar los planes hidrológicos que nos han acompañado hasta la actualidad conjuntamente con las nuevas técnicas de producción industrial de agua mediante la desalinización de agua de mar y la regeneración de aguas.

En la época actual, el escenario hidráulico de las islas debe ser una complementariedad entre los recursos convencionales, encabezados por las aguas subterráneas y los no naturales como la desalinización de agua de mar, donde las Islas Canarias son una potencia mundial.

En resumen, la correcta planificación hidrológica en las Islas supone un eje importante para la economía y desarrollo de la región. Existe un sector que consume muchos recursos, como la agricultura. El consumo por parte del turismo es importante, sobre todo en las islas capitalinas, pero no es un lastre importante para el sistema, a día de hoy.

En la gestión hidrológica en las Islas Canarias acontecen los siguientes problemas (tabla 11.1):

Tabla 11.1. Problemas con respecto a los recursos hídricos en cada isla

\begin{tabular}{clll}
\hline Isla & \multicolumn{1}{c}{ Problemas } & \multicolumn{1}{c}{ Posible solución } & \multicolumn{1}{c}{ Inconvenientes } \\
\hline Hierro & $\begin{array}{l}\text { Alta dependencia de la } \\
\text { desalinización de agua } \\
\text { de mar, fundamental- } \\
\text { mente para la agricul- }\end{array}$ & $\begin{array}{l}\text { Prospección de nuevos } \\
\text { alumbramientos de agua } \\
\text { subterráneas en el Valle del } \\
\text { tura. }\end{array}$ & $\begin{array}{l}\text { Coste elevado y tiem- } \\
\text { po de ejecución. In- } \\
\text { certidumbre de éxito } \\
\text { en la prospección. }\end{array}$ \\
& & & $\begin{array}{l}\text { Rechazo de la agri- } \\
\text { cultura al agua de } \\
\text { plantas desaladoras. }\end{array}$ \\
\hline
\end{tabular}




\begin{tabular}{|c|c|c|c|}
\hline Isla & Problemas & Posible solución & Inconvenientes \\
\hline Hierro & $\begin{array}{l}\text { Alta dependencia de } \\
\text { las energías fósiles. }\end{array}$ & $\begin{array}{l}\text { A pesar de las instalaciones } \\
\text { existentes de EE.RR. sigue } \\
\text { habiendo una irregulari- } \\
\text { dad en el suministro. }\end{array}$ & $\begin{array}{l}\text { Irregularidad del su- } \\
\text { ministro por EE.RR. }\end{array}$ \\
\hline Gomera & $\begin{array}{l}\text { Alta dependencia de } \\
\text { las energías fósiles. }\end{array}$ & $\begin{array}{l}\text { Aumentar el suministro } \\
\text { eléctrico por energías re- } \\
\text { novables (EE.RR.). }\end{array}$ & $\begin{array}{l}\text { Actualmente el creci- } \\
\text { miento anual de su- } \\
\text { ministro por EE.RR. } \\
\text { es el más bajo de las } \\
\text { Islas Canarias. }\end{array}$ \\
\hline \multirow[t]{4}{*}{$\begin{array}{l}\text { La } \\
\text { Palma }\end{array}$} & $\begin{array}{l}\text { Irregularidad de las } \\
\text { precipitaciones en los } \\
\text { últimos años. }\end{array}$ & $\begin{array}{l}\text { Aumento de la eficiencia en } \\
\text { las conducciones. }\end{array}$ & $\begin{array}{l}\text { Coste elevado y tiem- } \\
\text { po de ejecución. }\end{array}$ \\
\hline & $\begin{array}{l}\text { Elevada presión de la } \\
\text { agricultura en los re- } \\
\text { cursos hídricos. }\end{array}$ & $\begin{array}{l}\text { Mejora, automatización y } \\
\text { optimización de los riegos } \\
\text { mediante tecnologías, re- } \\
\text { ducción de la huella hídri- } \\
\text { ca de la platanera y otros } \\
\text { cultivos. }\end{array}$ & $\begin{array}{l}\text { Complejidad de las } \\
\text { redes de transporte } \\
\text { de aguas, sistemas } \\
\text { de riego en algunos } \\
\text { casos obsoletos. }\end{array}$ \\
\hline & $\begin{array}{l}\text { Afectación a los eco- } \\
\text { sistemas directamente } \\
\text { dependientes de las de } \\
\text { las aguas subterráneas }\end{array}$ & $\begin{array}{l}\text { "Caudales ecológicos», } \\
\text { creación de zonas de pro- } \\
\text { tección. }\end{array}$ & $\begin{array}{l}\text { El acuífero en las zo- } \\
\text { nas donde están es- } \\
\text { tos ecosistemas está } \\
\text { sobrexplotado y los } \\
\text { caudales superficia- } \\
\text { les son exiguos. }\end{array}$ \\
\hline & $\begin{array}{l}\text { Diferencia de recursos } \\
\text { disponibles norte-sur } \\
\text { de la isla. }\end{array}$ & $\begin{array}{l}\text { Sistemas de almacena- } \\
\text { miento y regulación de } \\
\text { agua/trasvases. }\end{array}$ & $\begin{array}{l}\text { Coste elevado y tiem- } \\
\text { po de ejecución. }\end{array}$ \\
\hline \multirow[t]{3}{*}{ Tenerife } & $\begin{array}{l}\text { Alta dependencia de } \\
\text { las energías fósiles. }\end{array}$ & $\begin{array}{l}\text { Aumentar el suministro } \\
\text { eléctrico por energías re- } \\
\text { novables (EE.RR.). }\end{array}$ & $\begin{array}{l}\text { Irregularidad del su- } \\
\text { ministro por EE.RR. }\end{array}$ \\
\hline & $\begin{array}{l}\text { Sobreexplotación del } \\
\text { acuífero. }\end{array}$ & $\begin{array}{l}\text { Establecer una reserva es- } \\
\text { tratégica, compensarlo con } \\
\text { la desalinización de agua } \\
\text { de mar. }\end{array}$ & $\begin{array}{l}\text { Rechazo por parte } \\
\text { de los propietarios } \\
\text { de los alumbramien- } \\
\text { tos de agua. Presión } \\
\text { por parte de las de- } \\
\text { mandas de agua de } \\
\text { agricultura. }\end{array}$ \\
\hline & $\begin{array}{l}\text { Falta de coordinación } \\
\text { entre la Administra- } \\
\text { ción Hidráulica y la } \\
\text { Medioambiental }\end{array}$ & $\begin{array}{l}\text { Coordinación en materia } \\
\text { de planificación hidrológi- } \\
\text { ca-forestal. } \\
\text { Las masas forestales como } \\
\text { reguladoras de los recursos } \\
\text { hídricos en las islas. }\end{array}$ & $\begin{array}{l}\text { Los proyectos hidro- } \\
\text { lógico-forestales son } \\
\text { a largo plazo (15-20 } \\
\text { años). }\end{array}$ \\
\hline
\end{tabular}




\begin{tabular}{|c|c|c|c|}
\hline Isla & Problemas & Posible solución & Inconvenientes \\
\hline \multirow[t]{4}{*}{ Tenerife } & $\begin{array}{l}\text { Afectación a los eco- } \\
\text { sistemas directamente } \\
\text { dependientes de las de } \\
\text { las aguas subterráneas }\end{array}$ & $\begin{array}{l}\text { «caudales ecológicos», } \\
\text { creación de zonas de pro- } \\
\text { tección. }\end{array}$ & $\begin{array}{l}\text { El acuífero en las zo- } \\
\text { nas donde están es- } \\
\text { tos ecosistemas está } \\
\text { sobrexplotado y los } \\
\text { caudales superficia- } \\
\text { les son exiguos. }\end{array}$ \\
\hline & $\begin{array}{l}\text { Baja capacidad de de- } \\
\text { puración de aguas re- } \\
\text { siduales, existencia de } \\
\text { vertidos, sanciones } \\
\text { por parte de la Comu- } \\
\text { nidad Europea. }\end{array}$ & $\begin{array}{l}\text { Construcción de depurado- } \\
\text { ras convencionales y de sis- } \\
\text { temas naturales de depura- } \\
\text { ción. }\end{array}$ & $\begin{array}{l}\text { Coste elevado y tiem- } \\
\text { po de ejecución. } \\
\text { Fiabilidad de los sis- } \\
\text { temas naturales de } \\
\text { depuración de aguas } \\
\text { residuales. }\end{array}$ \\
\hline & $\begin{array}{l}\text { Aumento de las necesi- } \\
\text { dades de agua por par- } \\
\text { te de la agricultura. }\end{array}$ & $\begin{array}{l}\text { Aumento y mejora de la ca- } \\
\text { lidad del agua regenerada. }\end{array}$ & $\begin{array}{l}\text { Rechazo de la cali- } \\
\text { dad del agua regene- } \\
\text { rada por parte de los } \\
\text { agricultores. }\end{array}$ \\
\hline & $\begin{array}{l}\text { Elevadas pérdidas en } \\
\text { el transporte de agua. }\end{array}$ & $\begin{array}{l}\text { Mejora y unificación de las } \\
\text { conducciones. }\end{array}$ & $\begin{array}{l}\text { Coste elevado, reti- } \\
\text { cencias por parte de } \\
\text { los propietarios de } \\
\text { las conducciones }\end{array}$ \\
\hline \multirow[t]{4}{*}{$\begin{array}{l}\text { Gran } \\
\text { Canaria }\end{array}$} & $\begin{array}{l}\text { Alta dependencia de } \\
\text { las energías fósiles. }\end{array}$ & $\begin{array}{l}\text { Aumentar el suministro } \\
\text { eléctrico por energías re- } \\
\text { novables (EE.RR.). }\end{array}$ & $\begin{array}{l}\text { Irregularidad del su- } \\
\text { ministro por EE.RR. }\end{array}$ \\
\hline & $\begin{array}{l}\text { Alta dependencia de la } \\
\text { desalinización de agua } \\
\text { de mar. }\end{array}$ & $\begin{array}{l}\text { Incrementar el agua rege- } \\
\text { nerada. }\end{array}$ & $\begin{array}{l}\text { Necesidad de cons- } \\
\text { truir infraestructu- } \\
\text { ras, elevados costes y } \\
\text { plazos. }\end{array}$ \\
\hline & $\begin{array}{l}\text { Fuerte binomio agua y } \\
\text { energía. }\end{array}$ & $\begin{array}{l}\text { Integración de las EE.RR. } \\
\text { en las plantas desalinizado- } \\
\text { ras de agua de mar. }\end{array}$ & $\begin{array}{l}\text { Disparidad y dife- } \\
\text { rencias entre unas } \\
\text { instalaciones y otras. } \\
\text { Inversiones iniciales } \\
\text { elevadas. }\end{array}$ \\
\hline & $\begin{array}{l}\text { Irregularidad de las } \\
\text { precipitaciones de los } \\
\text { últimos años. }\end{array}$ & $\begin{array}{l}\text { Mantenimiento de embal- } \\
\text { ses, reducción de los ate- } \\
\text { rramientos mediante la ac- } \\
\text { tuación en las cuencas } \\
\text { hidrográficas. }\end{array}$ & $\begin{array}{l}\text { Diferentes propieta- } \\
\text { rios, costes elevados. }\end{array}$ \\
\hline \multirow[t]{2}{*}{$\begin{array}{l}\text { Fuerte- } \\
\text { ventura }\end{array}$} & $\begin{array}{l}\text { Incremento del turis- } \\
\text { mo y de urbanizacio- } \\
\text { nes. }\end{array}$ & $\begin{array}{l}\text { Aumento de la oferta del } \\
\text { agua mediante desaliniza- } \\
\text { ción de agua de mar. }\end{array}$ & $\begin{array}{l}\text { Costes elevados, de- } \\
\text { pendencia combusti- } \\
\text { ble fósil. }\end{array}$ \\
\hline & $\begin{array}{l}\text { Cortes en el abasteci- } \\
\text { miento de agua. }\end{array}$ & $\begin{array}{l}\text { Aumento de la capacidad de } \\
\text { regulación del recurso me- } \\
\text { diante depósitos de agua. }\end{array}$ & Costes elevados. \\
\hline
\end{tabular}




\begin{tabular}{|c|c|c|c|}
\hline Isla & Problemas & Posible solución & Inconvenientes \\
\hline $\begin{array}{l}\text { Fuerte- } \\
\text { ventura }\end{array}$ & $\begin{array}{l}\text { Salinización acuífero } \\
\text { insular por sobrexplo- } \\
\text { tación. }\end{array}$ & $\begin{array}{l}\text { Aumento de la oferta del } \\
\text { agua mediante desaliniza- } \\
\text { ción de agua de mar. }\end{array}$ & $\begin{array}{l}\text { Costes elevados, de- } \\
\text { pendencia combusti- } \\
\text { ble fósil. }\end{array}$ \\
\hline \multirow[t]{3}{*}{$\begin{array}{l}\text { Lanza- } \\
\text { rote }\end{array}$} & $\begin{array}{l}\text { Incremento del turis- } \\
\text { mo/población. }\end{array}$ & $\begin{array}{l}\text { Aumento de la oferta del } \\
\text { agua. }\end{array}$ & $\begin{array}{l}\text { Coste elevado en in- } \\
\text { fraestructuras. }\end{array}$ \\
\hline & $\begin{array}{l}\text { Alta dependencia de la } \\
\text { desalinización del } \\
\text { agua de mar. }\end{array}$ & $\begin{array}{l}\text { Aumento de la fiabilidad } \\
\text { del sistema. }\end{array}$ & $\begin{array}{l}\text { Coste elevado en in- } \\
\text { fraestructuras }\end{array}$ \\
\hline & $\begin{array}{l}\text { Cortes en el abasteci- } \\
\text { miento de agua. }\end{array}$ & $\begin{array}{l}\text { Incremento de los depósitos } \\
\text { particulares, como así indi- } \\
\text { ca el Reglamento de Abaste- } \\
\text { cimiento y Saneamiento de } \\
\text { Lanzarote. } \\
\text { Aumento de la capacidad de } \\
\text { regulación del recurso me- } \\
\text { diante depósitos de agua. }\end{array}$ & $\begin{array}{l}\text { Complejo de inte- } \\
\text { grar en todas las edi- } \\
\text { ficaciones ya cons- } \\
\text { truidas. }\end{array}$ \\
\hline
\end{tabular}

Fuente: Elaboración propia

En general, con respecto a la integración de las energías renovables en las Islas Canarias un informe de 2018 de la empresa Red Eléctrica de España indican que El Hierro, con un $55 \%$, va a la cabeza de la utopía de llegar a la descarbonización total de las Islas. A la isla de El Hierro le siguen: Tenerife (19,7\%), Gran Canaria $(16,7 \%)$, La Palma (11,4\%), Lanzarote y Fuerteventura $(10,4 \%)$ y, finalmente La Gomera con un 0,2\%.

En este sentido se hace necesario aumentar los sistemas de almacenamiento de energía, como por ejemplo los embalses de agua para la producción de energía hidroeléctrica, donde sea técnica y económicamente viable. Crear en las Islas sistemas interconectados dados que estos son robustos y fáciles de gestionar. Sólo Lanzarote y Fuerteventura están conectados.

\subsection{Gobernanza del agua en las Islas Canarias}

Según la Organización para la Cooperación y el Desarrollo Económicos (OCDE) en 2015, los principios de la gobernanza del agua son los siguientes:

- "La efectividad se refiere a la contribución de la gobernanza en definir las metas y objetivos sostenibles y claros de las políticas del agua en todos los órdenes de gobierno, en la implementación de dichos objetivos de política, y en la consecución de las metas esperadas.

- La eficiencia está relacionada con la contribución de la gobernanza en maximizar los beneficios de la gestión sostenible del agua y el bienestar, al menor costo para la sociedad. 
- La confianza y participación están relacionadas a la contribución de la gobernanza en la creación de confianza entre la población, y en garantizar la inclusión de los actores a través de legitimidad democrática y equidad para la sociedad en general».

Figura 11.10. Visión general de los Principios de la Gobernanza del Agua de la OCDE

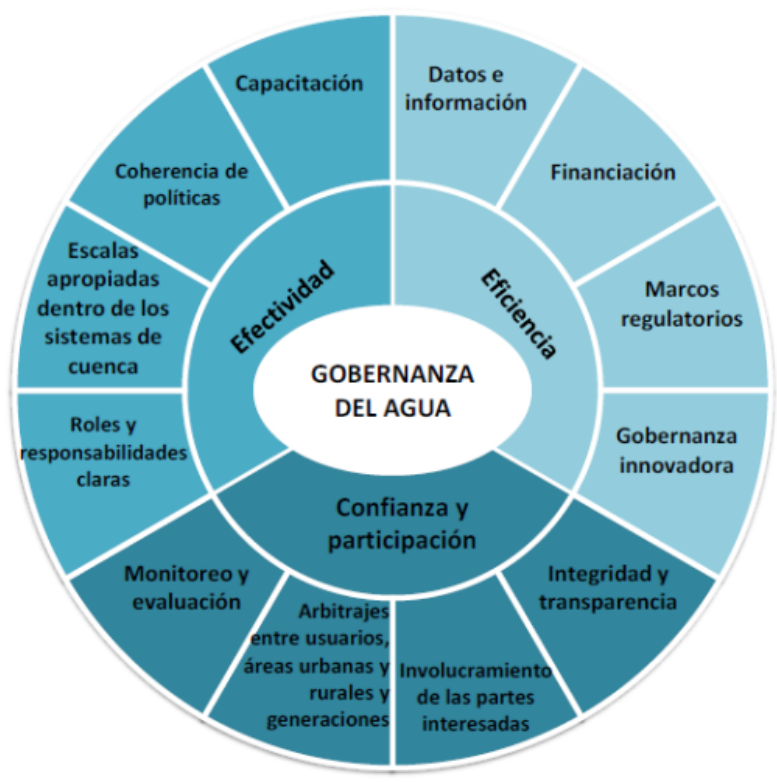

Fuente: OCDE (2015)

Los tres pilares fundamentales para el desarrollo de una región son la obtención del agua, la producción de energía y la soberanía alimentaria. En este sentido, la presión sobre el agua a escala global va en aumento. Los recursos hídricos en las Islas Canarias no son ajenos a esta presión, con unos sectores como el agrícola y el turístico que demandan gran cantidad de recursos en cantidad y calidad suficientes para satisfacer sus necesidades.

La sobrexplotación y contaminación de los acuíferos en las Islas plantearán retos importantes a corto y a medio plazo, a la seguridad y soberanía alimentaria, al suministro de agua potable, que cada vez dependerá más de la energía disponible. Dado que cada vez más recursos procederán de la producción industrial del agua, mediante plantas desalinizadoras. En el caso de las Islas Canarias la producción de energía proviene en su mayoría de combustibles fósiles, por lo que cualquier inestabilidad geopolítica a escala global afectará de modo directo a la producción de energía y, por lo tanto, a su autonomía hídrica. Por último, y no por ello menos importante, la soberanía alimentaria. Una mayor soberanía implica que un mayor porcentaje del consumo del territorio es cubierto con producción local, en el caso de las Islas Canarias esta soberanía no llega al 20\%. En las Islas existen dos tipos de agricultura, de exportación y la destinada al mercado local. 
Históricamente la agricultura de exportación comenzó con la caña de azúcar, el vino, la cochinilla y actualmente las flores y el plátano. La orientada al mercado local es fundamentalmente hortalizas, legumbres y frutas, siendo importante también la producción de vino. Esta producción no colma las necesidades de la población local ni de los visitantes a las islas (más de 12 millones de turistas al año). Otras limitaciones para no poder aumentar ese porcentaje de soberanía alimentaria es la insularidad, ser un territorio fragmentado, la lejanía al continente, la falta de capacidad de almacenaje de productos, los cambios de consumo de los ciudadanos, especialmente los más jóvenes.

En el caso de las Islas Canarias podemos dividir la gobernanza del agua en dos ámbitos, el público y el privado. El ámbito público lo conformaría:

- Comunidad Europea.

- Estado.

- Gobierno de Canarias.

- Cabildos Insulares (Consejos Insulares de Agua).

- Ayuntamientos

- Mancomunidades.

- Entidades públicas empresariales.

- Empresas concesionarias.

En el ámbito privado en las Islas Canarias estarían:

- Comunidades de Aguas.

- Comunidades de Regantes.

- Heredamientos.

Las Comunidades de Agua se configuran como entidades asociativas con personalidad jurídica propia otorgada por Ley 27 de diciembre de 1956, mediante la cual varias personas unen sus esfuerzos y medios para extraer y/o conducir aguas privadas participando todos ellos de los gastos de la comunidad y de sus réditos según el número de participaciones (acciones) que posean. La titularidad de las aguas alumbradas es de cada partícipe en proporción al número de acciones que posee, decidiendo individualmente el destino que quiere darle a la cuota de caudal que le corresponde. En una alta proporción los titulares de las aguas son a su vez agricultores, que las aplican en el riego de sus tierras; pero en otros casos optan por ofrecerlas en venta o en permuta.

Existen diferentes tipos de comunidades:

- Comunidades de alumbramientos.

- Comunidades de transporte.

- Comunidades de alumbramientos y transporte.

- Comunidades de alumbramientos, transporte e intermediarios. 
Las heredades de aguas, estarían formada por un conjunto de propietarios de una captación de aguas, ya sea de un naciente, pozo o galería. En algunas ocasiones, también se incluían los terrenos vinculados a esos recursos hídricos, como en el caso de la Heredad de Arucas y Firgas, en la isla de Gran Canaria. El agua se administraba desde estas sociedades, sobre todo para el uso agrícola.

La captación, asignación, distribución y utilización del agua subterránea en las Islas Canarias se ha venido realizando casi en su totalidad por la iniciativa privada ateniéndose al marco jurídico tradicional canario. La Administración Pública se ha limitado a ser el árbitro de conflictos entre particulares y a velar por el cumplimiento de la legalidad vigente. Hasta la entrada en vigor de la Ley 12/1990, de Aguas, el agua era propiedad de aquel que la extraía, pudiendo utilizarla para sus propios usos, o bien ofertarla a potenciales usuarios de la misma en función de sus necesidades. Esto supone, según Díaz-Frontón (2014):

- Atomización de la producción.

- Destino del agua a los usos más rentables.

- Dispersión e individualización de las infraestructuras (figura 11.11).

- Dispersión e individualización de los puntos de demanda.

Figura 11.11. Individualización de conducciones en el sur de la isla de Tenerife

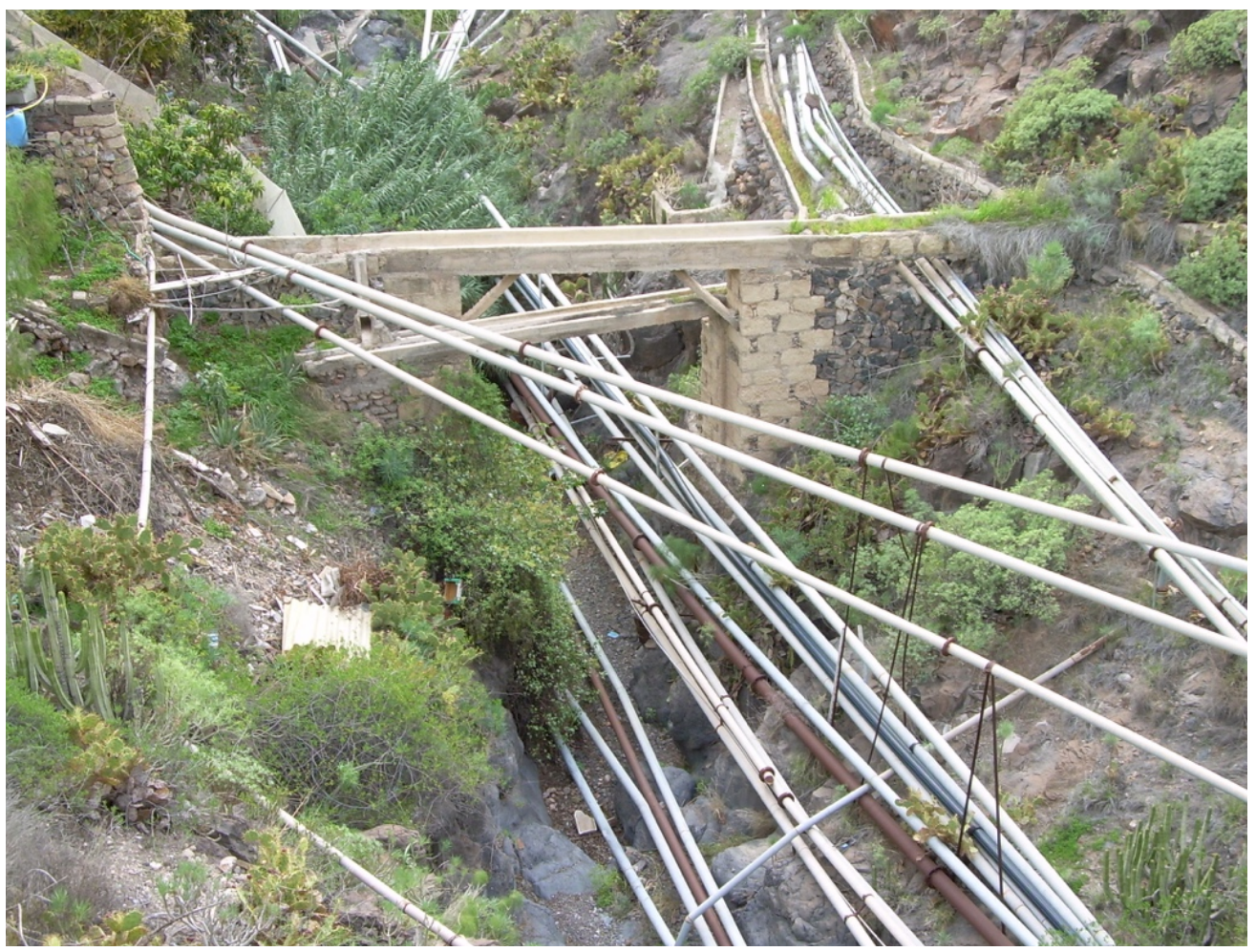

Fuente: Santamarta, J.C. 
Finalmente destacar que en los aspectos relativos a la gestión y economía del agua se avecina un importante cambio en el modelo de gestión del agua en Canarias. A partir de la Ley de Aguas de 1990, se otorgaron 50 años de periodo transitorio para el cambio de titularidad de las aguas del sector privado a titularidad pública. Este cambio ocurrirá en el año 2040, es decir, dentro de unos 20 años. Supondrá un periodo de incertidumbre importante, dada la magnitud del número de explotaciones e infraestructuras que pasarán a manos públicas. Es necesario comenzar a planificar desde ya el futuro escenario de la gestión del agua en Canarias.

Por otro lado, existe un gran desconocimiento de la realidad hidrológica de las islas volcánicas por parte de los no residentes en las islas u otras regiones europeas. Esto supone problemas a la hora de diseñar leyes y normativas que afecten a los recursos hídricos, incluso las que proceden de la legislación europea. Se recomienda siempre considerar la singularidad de las islas volcánicas a la hora de pronunciar leyes que afecten a la gestión o aprovechamiento de los recursos hídricos en general.

Los sistemas de gobernanza deben estar preparados para atender la creciente demanda de agua, en todos los sectores, los desafíos ambientales, el continuo proceso de urbanización, la variabilidad climática y los desastres ocasionados por el agua.

\subsection{La participación ciudadana en materia de aguas}

Es evidente que existe una nueva cultura del agua a nivel global en el país y, por lo tanto en las Islas Canarias. Este nuevo paradigma parte del antiguo modelo de gestión del agua desde un punto de vista tecnocrático, es decir, el agua es un factor de producción más y las decisiones se toman desde el punto de vista técnico y económico. El nuevo modelo planteado es una gestión más participativa, democrática, equitativa y con el agua como un valor ambiental. Con ello, los servicios que ofrece el agua no sólo son el abastecimiento a las poblaciones como agua potable o bien como vector para poder producir alimentos y energía. Se comienza a dar valor a otros nuevos servicios, como los ecosistémicos, recreativos y sociales. Este cambio de paradigma hace que se cambie el modelo de gestión, la cual debe ser más participativa, no solo por parte de los usuarios económicos si no, que se establecen métodos para que los ciudadanos participen.

En este sentido, es necesario establecer espacios y momentos para la información y consulta de los proyectos, planes hidrológicos y cuestiones de interés relacionados con el agua para los ciudadanos, incluyendo un proceso que incorpore la participación activa de las partes interesadas, los grupos de interés y la población.

Una herramienta esencial para la participación social en las decisiones que tengan como objetivo la gestión del agua subterránea es la organización de talleres sectoriales es esencial para lograr la participación de los agentes interesados. Estos talleres pueden ser organizados en dos líneas de trabajo, la primera es la 
orientación desde un alto grado de especialización, incluyendo a los colegios profesionales, representantes del sector empresarial y del sector primario, comunidades de agua y la Administración Pública. La segunda sería menos especializada y dirigida al público en general interesado.

\subsection{El libro verde de la gobernanza del agua}

Según el Ministerio para la Transición Ecológica (2019) un Libro Verde es un documento que se concibe para recopilar opiniones y aportaciones de los actores más relevantes con relación a un tema que se considera estratégico para la acción de gobierno. El Libro Verde de la Gobernanza del Agua en España busca abrir espacios de diálogo con las administraciones competentes en el ámbito local, autonómico y estatal y con las partes interesadas en los distintos territorios para recabar opiniones en relación con los retos del modelo de gobernanza vigente. Un proceso centrado en recabar propuestas de mejora de la Gobernanza del Agua en España. Este proceso se llevó a cabo en las Islas Canarias durante el año 2019. Como sedes se escogieron las dos capitales, Santa Cruz de Tenerife y Las Palmas de Gran Canaria. Los participantes pertenecían a diferentes sectores económicos vinculados con el ciclo integral del agua, como por ejemplo: los Consejos Insulares de Agua, empresas concesionarias del servicio de aguas, asociaciones, universidades, empresas consultoras y de la Administración Pública. Las conclusiones sobre la gobernanza del agua desarrollada en las Islas Canarias fueron muy interesantes y entre ellas se destacan, según el Ministerio para la Transición Ecológica (2019) las siguientes:

Aportaciones y sugerencia de la reunión de Santa Cruz de Tenerife:

- Existen muchas singularidades entre las islas, hidrología, sistemas de aprovechamiento y producción industrial de agua. Convendría crear un comité de autoridades competentes, así como un comité de zonas protegidas y costeras.

- Se recomienda articular instrumentos para la colaboración y coordinación entre los agentes que intervienen en el ciclo integral del agua.

- Es necesario crear un marco de colaboración entre las universidades y las administraciones en materia de investigación.

- Mayor participación en las propuestas de equipos interdisciplinares.

- Mejora en la incorporación de la administración electrónica y trabajo por objetivos en la administración.

- Hacer la normativa más comprensible por parte de la ciudadanía.

- Incorporación del "Big Data», aún sin explorar en las Islas Canarias.

- Creación de un marco regulatorio único, que unifique criterios y tarifas. De esta forma se realizaría una gestión única de incidencias y fomentaría la seguridad jurídica. 
- Regular la implementación de tecnologías apropiadas, bajo parámetros de economía circular y de mitigación de cambio climático. Fomentar la sostenibilidad (cuotas usuarios y vertidos cero).

- Traspasar competencias de los servicios públicos desde el municipio a órganos o instituciones que puedan desarrollarlas adecuadamente.

Aportaciones y sugerencias de la reunión de Las Palmas de Gran Canaria:

- Revisar la normativa en Canarias. Reforma conjunta de la normativa de aguas, ambiental y territorial ya que tienen objetivos, medios e información comunes. Sería necesario clarificar la legislación europea y territorial canaria y la ley de aguas canaria.

- Fomentar la reutilización con un cambio legislativo. Es necesaria la reforma del contexto legal en cuanto a la reutilización del agua, adaptada también a los pequeños municipios. No se transmite la cultura del agua regenerada, y es necesaria la coordinación vertical, desde Europa, pero también desde Canarias. Es importante unir la calidad del agua con los usos que se le vaya a dar.

- Fomento e inversión en $I+D+i$ que potencie la innovación y la modernización en la AdministraciónPpública.

- Realizar un control real de los consumos de agua, instrumento que vele por la racionalidad y la sostenibilidad (llevando un control de pérdidas).

- Reforma legislativa que garantice cánones y tarifas finalistas, con obligación de invertirlo en el servicio del agua, incentivando una buena gestión del servicio.

\subsection{El papel de la universidad en la gobernanza del agua}

La universidades y centros de investigación, tienen un papel fundamental en la gobernanza del agua en las Islas Canarias. Por un lado, son la herramienta para formar a los futuros gestores de los recursos hídricos mediante planes de estudio integrados en los diferentes grados y postgrados. En la universidad también se desarrollan investigaciones en formato de tesis o trabajos de grado (TFG) o fin de máster (TFM). En el caso de las Islas Canarias, a nivel de investigación, las tesis doctorales dedicadas al estudio de los recursos hídricos en islas volcánicas son escasas. Esto contrasta con la gran importancia que tiene este recurso en las islas. En el caso de Canarias, se han contabilizado 11 tesis doctorales. En particular hay 4 relacionadas con la ingeniería de los aprovechamientos del agua y 7 con la hidrogeología de las islas. Las islas estudiadas han sido, Tenerife, Fuerteventura, Gran Canaria, La Palma y La Gomera. Es este sentido es necesario desarrollar más investigaciones relacionadas con la hidrogeología de las Islas, en particular con la de El Hierro y con la de Lanzarote. La Administración Hidráulica y las Universidades de Canarias deben seguir investigando desde un punto de vista interdisciplinar el ciclo integral del agua. Estas investigaciones podrían desarrollarse en estos sectores estratégicos: 
- Aguas superficiales.

o Efecto de las avenidas e inundaciones.

o Mejora de la gestión de embalses, aterramientos, eutrofización.

o Medición de caudales.

- Aguas subterráneas.

o Prospección de nuevos recursos.

o Aprovechamiento sostenible de los acuíferos.

o Estudio de la contaminación difusa.

o Control de la intrusión marina.

o «Big data».

- Aguas costeras.

o Control de la contaminación, vertidos, salmuera.

o Mejora de la identificación de las especies costeras singulares de Canarias.

- Aguas desalinizadas procedentes del mar.

o Valorización de la salmuera.

o Optimización del proceso para la reducción del consumo energético.

o Incremento del uso de energías renovables para el funcionamiento del proceso.

- Aguas regeneradas.

o Estudio de los efectos de los contaminantes emergentes presentes en su uso agrícola.

o Estudio de su uso para la recarga artificial de acuíferos.

- Gestión del agua.

o Reducción de las pérdidas de agua en las conducciones.

o Estudio y puesta en valor de la cultura del agua en las Islas Canarias.

o Puesta en valor del patrimonio hidráulico de las Islas.

o Planes de difusión y educación en materias sobre el agua en los centros de formación.

\subsection{Algunas conclusiones sobre la gobernanza del agua en las Islas Canarias}

Los recursos hídricos en las Islas Canarias son limitados, dependen de dos fuentes, la natural, mediante las precipitaciones, la lluvia horizontal y la nieve. La fuente artificial de recursos, mediante la desalinización del agua de mar, que depende de los combustibles fósiles en un elevado porcentaje.

Las fuentes naturales se verán afectadas por el escenario de cambio climático que se hará patente con un cambio de los regímenes de las precipitaciones y una 
mayor evaporación de agua. Con respecto a la lluvia horizontal, se hace necesario una protección de las masas forestales vinculadas a esta fuente, como un elemento que favorece la infiltración y la conservación de los suelos volcánicos. El patrón de nieve también puede cambiar, aunque el impacto de esta en los acuíferos insulares es inferior, dado que la mayoría de la nieve se sublima (pasa a gas) y por lo tanto se evapora y no se infiltra en el terreno.

Con respecto a los recursos artificiales, estos dependerán del precio del petróleo, y de cualquier inestabilidad geopolítica que ocurra a nivel global. Reducir el consumo energético para la producción industrial del agua es complejo técnicamente y existe un límite. Por lo que el futuro de ese sistema de producción de agua en las Islas pasa por el uso de energías renovables para su funcionamiento.

Con respecto a los acuíferos insulares, se observa una reducción global de los recursos. Esta situación, aunque ha sido compensada en parte por la integración de plantas desalinizadoras de agua de mar en la oferta de agua.

En un escenario de cambio climático se observa que cada vez más la agricultura necesitará más recursos debido al cambio del patrón de temperaturas y una mayor evapotranspiración. En los últimos planes hidrológicos de las Islas Canarias, se observan numerosas masas de agua en mal estado, sobre todo por contaminación debida a nitratos procedentes de la agricultura y a la intrusión marina. Esta última también es debida a la actividad agrícola en su mayoría, dado que los pozos y sondeos costeros cada vez demandan más recursos hídricos, esto supone una salinización del acuífero por la penetración en el mismo del agua de mar.

Es necesario plantearse un cambio de los cultivos que actualmente existen en Canarias por otros menos demandantes de recursos hídricos o bien sustituir esos recursos de gran calidad por otros con una calidad más ajustada a su uso, como lo es el agua regenerada proveniente de plantas con sistemas modernos de depuración de aguas. En definitiva, se debe procurar cerrar el ciclo del agua en las Islas Canarias, mediante su uso circular como ocurren en otros lugares como Singapur. La actividad agrícola en las Islas Canarias es esencial para promover una soberanía alimentaria, pero se deben optimizar los consumos de agua.

Las infraestructuras hidráulicas en las Islas Canarias son muy obsoletas y necesitan una inversión muy importante para su mejora. Es evidente que en un territorio fragmentado y con la orografía que presentan las Islas la complejidad de la ejecución de las infraestructuras es elevada. En ocasiones no coincide las zonas de producción de agua con las de consumo. Con relación al transporte de agua es donde más se concentran las pérdidas de agua, también en las redes municipales, por lo que aumentar la oferta de agua para compensar esas pérdidas no parece una estrategia adecuada. Desde la Administración de debería hacer un plan integral para la mejora de las infraestructuras con el fin de reducir las pérdidas al máximo.

Para poder acometer una transición hidrológica en las Islas Canarias es necesario saber de que situación se parte. Este punto solo se logra con transparencia sobre cuales son los consumos reales de agua en las Islas, también el dato de cuanto es el agua se pierde en las redes. Solo así se puede llevar a cabo una estra- 
tegia para su gestión óptima que pasa también por una tarifa unificada, tanto de consumo como de vertido.

Por último y no menos importante, es necesario aumentar la participación ciudadana en los procesos de planificación así como una mayor implicación de las universidades y centros de investigación.

\section{Referencias bibliográficas}

Díaz Cruz, P. L. (2017). Tesis doctoral. El agua en Canarias: estudio de los aprovechamientos hídricos superficiales bajo la Ley de Agua de 1879 (1879-1959). XXII Coloquio de Historia Canario-Americana (2016), XXII-086b.

Directiva 2000/60/CE del parlamento europeo y del consejo de 23 de octubre de 2000 por la que se establece un marco comunitario de actuación en el ámbito de la política de aguas.

Díez Frontón, D. (2014). Fuentes de agua en Tenerife: estudio de la oferta y la demanda. Curso sobre Gestión eficiente del agua y Smart cities. Universidad de Verano de Adeje. Tenerife (Islas Canarias).

Informe de Fiscalización de la Cuenta General de la Comunidad Autónoma de Canarias, ejercicio 2017.

Ley 10/2010, de 27 de diciembre, de modificación de la Ley 12/1990, de 26 de julio, de Aguas.

Ley de Aguas de 1879.

Ley de 27 de diciembre de 1956, sobre heredamientos de aguas del archipiélago canario.

McGregor, D.P., MacKenzie, M.K. (2013). A brief summary of the history of Native Hawaiian governance in Hawaii. Honolulu, Hawai'i: Office of Hawaiian Affairs. Online at: http://www.kalihipalama.org/wp-content/uploads/2016/07/ A-Brief-Summary-of-the-History-of-NH-Governance-in-HIJuly-2013.pdf

Ministerio para la Transición Ecológica (2019). Libro Verde de la Gobernanza del Agua en España.

Ministerio para la Transición Ecológica (2019). Libro Verde de la Gobernanza del Agua en España, diálogos territoriales. Acta del Foro de debate de Canarias. Santa Cruz de Tenerife.

Ministerio para la Transición Ecológica (2019). Libro Verde de la Gobernanza del Agua en España, diálogos territoriales. Acta del Foro de debate de Canarias. Las Palmas de Gran Canaria.

Organización para la Cooperación y el Desarrollo Económicos (OCDE). (2015). Principios de Gobernanza del Agua de la OCDE.

Red Eléctrica de España. (2018). Las energías renovables en el sistema eléctrico español. Recuperado de https://www.ree.es/es/datos/publicaciones/informe-de-energias-renovables/informe-2018 
Santamarta J.C., (2016). Tratado de Minería de Recursos Hídricos en Islas Volcánicas Oceánicas. Sevilla: Colegio Oficial de Ingenieros de Minas del Sur.

Santamarta, J.C. (2012). Singularidades y evolución técnica de la ingeniería de presas en las Islas Canarias. Revista Obras Públicas nº159, pág. 33-50.

Santamarta, J.C. (2013). Hidrología y recursos hídricos en islas y terrenos volcánicos. Métodos Técnicas y Experiencias en las Islas Canarias. Madrid: Colegio Oficial de Ingenieros de Montes.

Santamarta, J.C., Hernández, L.E., Rodriguez-Losada, J.A. (2010a).Volcanic dikes engineering properties for storing and regulation of the underground water resources in volcanic islands.ISRM International Workshop on Rock Mechanics and Geoengineering in Volcanic Environments 2010, IWVE 2010, 2010, pp. 95-98

Santamarta, J.C., Seijas, J. (2010b). Fundamentos y tecnologías para la captación y uso del agua procedente de la lluvia horizontal en los montes canarios. Revista Montes $n^{\circ} 100$, pág. 15-21.

Soler Liceras, C. (2012). Obras hidráulicas en terrenos volcánicos. Madrid: Colegio de Ingenieros de Caminos Canales y Puertos.

SPA-15, (1974). Estudio científico de los recursos de agua en las Islas Canarias (SPA/69/515). Ministerio de Obras Públicas. Dirección General de Obras Hidráulicas. UNESCO. Las Palmas de Gran Canaria, Madrid. 3 volúmenes y mapas. 


\title{
Capítulo 12 \\ Retos de futuro de los recursos hídricos en las Islas Canarias
}

\author{
Juan Carlos Santamarta Cerezal \\ Doctor Ingeniero de Montes
}

\subsection{Introducción}

Las Islas Canarias, situadas en el océano Atlántico, son de origen volcánico. Esto implica una heterogeneidad en sus paisajes, orografía y materiales que se han ido apilando de una manera caótica a lo largo de las diferentes erupciones volcánicas que han acontecido a lo largo de su historia, las primeras hace unos 20 millones de años. Por lo tanto, tampoco se puede hablar de unas islas homogéneas, en relación a sus recursos hídricos disponibles y su manera de aprovecharlos. En base a esta premisa, se puede hablar de 8 islas y de 8 formas diferentes de entender el agua, su aprovechamiento y gestión.

Las Islas Canarias, pese a ser una región globalmente reconocida por su escasez de agua, es posible identificar diferentes singularidades, con respecto a los recursos hídricos, en las diferentes islas que componen el archipiélago. El abastecimiento de agua en las Islas Canarias varía de Oeste a Este. Mientras que en las islas occidentales el agua proviene fundamentalmente de las aguas subterráneas, las islas orientales se abastecen mediante la desalinización de agua de mar (Santamarta, 2017). Lanzarote, prácticamente obtiene todos sus recursos de la producción industrial del agua. Por otro lado, están los consumos de agua. Si bien, pudiera parecer que el mayor consumidor del agua es el turismo, esto solo ocurre en la isla de Lanzarote, en todas las demás el mayor consumo procede de la agricultura (Santamarta, 2013).

En las islas oceánicas, tales como Madeira (Portugal), Azores (Portugal), Hawái (EE.UU.), Jeju (Corea del Sur) (Jong-Ho, et al. 2005) o Fiji, destaca el sector primario, así como un potente sector de servicios orientados al turismo. El archipiélago canario sigue ese patrón. En general, en las Islas Canarias (y en otros sistemas insulares), el turista consume más recursos hídricos que los residentes (Ruiz de la Rosa et al. 2019).

Los recursos hídricos serán críticos en un escenario de cambio climático. Los territorios que primero sentirán los efectos serán los insulares por periodos de sequía más largos, como ya está ocurriendo en Cabo Verde, concentración de 
Figura 12.1. Paisaje semiárido de la isla oriental de Fuerteventura

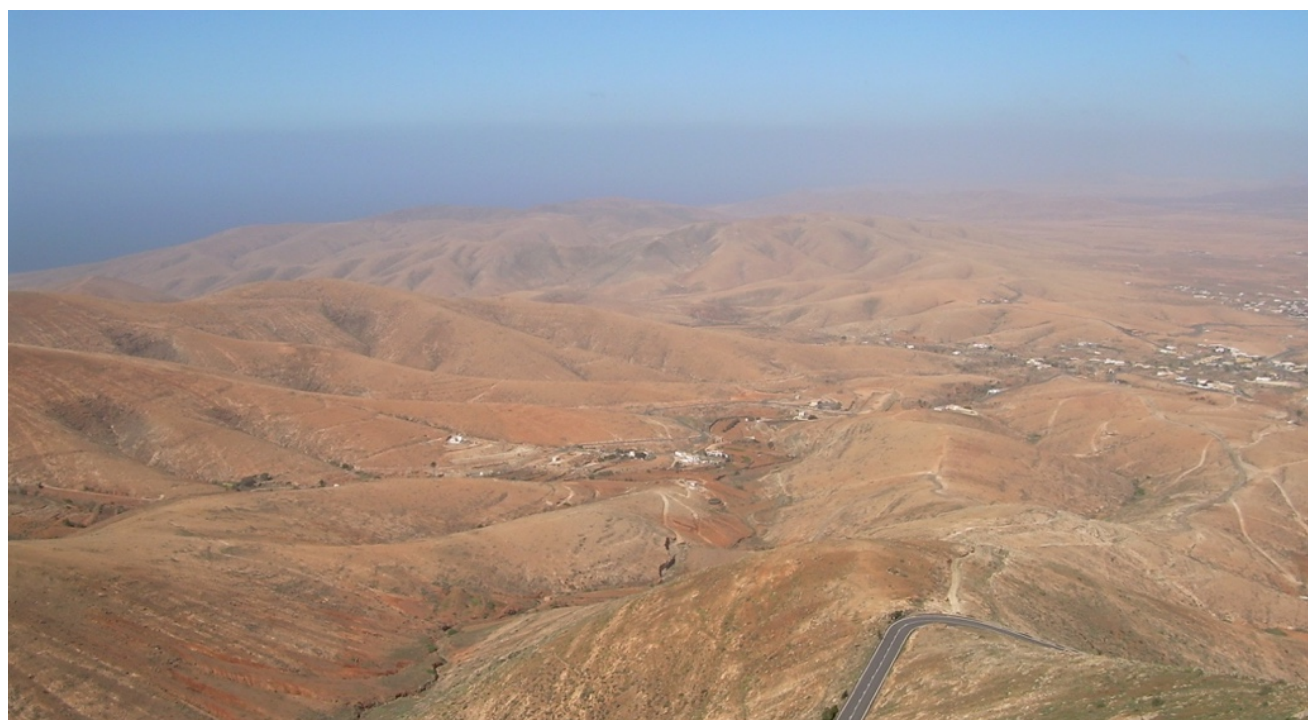

Fuente: Santamarta, J.C.

lluvias de manera irregular y de singularidad torrencial. El cambio climático obligará a replantear el uso del agua, gestionarla eficientemente y de manera integral será esencial en las Islas Canarias.

El presente capítulo, trata de identificar los aspectos clave relacionados con los recursos hídricos en las Islas Canarias en los próximos años.

Figura 12.2. Embalse en la Isla de San Vicente en Cabo Verde

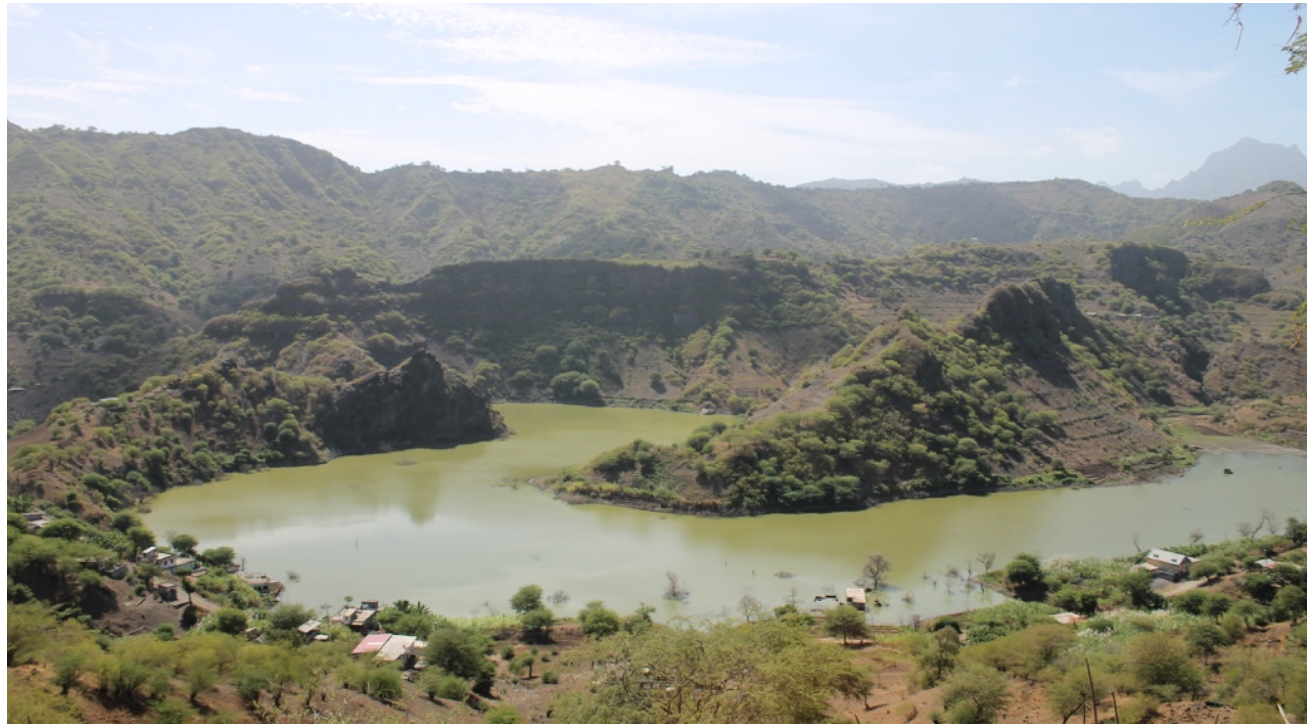

Fuente: Santamarta, J.C. 


\subsection{El agua en las Islas Canarias}

Como se ha comentado en la anterior sección a la hora de describir el aprovechamiento del agua en las Islas Canarias hay que diferencia entre las islas occidentales y las orientales.

En grupo occidental, el consumo de agua se abastece principalmente por aguas subterráneas, en algunos casos con porcentajes que superan el $80 \%$ del total del suministro en Tenerife y La Palma, complementado en menor medida por el suministro de agua procedente de plantas desalinizadoras de agua, sobre todo en la isla de Tenerife. Como excepción, comentar que en la isla de La Palma no existen, por el momento, plantas desalinizadoras de agua procedente del mar para suministro del abastecimiento de la población. Si bien, en esta última isla, el estrés hídrico al que ha estado sometida la isla durante 2019 y 2020 por parte de la presión sobre el recurso hídrico, que hace actualmente la agricultura, hace vislumbrar un futuro que pasa por aumentar la oferta y disponibilidad de los recursos hídricos subterráneos o recurrir finalmente a la producción industrial de agua.

Hay una parte muy residual de recursos hídricos superficiales viables para su uso, principalmente en La Palma y en La Gomera. En la isla de El Hierro, prácticamente no existen recursos superficiales y quedan unos manantiales muy estacionales, por ejemplo en Binto y en el Julán.

Figura 12.3. Barranco con agua en la isla de Tenerife, normalmente están secos, salvo el barranco de Las Angustias en La Palma o algunos arroyos en Gran Canaria y La Gomera

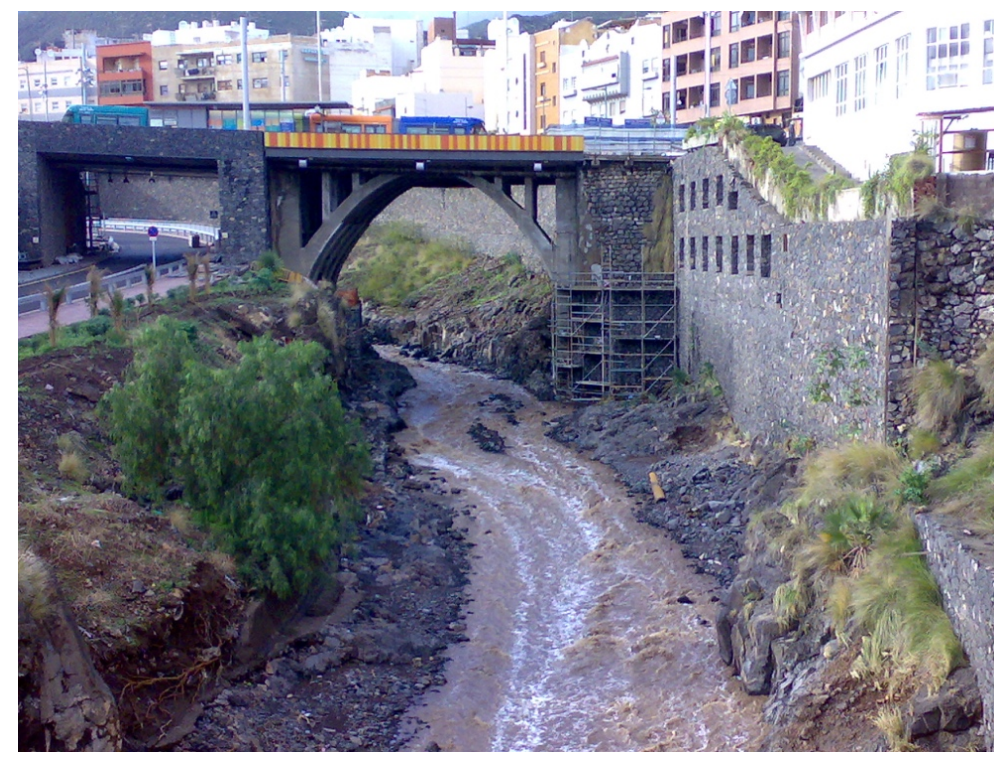

Fuente: Santamarta, J.C.

Es evidente que el crecimiento económico de las islas está vinculado a la producción de agua, en este sentido, la minería del agua que se ha hecho en las Islas 
Canarias ha sido uno de los vectores principales del desarrollo de las Islas en las islas occidentales a la vez que la desalinización de agua de mar lo ha sido de las orientales.

Los datos relacionados con el agua en las Islas Canarias son los siguientes: la extracción de agua subterráneas se divide entre, las galerías con $207 \mathrm{hm}^{3}$ y los pozos, con un caudal aproximado de $136 \mathrm{hm}^{3}$ (sin contar con Fuerteventura). Las aguas desalinizadas procedentes del mar suponen $236 \mathrm{hm}^{3}$ y finalmente, las aguas reutilizadas son alrededor de $20 \mathrm{hm}^{3}$ (Santamarta, 2017). Según datos del Gobierno de Canarias (2015) existen actualmente 319 plantas desalinizadoras de agua de mar en las Islas Canarias. La una capacidad de producción total de agua potable es superior a los $660.000 \mathrm{~m}^{3} /$ día en su capacidad anual de producción de agua dulce se estima en 240 hectómetros cúbicos al año. Como ejemplo, para poder comparar el orden de magnitud de estas cifras, la isla de Tenerife necesita unos $225 \mathrm{hm}^{3} /$ año de agua y la Isla de El Hierro aproximadamente unos $3 \mathrm{hm}^{3} /$ año. De la producción total de agua desalinizada, aproximadamente el $70 \%$ se destina al abastecimiento urbano, casi un $30 \%$ a la agricultura y menos de $1 \%$ al consumo industrial. También llama la atención el dato que, las islas de Lanzarote (la más dependiente de la desalinización de agua de mar, Fuerteventura y Gran Canaria, necesitan aproximadamente entre un $13 \%$ y un $18 \%$, de la energía producida, para desalinizar agua de mar. De ahí que siempre se hable de un fuerte binomio agua y energía en las Islas, siendo esto una debilidad del sistema hidráulico.

Tabla 12.1. Valoración de los recursos hídricos en las Islas Canarias y perspectivas de futuro

\begin{tabular}{llllll}
\hline Isla & $\begin{array}{c}\text { Recursos } \\
\text { hídricos } \\
\text { superficiales }\end{array}$ & $\begin{array}{c}\text { Recursos } \\
\text { hídricos } \\
\text { subterráneos }\end{array}$ & $\begin{array}{l}\text { Desalación y } \\
\text { reutilización }\end{array}$ & $\begin{array}{c}\text { Aprovechamiento } \\
\text { hídrico que } \\
\text { predomina }\end{array}$ & $\begin{array}{c}\text { Tendencia } \\
\text { en el futuro }\end{array}$ \\
\hline Hierro & Nulos & Altos & Bajos & $\begin{array}{l}\text { Pozos-galería de } \\
\text { agua }\end{array}$ & Desalación \\
\hline La Palma & Escasos & Altos & Nulos & $\begin{array}{l}\text { Galería de } \\
\text { agua-pozos }\end{array}$ & $\begin{array}{l}\text { Subterráneos- } \\
\text { Desalación }\end{array}$ \\
\hline Gomera & Medios & Altos & Nulos & $\begin{array}{l}\text { Pozos-galería de } \\
\text { agua }\end{array}$ & $\begin{array}{l}\text { Subterráneos- } \\
\text { superficiales }\end{array}$ \\
\hline Tenerife & Escasos & Altos & Medios & $\begin{array}{l}\text { Galería de } \\
\text { agua-pozos- } \\
\text { sondeos }\end{array}$ & $\begin{array}{l}\text { Subterráneos- } \\
\text { Desalación }\end{array}$ \\
\hline Gran Canaria & Medios & Medios & Medios & Pozos-presas & $\begin{array}{l}\text { Subterráneos- } \\
\text { Superficiales- }\end{array}$ \\
& & & & Desalación \\
\hline Lanzarote & Nulos & Escasos & Altos & Desalación & Desalación \\
\hline Fuerteventura & Escasos & Medios & Altos & Desalación-pozos & Desalación \\
\hline
\end{tabular}

Fuente: Elaboración propia adaptado de Santamarta (2011) 
Como se ha comentado, en el grupo oriental, el consumo de agua procede fundamentalmente de las plantas desalinizadoras de agua, con ciertas excepciones. Por ejemplo: en el caso de Gran Canaria existen notables recursos subterráneos, extraídos mayoritariamente por pozos de tipo «canario» (de cumbre y costeros) y sondeos, así como recursos superficiales, almacenados por una extensa red de grandes presas, unas 60. Los pozos pueden llegar a profundidades de 600 metros. Estos recursos hídricos se destinan fundamentalmente en la agricultura. En la isla de Fuerteventura, existen recursos hídricos subterráneos, pero de mala calidad (muy salinizados), el destino de este recurso es la agricultura. El abastecimiento urbano en Fuerteventura, es suministrado por plantas desalinizadoras de agua. En Lanzarote, el suministro prácticamente es por desalinización de agua de mar en un porcentaje que supera el $80 \%$. El consumo agrícola es importante pero el abastecimiento urbano y el destinado al turismo es mayor.

Figura 12.4. Sección de galería (mina) de agua en la isla de Tenerife

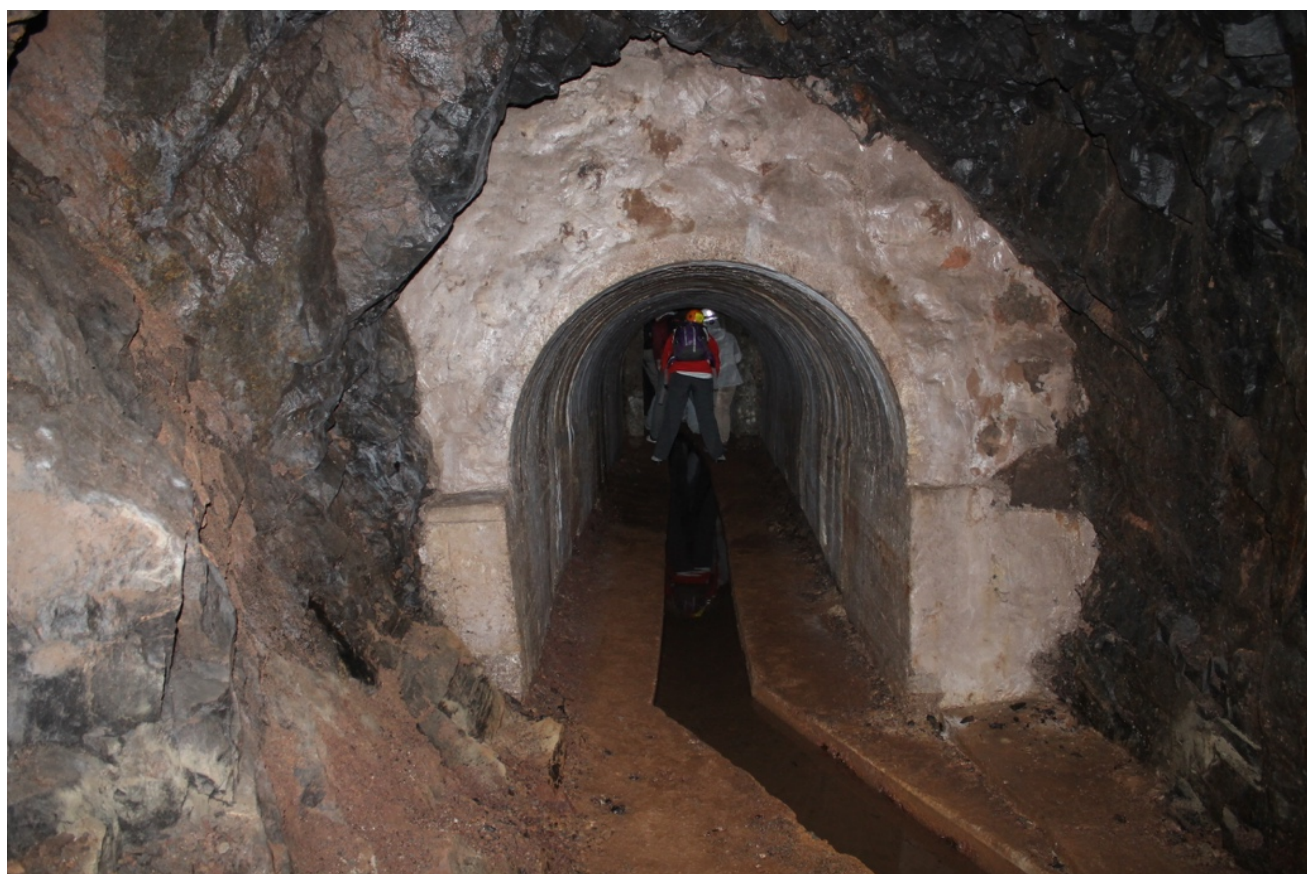

Fuente: Santamarta, J.C.

En el caso de las aguas subterráneas, el factor limitante para la explotación de un acuífero de una isla volcánica es la recarga disponible. Esta recarga, expresada como un porcentaje de la lluvia, obviamente depende de las precipitaciones disponibles, y que parte de esa precipitación, que se infiltra en el terreno llegue de manera efectiva a recargar el acuífero. Si explotamos un acuífero donde la recarga es muy reducida, lo que estamos drenando es agua fósil, que sólo podrán ser utilizadas, con la limitación impuesta por la calidad del recurso hídrico, durante un periodo muy corto de tiempo. Además, en el caso insular, esa recarga puede 
estar muy influenciada y afectada por el spray marino, es decir, por cloruros, lo cual hace que la recarga esté cargada de sales, el acuífero dispondrá de mala calidad de aguas.

Los valores de la recarga estimados en las Islas Canarias son muy variables, las fuentes suelen ser los planes hidrológicos de cada demarcación o bien estudios previos como el SPA-15 o científicos como las tesis doctorales. Así pues, nos podemos encontrar valores de un $20 \%$ en la isla de La Palma (Poncela, 2015). Lanzarote tiene estimada una recarga del $0,1 \%$, Gran Canaria 10,1\%, Tenerife, 18,3\% y El Hierro presenta una media de recarga de un $15 \%$, sobre un total de $100 \mathrm{hm}^{3}$ de precipitación, no obstante en este caso debemos indicar la variabilidad de este dato a lo largo de los años en los diferentes Planes Hidrológicos Insulares (PHI), como se puede observar en la tabla 12.2.

Tabla 12.2. Valoración de los datos de recarga del acuífero en la isla de El Hierro

\begin{tabular}{ccl}
\hline Año & Dato estimado de recarga & \multicolumn{1}{c}{ Fuente } \\
\hline 1975 & $21 \%$ & Estudio SPA-15 \\
\hline 2002 & $27 \%$ & PHI 2020 \\
\hline 2015 & $22 \%$ & PHI 1er ciclo \\
\hline 2018 & $12 \%$ & PHI 2do ciclo \\
\hline
\end{tabular}

Fuente: PHI de la isla de El Hierro, SPA15, Elaboración propia

Los modelos hidrológicos, que describen los acuíferos insulares volcánicos, a pesar de que son muy idealizados, explican de una manera bastante efectiva la disposición de los recursos hídricos en las islas volcánicas y las posibilidades de su aprovechamiento. Estos presentan algunas diferencias en función de diversos factores, como: el tipo de vulcanismo, la evolución geológica de la isla, localiza-

Figura 12.5. Sección geológica del modelo de isla Hawaiana con deslizamiento propuesto en 1954

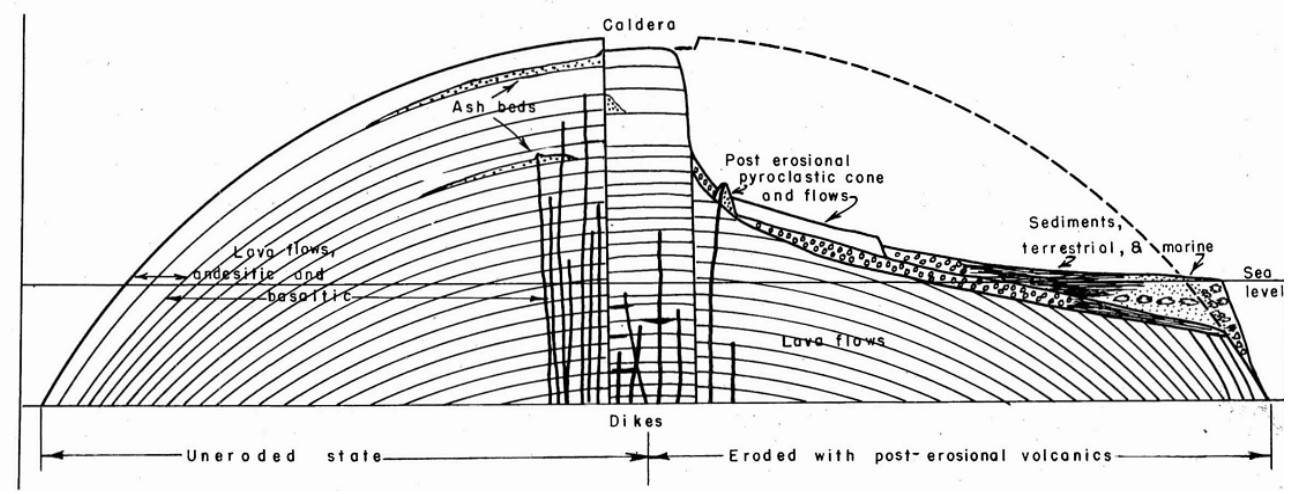

Fuente: Cox (1954) 
ción geográfica y deslizamientos posteriores. Así, podemos nombrar el primer modelo, de tipo hawaiano, propuesto por Cox en 1954, y los establecidos para las Islas Canarias, como los de Custodio (2004), Navarro \& Farrujia (1989) o diferentes esquemas hidrogeológicos de Telesforo y Bravo, como en el caso de La Palma, donde destaca el acuífero Coebra. En las islas volcánicas asiáticas destaca el modelo propuesto por Won (2006) para la isla de Jeju (Coera del Sur).

Figura 12.6. Sección de una isla hawaiana, desde el punto de vista hidrogeológico y aprovechamientos posibles propuesto en 1954

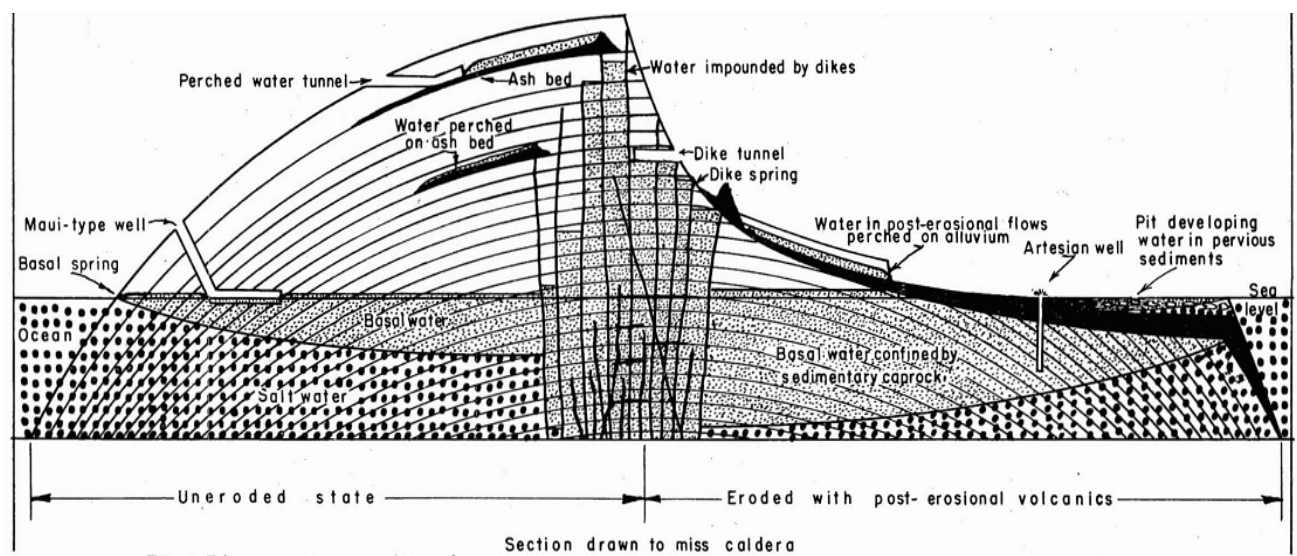

Fuente: Cox (1954)

Profundizando en el modelo de Cox (1954), dado que es el más antiguo y original, es muy interesante desde el punto de vista hidrogeológico y tiene aplicación en la mayoría de las islas volcánicas oceánicas, no sólo en las hawaianas que es el primer lugar donde se aplicó (Santamarta, 2017), si no en las Islas Canarias. Es la primera vez que se propone el modelo de acuífero sobre elevado mediante las diferentes familias de diques geológicos.

Por otro lado describe la geología y las estructuras de la isla que pueden condicionar el acuífero y el movimiento del agua (Figura 12.5). En este diagrama nos encontramos: las series de coladas superpuestas, los diques concentrados en la parte central de la isla, las diferentes capas de cenizas distribuidas entre las coladas, que hacen de capas impermeables y en algunos casos producen nacientes. El fallo que presenta el esquema geológico, es que en la zona donde está desmantelada la isla, el mecanismo propuesto es la erosión, cuando está aceptado científicamente que el mecanismo mediante el cual esa sección ha desaparecido es el deslizamiento gravitacional.

Relacionado con los aprovechamientos del agua, según Santamarta (2017), el aprovechamiento de este acuífero sobre elevado se haría mediante los «dike tunnel», lo que serían las galerías o minas de las Islas Canarias. Por otro lado, están los aprovechamientos de los acuíferos colgados denominados en la figura (12.6) como «perched water». Estos acuíferos, si interceptan la superficie se transformarían en manantiales o nacientes. También se pueden aprovechar mediante una 
obra de minería, en Canarias serían las galerías asociadas a nacientes, en el caso hawaiano se denominan «perched water tunnel». Aparecen más estructuras singulares que merecen la pena estudiar, como el aprovechamiento del acuífero de la cara de la isla no desmantelada, la cual, se aprovecha mediante los «Maui type well», lo que en Canarias se denomina las "galerías en trancada», al igual que en caso Hawaiano, la galería se construiría con una pendiente inclinada, orientada hacia el nivel freático. Alcanzado este se proyecta una galería horizontal para intentar obtener la máxima producción de agua, sin llegar al efecto de la intrusión marina.

En la costa aparecen los «basal spring». Este tipo de nacientes, también aparecían en Canarias, antes de la sobreexplotación del acuífero, en zonas costeras. Un ejemplo histórico era los pozos por donde se abasteció Colón, en la isla de La Gomera, cuando partió en su viaje para el descubrimiento de América.

Siguiendo el análisis de la zona desmantelada, aparece también los «dike spring», nacientes asociados a diques que aparecen en superficie, que serían similares a las «galerías de nacientes» canarias. Finalmente aparece el «artesian well», el cual es el pozo artesiano. El funcionamiento de este pozo se explica por la diferencia de cota, y por tanto de presiones, al estar el acuífero sobre elevado por el efecto de los diques, por lo que el agua fluye de este pozo sin necesidad de bombearla mecánicamente.

Como valor añadido a este modelo propuesto por Cox, podemos afirmar que explica completamente el funcionamiento del acuífero de el Hierro, salvo en la parte que tiene que ver con el desmantelamiento o desplome de parte de la isla, cuya mecanismo no es la erosión de los materiales si no un gran deslizamiento gravitacional.

Con respecto a la procedencia de los recursos hídricos en las Islas Canarias según la tabla 12.3, en su mayoría proceden de las aguas subterráneas y en menor cuantía de las aguas superficiales que sólo se usan para el sector primario. La desalinización de agua de mar tiene un peso importante y en los próximos años la tendencia es a aumentar, así como la regeneración de aguas.

Tabla 12.4. Procedencia del agua en las Islas Canarias

\begin{tabular}{ll}
\hline \multicolumn{1}{c}{ Procedencia del agua en Canarias } & \% del total \\
\hline Recursos subterráneos & $60,5 \%$ \\
\hline Desalinización agua de mar & $24 \%$ \\
\hline Recursos superficiales & $7,5 \%$ \\
\hline Reutilización de aguas & $8 \%$ \\
\hline
\end{tabular}

Fuente: Elaboración propia

Con respecto al los diferentes usos del agua en las Islas Canarias, basta con revisar la tabla 12.3, donde se comprueba que el mayor consumo proviene del sector primario. Seguido del urbano y el turístico, que están en aumento, año tras 
año. El cultivo con mayor demanda de agua en el archipiélago es el plátano, donde hay un mayor número de hectáreas plantadas es en la isla de Tenerife, seguido de La Palma y Gran Canaria. La huella hídrica del plátano es aproximadamente 500 litros por kilogramo producido. El aguacate crece en extensión cultivada en las Islas Canarias, donde su huella hídrica es mayor, casi el doble que el plátano, casi 3 veces mas de lo que necesitan las naranjas y 5 veces más que la de los tomates.

Tabla 12.4. Usos del agua en las Islas Canarias

\begin{tabular}{lc}
\hline Uso del agua en Canarias & $\%$ del total \\
\hline Agricultura & $51 \%$ \\
\hline Urbano & $25 \%$ \\
\hline Turismo & $10 \%$ \\
\hline Industrial & $4 \%$ \\
\hline
\end{tabular}

Fuente: Elaboración propia

Figura 12.7. Depósitos de agua y cultivos de platanera en la Isla de La Palma

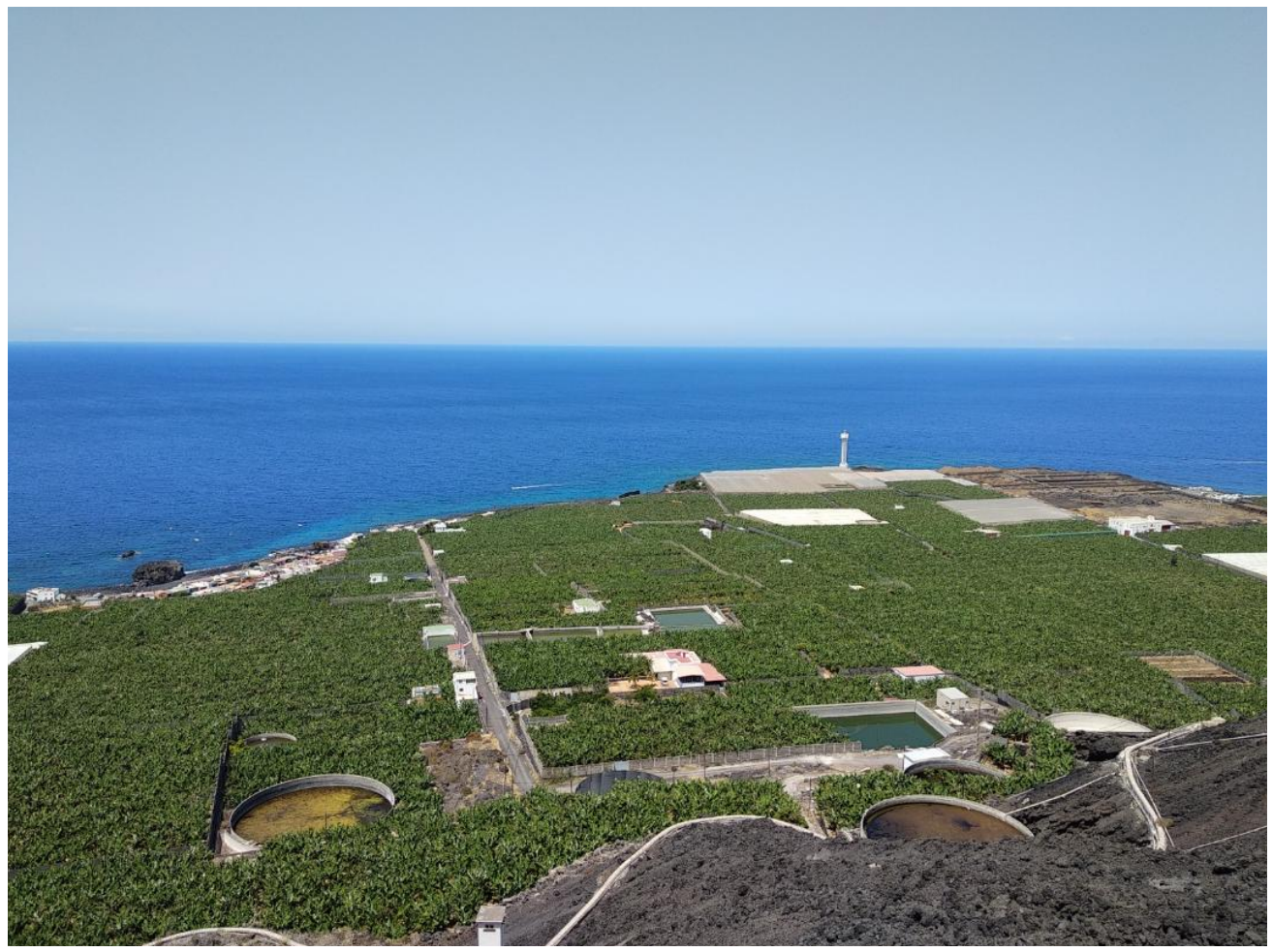

Fuente: Santamarta, J.C. 
En relación al abastecimiento de aguas, uno de los problemas en las Islas es que una vez captada o producida de manera artificial, el agua debe ser transportada de los centros de producción a los centros de consumo, que no siempre coinciden con los de captación/producción. En ese sentido hay que manifestar que la infraestructura hidráulica en las Islas Canarias es muy antigua, algunas obras fueron ejecutadas hace más de 100 años. En el transporte del agua, por ejemplo en la isla de Tenerife, las pérdidas pueden llegar a porcentajes que rondan el $60 \%$ (PHI de Tenerife 1er ciclo). Este es un punto clave en la gestión del agua de las Islas. No se comprende unas pérdidas tan elevadas con el coste del agua por metro cúbico que superan los 60 céntimos de euro.

Atendiendo a la calidad de los recursos alumbrados, las amenazas son las siguientes: desde el punto de vista natural las aguas subterráneas de Canarias tienen el problema del $\mathrm{CO}_{2}$ que afecta directamente a las aguas, que hace que estas sean más agresivas con respecto a la roca donde se localizan, lo cual genera salinización del acuífero, aguas bicarbonatadas sódicas y altos contenidos en flúor.

Figura 12.8. Conducciones de aguas subterráneas afectadas por depósitos de carbonatos en el sur de la isla de Tenerife

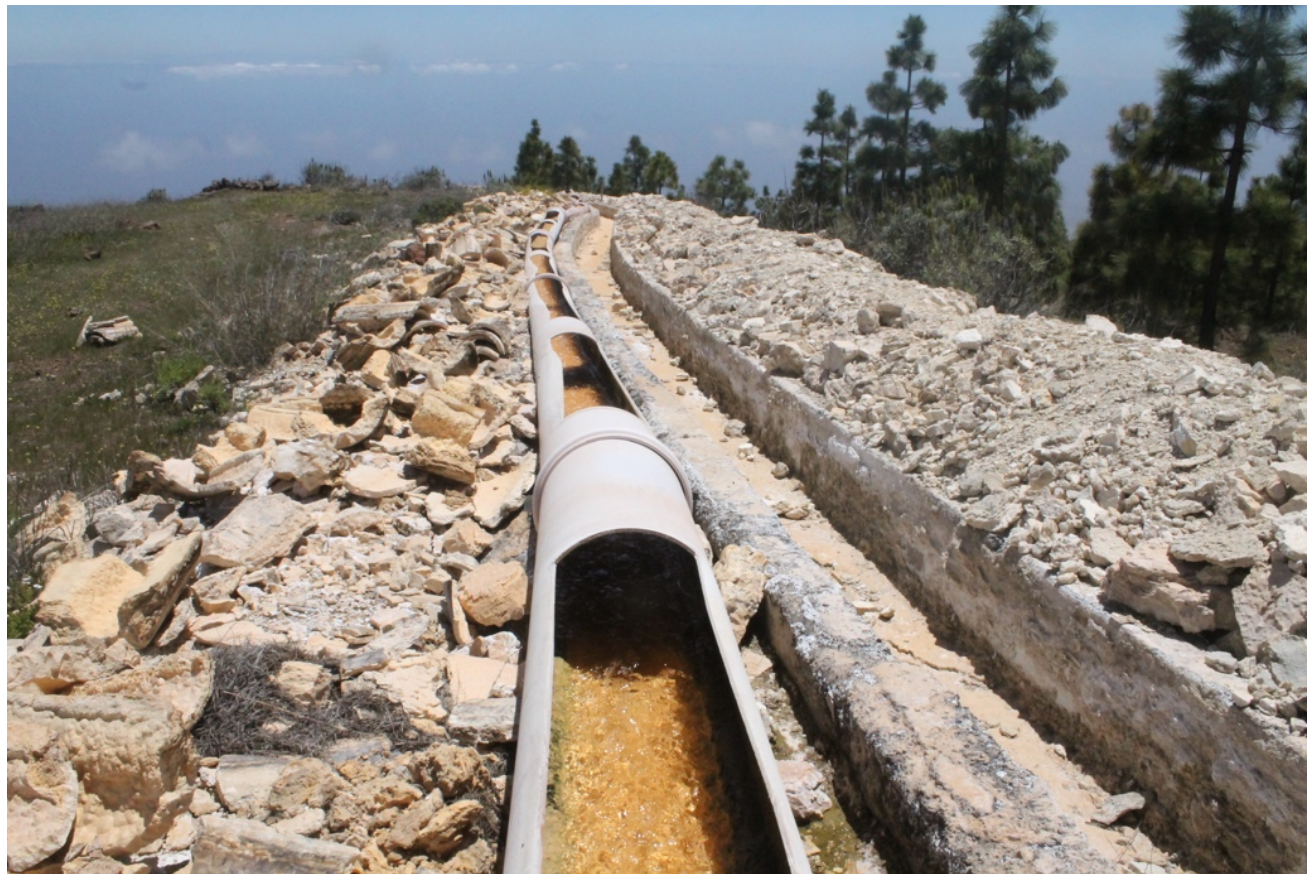

Fuente: Santamarta, J.C.

Cada vez se extraen mayor cantidad de aguas fósiles, es decir, con un tiempo de residencia en la formación geológica elevado, esto hace que se alumbren aguas con altos contenidos en sales y, por lo tanto, con mayores conductividades. 
Los principales problemas en relación a la calidad del recurso se pueden resumir en los siguientes:

- Contaminación por intrusión marina: Cloruro (Cl-). Fundamentalmente en las zonas de extracción de agua costeras.

- Contaminación por malas prácticas agrícolas: Nitratos $\left(\mathrm{NO}_{3}^{-}\right)$.

- Contaminación volcánica residual: bicarbonatos $\left(\mathrm{HCO}_{3}{ }^{-}\right)$, sodio $(\mathrm{Na}+)$ y flúor (F-).

Figura 12.9. Pozo canario en zona costera en la Isla de El Hierro

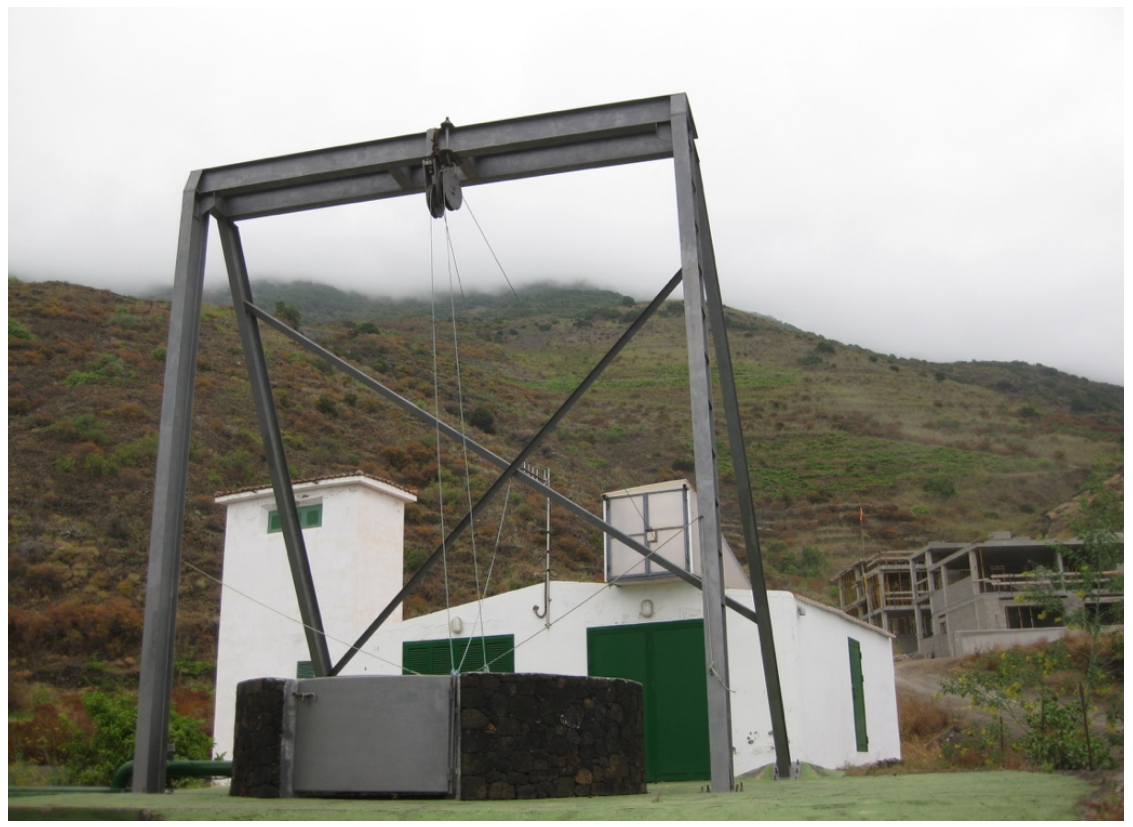

Fuente: Santamarta, J.C.

Como efectos antrópicos, debido a los bombeos y la sobreexplotación del acuífero, relacionados con la calidad del agua se encuentra la intrusión marina, la cual produce salinización del acuífero costero. La intrusión marina evoluciona progresivamente en la mayoría de los acuíferos costeros, y es el principal problema a nivel de gestión del acuífero en esas zonas. No sólo en las islas, si no a nivel de todo el país, fundamentalmente en el sur de España y la zona mediterránea. La solución a este problema pasa por detener la explotación del recurso hídrico en casos muy graves, o bien, en hacer la explotación más sostenible (no extraer más agua que la que realmente la instalación puede drenar de una manera renovable). Estas medidas no tienen mucha aceptación por parte de los gestores del aprovechamiento dada la presión que tienen los recursos hídricos en esas zonas agrícolas. Una vez que existen indicios de la contaminación por cloruros, su avance es progresivo y rápido (en función de la formación geológica y su permeabilidad), si no se toman medidas urgentes. Una medida que no se debería adoptar es el mon- 
taje de una instalación de desalobración de aguas. Con ello se consigue llegar a un daño irreversible de la explotación y con el tiempo, del acuífero, que puede afectar a otras explotaciones. En definitiva, este problema se debe acometer de una manera global en todas las instalaciones que exploten el acuífero costero de una determinada zona.

Otro efecto negativo importante son los retornos de riego, como por ejemplo los producidos por la contaminación por nitratos, salinización del acuífero y el efecto de los plaguicidas. En Canarias, esta contaminación es producida fundamentalmente por la actividad agrícola, en otros sistemas insulares, como por ejemplo en las Azores, la contaminación de nitratos ocurre por la existencia de una ganadería intensiva de vacuno. En particular, en Canarias, el exceso de nitratos tiene su origen en la zona baja del Valle de La Orotava. Este problema es muy intenso también en La Aldea de San Nicolás, en Gran Canaria.

Por último, están las contaminaciones puntuales, por vertidos de industrias o vertederos no autorizados. La contaminación por nitratos aparece en aguas captadas por las explotaciones mediante pozos y sondeos. Es prácticamente nula en la explotación de agua mediante las galerías, dada la cota a donde captan los recursos, en general no se ven afectadas por cultivos agrícolas.

Además de la presencia en el agua de carbonatos y nitratos, uno de los problemas más importantes en relación a la calidad del recurso alumbrado por las minas son los altos contenidos de flúor. Este problema de salud se extiende a numerosas islas volcánicas, como por ejemplo Terceira en Azores (Portugal), o en Madeira (Portugal). La aparición del flúor en las aguas alumbradas se vincula al drenaje de aguas muy fósiles, con mucho tiempo de residencia en el acuífero, o bien, en menor medida, a la actividad volcánica. La cuestión de los altos contenidos (mayores de $1,5 \mathrm{mg} / \mathrm{L}$ ) de flúor en el agua de abasto no es fácilmente solucionable. Requiere de un esfuerzo técnico muy importante y los resultados de aplicación de las diferentes técnicas no son muy satisfactorios, en relación al resultado final en calidad y a los aspectos económicos. Las galerías donde comienzan a aparecer grandes cantidades de flúor en sus aguas la única solución existente es el cese de la explotación para intentar la recuperación del acuífero. Este cese temporal no es cuestión de días, ni de meses, si no de décadas, lo cual no suele ser una solución que interese al gestor de la explotación.

Para concluir hay que hacer referencia al presente escenario de cambio climático a escala global que existe, dado que puede afectar a los recursos hídricos de las islas. Fundamentalmente, pueden verse muy afectadas por los cambios en los patrones de las precipitaciones. Esta situación es cada vez más incierta cuanto más lejano está el horizonte de estudio. Si bien, según los estudios de Santana (2012) que afirman que los cambios en los patrones de precipitación, si bien han venido siendo habituales en los últimos 50 años, analizando la tendencia se hace evidente que existe una reducción de las precipitaciones en las islas.

Hay que tener muy en cuenta que los actuales modelos climáticos predicen un aumento de la aridez, con cambios en los patrones de las lluvias y el aumento de las temperaturas, por lo que, es necesario implementar con carácter urgente acciones de adaptación estratégicas y mitigación a los efectos del cambio climático 
en las islas, en particular, en los sectores de la agricultura, recursos hídricos, conservación de los ecosistemas y zonas costeras de las Islas Canarias.

\subsection{Análisis de las Debilidades, Amenazas, Fortalezas y Oportunidades (DAFO) de los recursos hídricos en las Islas Canarias}

Todo estudio de un sistema hidráulico conviene comenzarlo con un análisis profundo de las variables de las que depende y singularidades que posee. En el caso del agua en las islas Canarias, este sistema es complejo y está condicionado por una serie de variables, como la fragmentación del territorio, la compleja orografía, un sector primario muy importante, una gran industria turística etc.

Para ello se ha establecido un análisis DAFO (Debilidades, Amenazas, Fortalezas y Oportunidades) del sistema. Este análisis está basado en un estudio de sus características internas (Debilidades y Fortalezas) y sus características externas (Amenazas y Oportunidades). Con ello se pretende tener un balance inicial de la situación de los recursos hídricos con el fin de plantear estrategias para los retos de futuro a los que se enfrenta el agua en las Islas.

\section{ANÁLISIS DAFO RECURSOS HÍDRICOS EN LAS ISLAS CANARIAS}

\begin{tabular}{|c|c|}
\hline Debilidades & Amenazas \\
\hline $\begin{array}{l}\text { Muy dependientes del petróleo, alto binomio agua } \\
\text { y energía. Coste elevado para producir energía. }\end{array}$ & $\begin{array}{l}\text { Pérdida de hábitats naturales vinculados a las } \\
\text { aguas subterráneas. }\end{array}$ \\
\hline $\begin{array}{l}\text { En algunas zonas la calidad del agua subterránea } \\
\text { está empeorando. }\end{array}$ & $\begin{array}{l}\text { Fin del periodo transitorio en el año 2040, cambio } \\
\text { de la titularidad en la gestión y explotación de las }\end{array}$ \\
\hline \multirow{2}{*}{$\begin{array}{l}\text { Incremento de la intrusión marina en captaciones } \\
\text { costeras. }\end{array}$} & \\
\hline & ional sin relevo. \\
\hline Elevadas pérdidas de agua en las redes. & erés en las aguas subterráneas. \\
\hline $\begin{array}{l}\text { Sector primario con cultivos muy demandantes de } \\
\text { agua. }\end{array}$ & $\begin{array}{l}\text { Influencia del cambio climático en los recursos } \\
\text { hídricos de las Islas. }\end{array}$ \\
\hline \multirow{2}{*}{$\begin{array}{l}\text { Las mayores zonas de consumo generalmente no } \\
\text { coinciden con las zonas de captación de agua sub- } \\
\text { terránea. }\end{array}$} & tura del agua en las Islas. \\
\hline & as no depuradas al mar, sanciones \\
\hline Elevados costes del agua. & Existencia de zonas sin saneamiento con numero- \\
\hline \multirow{3}{*}{$\begin{array}{l}\text { Escasa coordinación entre las administraciones } \\
\text { vinculadas a los recursos hídricos, por ejemplo: } \\
\text { medioambiente, agricultura y Consejos Insulares } \\
\text { de Aguas. }\end{array}$} & \\
\hline & del consumo de agua \\
\hline & $\begin{array}{l}\text { Parte del agua desalinizada producida en las plan- } \\
\text { tas está subvencionada. }\end{array}$ \\
\hline $\begin{array}{l}\text { Elevada burocracia a la hora de planificar los re- } \\
\text { cursos hídricos, un plan hidrológico por cada isla, } \\
\text { con su correspondiente administración hidráuli- }\end{array}$ & $\begin{array}{l}\text { Exigencias de la normativa europea en materia de } \\
\text { aguas que no se puedan asumir por falta de me- } \\
\text { dios o por la singularidad del territorio. }\end{array}$ \\
\hline & Aumento de la aridez del territorio y de las tempe- \\
\hline $\begin{array}{l}\text { Falta de medios y personal en la administración } \\
\text { hidráulica de las Islas. }\end{array}$ & \\
\hline $\begin{array}{l}\text { En la gestión del agua prima aumentar la oferta } \\
\text { de recurso hídrico en vez de reducir la demanda. }\end{array}$ & \\
\hline
\end{tabular}


Fortalezas

Oportunidades

Fiabilidad del sistema de captación, producción y Avances tecnológicos importantes que mejoran la distribución de aguas.

gestión y producción de agua.

Sistema mixto que combina las aguas subterrá- Margen de mejora importante en la gestión y efineas, las aguas procedentes de la desalinización ciencia del agua.

de agua de mar y las superficiales.

Periodo de transición ecológica e hidrológica.

Valores culturales del agua muy vinculadas a la Transferencia de tecnología y conocimiento adpoblación local.

Amplia experiencia en desalinización de agua de mar. quirido a otras regiones con similares características.

Aumento del interés en la gobernanza del agua por parte de las administraciones públicas.

Amplia experiencia en la gestión y captación de aguas subterráneas.

Disponibilidad de energía mediante el almacenaIncremento de la masa forestal, con ello se aumenta la infiltración y, por lo tanto, la recarga del acuífero insular.

miento de agua en embalses.

Integración del telecontrol y las TICs en la gestión del agua.

Técnicos muy cualificados.

Integración progresiva de las energías renovables vinculadas al ciclo integral del agua.

Uso de la teledetección como herramienta para el ahorro de agua en la agricultura.

Cambio de paradigma, actuar en la demanda de agua no en la oferta.

\subsection{La planificación hidrológica en las Islas Canarias}

Los planes hidrológicos son la herramienta fundamental para la gestión de los recursos hídricos en un territorio. La planificación hidrológica que se ha desarrollado en las Islas Canarias los últimos años ha sido problemática, esto ha sido debido a los retrasos en la revisión de los planes hidrológicos del segundo ciclo de cada una de las 7 islas, actualmente solucionado.

En las Islas Canarias se deben elaborar 7 Planes Hidrológicos Insulares, uno por isla que formaría la demarcación hidrológica y no todos los Consejos Insulares disponen de medios suficientes para poder acometer toda la documentación que es necesaria presentar en Europa. Esto hace que se deba recurrir a empresas públicas o privadas para hacer este trabajo. Los retrasos en la presentación de los documentos así como la burocracia generada puede hacer incurrir en sanciones por parte de Europa, si bien actualmente, las Islas Canarias han cumplido con todos los requisitos marcados por Europa.

Otro problema, en relación con la gestión del agua en las Islas Canarias, es la inexistencia en la mayoría de los casos de un control de los caudales alumbrados o de un sistema que sea capaz mediante TICs de controlar y conocer la cantidad de agua de la que dispone el sistema, salvo casos muy puntuales en empresas privadas vinculadas al ciclo integral del agua. Este control de caudales depende, en ocasiones, de una medida manual, que suele facilitar el propio gestor de la explotación.

Por parte de la Administración sería imposible asumir mediciones de caudal sistemáticas de manera manual, dado que existen sólo en las Islas Canarias más 
de 7000 explotaciones, incluyendo pozos y sondeos. En definitiva, el hecho no conocer en tiempo real la cantidad de recurso captado y producido impide hacer una gestión apropiada de la demanda y usos. Tampoco es posible disponer de una información real para el apoyo de decisiones en materia de gestión y planificación hidrológica.

Además de ese control y mejora del conocimiento de los acuíferos insulares, es necesario invertir más en investigación. En el caso particular de Canarias, los estudios realizados son muy dispersos, limitándose en algunas ocasiones a los Planes Hidrológicos Insulares de los correspondientes a los diferentes ciclos hidrológicos. Los últimos grandes estudios, datan de los años 70 como el proyecto SPA-15 (1975). Este gran proyecto auspiciado por la UNESCO y las investigaciones paralelas fueron pioneras en la hidrogeología de las islas volcánicas oceánicas. Este conocimiento se ha extendido gracias a los diferentes Planes Hidrológicos y a diferentes tesis doctorales impulsadas por Universidades Penínsulas y por la Universidad de Las Palmas de Gran Canaria, pero, a día de hoy, es insuficiente.

Canarias, actualmente, está desarrollando el Tercer Ciclo del Plan Hidrológico y del Segundo Ciclo de Planes de Inundaciones. Durante 2019 se publicaron los documentos del Esquema Provisional de Temas Importantes (EPTI) de las siete Demarcaciones Hidrográficas de Canarias.

\subsection{La agricultura y el agua}

La agricultura en las Islas Canarias está limitada por el mercado, existe consumo interior, pero un gran porcentaje se exporta. Hay muy poco territorio que será agrícola y el coste es elevado, tanto del terreno como del agua. Los terrenos agrícolas compiten en desventaja con otros usos del suelo como el residencial y el turístico. La agricultura se caracteriza por un minifundismo, es decir, la distribución de la propiedad es mediante terrenos de poca extensión y baja productividad.

La mayor parte de los recursos hídricos alumbrados en las Islas se destinan a la agricultura, para este sector se destinan unos porcentajes importantes, en algunos casos más del $80 \%$ de agua, en ocasiones es un recurso de calidad elevada. Este patrón de consumo se repite en la mayoría de las islas estudiadas y es generalizado a nivel mundial.

Actualmente, las aguas subterráneas son la base de la actividad agrícola en las islas Canarias, sector fundamental en las islas. No se prevé, que en los próximos años esta situación cambie, si bien, está aumentando la producción industrial de agua de mar, esta se destina, fundamentalmente, al abastecimiento urbano, en pocas ocasiones se derivan para su uso en agricultura, salvo que el cultivo compense el coste del agua producida.

Muchos de los cultivos desarrollados en las Islas Canarias están en zonas costeras, por ejemplo, las plantaciones de plataneras en La Palma o Tenerife, o la piña tropical en el Hierro (figura 12.10). Los recursos hídricos para el consumo de estos cultivos generalmente provienen de galerías dispuestas en cotas superiores o bien de pozos o sondeos costeros. Estas últimas captaciones aprovechan el 
Figura 12.10. Cultivo de piña tropical en la isla de El Hierro

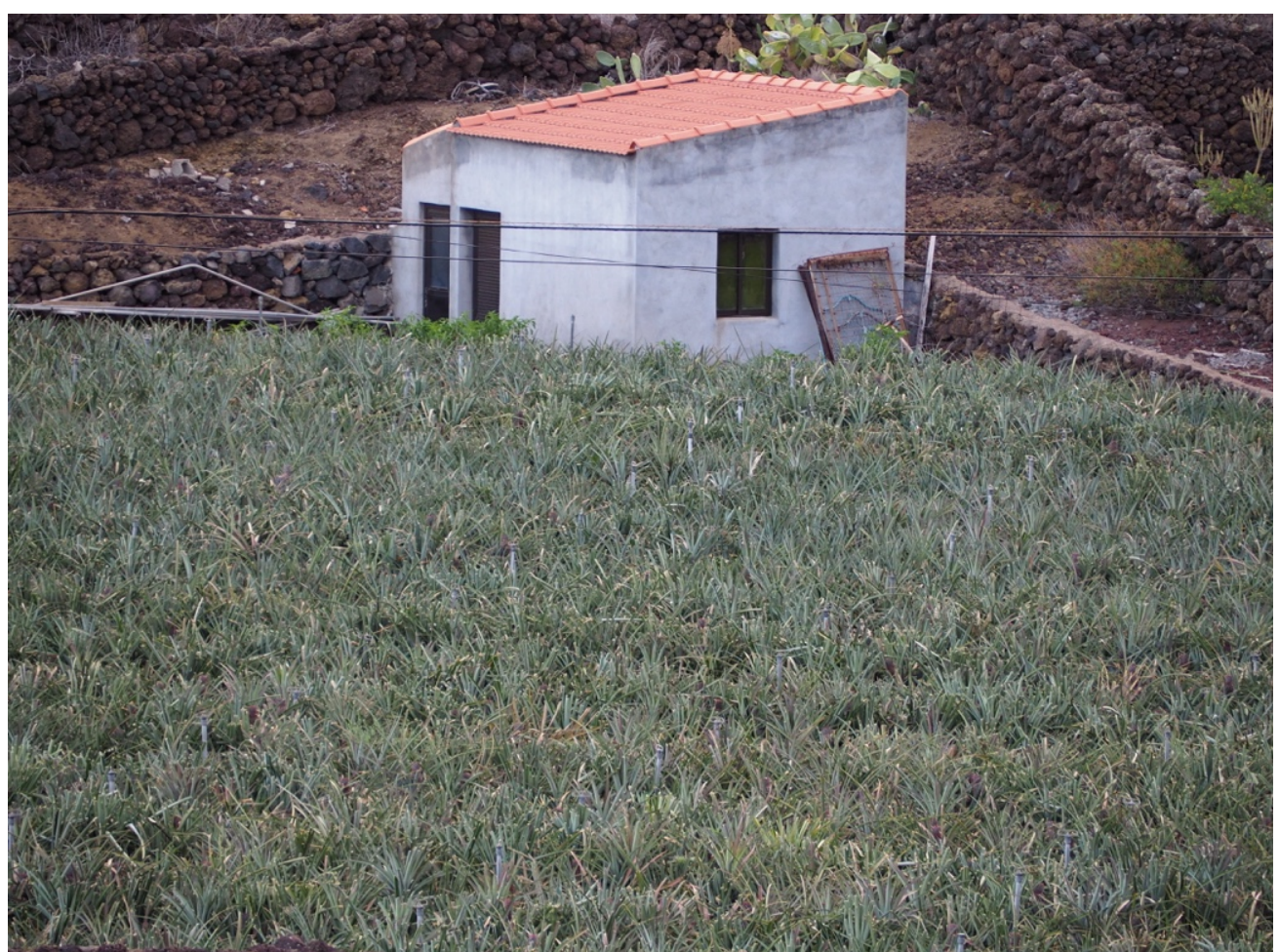

Fuente: Santamarta, J.C.

agua de los acuíferos costeros. Estos acuíferos son los más vulnerables. En este sentido, es necesario potenciar las redes de control y de prevención de la intrusión marina, un problema cuya solución es muy compleja. Sólo el plátano representa más del $20 \%$ de los terrenos cultivados en las Islas Canarias.

Tabla 12.5. Consumos Hídricos Agrícolas por islas

\begin{tabular}{lccc}
\hline \multicolumn{1}{c}{ Isla } & Consumo agrícola $\left(\mathbf{H m}^{3}\right)$ & \% sobre total & Año de referencia \\
\hline Lanzarote & 1,56 & $7,3 \%$ & 2015 \\
\hline Fuerteventura & 1,37 & $3,4 \%$ & 2015 \\
\hline Gran Canaria & 66,7 & $42,7 \%$ & 2015 \\
\hline Tenerife & 85,3 & $45,5 \%$ & 2012 \\
\hline La Gomera & 5,07 & $64,6 \%$ & 2015 \\
\hline La Palma & 71,1 & $87,7 \%$ & 2015 \\
\hline El Hierro & 1,72 & $51,8 \%$ & 2015 \\
\hline
\end{tabular}

Fuente: Planes Hidrológicos Insulares de $2^{\circ}$ ciclo 
Finalmente hay que destacar las externalidades que tienen los cultivos en Canarias, por un lado son sumideros de carbono, porque las plantas captan $\mathrm{CO}_{2}$, siempre que se haga mediante con técnicas de conservación de suelos y rotación de cultivos, fomentando la biodiversidad y manteniendo una cobertura vegetal de manera permanente. Por otro lado la agricultura disminuye la erosión, por ejemplo con la construcción de bancales, ya que sujetan el suelo en las laderas de pendientes importantes y mejoran la infiltración de la lluvia. También la huella de carbono de los productos de los cultivos tropicales y subtropicales es reducida, ya que el transporte es mejor, en comparación con los productos que vienen de Sudamérica. En este sentido, también la huella hídrica es menor por una mayor eficiencia en el uso del agua, así como el efecto de los pesticidas y fertilizantes que están más controlados al ser una región europea.

\subsection{Las masas forestales y el agua}

Los bosques en las Islas Canarias, han tenido y tienen, una gran importancia y relación con los recursos hídricos subterráneos. Fundamentalmente, porque son una vía de entrada de recursos a los acuíferos insulares. También hay que

Figura 12.11. Efecto en la captación de la precipitación horizontal en la isla de El Hierro

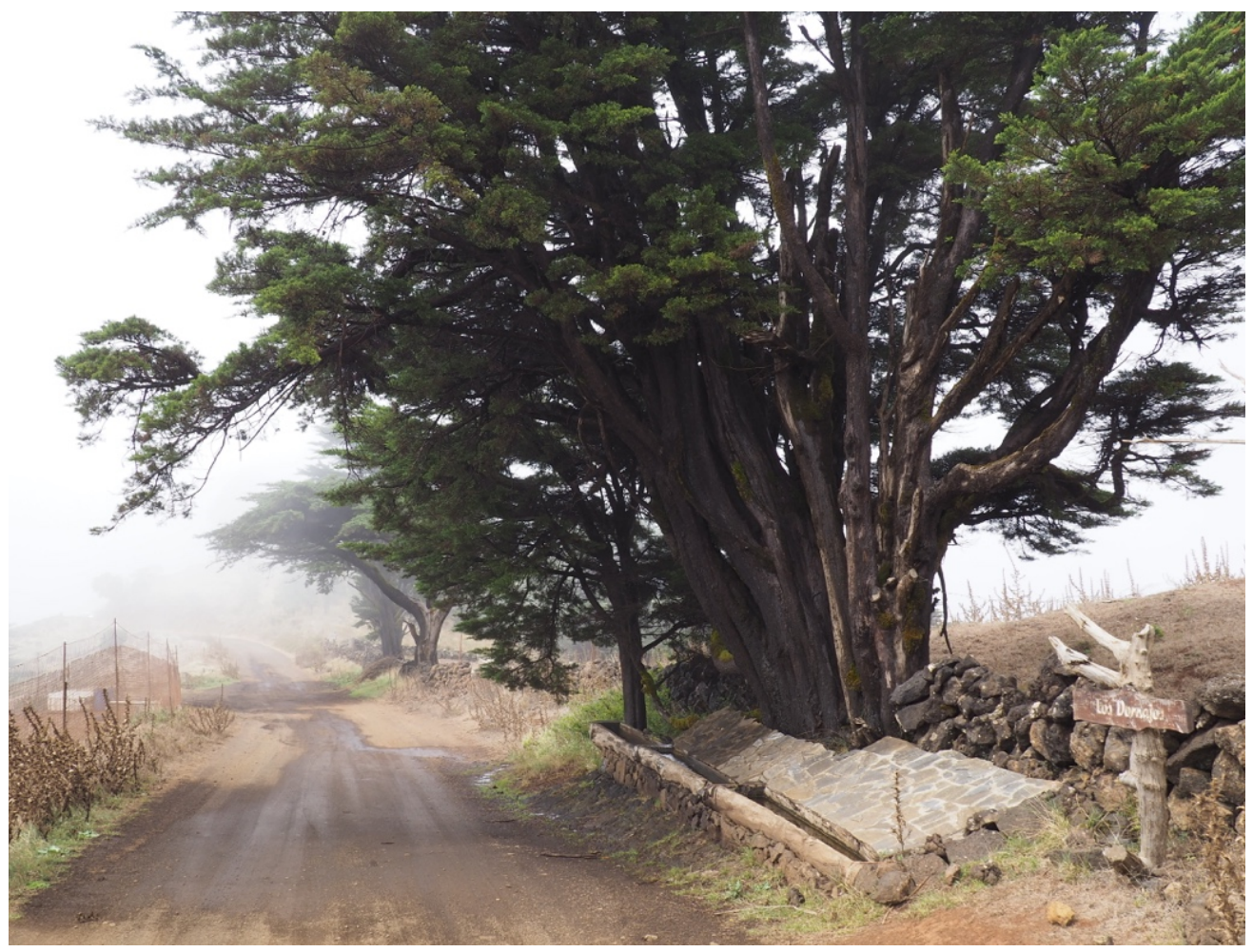

Fuente: Santamarta, J.C. 
destacar otras funciones relacionadas con el ciclo hidrológico, como la reducción de la erosión hídrica, sujetan el suelo y favorecen la infiltración con unos sistemas radiculares importantes. Por otro lado, cuando ocurren precipitaciones en las masas forestales, parte de esa precipitación es interceptada por el dosel de la vegetación, otra parte de la lluvia transcurre por el tronco antes de llegar al suelo, lo que también mejora la infiltración y posterior recarga del acuífero, si se dan las circunstancias oportunas.

Existen estudios que cuantifican la cantidad de precipitación que alcanza el terreno en función del tipo de especie. Por ejemplo, para el caso de la isla de Tenerife y seleccionando las siguientes especies pertenecientes a la laurisilva canaria; Erica arbórea, Ilex canariensis, Ilex perado, Laurus azorica, Myrica faya y la Persea, destaca el estudio de Aboal et al. (1999) donde pone de manifiesto que casi un $7 \%$ de la precipitación bruta alcanza el suelo. Las especies con mayor volumen de copa, con cierto aislamiento y con cortezas más lisas también captarían mayor volumen de agua. Entre las especies, los factores clave destacarían la rugosidad del tronco y la divergencia de las ramas respecto del tronco, por último, el tamaño de las hojas también sería importante. Otro aspecto relacionado con la infiltración que indica el citado estudio es que la lluvia podría concentrarse hasta 12,8 veces en las zonas de infiltración de los árboles.

Figura 12.12. Bosque de Galería formado por saucedas canarias en el barranco de Las Angustias en la isla de La Palma

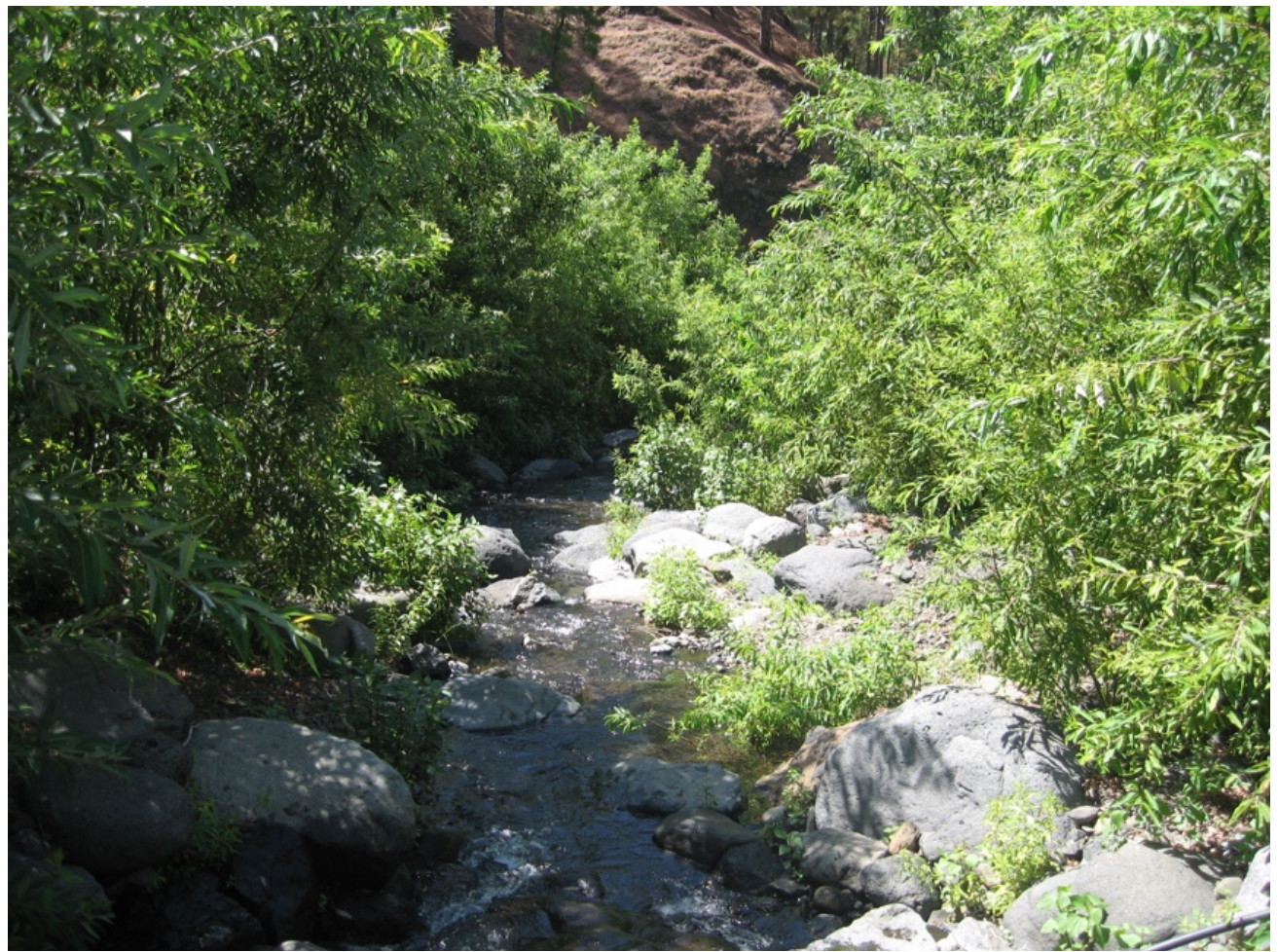

Fuente: Ángel Palomares Martín 
En relación a las masas forestales uno de los retos que se presentan en las Islas Canarias es la protección a los ecosistemas más vulnerables, en este sentido el artículo 6 de la Directiva Marco del Agua (DMA), Registro de Zonas Protegidas, establece que los Estados miembros velarán por que se establezca uno o más registros de todas las zonas incluidas en cada demarcación hidrográfica que hayan sido declaradas objeto de una protección especial, en virtud de una norma comunitaria específica. De los casos posibles de especies vinculadas a estos ambientes húmedos destacan los bosques de galería formados por la sauceda canaria, (Salix canariensis). Las saucedas canarias son ecosistemas terrestres directamente dependientes de las aguas subterráneas.

La presión sobre los recursos hídricos subterráneos en las Islas Canarias, principalmente en las islas Occidentales y en Gran Canaria, han producido un impacto constante a este ecosistema, que tiende a desaparecer o a ser sustituido por otras especies.

Uno de los primeros pasos que se deben dar para elaborar los planes hidrológicos de las 7 Islas Canarias (la isla de la Graciosa, va incluida en la Demarcación Hidrográfica de Lanzarote) es la realización de un análisis de las características de la demarcación. Entre los datos que hay que indicar se encuentra el listado de masas de agua subterránea de las que dependan directamente ecosistemas terrestres directamente dependientes de las aguas subterráneas (ETDAS).

En ese sentido las saucedas pueden considerarse dependientes de una masa subterránea porque se dan las siguientes circunstancias:

- Es un ecosistema que es alimentado directamente por la masa de agua subterránea de manera visible por nacientes.

- Es un ecosistema que presenta una comunidad característica directamente relacionada con la presencia de un nivel freático próximo y con la composición química de las aguas subterráneas.

- La hidrología del ecosistema está estrechamente vinculada a la masa de agua subterránea y a las variaciones de los niveles freáticos.

\subsection{El turismo y el agua}

Como ya se ha indicado en apartados anteriores, aunque pueda parecer lo contrario, por el volumen de turistas que anualmente visitan las Islas Canarias (más de 12 millones), el turismo no es el mayor consumidor de recursos hídricos en las Islas. No obstante, los consumos no son nada despreciables, y hay que tener en cuenta no solo al turista sino a la industria asociada, como parques acuáticos, piscinas, campos de golf, zoológicos etc.

Las Islas Canarias ratifican el hecho de que que las zonas más demandadas a nivel turístico coinciden con las de mayores problemas en el ámbito hidrológico.

Los datos de la OMS (Organización Mundial de la Salud, 2003) relacionados con el estudio del consumo de agua revelan que una persona necesita 50 litros de 
agua al día para cubrir sus necesidades básicas. Un turista puede llegar a gastar entre 300 y 800 litros al día (INE, 2017), mientras que los residentes en las Islas Canarias tienen un consumo aproximado de 150 litros por habitante y día, estando la media nacional de consumo medio por habitante y día en 132 litros. En este sentido, se considera un consumo ecológico de agua, aquel que es inferior a 10 litros por habitante y día.

Los consumos de agua y energía constituyen la segunda partida más relevante de costes en los establecimientos hoteleros, después de los gastos de personal.

Uno de los retos de la industria turística es desarrollar ciclos cerrados con respecto al agua, mediante el autoconsumo y reutilización de aguas residuales, ya sea en la propia instalación o en zonas cercanas. El autoconsumo de agua mediante instalaciones de desalinización de agua de mar en la industria turística es recomendable siempre que existan unas condiciones sanitarias y ambientales. Los problemas en este sentido es como usar la salmuera sobrante o bien como hacer que se impacte lo menos posible en el medio.

Esta opción no siempre coincide con los intereses de los gestores del agua con competencias en desalinización de agua de mar, como son los Consejos Insulares del Agua, que consideran que es una materia reservada y exclusiva para los Consorcios de Agua. No obstante, el Tribunal Superior de Justicia de Canarias, en el caso de la Isla de Lanzarote, dio la razón a los diferentes hoteles y alojamientos turísticos de la isla que habían instalado desalinizadoras de agua de mar para autoconsumo y cuestionó el modelo planteado por la Administración Hidráulica de la isla.

En definitiva, resulta fundamental encontrar equilibrios entre el desarrollo de la actividad turística y la gestión eficiente de los recursos hídricos, puesto que ambos están íntimamente interrelacionados (Ruiz-Rosa et al., 2019).

\subsection{El binomio agua y energía}

El ciclo integral del agua, en las islas en general y en el caso particular de Canarias, tiene una gran dependencia de los combustibles fósiles, esto supone un problema grave a la larga, porque los conflictos bélicos pueden afectar directamente a la gestión del agua en las islas al depender del petróleo el suministro energético.

Todas estas operaciones requieren producir energía para su uso y, este, es otro factor limitante en la disponibilidad del recurso hídrico. La generación eléctrica en Canarias tiene un coste muy elevado, dado que su funcionamiento, depende fundamentalmente de combustibles fósiles. Producir energía en Canarias por este método supone un coste aproximado de casi cuatro veces más que en el continente (península ibérica). Este tipo de combustibles (los fósiles) están condicionados por una política mundial, que hace que las Islas Canarias sean sensibles a cualquier perturbación del mercado del petróleo y sus derivados incluso, a conflictos políticos globales mundiales. 
Los pozos, las plantas desalinizadoras de aguas de mar, la depuración de aguas residuales y los bombeos a las zonas de consumo necesitan un aporte importante de energía para funcionar, en el caso de los pozo las elevaciones de bombeo pueden llegar a más de 400 metros. Por lo tanto existe un fuerte binomio agua y energía en las Islas Canarias.

La captación de aguas subterráneas mediante galerías horizontales no necesitan aporte energético para su funcionamiento, salvo en explotaciones de carácter mixto, es decir minas que tengan a lo largo de su traza catas o sondeos verticales que necesiten un aporte energético para poder bombear y transportar el recurso. Los consumos energéticos se limitan a la ventilación de la galería cuando está en fase de construcción, reperforación o bien, cuando es visitada por los operarios de mantenimiento o la dirección de la explotación.

Figura 12.13. Central eléctrica diésel en la isla de Gomera

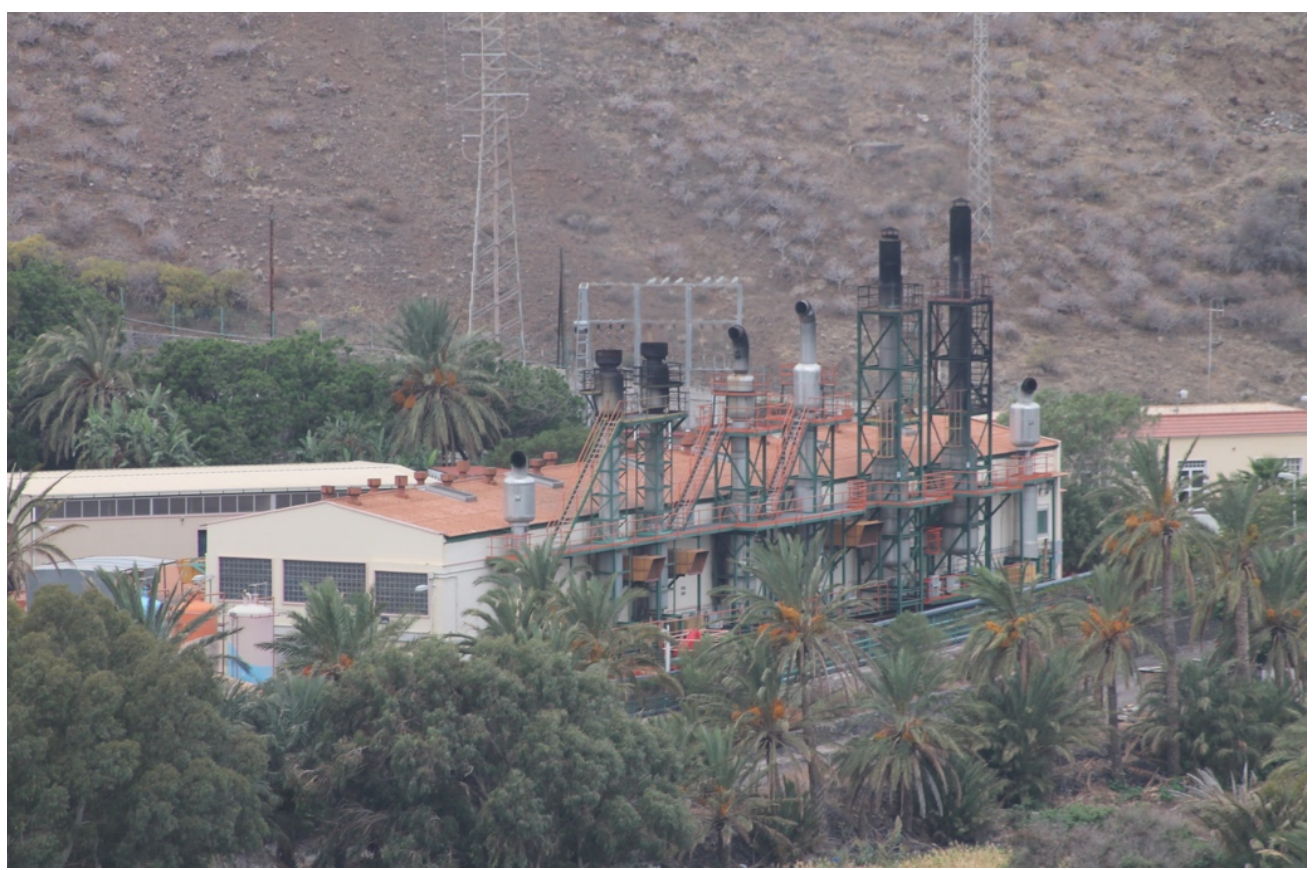

Fuente: Santamarta, J.C.

Este aspecto energético es quizás, la mayor ventaja que tienen este tipo de explotaciones. La cota a la que se construye la mina y la pendiente de la traza, hace que por gravedad se obtenga el recurso desde el frente de la galería. Esto también es beneficioso para su gestión, porque habitualmente, las poblaciones o cultivos a abastecer están en cotas inferiores (cultivos agrícolas) o incluso en zonas costeras (zonas urbanas o turísticas).

Las galerías de agua son las obras de captación cuyas emisiones de gases de efecto invernadero (GEI) durante su explotación es muy reducida, desde el punto 
de vista medioambiental son explotaciones cuyo impacto en el medioambiente es muy residual, al contrario de una planta desalinizadora de agua de mar. En una galería la cantidad de agua captada no afecta en la cantidad de gases de efecto invernadero emitidos.

En las Islas Canarias, existen numerosos ejemplos donde se puede constatar la relación profunda entre el ciclo del agua y la energía, por ejemplo, en la isla de Lanzarote, más del $27 \%$ de la energía que se consume se destina al ciclo del agua, y de ese porcentaje, el $75 \%$ se destina a desalar agua de mar (Peñate, 2004).

\subsection{Algunas conclusiones y retos planteados}

Entrados en el siglo XXI, Canarias afronta, con respecto al agua, unos retos importantes y vitales para la supervivencia del archipiélago. Entre los cuales es necesario destacar que se necesita una correcta transición hidrológica y unos cambios de paradigmas que van a ser complejos de aceptar. Es necesario recurrir a modelos de gestión sostenibles del agua que beneficien su propio desarrollo y preserven los recursos hídricos.

Desde el punto de vista natural, las Islas se deben adaptar al cambio climático. Diferentes estudios hablan de un patrón irregular de las precipitaciones y que estas tienen una tendencia general a reducirse. El papel de las masas forestales en las Islas va a ser fundamental en este siglo, como elementos que regulan los recursos hídricos y favorecen la infiltración del agua a los acuíferos insulares y reducen la erosión conservando los suelos. En este sentido, se echa de menos una mayor referencia a estos sistemas forestales en los planes hidrológicos de las islas y su importancia clave, conjuntamente con los ecosistemas directamente dependientes de las aguas subterráneas, referenciados en la Directiva Marco del Agua. Un ejemplo de estos ecosistemas son los típicos bosques de galería formados por la sauceda canaria que están desapareciendo o siendo sustituidos por otras especies, algunas no autóctonas.

Los acuíferos, drenados por más de 1700 galerías (minas) de agua y 3000 pozos y sondeos, están disminuyendo, pese a que la desalinización de agua de mar está compensando esa reducción, las demandas y presión que tienen los recursos subterráneos siguen siendo elevados. La calidad del agua subterránea en algunas zonas está empeorando, elevados contenidos en flúor, carbonatos, nitratos y el efecto de la intrusión marina en los acuíferos costeros sobreexplotados. Es necesario ordenar y controlar el aprovechamiento los recursos subterráneos, evitando su sobreexplotación.

Las pérdidas en las conducciones no son asumibles. Hay zonas donde los porcentajes superan el $50 \%$ de los caudales que transitan, esto hace que muchos gestores del agua, como los ayuntamientos, tengan que aumentar las dotaciones de agua para satisfacer sus necesidades. Por lo tanto, no están gestionando la demanda, que sería lo deseable, si no que aumentan la oferta de agua (práctica ineficiente), y esta, o bien escasea, por el problema comentado del descenso de nivel de los acuíferos, o bien, cuesta mucho producirla de manera artificial, por las 
plantas desalinizadoras de agua. Es más económico ahorrar un metro cúbico de agua que captarlo o producirlo artificialmente.

El saneamiento y la depuración de aguas es una asignatura pendiente en las Islas, si bien se está abordando con la construcción de nuevas infraestructuras dadas las amenazas de sanciones procedentes de Europa. La reutilización del agua depurada, por modernas instalaciones para su uso en la agricultura, es un hecho en este siglo y su porcentaje aumentará previsiblemente en las Islas, como ya ocurre en otras partes del mundo como Singapur que tiene un ciclo cerrado de agua, es decir aprovecha el $100 \%$ de sus aguas depuradas. Es necesaria la promoción de la regeneración o la reutilización del agua residual como una solución sostenible a largo plazo. La recarga artificial de acuíferos no se ha desarrollado prácticamente en el archipiélago, salvo algunos estudios, pero puede desarrollarse en este siglo si aumentan los recursos procedentes de la regeneración de aguas, siempre que esté acompañada de estudios científicos que avalen su uso y una respuesta positiva y sin riesgos del acuífero. La sostenibilidad de los acuíferos costeros pasa por comenzar con el empleo de la recarga de acuíferos con aguas regeneradas, con calidad suficiente para evitar la afección por contaminantes al equilibrio de las aguas subterráneas.

El binomio agua y energía de las Islas es muy acusado, no solo por las plantas desalinizadoras, si no por los bombeos de agua procedentes de los pozos, que en algunos casos pasan de los 400 metros de profundidad. En general, las zonas productoras de agua no coinciden con las consumidoras. A este binomio, se le añade que más del $90 \%$ de la energía que se produce en las Islas Canarias, es generada mediante energías fósiles, por lo que muchos consumos de agua dependen de la estabilidad geopolítica de los países que producen y comercian con este combustible. El reto, en este sentido es combinar la desalinización de agua de mar a través de energías renovables, hay experiencias importantes, mediante la energía solar y eólica.

La desalinización en cierta medida está solucionando los problemas de abastecimiento de las diferentes islas donde se ubican las plantas pero tiene el problema de sus elevados costes por la energía y la obsolescencia tecnológica de algunas plantas y que no tienen capacidad de regulación del agua producida. En algunos casos este agua se debe bombear a cotas superiores.

A nivel de gestión, el reto es claro. Es necesario incrementar la coordinación entre administraciones vinculadas a los recursos hídricos, por ejemplo: medioambiente, agricultura y Consejos Insulares de Aguas, estos últimos equivalentes a las Confederaciones Hidrográficas. Por otro lado, existe una elevada burocracia a la hora de planificar y gestionar los recursos hídricos. Esto se traduce en tener que redactar un plan hidrológico por cada isla, por su correspondiente administración hidráulica, cosa que no ocurre en las Islas Baleares, que es único. No todos los Consejos Insulares de Aguas tienen suficientes medios, aun así, tienen que asumir todas las fases que constituyen este proceso, lo que ocasiona retrasos en la entrega de los planes, aunque actualmente se encuentran todos en plazo. En este sentido, no se trata de reducir las singularidades o competencias de cada isla, sino concentrarlo todo en un solo documento con el fin de simplificar la burocracia excesiva, ser eficientes y cumplir los plazos con la Comunidad Europea. 
Dada la importancia que tiene el recurso subterráneo en las Islas Canarias, se recomienda encarecidamente promover un plan de investigación global para todo el archipiélago. Este plan debe responder cuantitativamente y cualitativamente a las siguientes preguntas ¿cómo están actualmente los acuíferos insulares? y, ¿cuál será su evolución en el tiempo al ritmo actual de extracción? Este estudio debe ser apoyado por las nuevas técnicas de investigación que actualmente pueden mejorar la incertidumbre en los parámetros que actualmente se estudian, como el porcentaje de recarga del acuífero, el nivel freático actual y modelos de descenso de ese nivel freático.

Para concluir, no por ello menos importante, hay que indicar que la mayor parte del agua extraída de los acuíferos insulares, está en manos privadas. Existe un mercado de agua en las Islas. Este derecho especial proviene de los periodos de la conquista española de las Islas y, en cierta manera ha llegado hasta nuestros días, con la propiedad privada del agua en numerosas explotaciones, principalmente las galerías de agua, que se perforaron entre varios socios, principalmente agricultores, compartiendo los gastos de su perforación y una vez que se alumbraban las aguas se dividían en acciones y se formaban Comunidades de Aguas. Hoy esas acciones, cada vez están más concentradas en unos pocos propietarios. La ley en su día reconoció este derecho, pero los cambios normativos de los años 90 lo modificaron creando un periodo transitorio, el cuál concluye en el año 2040. Durante ese año, habrá un cambio de la titularidad en la gestión y explotación de las aguas subterráneas. A día de hoy no ha habido ni un solo debate sobre qué ocurrirá en esa fecha. Más de 5000 galerías de agua, sondeos y pozos, así como miles de kilómetros de canales y conducciones pasarán a manos públicas y deberán gestionarlos, como actualmente hacen los titulares privados para garantizar el suministro de agua a los diferentes sectores y población.

En definitiva, este siglo aborda numerosos retos para las Islas Canarias, pero no nos cabe duda que, como en siglo pasado, el habitante de las Islas Canarias usará todo su ingenio para superarlos. Pero es necesaria una inversión en infraestructura tecnológica, planificación y gestión eficaz por parte de las Administraciones.

\section{Referencias bibliográficas}

Aboal, J.R., Morales, D., HERNÁNDEZ, M., JIMÉNEZ, M.S.,(1999).The measurement and modelling of the variation of stemflow in a laurel forest in Tenerife, Canary Islands. Journal of Hydrology 221:161-175.

Consejo Insular de Aguas de El Hierro, Cabildo Insular de El Hierro (2018). Plan Hidrológico de el Hierro Segundo Ciclo (2015-2021). http://www.aguaselhierro.org/planificacion/descargas

Consejo Insular de Aguas de La Gomera, Cabildo Insular de La Gomera (2018). Plan Hidrológico de la Gomera Segundo Ciclo (2015-2021). https://aguasgomera.es/planificacion-hidrologica/2o-ciclo-plan-hidrologico-2015-2021/ 
Consejo Insular de Aguas de La Palma, Cabildo Insular de La Palma (2018). Plan Hidrológico de la isla de la Palma Segundo Ciclo (2015-2021). https://apalmaaguas.com/planificacion/planificacion-hidrologica/

Consejo Insular de Aguas de Tenerife, Cabildo Insular de Tenerife (2018). Plan Hidrológico de la isla de Tenerife Segundo Ciclo (2015-2021). https://www. aguastenerife.org/index.php? option $=$ com_content\&view $=$ article \&i$\mathrm{d}=138 \&$ Itemid $=551$

Consejo Insular de Aguas de Tenerife, Cabildo Insular de Tenerife (2018). Plan Hidrológico de la isla de Tenerife Primer Ciclo.

Consejo Insular de Aguas de Gran Canaria, Cabildo Insular de Gran Canaria (2018). Plan Hidrológico de la isla de Gran Canaria Segundo Ciclo (20152021). http://www.aguasgrancanaria.com/plan_hidro.php

Consejo Insular de Aguas de Fuerteventura, Cabildo Insular de Fuerteventura (2018). Plan Hidrológico de la isla de Fuerteventura Segundo Ciclo (20152021). http://www.aguasfuerteventura.com/plan2015_2021.php

Consejo Insular de Aguas de Lanzarote, Cabildo Insular de Lanzarote (2018). Plan Hidrológico de la isla de Lanzarote Segundo Ciclo (2015-2021). https:// aguaslanzarote.com/planificacion.php\#

Custodio, E. (2004). Hydrogeology of volcanic rocks, in: Hydrogeology of Volcanic Rocks, UNESCO, Paris, 395-425.

Instituto Nacional de Estadística (INE). (2017). Estadísticas sobre el uso del agua [Conjunto de datos]. Recuperado de https:/www.ine.es/dyngs/INEbase/es/ operacion.htm $? \mathrm{c}=$ Estadistica_C\&cid $=1254736176839 \& \mathrm{menu}=$ ultiDatos\&idp $=1254735976602$

Jong-Ho, W., Ji-Wook, K., Gi-Won, K., Jin-Yong, L. (2005). Evaluation of hydrogeological characteristics in Jeju Island, Korea. Geosiences Journal, Vol 9, n⿳0 pp. 33-46.

Navarro, J.M., Farrujia, I. (1989). Zonificación hidrogeológica de Tenerife: Aspectos geológicos e hidrogeológicos. Plan Hidrológico Insular, Cabildo de Tenerife, Vol. I, p.145.

Organización Mundial de la Salud (2003). Informe sobre la salud en el mundo 2003: Forjemos el futuro. Suiza.

Peñate B., Martel, G., Piernavieja G. (2004). 40 años de desalación de aguas en el archipiélago canario. Gran Canaria: Instituto Tecnológico de Canarias.

Poncela, R. (2015). Hidrogeología del sistema acuífero volcánico de La Palma (Islas Canarias) (Tesis doctoral). Universidad de Alicante.

Ruiz-Rosa, I., García Rodríguez, J. L., Castilla Gutiérrez, C., Santamarta Cerezal, J. C.,Antonova, N. (2019). Agua y turismo en Tenerife: producción, gestión y consumo. Tenerife: Universidad de La Laguna.

Santamarta, J.C. (2017). Minería del agua en islas y terrenos volcánicos. Análisis hidrológico en explotaciones en la zona sureste de la isla de Tenerife, islas Canarias. Tesis. León: Universidad de León. 
Santamarta J.C., (2016). Tratado de Minería de Recursos Hídricos en Islas Volcánicas Oceánicas. Sevilla: Colegio Oficial de Ingenieros de Minas del Sur.

Santamarta, J.C. et al. (2013). Hidrología y recursos hídricos en islas y terrenos volcánicos. Colegio de Ingenieros de Montes.

Santana, L.M. (2012). ¿Existe cambio pluviométrico en los últimos 40 años en Tenerife? Tenerife: Cabildo de Tenerife (Agrocabildo).

SPA-15, (1974). Estudio científico de los recursos de agua en las Islas Canarias (SPA/69/515). Ministerio de Obras Públicas. Dirección General de Obras Hidráulicas. UNESCO. Las Palmas de Gran Canaria, Madrid. 3 volúmenes y mapas.

Won, J. H., Lee, J. Y., Kim, J. W., \& Koh, G. W. (2006). Groundwater occurrence on Jeju Island, korea. Hydrogeology Journal, 14(4), 532-547. 


\section{Capítulo 13 \\ Retos de futuro de los recursos hídricos en Baleares}

JoRdi Giménez García Doctor en Geología

\subsection{Características hidrogeológicas de las Islas Baleares}

Las islas Baleares son las partes emergidas del Promontorio Balear que constituye la prolongación nororiental del orógeno Bético-Rifeño. El promontorio está formado por dos bloques con profundidades inferiores a $200 \mathrm{~m}$ (Menorca Mallorca al Norte y Pitiusas al Sur), separados por el canal de Mallorca donde se alcanzan los $1000 \mathrm{~m}$ de profundidad. El relieve y la morfología de las islas está condicionado por las dos últimas etapas tectónicas que han afectado al archipiélago: compresión Alpina y extensión neógena. La compresión alpina estructura los materiales en pliegues y cabalgamientos con una vergencia mayoritaria al NO la cual condiciona la asimetría de las sierras y las alineaciones de los valles y sierras dentro de las zonas montañosas de cada isla. La extensión neógena posterior configura los grandes rasgos morfológicos actuales de las islas y del promontorio a través de fallas normales con orientaciones NE-SO y NO-SE (Giménez et al., 2007; Sàbat et al., 2011) (Figura 13.1).

Los principales rasgos morfológicos de Mallorca están relacionados mayoritariamente con la citada extensión neógena la cual estructura la isla en sierras y los llanos orientados en dirección NE-SO. Los Llanos se corresponden con bloques hundidos o cubetas tectónicas rellenas de materiales del Mioceno medio-superior al Plio-Cuaternario. Las sierras se corresponden con bloques levantados donde afloran materiales del Mesozoico y Cenozoico inferior afectados estructurados por la orogenia Alpina.

En Menorca se diferencian dos regiones geológicas diferentes: Tramuntana al Norte, donde afloran materiales paleozoicos y mesozoicos afectados por la orogenia alpina, y Migjorn al Sur, formado casi exclusivamente por calizas arrecifales del Mioceno.

El bloque de las Pitiusas presenta dos islas mayores, Eivissa y Formentera separadas por un canal con profundidades inferiores a los 50 metros. Las Pitiusas se pueden considerar como una sola unidad morfológica en la que se diferencia un dominio norte formado por Eivissa, donde básicamente afloran materiales 
plegados por la orogenia alpina, y otro meridional formado por Formentera y los islotes del canal de Formentera, en el que afloran materiales post-alpinos (Mioceno Superior y Plio-Cuaternario).

Figura 13.1. Entorno geológico de las Baleares

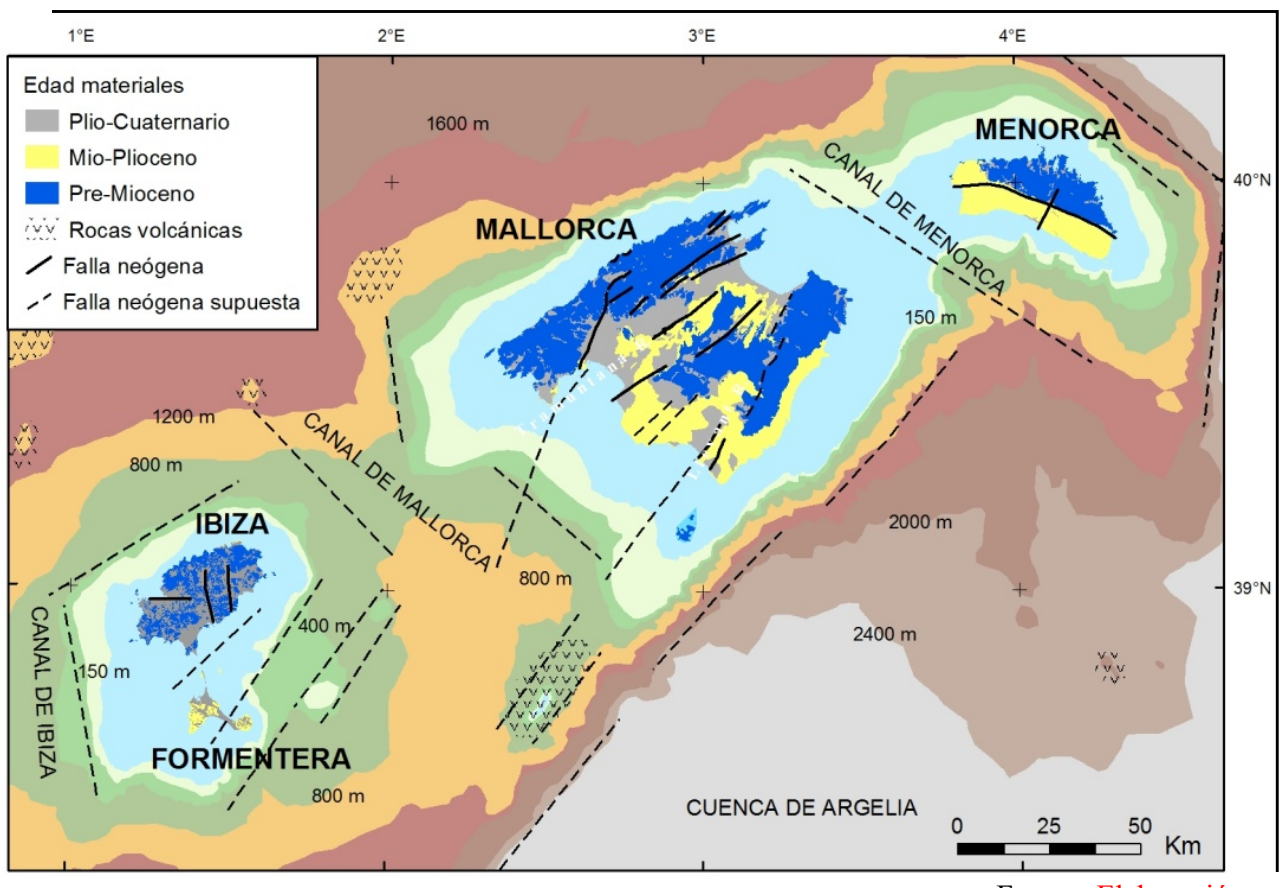

Fuente: Elaboración propia

Desde el punto de vista litológico en Baleares abundan los carbonatos de edad mesozoica y neógena, incluso la mayor parte de las rocas detríticas son de composición carbonatada. Las únicas rocas no carbonatadas son las arcillas y areniscas del Permo-Trias (facies Buntsandstein), los yesos y arcillas del Triásico (facies Keuper) y las pizarras del Paleozoico de Menorca (Fornós y Gelabert, 2011) (figuras 13.2, 13.3 y 13.4). Esta predominancia de carbonatos condiciona que los acuíferos de Baleares tengan en su gran mayoría un comportamiento cárstico. De hecho 45 de las 64 (el 69\% de la superficie) Masas de Agua Subterráneas (MASbt) de Mallorca tienen un comportamiento cárstico, en Menorca suponen 5 de las 6 MASbt (68\% de la superficie), 11 de las 16 MASbt en la isla de Ibiza (67\% de la superficie) y la totalidad de Formentera (Giménez et al, 2014). 
Figura 13.2. Delimitación de las MASbt de Mallorca con indicación de las litologías y permeabilidades

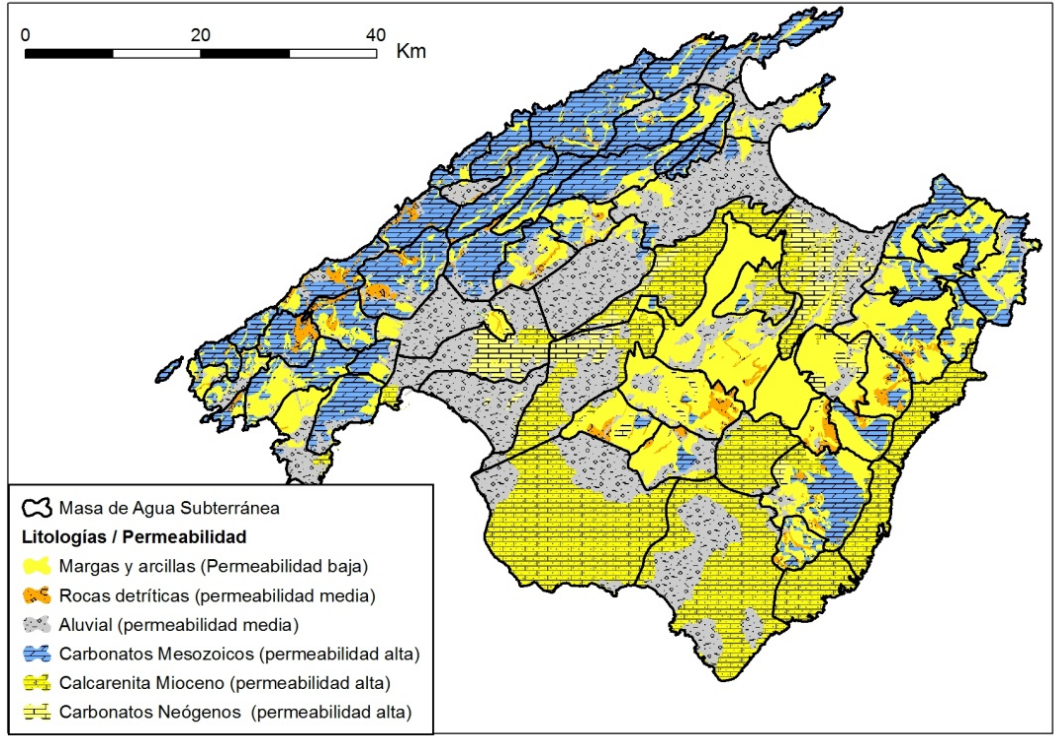

Fuente: Giménez et al., 2014

Figura 13.3. Delimitación de las MASbt de Menorca con indicación de las litologías y permeabilidades

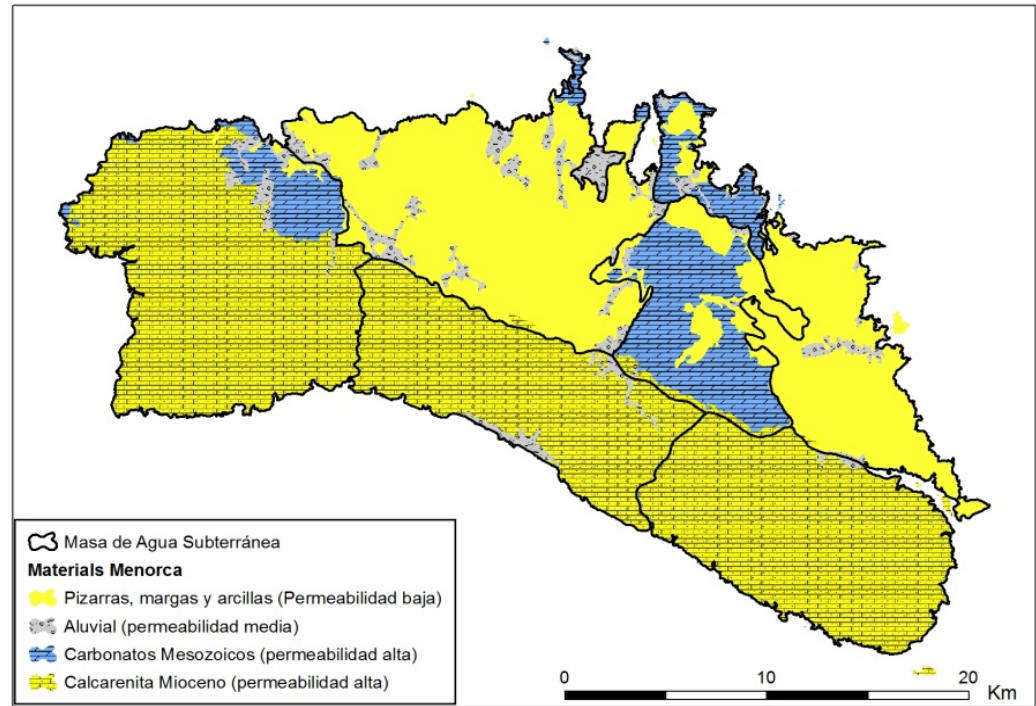

Fuente: Giménez et al., 2014

Las particularidades de los acuíferos kársticos hacen que su gestión sea más compleja que la de los acuíferos detríticos o de flujo difuso. Así, los acuíferos kárs- 
ticos se caracterizan por su alta heterogeneidad, la elevada velocidad de infiltración y circulación del agua, alta vulnerabilidad a la contaminación, almacenamiento relativamente escaso y grandes oscilaciones piezométricas. Por otro lado la explotación de los acuíferos kársticos puede acelerar el desarrollo de las morfologías kársticas subterráneas, y en consecuencia favorecer la formación de colapsos kársticos en superficie.

Figura 13.4. Delimitación de las MASbt de las Pitiusas con indicación de las litologías y permeabilidades

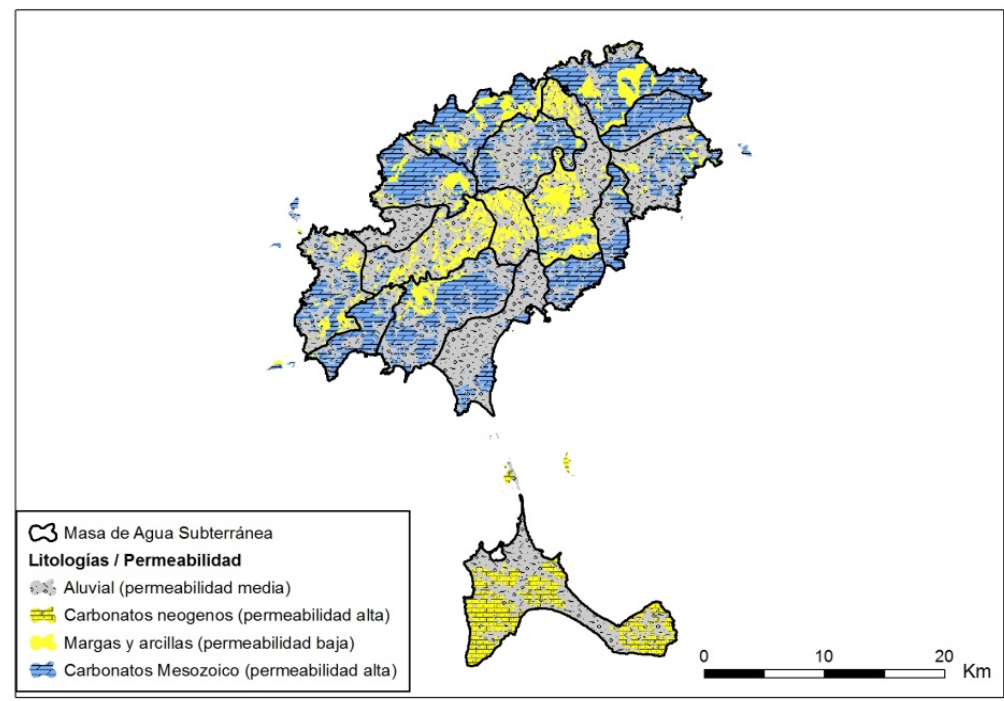

Fuente: Giménez et al., 2014

\subsection{Características climáticas de Baleares}

Las islas Baleares disfrutan de un clima típicamente Mediterráneo. En consecuencia el clima es poco lluvioso, con inviernos suaves, veranos calurosos y secos, y con frecuentes presencias de «gota fría en otoño. Las diferencias latitudinales dentro del archipiélago, así como las importantes diferencias orográficas dentro de cada una de las islas condicionan importantes diferencias climáticas dentro del territorio. Así, se observa un aumento de la aridez desde Menorca (con una precipitación media anual cercana a los $600 \mathrm{~mm}$ ) hacia Formentera (donde la media anual supera ligeramente los $400 \mathrm{~mm}$ ). Por otro lado, en la isla de Mallorca existen grandes diferencias ya que en el corazón de la Serra de Tramuntana las precipitaciones medias anuales pueden alcanzar los $1.200 \mathrm{~mm}$, mientras que en el extremo meridional las medias anuales no alcanzan los $400 \mathrm{~mm}$ (figura 13.5). Cabe resaltar que existe una coincidencia entre el periodo anual más seco (meses de verano) y el periodo de mayor demanda de agua debido a que la actividad turística se dispara. Este hecho incrementa la problemática del agua en Baleares. 
Figura 13.5. Precipitación media anual en las Baleares

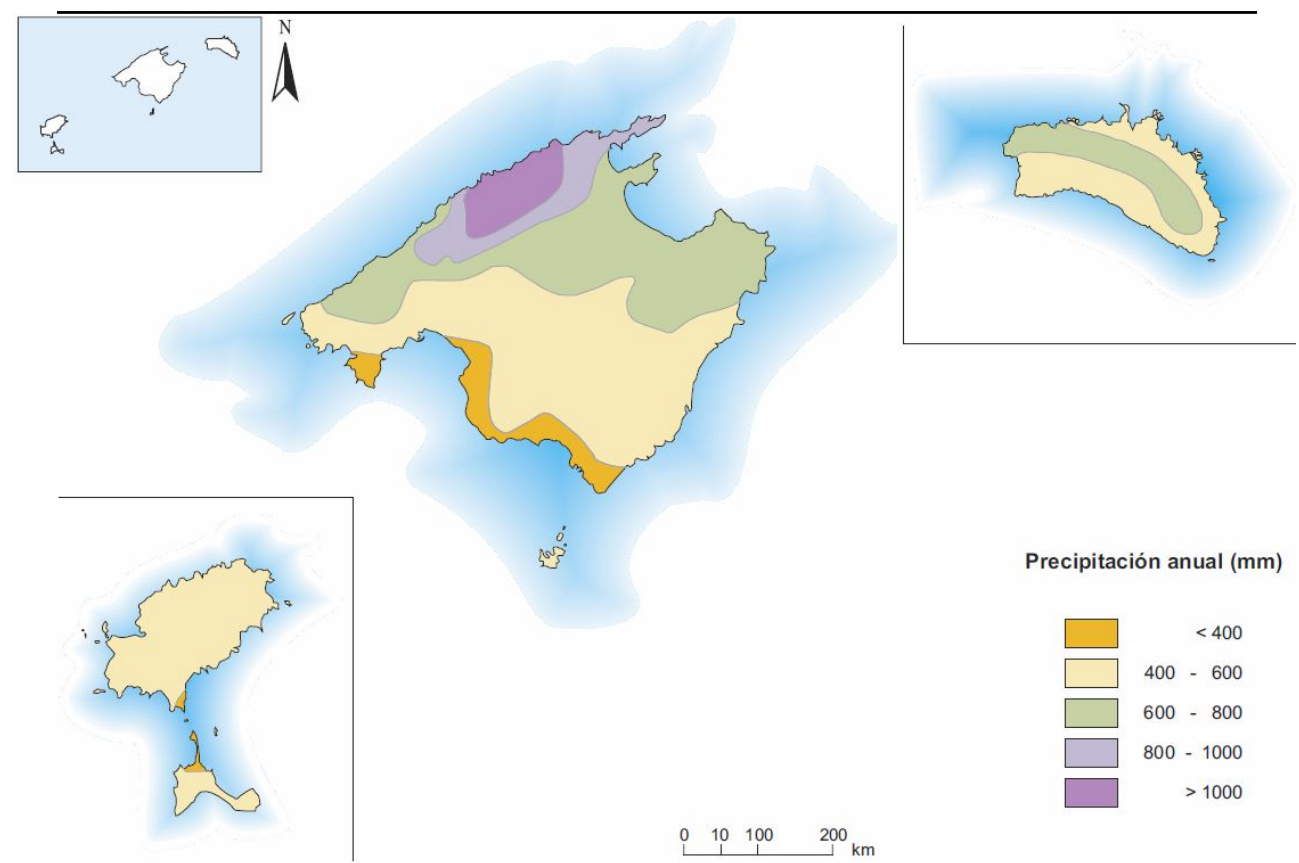

Fuente: Mateos, R.M. (2009)

Otra característica de los climas mediterráneos es la aparición de periodos de sequía que pueden alargarse varios años. La sequía meteorológica, o falta de precipitaciones, conduce a una sequía hidrológica, que es la falta de agua disponible para los diferentes usos. Para hacer frente a las sequías hidrológicas, la demarcación hidrográfica de las Illes Balears dispone de un Plan Especial de Actuaciones en Situación de Alerta y Eventual Sequía de las Illes Balears (PESIB) (BOIB 155, de 19 de diciembre de 2017). Este decreto establece, entro otros aspectos, la metodología para determinar el estado de sequía hidrológica y las acciones que debe llevar a cabo cada administración en los diferentes escenarios de sequía.

El PESIB define 10 Unidades de Demanda Urbanas para los que mensualmente se establece un indicador de sequía hidrológica a partir de las cotas piezométricas de diferentes pozos o piezómetros elegidos de manera estratégica. Paralelamente, a partir de la información de la Agencia Estatal de Meteorología (AEMET), se hace un seguimiento de la sequía meteorológica. Así, de manera anual se analizan los datos de precipitación en una serie de estaciones meteorológicas de la AEMET para establecer el Índice de Precipitación Estandarizado o Normalizado (SPI). El análisis de la incidencia de las sequías meteorológicas en las hidrológicas a lo largo del tiempo permite hacer predicciones sobre las futuras sequías hidrológicas.

En la figura 13.6 se presenta el Índice de Precipitación Estandarizado de la estación meteorológica B893 situada en la Unidad de Demanda de Menorca des- 
Figura 13.6. Evolución del índice de precipitación estandarizado en Menorca entre 1970 y 2018

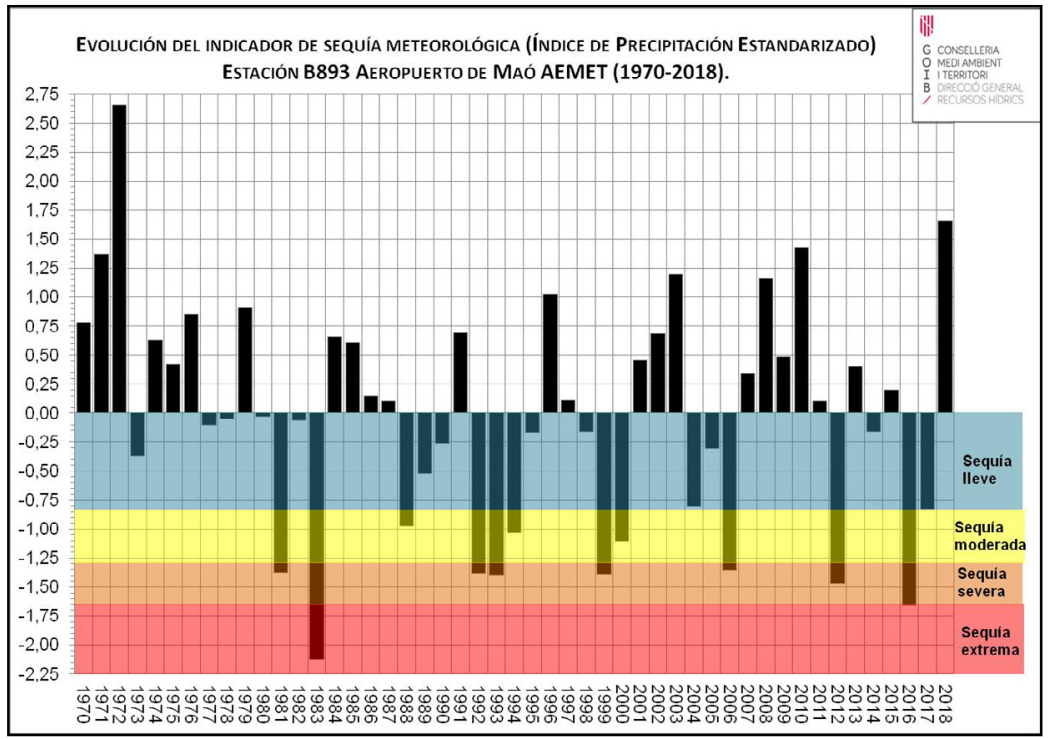

Fuente: http://www.caib.es/sites/aigua/ca/index_de_sequera/

Figura 13.7. Evolución del índice de sequía hidrológica en Menorca entre noviembre de 1983 y julio de 2019

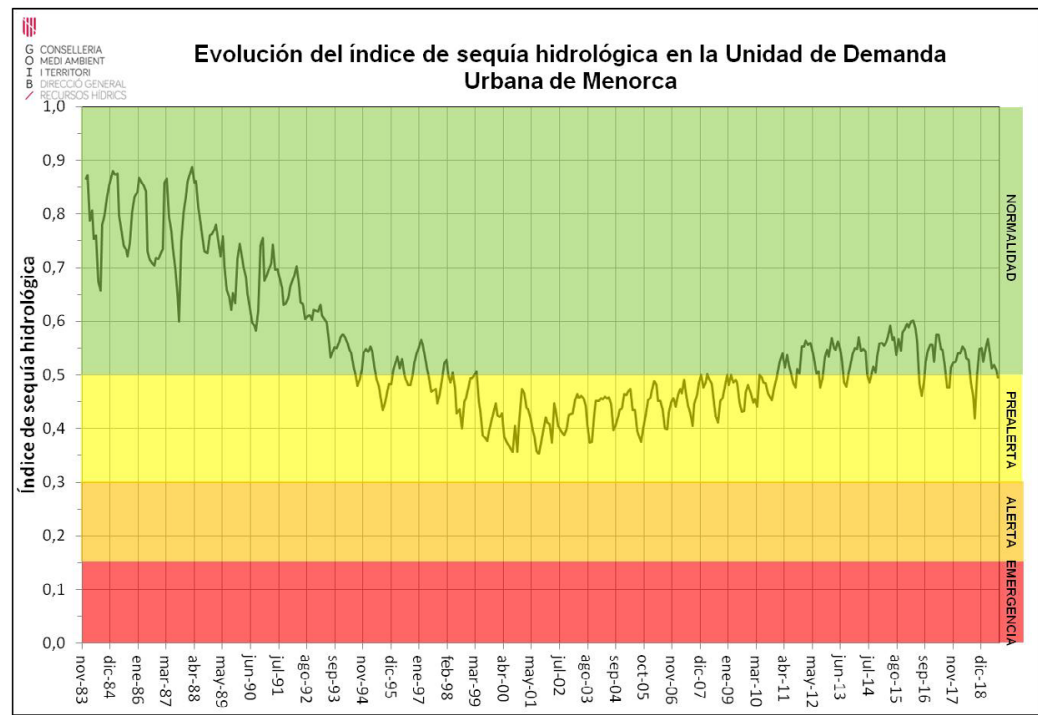

Fuente: http://www.caib.es/sites/aigua/ca/index_de_sequera/ 
de 1970 hasta 2018. En ella se puede observar como entre los años 1988 y 2000 (13 años) hubo 10 años secos, de los cuales 3 se consideran como sequía severa, 3 como moderada y los 4 restantes como sequía leve. Este periodo de falta de precipitaciones tuvo una influencia directa en el estado de los acuíferos. Así, en la evolución del índice de sequía hidrológico de Menorca (figura 13.7) se puede observar como en estos 13 años hay un descenso continuado del índice que a día de hoy (2019) todavía no ha podido ser recuperado. Por otro lado entre el año 2000 y el 2018 hay una ligera recuperación del índice de sequía hidrológica que coincide con un periodo relativamente húmedo (11 años húmedos frente a 7 de secos). Esta circunstancia pone de manifiesto que las extracciones que se realizan en esta unidad de demanda son del mismo orden que las entradas naturales por infiltración de agua de lluvia.

\subsection{Disponibilidades}

El Plan Hidrológico de las Illes Balears vigente, aprobado mediante el Real Decreto 51/2019 de 8 de febrero (PHIB 2019), estima que las disponibilidades de agua totales son del orden de los $423 \mathrm{hm}^{3}$ anuales. Por orden de importancia, las aguas subterráneas son las de mayor importancia, prácticamente el $80 \%$ de la disponibilidad en la isla de Menorca, o el $70 \%$ en Mallorca. Por el contrario, la disponibilidad de agua procedente de la desalación de agua de mar tiene un papel determinante en Formentera (más del 59\% del recurso disponible) y en Ibiza (superior al 29\%) (Tabla 13.1). Destaca también las disponibilidades de agua regenerada o depurada ya que se estima que se podrían llegar a reutilizar unos 68 $\mathrm{hm}^{3} /$ año, lo que supondría el $18 \%$ de las aguas disponibles. Por último, la disponibilidad de recursos hídricos superficiales (ríos y embalses) es prácticamente despreciable, ya que sólo tiene cierta importancia en Mallorca, donde existen dos embalses en la Sierra de Tramuntana que se destinan íntegramente al abastecimiento urbano.

Tabla 13.1. Recursos hídricos totales disponibles

\begin{tabular}{lccccccccc}
\hline \multirow{2}{*}{ Isla } & \multicolumn{2}{c}{ Superficiales } & \multicolumn{2}{c}{ Subterráneas } & \multicolumn{2}{c}{ Desalinizadas } & \multicolumn{2}{c}{ Regeneradas } & Suma \\
\cline { 2 - 10 } & $\mathrm{hm}^{3}$ & $\%$ & $\mathrm{hm}^{3}$ & $\%$ & $\mathrm{hm}^{3}$ & $\%$ & $\mathrm{hm}^{3}$ & $\%$ & $\mathrm{hm}^{3}$ \\
\hline Mallorca & 6,9 & $1,9 \%$ & 215,5 & $69,7 \%$ & 30,5 & $9,9 \%$ & 56,1 & $18,2 \%$ & 309,0 \\
\hline Menorca & 0 & $0,0 \%$ & 17,5 & $79,5 \%$ & 0 & $0,0 \%$ & 4,5 & $20,5 \%$ & 22,0 \\
\hline Ibiza & 0 & $0,0 \%$ & 16,0 & $48,6 \%$ & 9,8 & $29,8 \%$ & 7,1 & $21,6 \%$ & 32,9 \\
\hline Formentera & 0 & $0,0 \%$ & 0,4 & $18,2 \%$ & 1,3 & $59,1 \%$ & 0,5 & $22,7 \%$ & 2,2 \\
\hline Baleares & $\mathbf{6 , 9}$ & $1,6 \%$ & $\mathbf{2 4 9 , 4}$ & $68,1 \%$ & $\mathbf{4 1 , 6}$ & $11,4 \%$ & $\mathbf{6 8 , 2}$ & $18,6 \%$ & $\mathbf{4 2 3 , 3}$ \\
\hline
\end{tabular}

Fuente: Revisión anticipada del Plan Hidrológico de las Islas Baleares (2 ${ }^{\circ}$ Ciclo 2015-21) Anejo 3 de la Memoria 
Cabe recordar que el establecimiento de los recursos disponibles de agua subterránea se obtiene de la diferencia entre los recursos potenciales (entradas naturales por infiltración de agua de lluvia y/o infiltración a través de torrentes, más las entradas por pérdidas de redes urbanas y/o retornos de la agricultura) y las salidas necesarias para asegurar el buen estado de las aguas subterráneas y superficiales. De este modo para poder asegurar el buen estado de las Masas de Agua Superficiales y Subterráneas es necesario respetar las salidas mínimas al mar para evitar la salinización de los acuíferos costeros, y las salidas mínimas a torrentes y zonas húmedas (ZZHH) para asegurar que estas masas superficiales mantengan o alcancen el buen estado ecológico.

Como muestra la tabla 13.2, a nivel de demarcación las salidas mínimas suponen el $47 \%$ de los recursos potenciales. Cabe destacar que en el caso de Formentera se estima que las salidas mínimas suponen alrededor del $90 \%$ de las entradas lo cual indica que si se quiere alcanzar el buen estado de las masas de agua la explotación de los acuíferos debe ser inferior al $10 \%$ del recurso potencial.

Tabla 13.2. Recursos subterráneos potenciales y disponibles en Baleares

\begin{tabular}{|c|c|c|c|c|c|c|c|c|c|c|}
\hline \multirow{3}{*}{ Isla } & \multirow{3}{*}{$\begin{array}{c}\begin{array}{c}\text { Recurso } \\
\text { Potencial }\end{array} \\
\mathrm{hm}^{3}\end{array}$} & \multicolumn{8}{|c|}{ Salidas mínimas } & \multirow{3}{*}{$\frac{\text { Disponible }}{\mathrm{hm}^{3}}$} \\
\hline & & \multicolumn{2}{|c|}{ Al mar } & \multicolumn{2}{|c|}{ A Torrentes } & \multicolumn{2}{|c|}{ A ZZHH } & \multicolumn{2}{|c|}{ SUMA } & \\
\hline & & $\mathrm{hm}^{3}$ & $\%$ & $\mathrm{hm}^{3}$ & $\%$ & $\mathrm{hm}^{3}$ & $\%$ & $\mathrm{hm}^{3}$ & $\%$ & \\
\hline Mallorca & 371,9 & 111,6 & $30 \%$ & 22,6 & $6 \%$ & 22,2 & $6 \%$ & 156,4 & $42 \%$ & 215,5 \\
\hline Menorca & 64,1 & 43,1 & $67 \%$ & 1,9 & $3 \%$ & 1,6 & $2 \%$ & 46,6 & $73 \%$ & 17,5 \\
\hline Ibiza & 30,0 & 10,1 & $34 \%$ & 3,2 & $11 \%$ & 0,7 & $2 \%$ & 14,0 & $47 \%$ & 16,0 \\
\hline Formentera & 4,7 & 3,3 & $70 \%$ & 0,0 & $0 \%$ & 1,0 & $22 \%$ & 4,3 & $91 \%$ & 0,4 \\
\hline Baleares & 470,6 & 168,0 & $36 \%$ & 27,7 & $6 \%$ & 25,5 & $5 \%$ & 221,3 & $47 \%$ & 249,4 \\
\hline
\end{tabular}

Fuente: Elaborado a partir de la información de la revisión anticipada del Plan Hidrológico de las Islas Baleares ( $2^{\circ}$ Ciclo 2015-21).

\subsection{Demandas}

La demanda de agua en las islas Baleares ha sufrido un incremento muy importante a lo largo del siglo XX debido al incremento de la población y al incremento de la mayor actividad de las islas: el turismo. Así, en la actualidad (2019) la población residente supera los 1,1 millones de habitantes, lo cual duplica la población de 1970 (Figura 13.8). Por otro lado, debido a la llegada de turistas y visitantes, la población real que utiliza los recursos de las islas es de aproximadamente 1,5 millones, lo cual supone un $30 \%$ más que la población residente. Del mismo modo durante el mes de agosto de 2017 se alcanzaron los 2,01 millones de personas, lo que supone un incremento del $77 \%$ respecto de la población residente. Este porcentaje de incremento entre el máximo de agosto y la pobla- 
ción residente se ha mantenido más o menos constante en los últimos 20 años, aunque el número de residentes y de visitantes ha ido en constante aumento (Figura 13.9).

Figura 13.8. Evolución de la población de Baleares entre 1857 y 2011

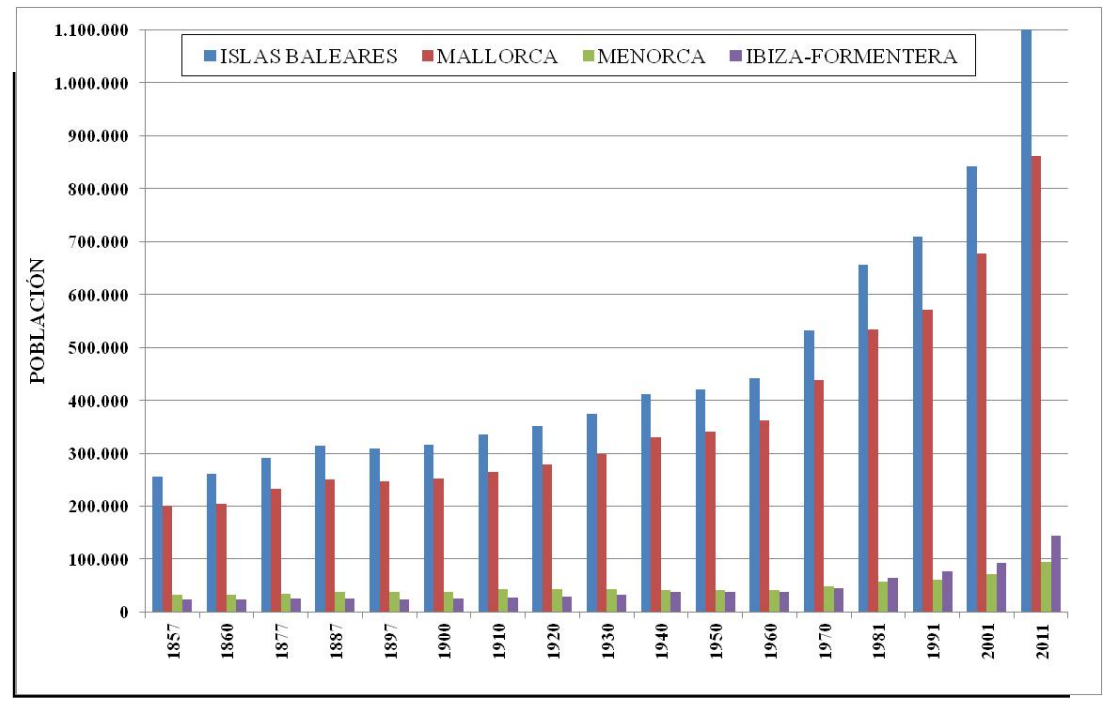

Fuente: IBESTAT https://ibestat.caib.es/ibestat/estadistiques/poblacio)

Figura 13.9. Evolución de la media de la población mensual en Baleares (1997-2018)

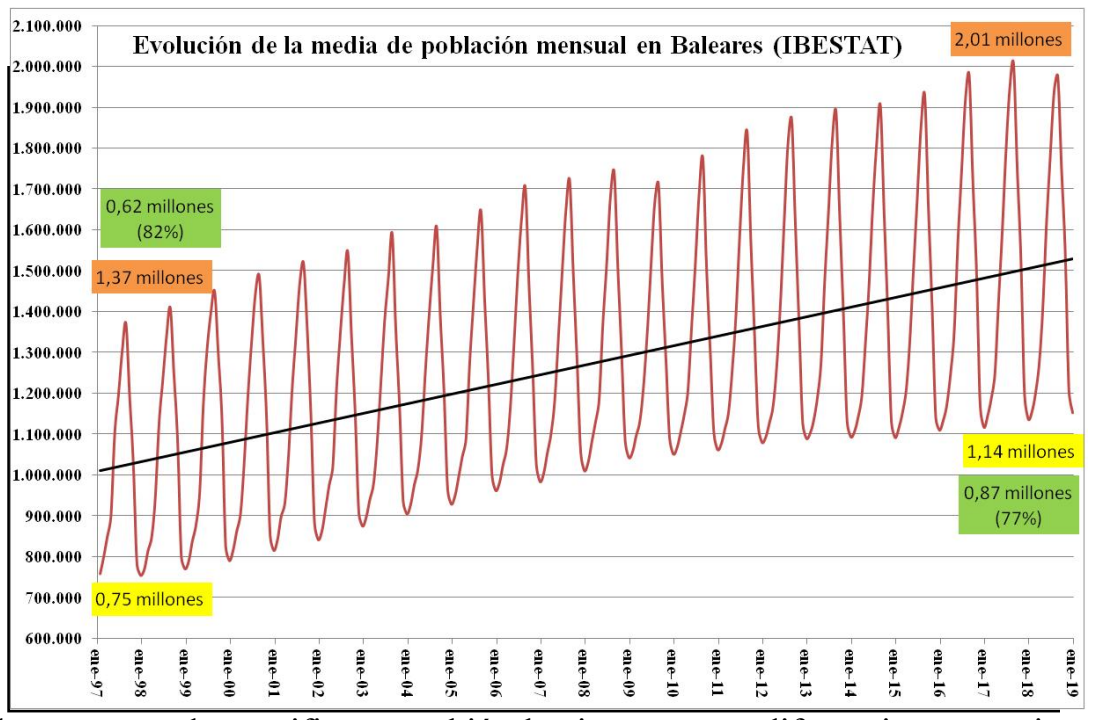

Fuente: IBESTAT https://ibestat.caib.es/ibestat/estadistiques/poblacio) 
Para hacer frente a esta importante demanda de agua urbana se usan básicamente (más de un 80\%) aguas subterráneas (Tabla 13.3). Los datos de procedencia del agua de la red urbana ponen de manifiesto también las importantes diferencias que existen entre islas. Así en Formentera el 100\% de las aguas proceden de desalación, mientras que en Menorca el 100\% de las aguas de uso urbano procedió de los acuíferos. Por otro lado, en Ibiza un poco más de la mitad del agua de red (59\%) procedía de acuíferos y el resto de plantas desalinizadoras.

Tabla 13.3. Procedencia del agua para abastecimiento urbano, consumo y pérdidas estimadas en el año 2015

\begin{tabular}{|c|c|c|c|c|c|c|c|c|c|}
\hline \multirow{3}{*}{ Isla } & \multicolumn{7}{|c|}{ Procedencia del agua de consumo urbano } & \multirow{3}{*}{$\begin{array}{c}\text { Consumo } \\
\mathrm{hm}^{3}\end{array}$} & \multirow{3}{*}{$\begin{array}{c}\text { Pérdidas } \\
\mathrm{hm}^{3}\end{array}$} \\
\hline & \multicolumn{2}{|c|}{ Subterránea } & \multicolumn{2}{|c|}{ Superficial } & \multicolumn{2}{|c|}{ Desalada } & \multirow{2}{*}{$\frac{\text { Suma }}{\mathrm{hm}^{3}}$} & & \\
\hline & $\mathrm{hm}^{3}$ & $\%$ & $\mathrm{hm}^{3}$ & $\%$ & $\mathrm{hm}^{3}$ & $\%$ & & & \\
\hline Mallorca & 86,62 & $85,6 \%$ & 10,31 & $10,2 \%$ & 4,28 & $4,2 \%$ & 101,20 & 78,71 & 22,49 \\
\hline Menorca & 11,63 & $100 \%$ & - & - & - & - & 11,63 & 8,44 & 3,18 \\
\hline Ibiza & 11,36 & $58,9 \%$ & - & - & 7,91 & $41,1 \%$ & 19,26 & 12,91 & 6,35 \\
\hline Formentera & - & - & - & - & 0,65 & $100 \%$ & 0,65 & 0,56 & 0,09 \\
\hline Baleares & 109,59 & $82,6 \%$ & 10,31 & $7,8 \%$ & 12,83 & $9,7 \%$ & 132,74 & 100,62 & 32,12 \\
\hline
\end{tabular}

Fuente: Revisión anticipada del Plan Hidrológico de las Islas Baleares (2 ${ }^{\circ}$ Ciclo 2015-21) Anejo 3 de la Memoria

Los porcentajes de procedencia del agua de consumo urbano dependen en gran medida de las características climáticas del año considerado. En un año seco las aguas desaladas pueden suponer más del $15 \%$ del total consumido, mientras que en un año húmedo el porcentaje puede descender hasta el $5 \%$. Estas diferencias son debidas a que los gestores de las redes urbanas siempre utilizan el agua más económica, y en consecuencia solo utilizan agua desalinizada (la menos económica) cuando es prácticamente la única alternativa.

Los datos de extracciones para el año 2015 indican que las dotaciones (entradas en la red urbana) de agua para consumo urbano fueron del orden de los 328 litros por habitante y día (1/hab/día) en caso de considerar solo la población residente (1,11 millones en 2015), y de 255 l/hab/día si se considera la población flotante (1,43 millones). En el caso de los consumos para el 2015 se obtiene un consumo medio de 248 l/hab/día frente a 193 l/hab/día si se considera la población flotante. Por lo tanto, existe una importante diferencia (un incremento cercano al $30 \%$ ) si se realizan los cálculos de consumos por habitante y día considerando solo la población residente o considerando la población real (residentes + visitantes). Estas diferencias son más acentuadas en las Pitiusas y Menorca, donde las diferencias entre población residente y flotante son mayores. 
A parte de la demanda urbana, el segundo sector en volumen de utilización del agua es el sector agrícola. Según el PHIB 2019 en el año 2015 el sector agrícola (incluyendo riego de parques urbanos y campos de golf) consumió unos 54 $\mathrm{hm}^{3}$, lo que supone una cuarta parte del consumo total de la demarcación (220 $\mathrm{hm}^{3}$ ). Cabe indicar que el consumo disperso (viviendas aisladas y pequeños huertos) se estima que consumió del orden de los $33 \mathrm{hm}^{3}$, es decir el $15 \%$ del total. El gran consumidor, con el $60 \%$ es el urbano (Tabla 13.4).

Tabla 13.4. Usos y procedencia del agua utilizada en el año 2015

\begin{tabular}{|c|c|c|c|c|c|c|}
\hline \multirow{2}{*}{ Uso } & \multirow{2}{*}{ Procedencia } & \multicolumn{4}{|c|}{ Isla/Sistema de explotación } & \multirow{2}{*}{ Baleares } \\
\hline & & Mallorca & Menorca & Ibiza & Formentera & \\
\hline \multirow{4}{*}{$\begin{array}{l}\text { Abastecimiento } \\
\text { urbano (incluye } \\
\text { industrial) }\end{array}$} & Subterráneas & 86,62 & 11,63 & 11,36 & 0,00 & 109,60 \\
\hline & Embalses & 10,31 & 0,00 & 0,00 & 0,00 & 10,31 \\
\hline & IDAM & 4,28 & 0,00 & 7,91 & 0,65 & 12,84 \\
\hline & Suma & 101,20 & 11,63 & 19,26 & 0,65 & 132,75 \\
\hline Viviendas aisladas & Subterráneas & 24,94 & 2,00 & 5,68 & 0,55 & 33,17 \\
\hline \multirow{4}{*}{$\begin{array}{l}\text { Sector agrícola } \\
\text { (incluye jardines } \\
\text { urbanos y golf) }\end{array}$} & Subterráneas & 17,96 & 1,42 & 1,75 & 0,00 & 21,13 \\
\hline & EDAR & 31,21 & 1,23 & 0,58 & 0,00 & 33,02 \\
\hline & IDAM & 0,02 & 0,00 & 0,00 & 0,00 & 0,02 \\
\hline & Suma & 49,19 & 2,65 & 2,33 & 0,00 & 54,17 \\
\hline Ganadería & Subterráneas & 0,23 & 0,20 & 0,01 & 0,00 & 0,44 \\
\hline TOTAL & & 175,56 & 16,48 & 27,28 & 1,20 & 220,52 \\
\hline
\end{tabular}

Fuente: Revisión anticipada del Plan Hidrológico de las Islas Baleares (2 Ciclo 2015-21) Anejo 3 de la Memoria

Si se considera la información al respecto de las extracciones de agua subterránea estimadas para el año 2015 y las disponibilidades para ese mismo periodo considerando las entradas de agua (Recursos potenciales) y las salidas mínimas para alcanzar el buen estado de las masas, se obtiene que los porcentajes de explotación a nivel de isla o sistema de explotación superan el $80 \%$ en todas las islas excepto en Mallorca. Esto indica que se está extrayendo más agua de la disponible (Tabla 13.5). Por otro lado, si se considera la información disponible al respecto de las concesiones de extracción de agua subterránea en el año 2018, es decir los derechos de explotación indicados en los títulos de los pozos, se llega a la conclusión que la suma de todos los derechos es superior a la disponibilidad de agua subterránea. 
Tabla 13.5. Porcentajes de explotación de las MASbt

\begin{tabular}{lccccc}
\hline $\begin{array}{c}\text { Isla / } \\
\text { Sistema de } \\
\text { explotación }\end{array}$ & $\begin{array}{c}\text { Recurso } \\
\text { disponible }\end{array}$ & $\begin{array}{c}\text { Extracciones } \\
\text { estimadas } \\
\mathbf{( 2 0 1 5 )}\end{array}$ & $\begin{array}{c}\text { Porcentaje } \\
\text { explotación }\end{array}$ & $\begin{array}{c}\text { Concesiones } \\
\text { informatizadas } \\
\mathbf{( 2 0 1 8 )}\end{array}$ & $\begin{array}{c}\text { Porcentaje } \\
\text { explotación }\end{array}$ \\
\hline Mallorca & 215,50 & 122,41 & $56,8 \%$ & 205,65 & $95,4 \%$ \\
\hline Menorca & 17,50 & 15,99 & $91,4 \%$ & 27,71 & $158,3 \%$ \\
\hline Ibiza & 16,00 & 19,40 & $121,3 \%$ & 25,46 & $159,1 \%$ \\
\hline Formentera & 0,40 & 0,58 & $145,0 \%$ & 0,378 & $94,5 \%$ \\
\hline Baleares & 249,40 & 158,38 & $63,5 \%$ & 259,20 & $103,9 \%$ \\
\hline
\end{tabular}

Fuente: Revisión anticipada del Plan Hidrológico de las Islas Baleares (2 Ciclo 2015-21) Anejo 3 de la Memoria

\subsection{Estado de las Masas de Agua Subterránea}

Como se ha puesto de manifiesto en apartados anteriores la extracción de agua subterránea en Baleares es superior a la disponibilidad de este recurso. Esta circunstancia ha conllevado a que una parte importante de las MASbt de la demarcación estén en mal estado cuantitativo o presenten problemas de salinización por intrusión marina. A parte de la importante demanda de agua anual, debe destacarse que la mayor demanda se produce en la época de menor disponibilidad (verano). A parte de la salinización y descenso de niveles relacionados con las elevadas extracciones de agua subterránea, los acuíferos de la demarcación se ven afectados también por contaminación asociada a la deficiente depuración de las aguas residuales (ya sea en las redes urbanas como en las viviendas aisladas en suelo rústico) y la actividad agrícola (sobretodo el mal uso de los abonos nitrogenados o el uso excesivo de pesticidas y/o plaguicidas). En resumen, la presión humana ha provocado una sobreexplotación de los acuíferos (descenso de niveles e intrusión salina en los acuíferos costeros) y contaminación por nitratos en una parte importante de los acuíferos.

La fuerte presión humana en Baleares no es nueva ya que los problemas de salinización en la costa ya se detectaban ampliamente en los años 70 del siglo XX. Por otro lado, la presión del sector agrícola ha ido disminuyendo en los últimos años debido al abandono del campo, lo cual puede explicar la disminución en la concentración en nitratos que se detecta en algunas de las zonas agrícolas tradicionales. Cabe indicar que la presencia de nitratos en algunos acuíferos de Baleares debe asociarse a los vertidos de aguas residuales o aguas poco depuradas. En cualquier caso, la información aportada por las redes de seguimiento de calidad y piezometría indica que una buena parte de los acuíferos están en mal estado y en consecuencia en riesgo de no alcanzar los objetivos de calidad de la Directiva Marco del Agua (DMA). Como muestra la tabla 13.6 el 57\% de las MASbt está en mal estado; el 39\% de las MASbt por exceso de cloruros, el $18 \%$ por exceso de nitratos, y el $34 \%$ por sobreexplotación. 
Tabla 13.6. Estado cualitativo y cuantitativo de las MASbt según PHIB 2019

\begin{tabular}{|c|c|c|c|c|c|c|c|c|c|c|c|}
\hline \multirow[t]{2}{*}{$\begin{array}{c}\text { Isla / } \\
\text { Sistema de } \\
\text { explotación }\end{array}$} & \multirow[t]{2}{*}{$\begin{array}{l}\text { Núm. } \\
\text { MASbt }\end{array}$} & \multicolumn{2}{|c|}{$\begin{array}{l}\text { Mal estado } \\
\text { químico } \\
\text { por } \\
\text { Nitratos }\end{array}$} & \multicolumn{2}{|c|}{$\begin{array}{l}\text { Mal estado } \\
\text { químico por } \\
\text { Cloruros }\end{array}$} & \multicolumn{2}{|c|}{$\begin{array}{l}\text { Mal estado } \\
\text { químico }\end{array}$} & \multicolumn{2}{|c|}{$\begin{array}{c}\text { Mal estado } \\
\text { cuantitativo }\end{array}$} & \multicolumn{2}{|c|}{ Mal estado } \\
\hline & & Núm. & $\%$ & Núm. & $\%$ & Núm. & $\%$ & Núm. & $\%$ & Núm. & $\%$ \\
\hline Mallorca & 64 & 14 & 22 & 23 & 36 & 30 & 47 & 16 & 25 & 34 & 53 \\
\hline Menorca & 6 & 2 & 33 & 2 & 33 & 2 & 33 & 4 & 67 & 4 & 67 \\
\hline Eivissa & 16 & 0 & 0 & 8 & 50 & 8 & 50 & 9 & 56 & 11 & 69 \\
\hline Formentera & 1 & 0 & 0 & 1 & 100 & 1 & 100 & 1 & 100 & 1 & 100 \\
\hline Illes Balears & 87 & 16 & 18 & 34 & 39 & 41 & 47 & 30 & 34 & 50 & 57 \\
\hline
\end{tabular}

Fuente: Revisión anticipada del Plan Hidrológico de las Islas Baleares (2 Ciclo 2015-21)

A raíz de estos datos el PHIB 2019 considera que solo el 74\% de las MASbt está en riesgo de no alcanzar el buen estado en 2021. De entre estas MASbt en riesgo el PHIB 2019 considera que solo el 29\% alcanzará el buen estado en 2021, el $23 \%$ no lo alcanzará hasta 2027, el $16 \%$ lo alcanzará en 2033, y un $6 \%$ de las MASbt se consideran excencionables, es decir que no alcanzaran el buen estado como mínimo hasta más allá de 2033 (figura 13.10).

Figura 13.10. Riesgo de no alcanzar los objetivos de la DMA según PHIB 2019

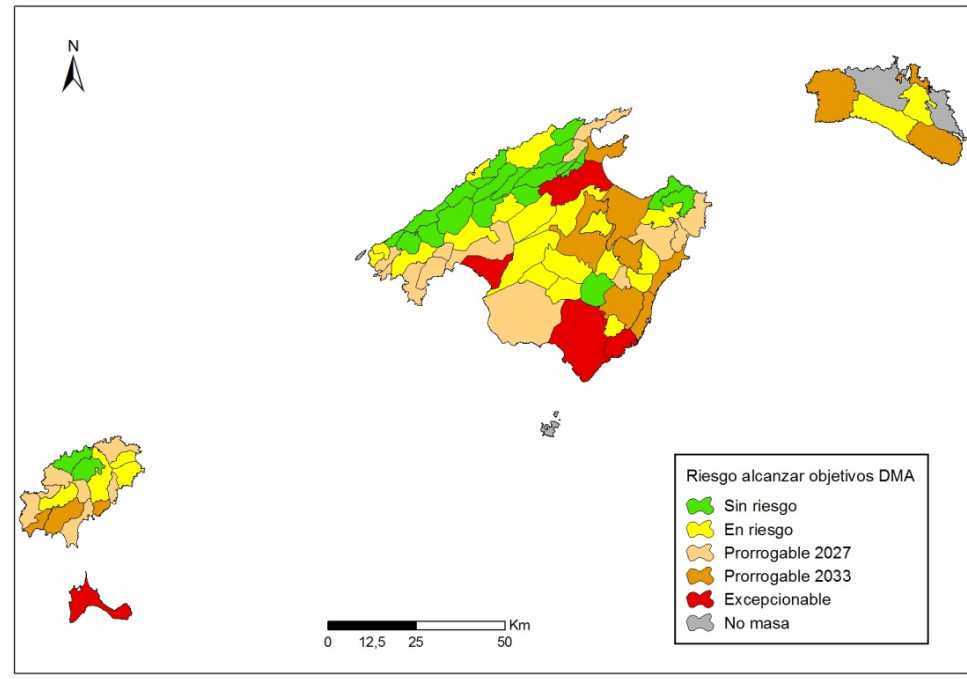

Fuente: PHIB (2019)

Las presiones que afectan a las MASbt afectan también al resto de masas de agua de la demarcación, aunque de diferente forma. Así los trabajos de evaluación del estado ecológico de las masas de agua superficiales (MASup) han puesto 
de manifiesto que una parte importante (el 19\%) no alcanza los objetivos de calidad establecidos por Europa. En la mayoría de los casos el mal estado ecológico observado está relacionado con vertidos de aguas depuradas o malas praxis ya que las MASup prácticamente no tienen usos consuntivos, aunque la sobreexplotación de los acuíferos también es determinante en el estado de las MASup, ya que limita en gran manera los caudales circulantes en los torrentes, así como la llegada de agua a las masas de transición.

Tabla 13.7. Estado ecológico de las MASup (PHIB 2019)

\begin{tabular}{lcrrrrrr}
\hline \multirow{2}{*}{ Tipo / categoría } & Número & \multicolumn{2}{c}{$\begin{array}{c}\text { Buen estado o } \\
\text { mejor }\end{array}$} & \multicolumn{2}{c}{$\begin{array}{c}\text { Peor que } \\
\text { bueno }\end{array}$} & \multicolumn{2}{c}{ No evaluado } \\
\cline { 3 - 8 } & & Num & $\%$ & Num & $\%$ & Num & $\%$ \\
\hline Ríos naturales & 90 & 23 & 25,6 & 24 & 26,7 & 43 & 47,8 \\
\hline Ríos muy modificados & 3 & 0 & 0,0 & 0 & 0,0 & 3 & 100,0 \\
\hline Transición & 35 & 23 & 65,7 & 7 & 20,0 & 5 & 14,3 \\
\hline Costeras & 36 & 23 & 63,9 & 7 & 19,4 & 6 & 16,7 \\
\hline Todas las categorías & 171 & 75 & 43,9 & 33 & 19,3 & 62 & 36,3 \\
\hline
\end{tabular}

Fuente: Revisión anticipada del Plan Hidrológico de las Islas Baleares (2 Ciclo 2015-21)

\subsection{Retos de futuro}

Para poder cumplir con los objetivos de la DMA y llegar al buen estado de las masas de agua es necesario llevar a cabo diferentes acciones o retos. Más aún si se considera que las previsiones del cambio climático indican que la disponibilidad de recursos hídricos se va a ver disminuida debido al incremento de las temperaturas y de la aridez en general en la región mediterránea. Por otro lado, se prevé un incremento de la demanda urbana ya que la sociedad actual está basada en el crecimiento económico, lo cual implica un mayor consumo de recursos.

El programa de medidas del PHIB 2019 expone que en los tres ciclos de planificación (2009 a 2027) establecidos por la DMA se prevé una inversión de más de 2.000 millones de $€$ que debería permitir alcanzar los objetivos de calidad y ambientales de la DMA así como satisfacer las demandas futuras. A fecha de final de 2018 se han invertido del orden de 466 millones de $€$, que suponen el $99 \%$ de las inversiones previstas para el primer ciclo (2009-2015) y el 30\% de las previstas para el segundo ciclo (2016-2021). Como se observa en la figura 13.11 de la inversión prevista se puede destacar que el $44 \%$ del presupuesto se destina a objetivos medioambientales, el 29\% a gobernanza y conocimiento, y el 19\% a satisfacción de la demanda. Entre los grupos de inversiones previstas destacan aquellas destinadas a la mejora de la depuración de aguas residuales (807 millones de $€$ ), y a la gestión y mantenimiento de las EDARs (549 millones de €). Destaca también las 
inversiones previstas en la satisfacción de la demanda urbana (297 millones de €), así como la prevención y defensa de avenidas (195 millones de €).

Figura 13.11. Inversiones previstas en el programa de medidas del PHIB

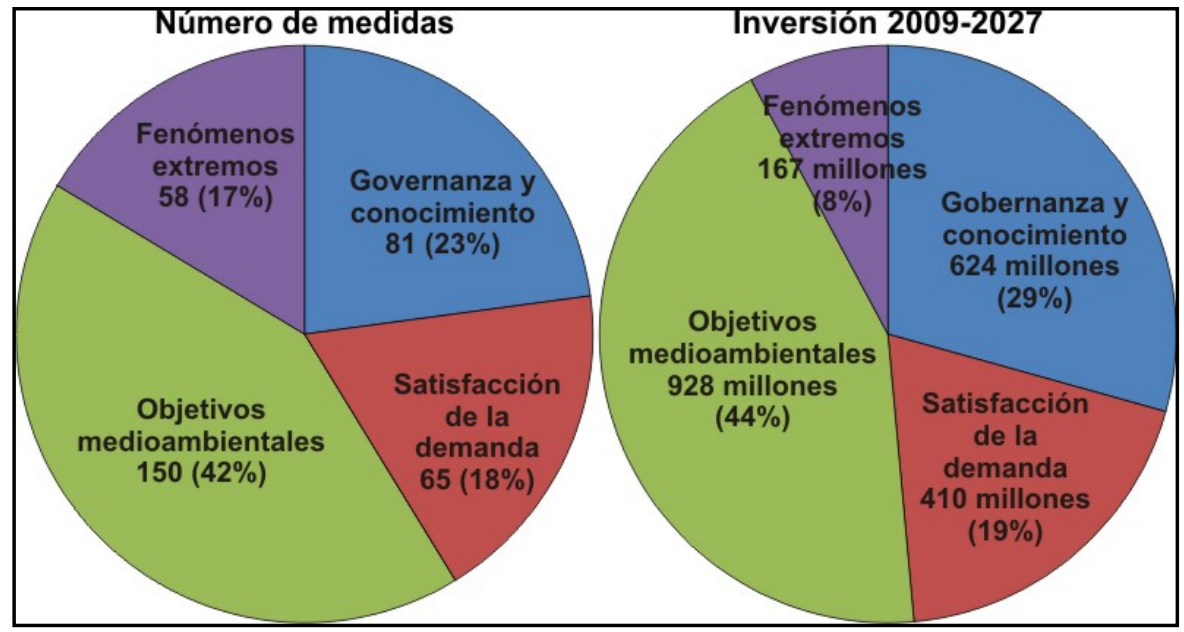

Fuente: PHIB (2019)

Dada la situación actual de las masas de agua y el hecho de que la presión antrópica no va a disminuir, si Baleares quiere cumplir con los objetivos de la DMA se enfrenta a un reto principal: reducir el consumo de agua subterránea. Así, las obras e infraestructuras que pueden ser necesarias para lograr que el agua potable llegue a todos los rincones de del archipiélago no son suficientes, sino que es necesario que la población sea consciente de la importancia del recurso y del coste del mismo.

Para llevar a cabo el reto de la reducción de las extracciones de agua subterránea es necesario poner en marcha todas las acciones posibles. Reducir las pérdidas de las redes de distribución de agua potable permitirá reducir las extracciones, aunque no el consumo. El PHIB 2019 ya contempla la obligatoriedad de reducir las pérdidas hasta el $17 \%$ para 2027.

Reutilizar el $100 \%$ de las aguas depuradas es un reto que permitiría reducir en gran medida las extracciones. Llegar a este objetivo no es posible en la actualidad así que es necesario mejorar los sistemas de depuración. Esta reutilización del agua depurada no tiene que ser directa (reutilización del agua depurada para el riego o baldeo de calles), sino que puede ser indirecta, como puede ser la puesta en marcha sistemas que permitan infiltrar el agua depurada en los acuíferos para que ésta pueda ser captada aguas abajo o que sirva para frenar la intrusión salina. Estos últimos casos no reducen las extracciones propiamente dichas, pero aumentan el recurso disponible y en consecuencia mejoran es estado de las masas.

Incrementar la desalación de aguas de mar es otro de los retos futuros. En Baleares el conjunto de plantas desalinizadoras existentes podría ser capaz de 
producir del orden de los $50 \mathrm{hm}^{3}$ anuales si funcionaran todo el año a máximo rendimiento. Por otro lado, entre 2015 y 2018 se ha desalado una media de 22 $\mathrm{hm}^{3}$ anuales, lo cual supone un incremento importante respecto a años anteriores, aunque todavía lejos de la producción máxima. Para reducir las extracciones es necesario amortizar al máximo las plantas desalinizadoras.

La implantación de una red de agua potable (red en alta) que llegue a los principales puntos de demanda de Baleares es también un gran reto que ya plantea el PHIB 2019. Esta red debe permitir reducir al máximo las extracciones en las MASbt en peor estado para que alcancen los objetivos de la DMA.

Todas estas medidas o retos suponen grandes inversiones por lo que será necesario incrementar las tarifas del agua con el objetivo que se haga un uso más responsable, es decir, concienciar a la población de la falta de recurso.

Por último, el mayor de los retos es hacer que la sociedad sea partícipe de esta recuperación o estos objetivos. Así es necesario que todos los usuarios entiendan que el agua es un recurso limitado y que, según las previsiones del cambio climático, cada vez será más escaso. En el caso de Baleares dado que el mayor consumidor es el uso urbano los máximos esfuerzos deben destinarse a este sector. Por otro lado, el sector agropecuario, aun sin ser el más consumidor, debe también concienciarse para evitar al máximo las malas praxis agrícolas que pueden deteriorar la calidad del recurso.

\section{Referencias bibliográficas}

Fornós, J.J. y Gelabert, B. (2011) «Condicionants Litològics i estructurals del Carst a les Illes Balears» ENDINS v. 35 / Mon. Soc. Hist. Nat. Balears, v. 17, pp. 37-52.

Giménez, J., Gelabert, B. y Sábat, F. (2007). «El relieve de las Islas Baleares» en Enseñanza de las ciencias de la Tierra, v 15.2, pp. 175-184.

Giménez, J., Barón, A., Comas, M., González, C, Garau, J., Beidas, O., Oliver, M. y Nadal F.X. (2014). "Hidrogeologia de les Illes Balears: Les masses d'aigua càrstica» en ENDINS v. 36, pp. 9-26.

Mateos, R.M. (2009). Los caminos del agua en las islas Baleares. Acuíferos y manantiales. Madrid: Instituto Geológico y Minero de España / Conselleria de Medi Ambient de les Illes Balears. [Coordinación: Mateos, R.M. y Gonzalez, C] 280 pág.

Sàbat, F., Gelabert, B. Rodríguez-Perea, A. \& Giménez, J. (2011) «Geological structure and evolution of Majorca: Implications for the origin of the Western Mediterranean» Tectonophysics v. 510, pp. 217-238.

Portal del agua de las Islas Baleares http://www.caib.es/sites/aigua/ca/pagina_dinici-6476/?campa=yes

Planificación hidrológica demarcación Illes Balears http://www.caib.es/sites/aigua/ca/planificacio_hidrologica/ 
Documentación básica elaboración planes hidrológicos Illes Balears. http://www.caib.es/sites/aigua/ca/documentacio_basica_pla_hidrologic/

Seguimiento sequía http://www.caib.es/sites/aigua/ca/index_de_sequera/

Instituto Balear de Estadística: Datos de población https://ibestat.caib.es/ibestat/ estadistiques/poblacio

Comunitat Autónoma de les Illes Balears. Decret 54/2017, de 15 de desembre, pel qual s'aprova el Pla Especial d'Actuació en Situacions d'Alerta i Eventual Sequera de les Illes Balears. BOIB, 19 de diciembre de 2017, num. 155, p. 40.882-40.900.

Comunitat Autónoma de les Illes Balears. Resolució de la directora general de Recursos Hídrics mitjançant la qual es disposa la publicació de les determinacions del contingut normatiu del Pla Hidrològic de les Illes Balears, aprovat mitjançant el Reial decret 51/2019, de 8 de febrero. BOIB, 4 de abril de 2019, num. 43, p. 12.545-13.129.

España. Real Decreto 51/2019, de 8 de febrero, por el que se aprueba el Plan Hidrológico de la Demarcación Hidrográfica de las Illes Balears. BOE, 23 de febrero 2019, num. 47, p. 17.601-17.603. 



\title{
Capítulo 14 \\ Cinco aspectos clave en la gestión del agua en las Islas Baleares
}

\author{
Celso García \\ Doctor en Geografía \\ Pablo Rodríguez-Lozano \\ Doctor en Ecología
}

\subsection{Consideraciones}

El presente capítulo tiene por objetivo mostrar en detalle la situación actual y la evolución futura, ante un escenario de cambio climático, de cinco aspectos que consideramos clave en el futuro de los recursos hídricos de las Baleares. Para cada uno de estos aspectos se intenta evaluar, de una manera crítica y constructiva, los elementos que se han ignorado o no se han abordado en los diferentes planes hidrológicos de la Demarcación Hidrográfica de las Illes Balears.

Los cinco temas (o aspectos clave) son las aguas subterráneas: salinización y sobreexplotación; el estado ecológico de las masas de agua superficial categoría río; las desaladoras y la producción de agua desalada; las sequías; y la gestión de la demanda en función de la tipología de usuario. En todos ellos hay un hilo conductor, de conexión más allá de la hidrológica, y para cada uno se aborda la situación actual, fruto de la gestión de los últimos años, y cómo se supone que puede responder ante un futuro incierto, como es el cambio climático, cuyos efectos negativos multiplicarán los ya de por si maltratados recursos hídricos y los ecosistemas acuáticos a los que estos están ligados.

\subsection{Las masas de agua subterránea: sobreexplotación y salinización}

El aprovechamiento del agua en las 87 masas de agua subterránea (MASbt) que hay en las Baleares, repartidas en los 4 sistemas de explotación o islas, es el principal recurso para la Demarcación. Y aunque en la revisión anticipada del Plan Hidrológico de las Illes Balears (2 Ciclo 2015-21) se dice que el agua subterránea es un $68 \%$ del recurso hídrico total utilizado en las Baleares, este porcentaje cambia por islas, siendo mucho menor en las Pitiusas; y por años, en función de si fue húmedo o seco. Por ejemplo, si analizamos el consumo de agua urbano en la isla de Mallorca, la extracción de agua subterránea representó más del $85 \%$ 
del total del recurso para el período 2010-2015, con un máximo del 92,5\% el año 2011 , o supuso un notable $82 \%$ el año 2018. Es evidente que a pesar del aumento del agua procedente de la desalación, especialmente en Mallorca, durante los años húmedos las extracciones de agua subterránea aumentan considerablemente debido a su precio más bajo y a la facilidad en la extracción al subir los niveles piezométricos. Este hecho muestra con claridad que las islas de Mallorca y Menorca dependen de las masas de agua subterránea. Si a la extracción de agua subterránea para la demanda urbana le sumamos la agrícola, el peso del agua subterránea continúa siendo muy importante. Aunque la agricultura utiliza unos $15,3 \mathrm{hm}^{3}$ de agua reutilizada, lo que supone el $42 \%$ del total utilizado por todo el sector en la Demarcación $\left(36,4 \mathrm{hm}^{3}\right.$, valores para el año 2015 en el PHIB 20 ciclo), la presión que ejerce sobre los acuíferos todavía es muy importante. De hecho, las presiones por extracción de agua para el horizonte 2021 de la agricultura afectan a más del $90 \%$ de las MASbt y las de la ganadería, con un valor muy inferior de extracciones $\left(0,44 \mathrm{hm}^{3}\right.$ repartido por igual entre Mallorca y Menorca), al $93 \%$ de las MASbt (Tabla 14.1). Es evidente que ha habido un descenso en el consumo de agua por parte de la agricultura, pero su impacto sobre el territorio, en forma de contaminación por nitratos, continúa afectando a una importante cantidad de acuíferos en la Demarcación. De hecho, aún hay municipios en las Baleares que carecen de suministro de agua potable, con elevada concentración de nitratos, debido al mal estado de las MASbt y a la falta de otra alternativa de suministro.

Tabla 14.1. Presiones por extracción de agua sobre las masas de agua subterránea (horizonte 2021)

\begin{tabular}{lccc}
\hline $\begin{array}{c}\text { Tipos de presión por } \\
\text { extracción de agua }\end{array}$ & $\begin{array}{c}\text { Volumen anual } \\
\text { extraído }\left(\mathbf{h m}^{\mathbf{3}} \mathbf{\text { año }}\right)\end{array}$ & $\begin{array}{c}\text { Número de } \\
\text { MASbt afectadas }\end{array}$ & $\begin{array}{c}\text { Porcentaje de } \\
\text { masas afectadas }\end{array}$ \\
\hline Agricultura & 39,34 & 79 & 90,8 \\
\hline Ganadería & 2,24 & 81 & 93,1 \\
\hline $\begin{array}{l}\text { Abastecimiento público de } \\
\text { agua }\end{array}$ & 92,89 & 73 & 83,91 \\
\hline Consumo disperso & 30,72 & 87 & 100 \\
\hline
\end{tabular}

Fuente: Plan Hidrológico de la Demarcación Hidrográfica de las Illes Balears. Revisión de tercer ciclo (2021-2027) (Octubre 2019) http://www.caib.es/sites/aigua/ca/docs_phib_2021_2027/

Las extracciones de agua de las MASbt provocan su sobreexplotación y las presiones por extracción de agua para abastecimiento urbano y el consumo disperso afectan a un número elevado de masas (ver Tabla 14.1). Se extrae más de lo que se recarga y eso genera un impacto sobre la mayoría de las masas de las islas con la consecuente dificultad de recuperación de los niveles piezométricos promedio. Esta afección a los niveles piezométricos es desigual por islas, con sobreexplotaciones cercanas al $150 \%$ en Menorca e Ibiza, y por MASbt. La desigual característica de los acuíferos costeros en cuanto a capacidad y recarga, con un gradiente pluviométrico muy acentuado, por ejemplo en el levante de la isla de 
Mallorca en comparación con los acuíferos en la sierra de Tramuntana, provoca que la posible recuperación de una MASbt a la sobreexplotación y a una sequía sea una quimera. Las MASbt costeras del levante mallorquín (18.20 M1, M2 y M3) tienen un recurso disponible inferior a $1 \mathrm{hm}^{3} /$ año, o entre 1 y $5 \mathrm{hm}^{3} /$ año $(18.17 \mathrm{M} 1$ y M2), en una franja litoral donde la presión por abastecimiento de agua durante la temporada turística es elevada. El resultado es una sobreexplotación y, al ser MASbt costeras, una creciente salinización (estado químico malo por cloruros) que empeora la calidad del agua y dificulta su recuperación. Lo mismo sucede en la isla de Ibiza, con las MASbt costeras del sur con recursos inferiores al $1 \mathrm{hm}^{3} /$ año y que reciben una presión estacional muy elevada.

Figura 14.1. Riesgo de las MASbt de no alcanzar el buen estado global

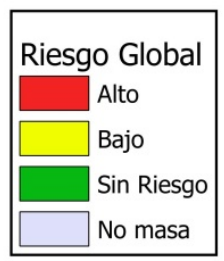
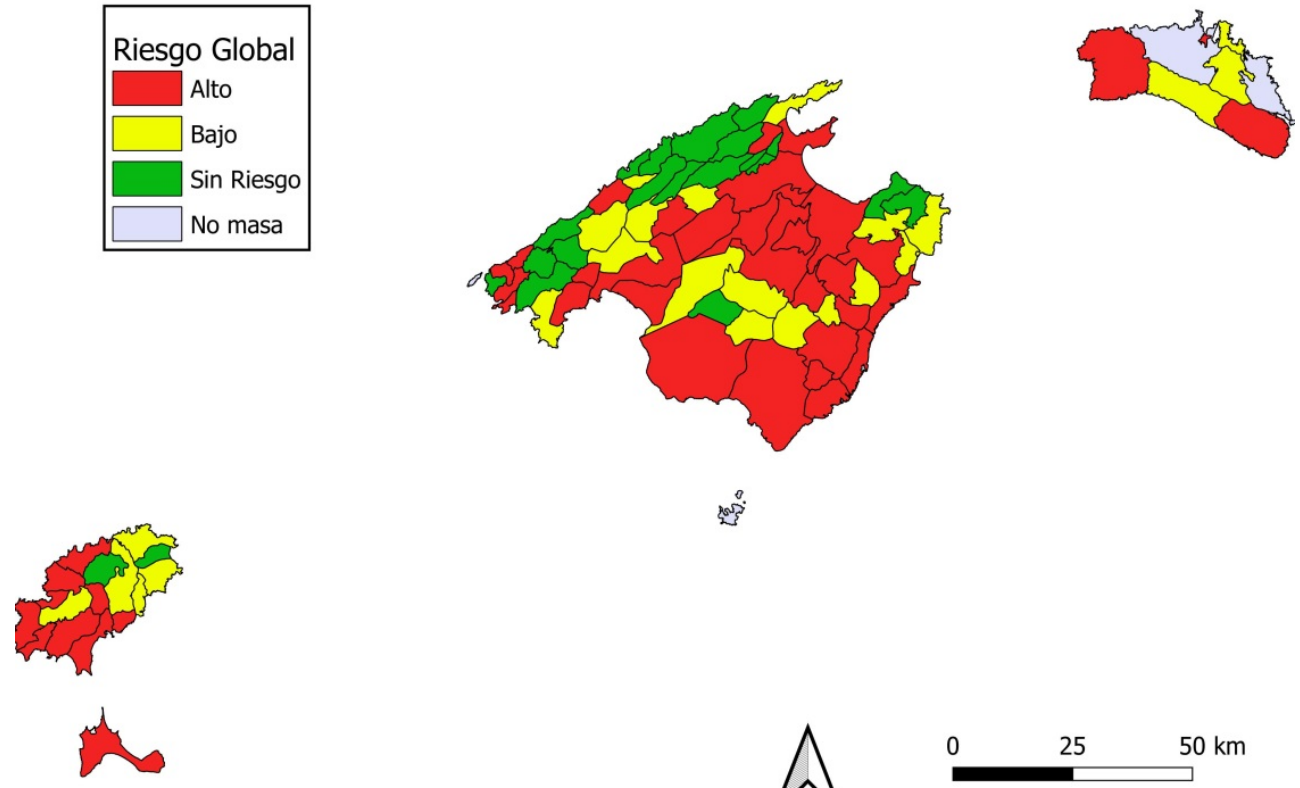

एक

Fuente: Plan Hidrológico de la Demarcación Hidrográfica de las Illes Balears. Revisión de tercer ciclo (2021-2027) (Octubre 2019) http://www.caib.es/sites/aigua/ca/docs_phib_2021_2027/

Como resultado de todas las presiones, el estado cuantitativo (descenso de los niveles piezométricos y explotación superior al $80 \%$ ) y el estado químico (por nitratos y cloruros) provocan en 42 MASbt que haya un riesgo alto de no alcanzar el buen estado global (Figura 14.1) .

Una mirada detallada de los resultados muestra claramente el efecto de las presiones antrópicas en las MASbt costeras con presencia elevada de cloruros por intrusión salina; o las del interior, principalmente en Mallorca, con una menor presencia turística pero con una actividad agrícola que provoca contaminación por nitratos. Con esta situación, la mitad de las MASbt de la Demarcación en riesgo, y las décadas de sobrexplotación y contaminación química, parece difícil poder recuperar algún día todas las MASbt de la Demarcación y cumplir los obje- 
tivos medioambientales marcados por la directiva marco de agua. En los casos de los acuíferos costeros, con precipitaciones menores que ralentizan su recarga, parece evidente que los períodos húmedos, de años con precipitaciones superiores a la media, deberían ser aprovechados para recuperar niveles piezométricos normales e intentar que la intrusión salina retroceda. El principal problema se encuentra en las presiones antrópicas que reciben las MASbt, muy concentradas durante la temporada turística, y no disponer de una alternativa a las extracciones de agua subterránea, como sucede en el levante mallorquín o en la zona oriental de Menorca. Parece claro que el objetivo de la Demarcación es hacer llegar agua a estas zonas a través de la interconexión con el sistema de abastecimiento en alta, red conectada a las desaladoras o a los excedentes de los acuíferos de Tramuntana. Aun así, como se puede leer más adelante, las desaladoras reducen su producción cuando los niveles piezométricos aumentan durante los años con precipitación superiores a la media. En el caso de la isla de Ibiza, y a pesar de disponer de desaladoras, recuperar los niveles piezométricos de referencia continúa siendo un tema pendiente, con una presión estacional del turismo muy fuerte. En estos acuíferos costeros, la amenaza de la subida del nivel del mar o el descenso en las precipitaciones, ya de por sí muy bajas, representa otro obstáculo en el camino hacia la recuperación de estas masas de agua. Es evidente que en algunos casos se debería contemplar un mayor aprovechamiento de las aguas depuradas para reducir la explotación o recuperar algunos acuíferos.

\subsection{El estado ecológico de las masas de agua superficial categoría río}

La planificación hidrológica en las Baleares gira en torno a sus aguas subterráneas, lo cual marca una de las grandes diferencias respecto a la gestión del agua en las demarcaciones hidrográficas peninsulares, que se centra en mayor medida en las aguas superficiales. Esta diferencia radica en dos puntos íntimamente relacionados: la ausencia de cursos de agua superficiales con caudal permanente en las Baleares y el hecho de que las aguas subterráneas sean el principal recurso hídrico, como se ha destacado en el apartado anterior. De hecho, la estrecha relación entre estos dos puntos es lo que convierte en un aspecto clave el objetivo de alcanzar un buen estado para las masas de agua superficial. La conectividad vertical entre las aguas subterráneas y superficiales hace que la explotación de los recursos hídricos subterráneos reduzca la disponibilidad de agua superficial en los ecosistemas acuáticos continentales. Un claro ejemplo es el río de Santa Eulària (Ibiza), el único curso fluvial que tenía caudal superficial permanente en las Baleares, pero que desde comienzos del siglo XX tiene un régimen hidrológico intermitente debido al descenso del nivel piezométrico por la explotación de las aguas subterráneas. En este sentido, cabe destacar que si bien el resto de los cursos fluviales de la islas, denominados torrentes, tienen un carácter intermitente o efímero natural, también presentan tramos permanentes en sus cabeceras y cerca de sus desembocaduras, los cuales han sufrido, especialmente estos últimos, un impacto por sobreexplotación de las MASbt que los alimenta a través 
de surgencias. El régimen hidrológico de los torrentes también ha cambiado durante las últimas décadas, por ejemplo, el número de días al año que los torrentes de la Tramuntana tienen caudal superficial ha disminuido durante el periodo 1977-2009 debido a la diminución de la precipitaciones y al incremento de temperatura y cobertura forestal (García et al. 2017).

En los años 2005-2008 se realizaron las primeras campañas para evaluar el estado ecológico de los torrentes de las Islas Baleares. Si bien el Plan Hidrológico del 2009 incorporó algunos resultados, fue el Plan Hidrológico aprobado en 2011 el que definió claramente las 91 masas de agua superficial (MASup) naturales categoría río, localizadas en las islas de Mallorca (72 masas), Menorca (12 masas) e Ibiza (7 masas). Cabe clarificar que estas 91 masas de agua no representan la totalidad de la red hidrográfica de las Baleares, existiendo tramos que unen las mismas así como otros torrentes localizados tanto en Mallorca, Menorca e Ibiza, como en Formentera y Cabrera. Para la evaluación de su estado, las 91 masas de agua se clasificaron en tres tipologías: ríos de llano (48 masas de agua localizadas en Mallorca, Menorca e Ibiza), ríos de cañón (12 masas de agua en Mallorca) y ríos de montaña (31 masas de agua en Mallorca). El estado ecológico se evaluó en base al estado biológico, físico-químico e hidromorfológico, empleándose para evaluar el estado biológico dos índices multimétricos adaptados a las Baleares basados en las comunidades de diatomeas e invertebrados bentónicos (Delgado et al. 2012; García et al. 2014). A pesar de que solo se evaluaron 47 de las 91 masas de agua (ver Tabla 14.2), este fue un trabajo sin precedentes en nuestro país y en la Unión Europea. Mientras el resto de demarcaciones aún evitaban o se aproximaban con grandes dificultades a la evaluación del estado ecológico de los cursos fluviales no permanentes, la Demarcación Hidrográfica de las Illes Balears había logrado discernir entre tres tipologías de estas masas de agua y adaptar dos índices biológicos para su evaluación. Cabe destacar que este logro no hubiera sido posible sin el conocimiento científico previo de estos ecosistemas a nivel hidrológico, biológico y ecológico.

Sin embargo, este esfuerzo sobresaliente no ha sido continuado en el tiempo. Los planes hidrológicos posteriores se han limitado a copiar la información del Plan Hidrológico del 2011. No fue hasta 2017 cuando se realizó una segunda campaña para evaluar el estado ecológico de estas masas de agua, cuyos resultados han sido incorporados en la revisión de tercer ciclo (2021-2027) del Plan Hidrológico. Esta campaña no tuvo como objetivo evaluar las 91 masas de agua, sino tan sólo aquellas incluidas en las redes de referencia ( 9 masas) y de control operativo (27 masas de agua), siendo finalmente evaluadas 33 masas ya que tres de ellas no presentaron agua superficial en el momento de los muestreos. Esto se traduce en que el estado ecológico del $48 \%$ de las MASup categoría río nunca ha sido evaluado y otro $15 \%$ no ha sido evaluado desde hace más de una década.

La revisión anticipada del Plan Hidrológico de las Illes Balears $\left(2^{\circ}\right.$ Ciclo $2015-$ 21) ya establecía la necesidad de efectuar como mínimo un control de indicadores biológicos e hidromorfológicos cada seis años en las estaciones de la red de control de vigilancia y reconocía la necesidad de extender los programas de control a masas sin evaluar. Sin embargo, esta misma revisión ni siquiera establece estaciones de muestreo para todas las masas de agua superficial categoría río en la red 
de control de vigilancia, dejando el $46 \%$ de estas masas de agua fuera del programa de seguimiento. Es evidente, por tanto, que la Demarcación Hidrográfica de las Illes Balears ha fallado en el cumplimiento de sus obligaciones en el ámbito de la Directiva Marco del Agua y que esta tendencia aún no ha comenzado a revertirse.

Tabla 14.2. Estado ecológico de las MASup categoría río de la Demarcación Hidrográfica de las Illes Balears según su evaluación en 2005-2008 y en 2017

\begin{tabular}{|c|c|c|c|c|}
\hline & \multicolumn{2}{|c|}{ Campañas 2005-2008 } & \multicolumn{2}{|c|}{ Campañas 2017} \\
\hline & $\mathbf{N}^{\mathbf{o}}$ masas & $\%$ masas & $\mathbf{N}^{\mathbf{o}}$ masas & $\%$ masas \\
\hline Muy bueno & 10 & 11,0 & 2 & 2,2 \\
\hline Bueno & 13 & 14,3 & 11 & 12,1 \\
\hline Moderado & 7 & 7,7 & 19 & 20,9 \\
\hline Deficiente & 13 & 14,3 & 6 & 6,6 \\
\hline Malo & 4 & 4,4 & 0 & 0,0 \\
\hline Sin evaluar & 44 & 48,4 & 58 & 63.7 \\
\hline
\end{tabular}

Fuente: elaboración propia a partir de la revisión anticipada del PHIB del segundo ciclo (2015-2021) y del informe de la campaña de 2017 (http://www.caib.es/sites/aigua/es/nuevos_trabajos_2016_aguas_ superficiales/)

A pesar de la escasez de datos, estos confirman que una gran proporción de las masas de agua superficial categoría río no alcanzan los objetivos medioambientales del buen estado y, por tanto, requieren de medidas para su recuperación. En ambas campañas, más del $25 \%$ de las MASup categoría río tenían un estado ecológico peor que bueno, lo que representa el $51 \%$ de las masas evaluadas en 2005-2008 y el 61\% de las evaluadas en 2017 (Tabla 14.2). Es importante resaltar que al comparar estas dos campañas, tan solo dos de las nueve masas de agua de referencia mantuvieron un estado ecológico «muy bueno» (ambas ríos de montaña), mientras que tres de ellas pasaron del estado «muy bueno» a «moderado». Estos datos demuestran que la Demarcación no sólo no ha cumplido los compromisos de evaluación del estado de las MASup categoría río, sino que tampoco ha conseguido mejorar aquellas que presentaban un estado peor que bueno, ni proteger las masas que estaban en un buen estado, llegando a deteriorarse algunas de las masas de agua mejor conservadas que actuaban de referencia.

Debemos también comentar que el estado de las MASup debe evaluarse tanto a partir del estado ecológico como del estado químico. En la publicación de la revisión de tercer ciclo (2021-2027) del Plan Hidrológico se ha incluido, por primera vez, la evaluación del estado químico del $57 \%$ de las MASup categoría río, detectándose un estado químico peor que bueno para tres de las masas evaluadas. Los planes hidrológicos anteriores no habían evaluado el estado químico de los torrentes al considerarlo innecesario por no ser empleados para el consumo humano. 
Con el fin de solucionar la problemática actual en torno a las MASup categoría río, existen dos líneas de trabajo claramente diferenciadas. En primer lugar, es necesario mejorar la evaluación del estado ecológico, y también químico, de las MASup categoría río. Todas las masas deben ser evaluadas con periodicidad suficiente, en especial aquellas en estado peor que bueno cuyo seguimiento debe corroborar si las medidas establecidas por la planificación hidrológica han logrado alcanzar el buen estado. Si bien los trabajos de la Demarcación Hidrográfica de las Illes Balears resultaron pioneros en la primera década de este siglo, en los últimos años otras demarcaciones en España y a lo largo de la Unión Europea se han esforzado en desarrollar nuevas herramientas para evaluar el estado de los ríos intermitentes y efímeros, como son las métricas basadas en aspectos funcionales (Soria et al. 2020) o las que, en ausencia de agua superficial, emplean comunidades biológicas de organismos terrestres (Stubbington et al. 2019). La posibilidad de evaluar el estado ecológico de las masas de agua en ausencia de agua superficial es de gran interés en la Demarcación de las Illes Balears, ya que el número de días sin agua superficial en los torrentes durante primavera y verano ha aumentado en las últimas décadas debido a los cambios en precipitación y temperatura (García et al. 2017). La Demarcación debería trabajar en esta línea para poder adaptar los métodos de evaluación al contexto actual de cambio climático y así posibilitar la evaluación de un mayor número de MASup categoría río.

La segunda línea de trabajo gira en torno a la protección y mejora del estado de las masas de agua. Entre las presiones que afectan a los torrentes, destacan la contaminación, tanto puntual, por efluentes de depuradoras de agua residuales, como difusa, debido a la actividad agrícola y ganadera, así como los impactos de tipo hidromorfológico (p.ej., presas, canalizaciones). En esta línea, uno de los principales retos es diseñar e implementar caudales ambientales que eviten la disminución del periodo que los torrentes presentan caudal superficial debido a la explotación de las aguas subterráneas y, además, incrementen la capacidad de dilución de la contaminación que estos ecosistemas reciben. Si bien este objetivo se lleva planteando desde hace más de una década en los diferentes planes hidrológicos de la Demarcación, aún no se ha comenzado a trabajar en él. El diseño de los caudales ambientales no es una tarea fácil y requerirá años de investigación, ya que estos se deberán establecer en relación con las MASbt y, por tanto, la implementación de los mismos requerirá la recuperación de sus niveles piezométricos. Debemos tener presente en todo momento que el cumplimiento de los objetivos medioambientales para las MASup es dependiente de la recuperación de las MASbt a las que las primeras están ligadas, por lo que la gestión actual de los recursos hídricos en las Baleares, centrada en la explotación de las aguas subterráneas, dificulta que las MASup alcancen el buen estado.

\subsection{Las sequías}

La Demarcación Hidrográfica de las Illes Balears hace frente a las sequías hidrológicas a partir de un plan especial de sequía (PES) (https://www.caib.es/sites/aigua/es/plan_especial_de_actuacion_en_situaciones_de_alerta_y_eventual_ 
sequia-23087/) a través del seguimiento de la sequía meteorológica que proporciona la Agencia Estatal de Meteorología (AEMET) y que establece el Índice de Precipitación Estandarizado o Normalizado (SPI) (más información en el capítulo 12). En nuestro caso, queremos afrontar la sequía desde el punto de vista del balance de agua utilizando el índice de Precipitación-Evapotranspiración Estandarizado (SPEI) como el índice de sequía multiescalar basado en datos climáticos que puede ser utilizado para determinar el inicio, la duración y la magnitud de las

Figura 14.2. Índice SPEI a 12 meses en las islas de (A) Menorca (B) Mallorca y (C) Ibiza para el periodo enero de 1980 a diciembre de 2019
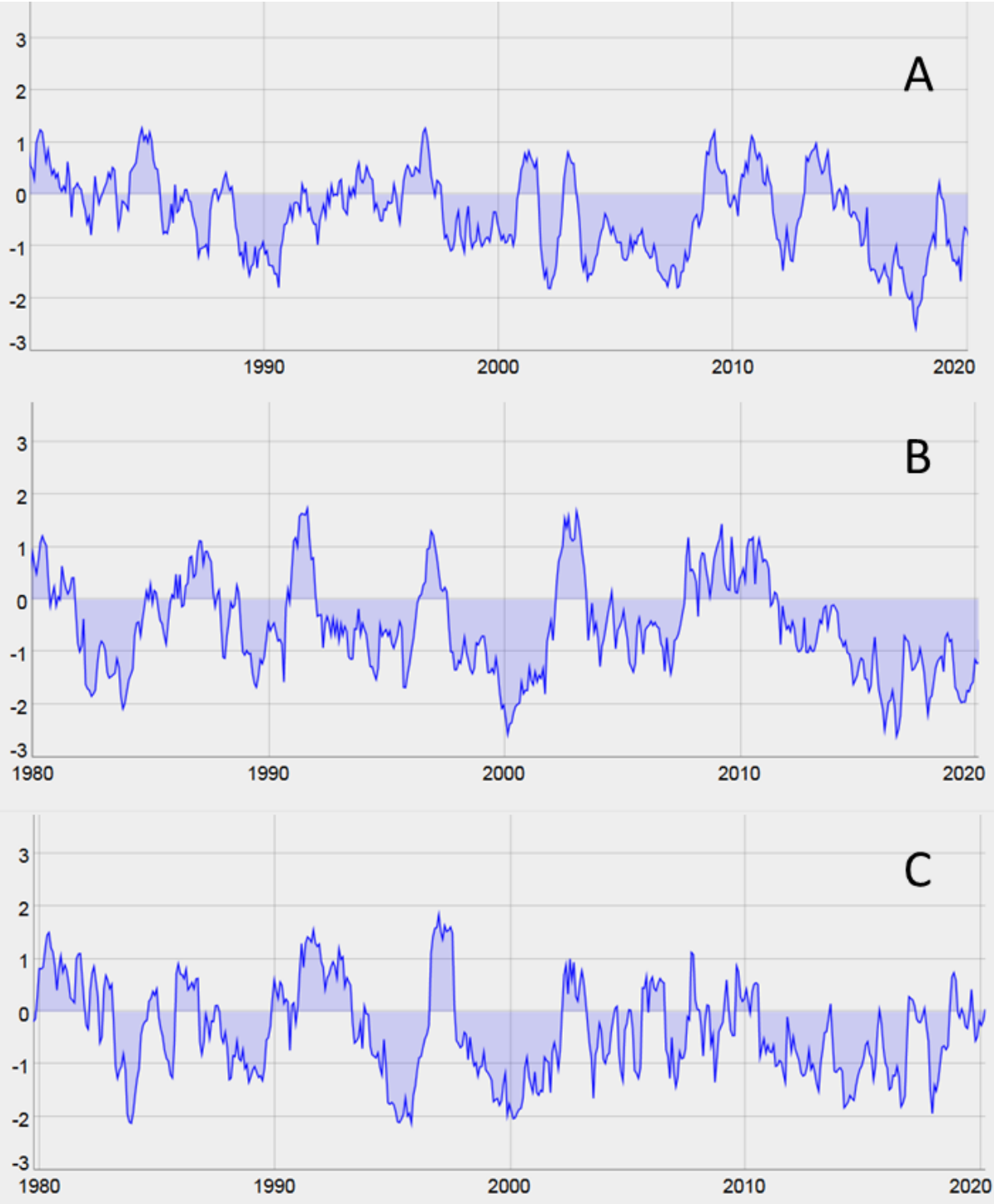

Fuente: SPEI Global Drought Monitor (https://spei.csic.es/map/maps.html) 
condiciones de sequía respecto a las condiciones normales en un sistema como puede ser una cuenca, una isla o una demarcación hidrográfica (Vicente-Serrano et al., 2010). La ventaja es su monitor de sequía global que permite ver la evolución temporal del SPEI, en escalas de entre 1 y 48 meses, en un punto o región del planeta con un período de calibración entre enero de 1950 y diciembre de 2010 (https://spei.csic.es/map/maps.html\#months=1\#month=2\#year=2020).

En la figura 14.2 se ha calculado el SPEI a 12 meses para las islas de Mallorca e Ibiza para el período 1980-2019. El índice nos da un valor del balance de agua para la región siendo los valores negativos un período seco o anomalía respecto a la media. Como puede observarse, en las tres islas se da un aumento en los valores negativos del SPEI (balance de agua negativo para la región) en los últimos 40 años. Hay períodos secos muy claros, con diferente intensidad y duración en cada una, aunque parece evidente que en los últimos años los períodos secos han aumentado en las tres islas de la Demarcación. Esto significa un mayor estrés hídrico sobre los recursos hídricos en cada una de las islas.

Para evaluar estadísticamente si existe una tendencia monótona ascendente o descendente del índice SPEI a lo largo del tiempo, se ha utilizado el test no paramétrico de Mann-Kendall (Mann 1945, Kendall 1975), modificado para corregir los datos debido a su autocorrelación o correlación serial con el método de corrección de la varianza (Yue y Wang, 2004).

Tabla 14.3. Resultados del test de tendencia Mann-Kendall para las series de SPEI a 12 meses

\begin{tabular}{llllll}
\hline Isla & $\begin{array}{c}\text { Valor de } \\
\text { significancia } \\
\text { (p-value) }\end{array}$ & Valor $\mathbf{Z}_{\text {MK }}$ & $\begin{array}{c}\text { Tau de } \\
\text { Kendall }\end{array}$ & $\begin{array}{c}\text { Pendiente } \\
\text { de Sen }\end{array}$ & $\begin{array}{c}\text { Coeficiente } \\
\text { de correlación } \\
\text { de Spearman }\end{array}$ \\
\hline Menorca & 0,0002 & $-5,446$ & $-0,166$ & $-0,0017$ & $-0,234$ \\
\hline Mallorca & 0,002 & $-5,019$ & $-0,153$ & $-0,0016$ & $-0,217$ \\
\hline Ibiza & 0,003 & $-3,499$ & $-0,124$ & $-0,0017$ & $-0,182$ \\
\hline
\end{tabular}

Fuente: Elaboración propia

Los resultados de la Tabla 14.3 muestran que hay una tendencia estadísticamente significativa en el déficit del balance de agua (incremento de los valores negativos) en los últimos 40 años. Para las tres islas, los períodos secos han aumentado con una tendencia descendente parecida (pendiente de Sen), aunque con una mayor intensidad en Menorca, donde los períodos secos de los dos primeros decenios no fueron tan intensos como en las otras dos islas.

Es evidente, con los datos analizados, que los períodos secos han aumentado significativamente en las tres islas, lo que comporta un balance de agua negativo en los últimos 40 años. A esto, hay que añadir que el último período seco, año hidrológico 2015-16, presentó un descenso en las precipitaciones invernales, con los valores más bajos en 43 años, lo que causó una las más intensas sequías que se recuerdan (Ramis et al. 2017). Los impactos de estas sequías tienen diferente repercusión sobre las MASbt, ya que la repuesta temporal de éstas (corto plazo, <6 
meses; medio, 6-24 meses, y largo, >24 meses) es diferente (Lorenzo-Lacruz et al. 2017). Las sequías ponen en peligro la situación de sobreexplotación y salinización de algunas de estas masas, especialmente las que tienen una respuesta más corta a la sequía; es decir, una sequía de dos años de duración compromete el balance de agua de una MASbt con una respuesta corta y media a la sequía. Siempre teniendo en cuenta que la MASbt puede venir de una situación previa de sobreexplotación; y esto sucede en la mayoría de las masas con un riesgo global alto (ver Figura 14.1).

Si a esta situación actual le añadimos la futura, parece evidente que el balance de agua continuará siendo negativo las próximas décadas. Así lo confirma un informe técnico del Centro de Estudios Hidrográficos (2017) donde se evalúa el impacto del cambio climático en los recursos hídricos y las sequías para el período 2010-2099 (ver resumen en Barranco et al. 2018). En los dos escenarios de forzamiento radiativo contemplados (RCP de 4,5 y $8,5 \mathrm{Wm}^{-2}$ ) hay una tendencia decreciente en la precipitación para la Demarcación de las Illes Balears (pendiente de $-0,11$ y $-0,18$ para cada RCP) y, de vital importancia en la demarcación, hay un tendencia decreciente en la recarga de los acuíferos con valores en la pendiente de $-0,26$ y $-0,43$ para los dos escenarios de RCP.

\subsection{Las desaladoras y la producción de agua desalada}

La Demarcación de las Illes Balears tiene una capacidad máxima de producción de agua desalada de más de $55 \mathrm{hm}^{3}$ /año, con ocho desaladoras: una en Formentera $\left(1,4 \mathrm{hm}^{3} /\right.$ año), tres en Ibiza $\left(16,6 \mathrm{hm}^{3} /\right.$ año), tres en Mallorca $\left(33,8 \mathrm{hm}^{3} /\right.$ año) y una en Menorca (3,5 hmªño). Las dos últimas, que han entrado en pleno funcionamiento el año 2019 (Santa Eulalia y Ciudadela), son herencia del plan AGUA y alguna, como la de Ciudadela, ya estaba contemplada en el Plan Hidrológico Nacional (2001). En los dos casos, la planta, ya construida, estuvo parada seis y nueve años sin funcionar por falta de conexión con la red en alta o, dicho de otro modo: por desavenencias económicas entre las administraciones. Y aunque la capacidad máxima actual ronda esos $55 \mathrm{hm}^{3}$ /año, el año 2019 en las Baleares se produjeron unos $27 \mathrm{hm}^{3}$, con las ocho desaladoras en funcionamiento. La máxima producción se alcanzó durante la sequía de 2016 con $29,7 \mathrm{hm}^{3}$ seguida de los $28 \mathrm{hm}^{3}$ del año 2005 y los $27,9 \mathrm{hm}^{3}$ del año 2001. La máxima producción se alcanza durante los años secos y los mínimos en la producción $\left(7,4 \mathrm{hm}^{3}\right.$ del 2010 o los $9,5 \mathrm{hm}^{3}$ del 2013) se registran en años húmedos o que culminan un período de precipitaciones por encima de la media. El aumento en la ampliación de las líneas de producción de agua desalada se dispara a partir de la crisis del agua del año 1999 (Garcia y Servera, 2003), con la ampliación de la desaladora de la bahía de Palma y la utilización de módulos portátiles de desalación en Camp de Mar y Son Ferrer, que llegaron a producir 4,7 hm el año 2001.

En la figura 14.3 se ha calculado el coeficiente de utilización para las seis desaladoras con un registro de producción activo los últimos nueve años. El coeficiente muestra, en porcentaje, cuánta agua desalada produce cada desaladora 
en función de su capacidad anual. La figura muestra claramente tres aspectos en la demarcación:

- Las utilización de las desaladoras en la isla de Mallorca se mueve al ritmo de período seco (aumento de la producción) y período húmedo (descenso de producción). Destaca la desaladora de Palma que no ha vuelto a alcanzar el 80\% de utilización del 2001 o el $90 \%$ del 2005.

- En la isla de Ibiza la producción ha ido oscilando pero siempre con una tendencia al alza, situándose en la actualidad en niveles del 70 y $80 \%$.

- En la isla de Formentera la producción presenta un aumento paulatino, hasta el $50 \%$ de utilización, con un incremento constante en la demanda aunque con su marcada estacionalidad que impedirá subir a niveles mucho más altos.

Figura 14.3. Coeficiente de utilización de las principales desaladoras de las Baleares

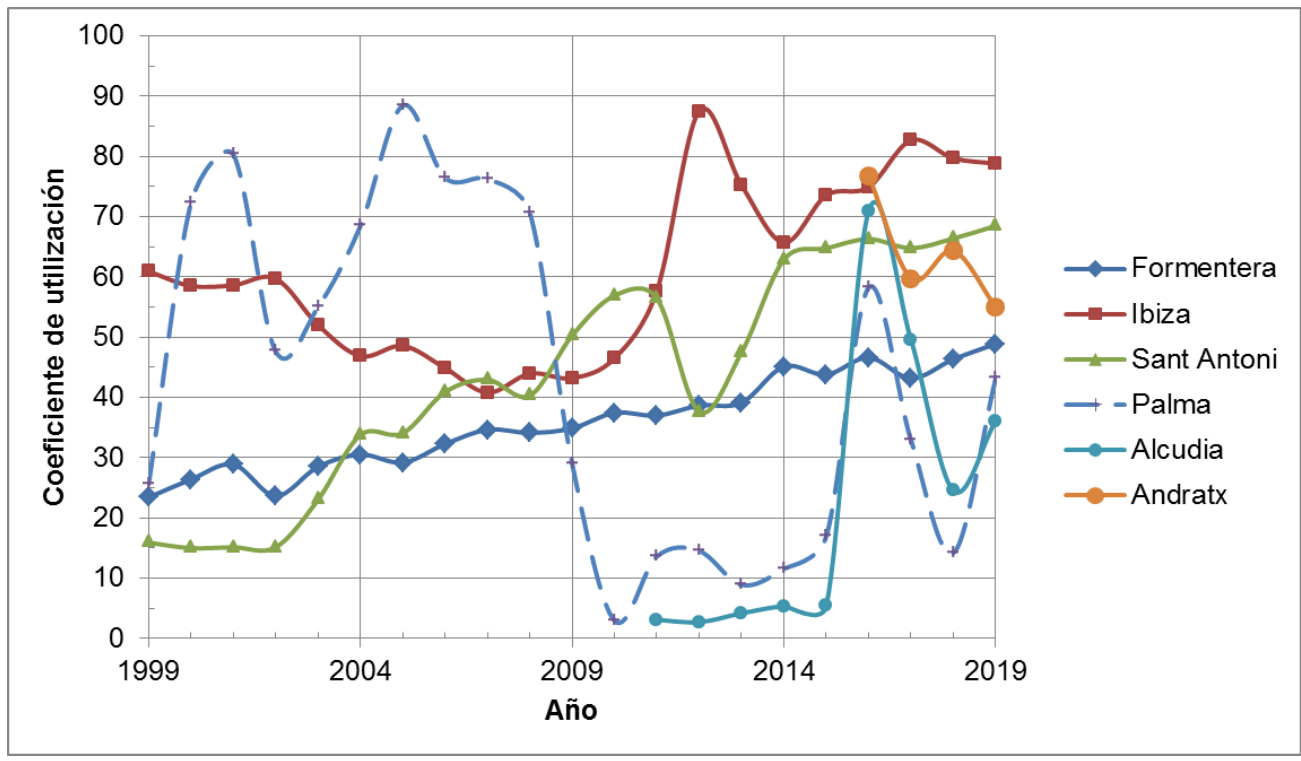

Fuente: Elaboración propia a partir de los datos de ABAQUA (2019)

Parece muy claro que se ha apostado por la desalación como medida frente a los períodos secos y la falta del recurso subterráneo: casos de las Pitiusas y la isla de Mallorca. Cada período seco representa un aumento en la producción de agua desalada. El problema viene cuando, en períodos húmedos, se sustituye por una fuente tradicional más económica; un hecho que se repite en otras demarcaciones españolas donde la desaladora es garantía de suministro y fuente de agua aislada y de emergencia (Cabrera et al., 2019). En el caso de la Demarcación de las Illes Balears, además de garantía de suministro (de algunas zonas), siempre se mostró la desalación como recurso que permitiría recuperar los acuíferos; aunque la llegada del período húmedo comportaba la reducción en su producción culpando a 
los ayuntamientos de no querer comprar agua desalada. El caso es que la desalación en las Baleares debe formar parte de la gestión integrada de los recursos hídricos, para así poder recuperar las MASbt con riesgo alto de no alcanzar el buen estado global, reduciendo su explotación durante períodos húmedos y manteniendo la producción de agua desalada.

\subsection{La gestión de la demanda de agua en función de la tipología del usuario}

Uno de los principales problemas que se encuentran al analizar los consumos urbanos en demarcaciones turísticas, como la de Baleares, es disponer de datos desagregados que permitan conocer el consumo del sector turístico diferenciándolo del residente. La imposibilidad de disponer de estos datos, ya que la mayoría de hoteles o los pisos turísticos están conectados a la red urbana de abastecimiento, añade un componente de incertidumbre al hablar de dotaciones por habitante o de consumos turísticos. Eso implica que los planes hidrológicos utilizan la población del padrón de habitantes o, en el mejor de los casos, la población flotante a partir de las plazas turísticas y las pernoctaciones.

El INE (2018), en la encuesta sobre el suministro y saneamiento del agua del año 2016 (INE, 2018), da a los hogares de las Baleares un consumo neto medio de agua de 134 l/hab/dia; resultantes de dividir el volumen consumido en los hogares $\left(55,9\right.$ millones de $\mathrm{m}^{3}$ ) entre la población de las islas. Este consumo se va hasta los 178,5 1/hab/día (bruto) al incluir el 24,9\% de pérdidas.

Es evidente que los diferentes valores de dotación bruta fluctúan, y mucho, si el valor de agua suministrada se divide solamente entre la población residente o también se incluye la población flotante, aspecto que parece lógico en una demarcación turística. Por ejemplo, si se coge el total de agua urbana suministrada el 2017 y se divide entre la población residente se obtiene una dotación bruta de 338 1/hab/día. En cambio, si a la población residente se le suman las pernoctaciones la dotación baja a los 287,8 1/hab/día.

Estas cifras enmascaran el consumo que tiene un turista, aunque también da un valor promedio a cada residente, aspecto que sabemos es muy diferente en función de la tipología de vivienda (Deya-Tortella et al., 2017). La Demarcación de las Illes Balears, por primera vez, en la revisión de tercer ciclo de planificación (2021-2027), hace una aproximación al consumo de agua asociado a la actividad turística para el año 2017. A través de las pernoctaciones y según el tipo de alojamiento turístico, fija un valor de dotación neta, por ejemplo, de 297 litros por pernoctación para los hoteles. Con estos cálculos, si en las Baleares el año 2017 se consumieron 103,7 millones de $\mathrm{m}^{3}$, los hoteles representaron el $17 \%$ del consumo urbano.

Hemos realizado nuestros propios cálculos para el año 2018 separando a los residentes de las pernoctaciones según la tipología del establecimiento (Tabla 14.3). Para ello, en el caso de los hoteles, las pernoctaciones se separaron en función de la categoría del hotel y se utilizó para cada categoría el valor de consumo por pernoctación que dan Tirado et al. (2019). 
Los valores obtenidos muestran cómo la población residente continúa dominando el volumen de agua suministrada (82\%) y los hoteles superan el $15 \%$. Lo que permite ver con claridad la Tabla 14.4 es la diferencia en los consumos per cápita. Los hoteles tuvieron un consumo bruto de 356 l/pernoctación, por los 295 de apartamentos turísticos y los 269 de los residentes. El valor neto de los hoteles (268 l) es inferior al que adjudica la revisión del tercer ciclo de la Demarcación (297 1). El valor de consumo neto en los hoteles se ha comparado con los datos de consumo en el municipio de Palma para calibrar los resultados. En el año 2017, los hoteles consumieron 2,37 millones de $\mathrm{m}^{3}$ con un total de 8,7 millones de pernoctaciones en el municipio, lo que representa un consumo neto de $272 \mathrm{l} / \mathrm{pernoc}$ tación. Todo parece indicar que, en la Demarcación Hidrográfica de las Illes Balears, el consumo medio neto para los hoteles se sitúa en torno a los 270 l/ pernoctación.

Tabla 14.4. Estimación de los volúmenes suministrados y los consumos para residentes y según la tipología del establecimiento turístico en la Demarcación de las Illes Balears para el año 2018

\begin{tabular}{lccccc}
\hline & Residentes & Hoteles & $\begin{array}{c}\text { Apartamentos } \\
\text { turísticos }\end{array}$ & $\begin{array}{c}\text { Turismo } \\
\text { rural }\end{array}$ & Total \\
\hline $\begin{array}{l}\text { Volumen agua } \\
\text { suministrada, } \mathbf{m}^{3}\end{array}$ & $\begin{array}{c}110.877 .575 \\
(82,1 \%)\end{array}$ & $\begin{array}{c}21.077 .286 \\
(15,6 \%)\end{array}$ & $\begin{array}{c}2.816 .801 \\
(2,1 \%)\end{array}$ & $\begin{array}{c}269.540 \\
(0,2 \%)\end{array}$ & 135.041 .201 \\
\hline $\begin{array}{l}\text { Consumo bruto }(\mathbf{l} / \\
\text { hab/día) }\end{array}$ & 269,1 & 356,2 & 295,1 & 220,6 & 280,2 \\
\hline $\begin{array}{l}\text { Consumo neto } \\
\text { (l/hab/día) }\end{array}$ & 202,5 & 268 & 222 & 166 & 210,8 \\
\hline
\end{tabular}

Fuente: Elaboración propia a partir de los consumos urbanos facilitados por la Dirección Gral. de Recursos Hídricos del Govern Balear y las pernoctaciones del IBESTAT (2018)

Con los resultados obtenidos, está claro que el valor de consumo para la población residente, muy superior al total de pernoctaciones, es más bajo, aunque oculta las diferencias debidas a las tipologías de usuario y, en los últimos años, a un turismo vacacional que no utiliza los alojamientos tradicionales de hoteles y apartamentos: el auge de los pisos turísticos (Valdivielso y Moranta, 2019). En el primer caso, las investigaciones realizadas los últimos años muestran con claridad diferencias en el consumo según la tipología de la vivienda (p.ej.: Morote et al. 2016, Hoff y Blázquez-Salom, 2015). Deyà-Tortella et al. (2017) analizaron la evolución en el consumo de agua y su respuesta a una subida el año 2013 del canon de saneamiento en tres tipologías de vivienda en el municipio de Calviá. El estudio muestra como las viviendas de lujo, con solares de más de $1000 \mathrm{~m}^{2}$, redujeron levemente el consumo después del incremento del precio del canon para luego volver a valores superiores a los años anteriores (medias entorno a los 490 1/hab/día); en cambio, las otras dos tipologías, especialmente la intermedia, redujeron su consumo de manera considerable bajando a los 150 y 110 l/hab/día, respectivamente. 
Es evidente que cualquier plan de gestión de la demanda de agua puede fracasar o reducir su efectividad si el grupo al cual va destinado es heterogéneo y se desconoce sus consumos. Es el caso de la implantación de sistemas tarifarios, de competencia municipal, que fomenten el uso eficiente y la recuperación de costes. La mayoría de veces, las subidas de las tarifas progresivas no penalizan a los mayores consumidores, ni son socialmente equitativas porque no se ha realizado un estudio previo sobre las tipologías y consumos en el municipio. El resultado puede ser temporalmente válido, pequeña reducción del consumo los primeros meses de aplicación, pero puede tener un impacto sobre las clases sociales más desfavorecidas y acabar siendo un mero tributo recaudatorio que no fomenta el uso eficiente del agua.

En el caso del impuesto autonómico del canon de saneamiento, la subida del año 2013 con bloques progresivos, anunciada como una medida que reduciría el consumo de agua, fue inefectiva por su mal diseño, al desconocer las diferentes tipologías tanto del sector turístico (Deya-Tortella et al. 2019), como del residencial (Deyà-Tortella et al. 2017).

Pasan los años y el parámetro donde se sustenta la gestión del agua está incompleto: no hay datos desagregados. A día de hoy el consumo de agua por parte del sector turístico es una estimación, con datos parciales sobre el consumo hotelero en algún municipio. Esta carencia de datos o datos que se repiten o se contradicen en los planes hidrológicos, complica cualquier diagnóstico que se haga sobre la sostenibilidad hídrica en la Demarcación (Navarro Sousa et al. 2020). Hay una desconfianza entre todos los sectores que impide mostrar a la sociedad lo que consume cada tipología. Incluso se desconocen los diferentes consumos entre la población residente. El aumento de la oferta extrahotelera, con el boom del alquiler turístico, complica aún más si cabe la tipología de usuarios en el consumo urbano. En un momento donde el big data proporcionado por contadores inteligentes permite una gestión detallada de los consumos y mejoras en la detección de las pérdidas, los datos básicos continúan sin aparecer en los planes hidrológicos de la Demarcación. El aumento de la población y del alquiler turístico continuará incrementado el consumo urbano y complicando la gestión de la demanda.

Parece obvio que el cambio climático intensificará unos problemas que ya son una realidad en el día a día de la gestión del agua en las Baleares. Se requieren esfuerzos para reducir la demanda de agua urbana y utilizar los recursos no convencionales, como la reutilización de aguas grises, para cubrir aspectos del ciclo urbano del agua, que permitirían una reducción en el consumo de agua, así como en el sector turístico como medida de ahorro y de apuesta por la sostenibilidad.

\section{Referencias bibliográficas}

Barranco, L.M., Dimas, M., Jiménez, A. y Estrada, F. (2018). «Nueva evaluación del impacto futuro del cambio climático en los recursos hídricos en España» en Ingeniería Civil, vol. 191, pp. 34-55. 
Cabrera, E., Estrela, T. y Lora, J. (2019). «Pasado, presente y futuro de la desalación en España» en Ingeniería del Agua, vol. 23(3), pp. 199-214.

CEDEX (2017). Evaluación del impacto del cambio climático en los recursos hídricos y sequías en España. Informe Técnico Centro de Estudios Hidrográficos CEDEX, Tomo único, clave CEDEX 42-415-0-001. Centro de Publicaciones, Secretaría General Técnica del Ministerio de Fomento. http://www.cedex.es/ CEDEX/LANG_CASTELLANO/ORGANISMO/CENTYLAB/CEH/Documentos_Descargas/ (acceso 03-04-2018)

Delgado, C., Pardo, I. y García, L. (2012) «Diatom communities as indicators of ecological status in Mediterranean temporary streams (Balearic Islands, Spain)» en Ecological Indicators, vol. 15, pp. 131-139.

Deyà-Tortella, B., Garcia, C., Nilsson, W. y Tirado, D. (2017). «Analysis of water tariff reform on water consumption in different housing typologies of Calvià (Mallorca)» en Water 9, 425; doi:10.3390/w9060425

Deyà-Tortella, B., Garcia, C., Nilsson, W. y Tirado, D. (2019). «Hotel Water Demand: The Impact of Changing from Linear to Increasing Block Rates» en Water 11, 1604

García, C., Amengual, A., Homar, V. y Zamora, A. (2017) «Losing water in temporary streams on a Mediterranean island: Effects of climate and land-cover changes» en Global and Planetary Change, vol. 148, pp. 139-152.

Garcia, C. y Servera, J. (2003). «Impacts of tourism development on water demand and beach degradation on the island of Mallorca (Spain)» en Geografiska Annaler: Series A, Physical Geography, vol. 85A, pp. 287-300.

García, L., Pardo, I. y Delgado, C. (2014) «Macroinvertebrate indicators of ecological status in Mediterranean temporary stream types of the Balearic Islands» en Ecological Indicators, vol. 45, pp. 650-663.

Hof, A. y Blázquez-Salom, M. (2015). «Changing tourism patterns, capital accumulation, and urban water consumption in Mallorca, Spain: A sustainability fix?» en J. Sustain. Tour. Vol. 23, 770-796.

Kendall, M.G. (1975). Rank Correlation Methods. London: Charles Griffin.

Lorenzo-Lacruz, J., Garcia, C. y Morán-Tejeda, E. (2017). «Groundwater level responses to precipitation variability in Mediterranean insular aquifers» en Journal of Hydrology, vol. 552, pp. 516-531.

Mann, H.B. (1945). « Non-parametric tests against trend» en Econometrica, vol.13, pp. 163-171.

Morote, Á.F., Hernández, M. y Rico, A.M. (2016). «Causes of Domestic Water Consumption Trends in the City of Alicante: Exploring the Links between the Housing Bubble, the Types of Housing and the Socio-Economic Factors» en Water 8,374 .

Navarro Sousa, S., Estruch-Guitart, V. y García, C. (2020). «Use of causeeffect indicators for the diagnosis of water sustainability in the Balearic Islands (Spain)»en Boletín de la Asociación de Geógrafos Españoles vol. 85, issue 2833, pp. 1-48. 
Ramis, C., Romero, R., Homar, V., Alonso, S., Jansà, A. y Amengual, A. (2017). "On the drought in the Balearic Islands during the hydrological year 20152016» en Natural Hazards and Earth System Sciences, vol. 17, pp. 2351-2364.

Soria, M., Gutiérrez-Cánovas, C., Bonada, N., Acosta, R., Rodríguez-Lozano, P., Fortuño, P., Burgazzi, G., Vinyoles, D., Gallart, F., Latron, J., Llorens, P., Prat, N. y Cid, N. (2020) «Natural disturbances can produce misleading bioassessment results: Identifying metrics to detect anthropogenic impacts in intermittent rivers» en Journal of Applied Ecology, vol. 57, pp. 283-295.

Stubbington, R., Paillex, A., England, J., Barthès, A., Bouchez, A., Rimet, F., Sánchez-Montoya, M.M. Westwood, C.G. y Datry. T. (2019) «A comparison of biotic groups as dry-phase indicators of ecological quality in intermittent rivers and ephemeral streams» en Ecological Indicators, vol. 97, pp. 165-174.

Tirado, D., Nilsson, W., Deyà-Tortella, B. y García, C. (2019). «Implementation of Water-Saving Measures in Hotels in Mallorca» en Sustainability 11, 6880.

Valdivielso, J. y Moranta, J. (2019) «The social construction of the tourism degrowth discourse in the Balearic Islands» en Journal of Sustainable Tourism, vol. 27, issue 12, pp. 1876-1892.

Vicente-Serrano, S.M., Beguería, S. y López-Moreno, J.I. (2010). «A Multi-scalar drought index sensitive to global warming: The Standardized Precipitation Evapotranspiration Index - SPEI» en Journal of Climate, vol. 23, pp. 16961718.

Yue, S. y Wang, C.Y. (2004) «The Mann-Kendall Test Modified by Effective Sample Size to Detect Trend in Serially Correlated Hydrological Series» en Water Resources Management, vol.18, pp. 201-218.

Revisión anticipada del segundo ciclo (2015-2021) del Plan Hidrológico de la Demarcación Hidrográfica de las Islas Baleares. http://www.caib.es/sites/aigua/ es/revision_anticipada_del_plan_hidrologico_de_las_islas_baleares/

Revisión del tercer ciclo (2021 - 2027) del Plan Hidrológico de la Demarcación Hidrográfica de las Islas Baleares. http://www.caib.es/sites/aigua/es/docs_ phib_2021_2027/

Plan especial de actuaciones en situación de alerta y eventual sequía en las Illes Balears. https://www.caib.es/sites/aigua/es/plan_especial_de_actuacion_en_situaciones_de_alerta_y_eventual_sequia-23087/

Informe 2017. Direccion General de Recursos Hidricos. Ejecucion de trabajos de monitoreo y evaluacion del estado ecologico de las masas de agua epicontinentales en la Demarcacion Hidrografica de las Illes Balears. Informe campaña primavera 2017. http://www.caib.es/sites/aigua/es/nuevos_trabajos_2016_ aguas_superficiales/ 
ANEXO

Fichas de los autores 



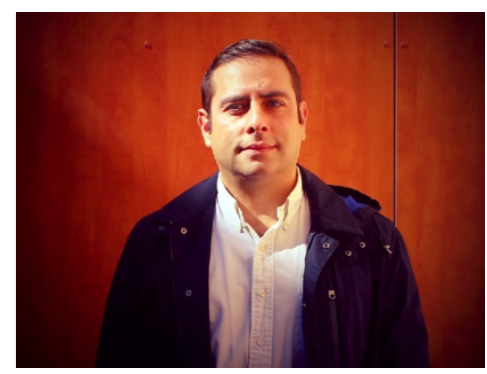

Juan Carlos Santamarta Cerezal

Doctor Ingeniero de Montes (UPM)

Ingeniero Civil, en Recursos Energéticos e Ingeniero Técnico de Minas (UPM)

Universidad de La Laguna

\section{Breve trayectoria profesional}

Doctor en Ingeniería Hidráulica y Energética por la UPM en la ETSICCP y Doctor con mención internacional en Geología Aplicada y Ambiental por la Universidad de León en la Escuela Técnica y Superior de Ingenieros de Minas. Ingeniero Civil, Ingeniero en Recursos Energéticos e Ingeniero Técnico de Minas por la UPM. Profesor de la Universidad de La Laguna desde el año 2008, fue científico colaborador del Water Resources Research Center (WRRC) de EE.UU. Profesor Visitante de la George Mason University, College of Science, Virginia, EE.UU. Investigador colaborador del Instituto Universitario del Agua y las Ciencias Ambientales (IUACA) de la Universidad de Alicante e investigador adscrito al Instituto del Agua de la Universidad de Barcelona. Profesor del programa de doctorado en Ingeniería y Gestión del Medio Natural de la UPM. Su actividad investigadora se resume en 196 publicaciones científicas (50 artículos científicos, 55 capítulos de libros, 22 libros editados, 69 congresos nacionales e internacionales) relacionadas con el agua y el medioambiente en las islas volcánicas. Ha participado en 28 proyectos de investigación. Ha dictado más de 30 asignaturas relacionadas con el agua, el medioambiente, la ingeniería civil e industrial. Más de 140 seminarios y cursos impartidos relacionados con el agua en diferentes universidades españolas y europeas, ha dirigido más de 100 cursos de verano, de extensión universitaria y cursos técnicos profesionales. Experiencia profesional de más de 20 años en proyectos y dirección de obras y proyectos de ingeniería civil y ambiental. Decano del Colegio Oficial de Ingenieros de Montes en Canarias. Premio en Innovación Docente en 2013 (menciones de calidad en 2012, 2014 y 2015).Premio de Investigación de Canarias en materia de ingeniería civil «Agustín de Betancourt» 2018.

\section{Situación profesional actual y contacto}

Director Adjunto de la Sección de Ingeniería Agraria

Escuela Politécnica Superior de Ingeniería. Universidad de La Laguna

E-mail: jcsanta@ull.es

Teléfono: 922316502 Extensión 6053 


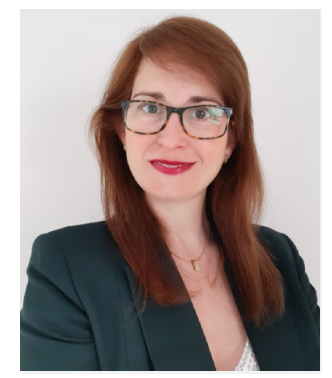

\section{Jésica Rodríguez Martín \\ Doctora Ingeniera de Caminos, Canales y Puertos \\ Universidad de La Laguna}

\section{Breve trayectoria profesional}

Doctora Ingeniera de Caminos, Canales y Puertos, programa Tecnología Medioambiental (Sobresaliente «Cum Laude»), con Diploma de Estudios Avanzados en el Programa de Doctorado «Territorio y Medio Ambiente» del Departamento de Ingeniería Civil: Ordenación del Territorio, Urbanismo y Medio Ambiente « de la ETSICCP de la Universidad Politécnica de Madrid (UPM). A nivel profesional ha realizado proyectos por un valor total de casi $11 \mathrm{M} €$, incluyendo direcciones facultativas de obras y contratos por un total de $30 \mathrm{M} €$. Los proyectos comprenden obras marítimas, obras hidráulicas y edificaciones en general, incluyendo proyectos relacionados con la extracción de áridos. Fue la responsable de la oficina técnica de la empresa SATOCAN durante 10 años, actualmente en excedencia trabajando para el Cabildo de Tenerife, Consejo Insular de Aguas, como apoyo a la Dirección de obras tan importantes como la EDARU y EDARI de Güímar en el T.M. de Arafo. En 2019 obtuvo la Mención Honorífica en el Premio Agustín de Betancourt a la mejor obra de Ingeniería Civil en el periodo 2014-2018 a la Marina Deportiva de Puerto de Tazacorte en La Palma, otorgado por el Colegio de Ingenieros de Caminos, Canales y Puertos. A nivel docente e investigador, es Profesora Asociada en la Escuela Politécnica Superior de Ingeniería de Universidad de La Laguna, en el Departamento de Técnicas y Proyectos en Ingeniería y Arquitectura. Su experiencia investigadora la desarrolla en el grupo de investigación de la ULL INGENIA con 40 publicaciones, en capítulos de libros, artículos en revistas y congresos.

\section{Situación profesional actual y contacto}

Dirección de obras de Ingeniería Civil y Docente e Investigadora

Escuela Politécnica Superior de Ingeniería. Universidad de La Laguna

E-mail: jrodrima@ull.edu.es

Teléfono: 922316502 Extensión: 986 


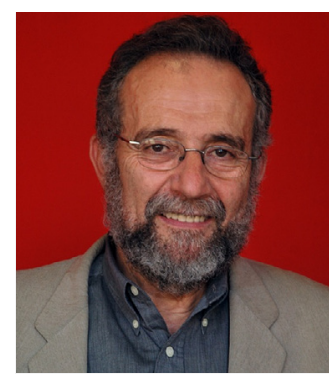

\section{Pedro Arrojo Agudo}

Doctor en C.C. Físicas

Universidad de Zaragoza

\section{Breve trayectoria profesional}

Doctor en C.C. Físicas y Profesor Emérito de Análisis Económico de la Universidad de Zaragoza. Su investigación, centrada en la «Economía y Gestión del Agua», se ha publicado en 70 libros y más de 100 artículos científicos.Miembro durante 12 años del comité científico del Programa MAB de UNESCO; fue Presidente de la Fundación Nueva Cultura del Agua, de los dos primeros Congresos Ibéricos sobre Planificación y Gestión de Aguas (Zaragoza-1998; Oporto-2000) y del Encuentro Latinoamericano por la Nueva Cultura del Agua (Fortaleza-Brasil-2005); promovió la Declaración Europea por la Nueva Cultura del Agua, firmada por 100 científicos de la UE; dirigió el «Foro Ético del Agua», en la Expo sobre Agua y Sostenibilidad (Zaragoza-2008).En 2003 recibió en S. Francisco (EEUU) el Premio Goldman de Medio Ambiente; en 2004 el Memorial Juan XXIII por la Paz, en Barcelona (España); en 2006 la Medalla al Mérito Universitario de la Univ. Veracruzana (México); y el nombramiento de Profesor Honorario de la Universidad Nacional de Ingeniería del Perú, en 2011 (Lima). En las legislaturas XI y XII fue diputado por Zaragoza en el Congreso. Relator especial de las ONU para el derecho humano del acceso al agua y saneamiento.

\section{Situación profesional actual y contacto}

Profesor Emérito de Análisis Económico

Universidad de Zaragoza

E-mail: arrojo@unizar.es 


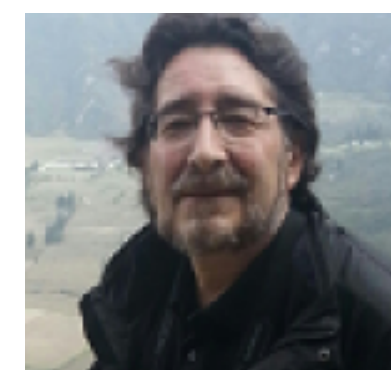

\section{Alberto Fraguas Herrero \\ Biólogo \\ Instituto de Estudio de la Tierra}

\section{Breve trayectoria profesional}

Biólogo, especializado en Ecología y Máster en Gestión Ambiental del Desarrollo, con más de 35 años de experiencia en gestión y planificación ambiental y en concreto en Evaluación Ambiental de Proyectos y Políticas Públicas.Como Consultor Ambiental actualmente desarrolla su actividad como Director Ejecutivo en el Instituto de Estudio de la Tierra S.L. (IET), colaborando a su vez con distintas instituciones Públicas y Privadas.Ha sido Consejero Delegado y fundador de GEMAP S.A. y Consejero de la empresa de reforestación y restauración ambiental ECOVIVEROS S.L. Asimismo, en su faceta profesional pasada fue Consultor Senior de la empresa de ingeniería norteamericana Gibbs \& Hill (GHESA).Fue Asesor de la Dirección General de Medio Ambiente del Ministerio de Obras Públicas y Urbanismo, Decano Delegado del Colegio Oficial de Biólogos en Madrid y Presidente de APROMA (Asociación de Profesionales de Medio Ambiente). Actualmente también es Director Ejecutivo de la ONG Green Cross España fundada por Mijail Gorbachev y coordinador de sostenibilidad de la también ONG Alianza Por La Solidaridad ( Red Action Aid ).Ha participado y dirigido más de 700 Estudios Ambientales tanto de Proyectos y Planes de infraestructuras públicas como instalaciones industriales relacionados con la previsión de impactos, corrección y control de efectos ambientales. Asimismo ha asesorado a Responsables públicos en materia de Planes estratégicos de gestión de medio natural, residuos y fundamentalmente en gestión integral del agua. Es este sentido para el Ministerio de Transición Ecologica y Reto Demografico actual , ha elaborado distintos borradores orientativos para una nueva política de Transicion Hidrologica .Adicionalmente posee dilatada experiencia docente en cursos y máster tanto públicos como privados (ha dado más de 200 Conferencias y Ponencias) siendo autor de más de 80 Artículos en revistas técnicas y de divulgación, habiendo participado como colaborador en diversos medios de comunicación (Radio, TV,. Prensa) de cara a sensibilizar a la ciudadanía sobre la importancia de la protección ambiental y del cambio climático.

\section{Situación profesional actual y contacto}

Director Ejecutivo en el Instituto de Estudio de la Tierra S.L

E-mail: albertofraguas@ietierra.es 


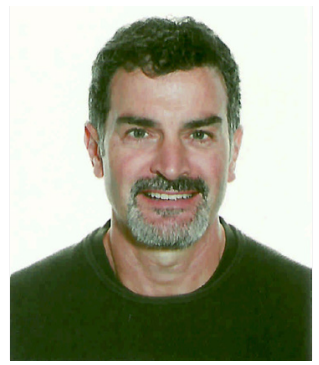

Celso García

Doctor en Geografía

Universitat de les Illes Balears

\section{Breve trayectoria profesional}

Doctor en Geografía por la Universitat de Barcelona (1997). Catedrático de Geografía Física en la Universitat de les Illes Balears desde 1998. Sus intereses de investigación incluyen los recursos hídricos (demanda de agua, gestión del agua en zonas turísticas y urbanas), la hidrología de aguas superficiales y subterráneas en climas mediterráneos y los ríos temporales (ecología, hidrología y transporte de sedimentos). Su investigación sobre la gestión del agua ha sido utilizada por los municipios de Barcelona en su Ordenanza sobre ahorro de agua del 2005, y sus medidas propuestas en Las Sequías y el Sector Turístico fueron en parte implementadas por la Generalitat de Catalunya el año 2008. Es el investigador principal del grupo de investigación GLOWATER sobre recursos hídricos y cambio global. https://orcid.org/0000-0002-4584-9732. Scopus Author ID: 7401486213.

\section{Situación profesional actual y contacto}

Catedrático de Universidad

Departamento de Geografía, Universitat de les Illes Balears

E-mail: celso.garcia@uib.es

Teléfono: 971172793 


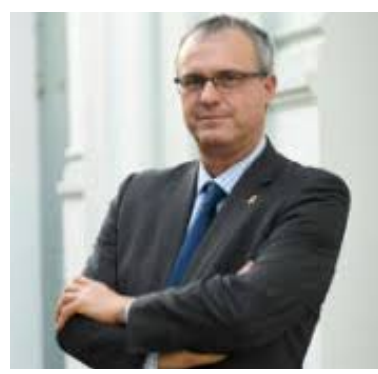

Eduardo Rojas Briales

Doctor Ingeniero de Montes

Universitat Politècnica de València

\section{Breve trayectoria profesional}

Ingeniero de Montes por la Universidad de Freiburg (1985), Dr. Ingeniero de Montes por la Universidad Politécnica de Madrid (1996). Profesor de las Universidades de Lleida (1994-2000) y Politécnica de Valencia (2001-). Gerente del Consorci Forestal de Catalunya (1992-98). Responsable del Área de Política Forestal del CTFC (1996-99). Subdirector de la ETSI Agrónomos de la Universitat Politècnica de València (2004-10). Decano del Colegio en la Comunitat Valenciana (200410). Subdirector general y responsable del Departamento Forestal de la FAO (2010-15) y Presidente del Collaborative Partnership on Forests (2010-15). Co-presidente de ONU-REDD (2014), Comisario general de la ONU para la Exposición Universal de Milán 2015. Miembro del Consejo Científico Asesor del EFI (19982002), Miembro del Board of Directors de PEFC-International. Decano del Colegio y Presidente de la Asociación de Ingenieros de Montes y Presidente de la Fundación Capital Natural (2016- ), Secretario de la UPCI (2018- ).

\section{Situación profesional actual y contacto}

Profesor de la Universitat Politècnica de València

Escuela Técnica Superior de Ingeniería Agronómica y del Medio Natural

E-mail: edrobr@prv.upv.es

Teléfono: 963877000 Extensión 73322 


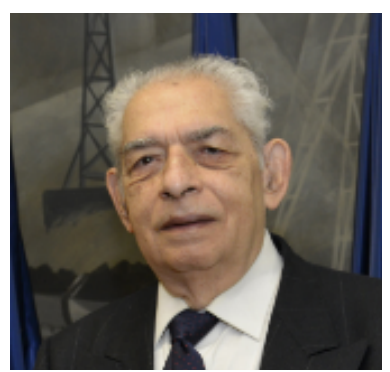

\section{Emilio CUSTODIO Gimena \\ Doctor Ingeniero Industrial \\ Real Academia de Ciencias \\ Universidad Politécnica de Cataluña}

\section{Breve trayectoria profesional}

Doctor Ingeniero Industrial. Miembro correspondiente de la Real Academia de Ciencias Exactas, Físicas y Naturales. Especialización en hidrogeología e hidrología subterránea. Profesor de la Universidad Politécnica de Cataluña: Adjunto de Tecnología Nuclear y Recursos Energéticos (ETS Ingenieros Industriales) y Catedrático de Universidad en Hidrología Subterránea (ETS Ingenieros de Caminos Canales y Puertos). Ingeniero del Ministerio de Obras Públicas. Director General del Instituto Geológico y Minero de España. Curso Internacional de Hidrología Subterránea. Profesor de la Universidad de la República (Uruguay). Medalla Narcís Monturiol al mérito científico y tecnológico, otorgada por la Generalitat de Catalunya. Doctor Honoris Causa por la Universidad de Tucumán (Argentina). Miembro ad honorem de la Asociación Internacional de Hidrología Subterránea $(\mathrm{AIH})$ y de la Asociación Latinoamericana de Hidrología Subterránea para el Desarrollo (ALHSUD). Profesor honorario de las Universidades de Santa Fe y Río Cuarto (Argentina). Autor o coautor de 15 textos y editor de otros 10. El texto Hidrología Subterránea es un referente general. Autor de 550 escritos y comunicaciones, y 150 artículos en revistas de investigación o de difusión general. Director o codirector de 20 tesis doctorales. Director o codirector de 10 proyectos públicos de investigación competitivos nacionales e internacionales y miembro de otros 20 .

\section{Situación profesional actual y contacto}

Profesor emérito

Grupo de Hidrología Subterránea, Departamento de Ingeniería Civil y Ambiental, Universidad Politécnica de Cataluña

E-mail: emilio.custodio@upc.edu

Teléfono: 34934016919 


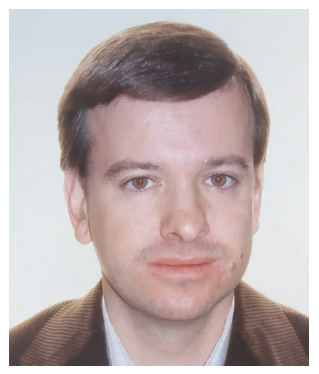

Luis Martínez Cortina

Doctor Ingeniero de Caminos, Canales y Puertos (Universidad de Cantabria)

\section{Breve trayectoria profesional}

Doctor Ingeniero de Caminos, Canales y Puertos por la Universidad de Cantabria. Pertenece a la Escala de Científicos Titulares de Organismos Públicos de Investigación. En la actualidad es Subdirector Adjunto de la Subdirección General de Planificación Hidrológica, de la Dirección General del Agua (Ministerio para la Transición Ecológica y el Reto Demográfico). Ha sido asesor científico del Proyecto Aguas Subterráneas de la Fundación Botín e Investigador Titular en el Instituto Geológico y Minero de España. Autor o co-autor de 4 libros y monografías y de unos 50 artículos científicos. Profesor habitual de Master relacionados con la Hidrología, la Hidrogeología y la gestión de Recursos Hídricos (CEDEX, EOI, diversas Universidades). Es vocal de la Junta Directiva del Grupo Español de la Asociación Internacional de Hidrogeólogos.

\section{Situación profesional actual y contacto}

Subdirector Adjunto de la Subdirección General de Planificación Hidrológica. Dirección General del Agua, Ministerio para la Transición Ecológica y el Reto Demográfico.

Plaza San Juan de la Cruz s/n. 28071-Madrid

E-mail: LMCortina@miteco.es

Teléfono: 915975599 


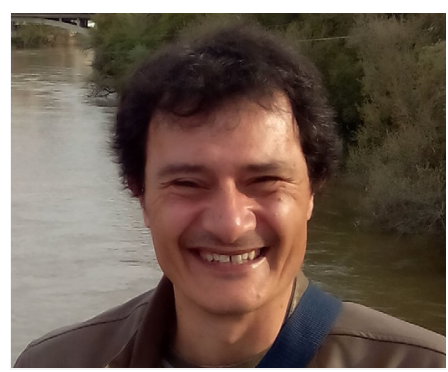

\section{Jordi Giménez Garcia \\ Doctor en Geologia}

\section{Breve trayectoria profesional}

Doctor en Geología por la Universidad de Barcelona. Funcionario de carrera desde 2003 (técnico súperior, especialidad geología) del Servicio de Estudios y Planificación de la Dirección General de Recursos Hídricos de la Comunitat Autónoma de les Illes Balears. Sus trabajos se centran en la elaboración de la planificación hidrológica, y en estudios sobre contaminación y estado de las aguas subterráneas. Ha impartido diferentes asignaturas en la Facultad de Geología de la Universidad de Barcelona (área de geodinàmica) (1993 - 1997), y en los departamentos de la Universitat de les Illes Balears de Ciencias de la Tierra (1998 2004) y Biología (2017 - 2019). Su actividad investigadora se resume en más 30 publicaciones científicas y libros relacionadas con el agua subterránea de las Islas Baleares y con la geodinámica (tectónica, sismología y riesgos geológicos). Ha participado en más de 10 proyectos de investigación.

\section{Situación profesional actual y contacto}

Jefe de la sección VII del Servicio de Estudios y Planificación

Dirección General de Recursos Hídricos

E-mail: jgimenez@dgreghig.caib.es

Teléfono: 971176662 


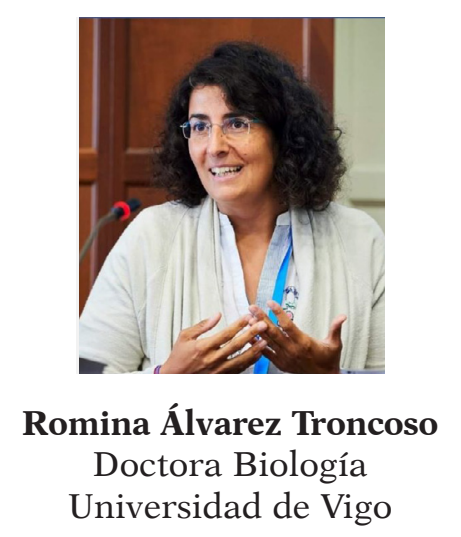

\section{Breve trayectoria profesional}

Doctora en Biología por la UVIGO. Experta y gestora internacional de proyectos de medioambiente basados en el estudio de la calidad ambiental de los ecosistemas acuáticos, gestión de fauna y flora, educación y formación ambiental. Investigadora externa del grupo de Entomología Acuática de la UVIGO con más de 10 publiciones internacionales y más de 30 aportaciones a Congresos. Experiencia de más de 10 años en gestión de proyectos de medioambiente, Directiva Marco del Agua (DMA) (2000/60/EC), Directiva Hábitats, Red Natura 2000, redes de control de calidad del agua en tiempo real, etc. Gestión y colaboración con una amplia red de expertos nacionales e internacionales. Colaboración en preparación de propuestas $\mathrm{I}+\mathrm{D}+\mathrm{I}$. Responsable del diseño, implantación y gestión de la calidad de la norma ISO 17020 en aguas continentales y residuales. Preparación de documentación de ofertas a nivel técnico y administrativo, redacción de contratos, gestión de la relación con socios y expertos, generación de presupuestos, negociación con cliente y socios, redacción de acuerdos de colaboración, etc. Editora de artículos biológicos. Realización de peritaje ambiental para diferentes clientes como base de la defensa judicial. Experiencia en laboratorio de microscopía electrónica, identificación de macroinvertebrados y análisis fisicoquímico. Divulgadora ambiental con amplia experiencia organizando jornadas, talleres, cursos y charlas. Peer review de diferentes revistas y evaluadora de propuestas internacionales para programas de innovación como HORIZON2020, Eureka, COST, INNOWWIDE, Irish Research Council, etc.

\section{Situación profesional actual y contacto}

Consultora independiente en proyectos nacionales e internacionales de agua y medioambiente.

E-mail: ralvareztroncoso@gmail.com 


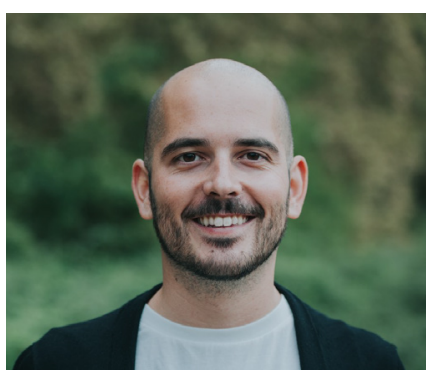

Pablo Rodríguez-Lozano

Doctor en Ecología

Universitat de les Illes Balears

\section{Breve trayectoria profesional}

Doctor en Ecología por la Universitat de Barcelona (2016, Excelente Cum Laude, Mención Internacional, Premio Extraordinario). Licenciado en Ciencias Ambientales por la Universidad Autónoma de Madrid (2009, Premio Nacional de Fin de Carrera) y Máster en Ecología Fundamental y Aplicada por la Universitat de Barcelona y la Universitat de Girona (2010). Tras doctorarse, realizó un primer postdoc (2016-2019) en el Department of Environmental Sciences, Policy, and Management de la Universidad de Californa en Berkeley. Actualmente trabaja como investigador postdoctoral en el Departamento de Geografía de la Universitat de les Illes Balears, dentro del grupo del investigación GLOWATER sobre recursos hídricos y cambio global. Su investigación gira en torno a los ecosistemas acuáticos continentales, centrándose especialmente en ríos intermitentes, desde una mirada inter y transdisciplinar que incluye la ecología acuática, la percepción ambiental, la gestión del agua, el análisis de conflictos socio-ecológicos y la ética ambiental.

\section{Situación profesional actual y contacto}

Investigador Postdoctoral

Departamento de Geografía, Universitat de les Illes Balears

E-mail: pablo.rodriguez@uib.es

Teléfono: 971172793 


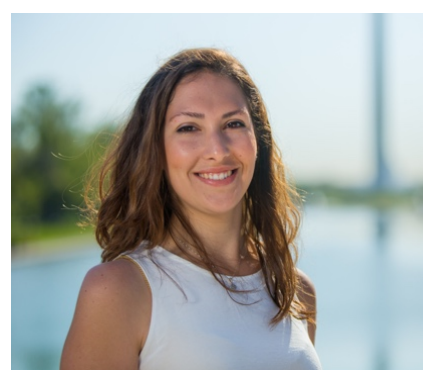

Noelia Cruz Pérez

Ingeniera Civil e Ingeniera de Edificación

Universidad de La Laguna

\section{Breve trayectoria profesional}

Graduada en Ingeniería de Edificación e Ingeniería Civil por la Universidad de La Laguna. Master en Tecnología y Gestión del Agua por la Universidad Politécnica de Cataluña y Master en Desarrollo Regional por la ULL. Investigadora en el grupo Ingenia.

Participación en diversos proyectos europeos relacionados con el medioambiente y la gestión eficaz de los recursos en las Islas. Experiencia en el cálculo de la huella de carbono y la huella hídrica en diferentes instalaciones, con publicaciones internacionales y aportaciones a Congresos.

Gestión y colaboración con una amplia red de expertos nacionales e internacionales. Preparación de documentación de memorias de proyectos internacionales a nivel técnico, así como gestión de la relación con socios y expertos, redacción de acuerdos de colaboración, etc.

\section{Situación profesional actual y contacto}

Investigadora en la Universidad de La Laguna, Coordinadora de proyectos internacionales de $\mathrm{I}+\mathrm{D}+\mathrm{i}$

E-mail: ncruzper@ull.edu.es 


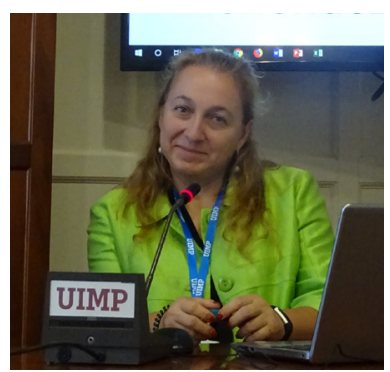

\section{Marta Robledo Jiménez \\ Ingeniero Agrónomo \\ Universidad Politécnica de Madrid}

\section{Breve trayectoria profesional}

Comenzó a trabajar en Tragsatec, en 1998, realizando labores de coordinación en los trabajos de fotointerpretación y superposición en el proyecto SIGPAC, de regímenes de ayuda directa en el marco de la PAC y, anteriormente, en el proyecto SIG OLEÍCOLA, de ajuste del parcelario y fotointerpretación del olivar español. Posteriormente, en 2005, también en Tragsatec, realizando controles de calidad de los trabajos realizados en la tramitación y grabación de expedientes sobre usos de agua (concesiones y pozos) en la aplicación ALBERCA, utilizada en las Confederaciones Hidrográficas. En 2007, labores de coordinación del equipo de vertidos danto apoyo a la gestión del Censo Nacional de Vertidos. Proyect Manager en el proyecto Europe/Aid134561/D/SER/TR-Thecnical Assistance for Conversion of River Basin Action Plans into River BasinManagement Plans, de elaboración de 4 Planes Hidrológicos de cuatro Demarcaciones Hidrológicas en Turquía en 2015. Desde 2017, también en Tragsatec, apoyo en la elaboración de los Planes Hidrológicos del segundo ciclo de planificación de las Demarcaciones Hidrográficas canarias conforme Directiva Marco del Agua. Actualmente, elaboración de los Planes de Gestión de Riesgo de Inundaciones y Planes Hidrológicos y sus Estudios Ambientales Estratégicos correspondientes a este ciclo de planificación.

\section{Situación profesional actual y contacto}

Tecnología y Servicios Agrarios, TRAGSATEC

Calle Julián Camarillo 6B 3A - 28037 Madrid

E-mail:mrj@tragsa.es

Teléfono: 913226792 


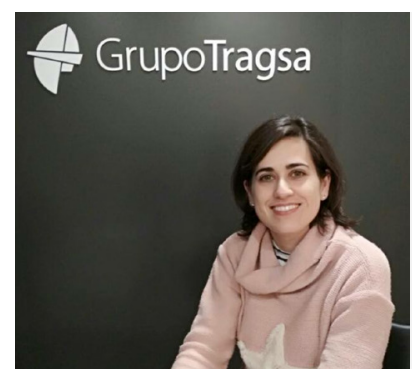

\section{Henar Ercilla Ventura}

Licenciada en Ciencias Ambientales

Universidad de Alcalá

\section{Breve trayectoria profesional}

Licenciada en Ciencias Ambientales por la Universidad de Alcalá con diversos cursos de postgrado en relaciones internacionales, prevención de riesgos laborales y en materia de aguas. Comenzó su carrera profesional como técnico de movilidad sostenible en Francia. Desde 2007 desempeña labores de asistencia técnica en planificación hidrolófica en España y Turquía, además colabora en la internalización de Tragsatec.

\section{Situación profesional actual y contacto}

Tecnología y Servicios Agrarios, TRAGSATEC

Calle Julián Camarillo 6B 3A - 28037 Madrid

E-mail: hev@tragsa.es

Teléfono: 917322063 
La planificación de los recursos hídricos a largo plazo enfrenta muchos desafíos vinculados al alto grado de incertidumbre asociado tanto al uso del recurso como a la disponibilidad del mismo en las próximas décadas, esta incertidumbre es agravada por un contexto de Cambio Climático.

Según el Plan Nacional de Adaptación al Cambio Climático, España y sus regiones insulares (Canarias y Baleares), por su situación geográfica y sus características socioeconómicas, es un país muy vulnerable al cambio climático, como así se viene poniendo de manifiesto en los más recientes análisis e investigaciones. El cambio climático, con aumento de la temperatura y, en España, disminución en general de la precipitación, causará una reducción de las aportaciones hídricas y una modificación de la demanda de agua en los sistemas de regadío.

El presente libro está dirigido a profesionales que trabajan tanto en el ámbito científico (investigadores, profesores universitarios, etc.) como a personal pertenecientes a las Administraciones Públicas con gestión directa en la planificación y gestión de los recursos hídricos, como una herramienta más para la mejora de la transición hidrológica. Se ha hecho mayor intensidad en las regiones insulares dado que serán las más sensibles al cambio climático.

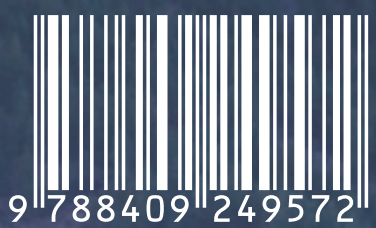

